\title{
Social roles and lifetime development in the chronic mentally ill : a study into the reliability and validity of the social role performance and development inventory : an open interview-based lifetime assessment of the social integration of chronic mentally ill
}

Citation for published version (APA):

Noorthoorn van der Kruijff, E. O. (1994). Social roles and lifetime development in the chronic mentally ill : a study into the reliability and validity of the social role performance and development inventory : an open interview-based lifetime assessment of the social integration of chronic mentally ill. [Doctoral Thesis, Maastricht University]. Datawyse / Universitaire Pers Maastricht. https://doi.org/10.26481/dis.19940217en

Document status and date:

Published: 01/01/1994

DOI:

10.26481/dis.19940217en

Document Version:

Publisher's PDF, also known as Version of record

Please check the document version of this publication:

- A submitted manuscript is the version of the article upon submission and before peer-review. There can be important differences between the submitted version and the official published version of record.

People interested in the research are advised to contact the author for the final version of the publication, or visit the DOI to the publisher's website.

- The final author version and the galley proof are versions of the publication after peer review.

- The final published version features the final layout of the paper including the volume, issue and page numbers.

Link to publication

\section{General rights}

Copyright and moral rights for the publications made accessible in the public portal are retained by the authors and/or other copyright owners and it is a condition of accessing publications that users recognise and abide by the legal requirements associated with these rights.

- Users may download and print one copy of any publication from the public portal for the purpose of private study or research. - You may not further distribute the material or use it for any profit-making activity or commercial gain

- You may freely distribute the URL identifying the publication in the public portal.

If the publication is distributed under the terms of Article $25 \mathrm{fa}$ of the Dutch Copyright Act, indicated by the "Taverne" license above please follow below link for the End User Agreement:

www.umlib.nl/taverne-license

Take down policy

If you believe that this document breaches copyright please contact us at:

repository@maastrichtuniversity.nl

providing details and we will investigate your claim. 
SOCIAL ROLES AND LIFETIME DEVELOPMENT IN THE CHRONIC MENTALLY ILL 
CIP DATA KONINKLIJKE BIBLIOTHEEK, DEN HAAG

Noorthoom van der Kruijff, Eric Onno

Social roles and lifetime development

in the chronic mentally ill: a study into

the reliability and validity of the

Social Role Performance and Development Inventory

- an open interview based lifetime assessment

of the social integration of chronic mentally ill /

Eric Onno Noorthoom van der Kruijff. -

Universitaire Pers Maastricht.

Thesis Maastricht. - With ref.

ISBN $90-5278-121-4$

Subject headings: chronic mentally ill; social roles / mental health.

Publication of this book was supported by:

Het Nationaal Fonds voor de Geestelijke Volksgezondheid Lundbeck b.v., Amsterdam

Solvay - Duphar, Weesp 


\title{
SOCIAL ROLES AND LIFETIME DEVELOPMENT IN THE CHRONIC MENTALLY ILL
}

\author{
A STUDY INTO THE RELIABILITY AND VALIDITY OF \\ THE SOCIAL ROLE PERFORMANCE AND DEVELOPMENT INVENTORY \\ AN OPEN INTERVIEW-BASED LIFETIME ASSESSMENT \\ OF THE SOCIAL INTEGRATION OF CHRONIC MENTALLY ILL
}

\section{PROEFSCHRIFT}

ter verkrijging van de graad van doctor aan de Rijksuniversiteit Limburg te Maastricht, op gezag van de Rector Magnificus, Prof. Dr. H. Philipsen, volgens het besluit van het College van Dekanen, in het openbaar te verdedigen op donderdag 17 februari 1994

om 16.00 uur

door

Eric Onno Noorthoorn van der Kruijff 
Promotores:

Prof. dr. M.A.J. Romme

Prof. dr. H. Philipsen

Beoordelingscommissie: Prof. dr. G.J. Kok (voorzitter)

Prof. dr. B.P.R. Gersons (Universiteit van Amsterdam)

Prof. dr. F. Sturmans

Dr. D. Wiersma (Rijksuniversiteit Groningen)

Dr. J. Diederiks 


\section{DANKWOORD}

Een proefschrift lijkt soms het werk van één persoon. In ieder geval is dat iets wat van dit proefschrift niet kan worden gezegd. Dit proefschrift is een product van samenwerking. Samenwerking met "het veld". Samenwerking binnen een variabele en soms kleine groep van medewerkers op het project. En samenwerking met de vele adviseurs, die mij in de vele kanten van het onderzoek hebben ondersteund en mij op ideeën brachten ten aanzien van "alweer nieuwe" - analyses. Allereerst het "veld". Zonder de bereidwillige en geduldige inzet van de leden van het team van de Sociaal Psychiatrische Dienst was dit onderzoek er niet geweest. In de verschillende fasen van het onderzoek hebben zij meer dan 300 patiënten met het onderzoeksteam besproken en in totaal 726 vragenlijsten van allerlei soorten en maten ingevuld. In het centrale gedeelte van het onderzoek waren 56 patiënten zo vriendelijk zich door mij en mijn medewerkers doorgaans in drie gesprekken uitvoerig te laten bevragen over hun levensloop, het functioneren in het huidige leven en de effecten van hun ziekte op het functioneren. Dit alles heeft mij de mogelijkheid geboden het onderwerp van dit proefschrift van vele zijden te benaderen.

Dan de samenwerking binnen de variabele projectgroep. Allereerst zijn daar mijn beide promotoren, Marius Romme en Hans Philipsen. In Marius heb ik een geduldige en scherpzinnige (her- her- her) lezer van vele tientallen concepten van artikels, hoofdstukken en vragenlijstconcepten getroffen. Je voortdurende bijsturing als hulpverlener en man van de praktijk heeft het project met name in de laatste jaren een flinke stimulans gegeven. Hans was de drijvende kracht op de achtergrond die met name essentiële beslissingen rond de opzet van het hoofdonderzoek heeft helpen nemen. Die de uitvoering van het onderzoek heeft helpen entameren. Ook in mijn huidige werk in nieuwe projecten blijft Hans een goede en scherpzinnige adviseur op de achtergrond. De prettige samenwerking en jullie vertrouwen in mijn capaciteiten heeft mij gestimuleerd het gekozen pad van onderzoeker verder uit te bouwen en te gaan werken aan een praktische toepassing van dit getheoretiseer. Gelukkig werd jullie vertrouwen ook gedeeld door het Nationaal Fonds, zodat we momenteel verder werken aan het vervolg.

Natasja van de Weg was mijn eerste studentassistente, die in een nog zoekende fase van het onderzoek een onmisbare rol heeft gespeeld in het structureren van de creatieve en wel eens chaotische discussies met Marius Romme. Nadat het budget Natasja's aanwezigheid niet meer kon trekken heeft Sandra Escher vervolgens in de uitvoerende fase van het onderzoek de interviews met de hulpverleners verder op zich genomen. Daarnaast is zij steeds diegene geweest die mij hielp kijken naar de positie van de patiënt. Haar adviezen hielpen mij in het simplificeren van mijn soms vage en abstracte ideeën en formuleringen.

De derde schakel in deze keten van assistentes vormt Wiesette Krol. Wiesette's nauwkeurigheid en consequent doorzettingsvermogen in het op orde brengen 
van alle cijfertjes heeft mij veel tijd bespaard en mij de ruimte gegeven het schrijfwerk aan dit boek te beginnen. Ondertussen is het nu ook twee jaar geleden dat Alex Buiks het onderzoeksteam versterkte. Dankzij je goede persoonlijke band met "het veld" konden we voldoende patiënten samplen om ook nog wat te kunnen rekenen. Daarnaast waren de discussies met jou rond theorie en praktijk een goed klankbord voor mijn eigen werk. Het bracht me op ideeën en dwong mij soms om zaken te herzien. Deze discussies vormen de basis voor de vervolgstudie.

Tenslotte, de adviseurs, steuners en hulpjes. Het formele en informele support netwerk. In de beginfase hebben Hub Hamers en Herro Kraan een duidelijk stempel gedrukt op de gekozen werkwijze in de verscheidene fasen van het onderzoek. Hub was vooral een wegwijzer en leermeester in de sociologie en methodologie. Herro was een altijd bereikbare en onmisbare vraagbaak waar het neerkwam op instrumentontwikkeling. In Gerard van Breukelen heb ik een praktisch gerichte statisticus gevonden die mij veel geleerd heeft over de relativiteit en interpreteerbaarheid van een aantal van de meer complexe analyses. Ate Frans de Bruin was tot slot een nuttige hulp in het aanleveren van kennis, niet alleen ten aanzien van zijn eigen specialiteit, de Sickness Impact Profile, maar ook ten aanzien van mijn eerste pogingen met factor en ander correlationele analyses.

Als belangrijke factor in de achtergrond wil ik op deze plek enige ruimte vrij maken voor Luc de Witte. Luc is op verschillende momenten door de jaren heen een klankbord geweest. In noodgevallen of moeilijke momenten was je niet alleen een persoonlijke steun die mij - ook letterlijk - voeding gaf, maar was je bereid een kritische en bij tijden confronterende blik te werpen op soms inderhaast opgestelde concepten dan wel warrige "definitieve" versies.

De leden van de beoordelingscommissie hebben een belangrijke bijdrage geleverd in het completeren van het eindproduct. Hun suggesties hebben vooral de structuur en de zorgvuldigheid van de presentatie in zowel het theoretische als het praktische deel van het boek sterker gemaakt.

Dennis Bailey, Bob Wilkinson, Carolien Dijkman en Simonne Delnooz dank ik voor de correcties en aanvullingen op mijn soms haperend Engels taal gebruik. Waar mijn denken soms stappen oversloeg dan wel verzandde in vaagheden, spoorden zij de hiaten adequaat op. Elly Meij dank ik, tenslotte, voor het vele werk dat zij zowel ten aanzien van data-invoer, de organisatie van mijn administratie, als ten aanzien van dit en andere manuscripten voor mij heeft gedaan. Elly, de samenwerking heb ik altijd als zeer prettig ervaren. Ik hoop dat we op deze voet verder mogen gaan.

Een essentiële morele steun komt van mijn moeder. Op moeilijke momenten was zij bereid mijn zorgen tot de hare te maken, zodat ik weer verder kon.

Eric Noorthoorn, 7 november, 1993 


\section{Contents}

\section{DANKWOORD}

PART 1 INTRODUCTION 1

1 Introduction and history $\quad 3$

1.1 The aims and the scope of this thesis 3

1.2 Following a tradition 3

1.3 Preliminary studies 5

$\begin{array}{lll}\text { 1.3.1 } & \text { First effort } & 6\end{array}$

1.3.2 Second effort $\quad 6$

1.3.3 Conclusions of the preliminaries $\quad 8$

$\begin{array}{lll}1.4 & \text { The state of the art } & 8\end{array}$

1.5 The professional's options - a need for systematic inventories 11

1.6 Frame of reference: social homeostasis 12

1.7 General perspectives $\quad 14$

$1.8 \quad$ Research questions of the current study 15

1.9 The structure of this book 16

$2 \quad$ Presenting an effort $\quad 17$

$\begin{array}{lll}2.1 & \text { Abstract } & 17\end{array}$

$\begin{array}{lll}2.2 & \text { Context of the study } & 17\end{array}$

2.3 Evaluation of current diagnostic instruments in psychiatry 18

2.4 Objectives and important questions 19

2.5 Social isolation as a developmental circular process $\quad 19$

$\begin{array}{lll}2.6 & \text { A rehabilitation model aimed at development and integration } & 22\end{array}$

2.7 Arrangement of roles in main areas of daily functioning 25

$2.8 \quad$ A single case history 26

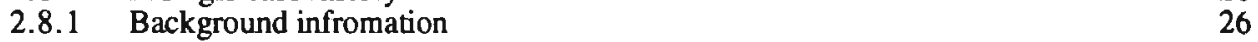

$\begin{array}{ll}2.8 .2 & \text { Social span of control }\end{array}$

2.8.3 Evaluation of her span of control 27

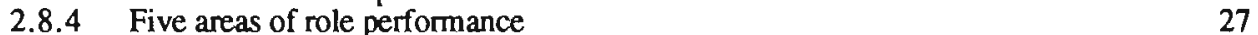

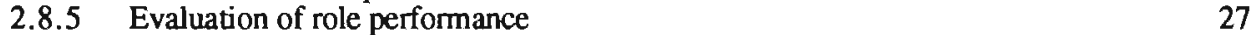

$\begin{array}{ll}2.8 .6 & \text { Implications for treatment }\end{array}$

$\begin{array}{lll}2.9 & \text { Epilogue } & 28\end{array}$

PART 2 SAMPLE DESCRIPTION AND INSTRUMENT DEVELOPMENT 31

3 Defining chronicity within the samples 33

3.1 The rehabilitation service of the Maastricht CMHC 33

3.2 Chronicity in psychiatry: a short review of literature 34

3.2.1 Various views concerning chronicity 34

3.2.2 Chronicity related to schizophrenia 34

3.2.3 Chronicity and length of treatment: the number of years after onset of treatment 35

3.2.4 Chronicity and dependency of care 36

3.2.5 Multi-axial definitions and descriptions of chronicity 36

3.2.6 Chronicty related to society and social integration 38

$\begin{array}{ll}3.3 & \text { Definition of chronicty in this study } \\ 39\end{array}$

3.4 Demographic and patient career characteristics of the chronic population 39

3.5 The different samples 40

3.5.1 Phase 1 - pilots 42

3.5.2 Phase 2 - target groups sampling 43

3.6 Non response 43

3.7 Comparison of the chronic population with the population of the district 44

3.8 Comparison of the samples with the patient cohors 45

3.8.1 Sociodemographic data 45

3.8.2 Investigation of selection bias 46

3.8.3 Patient career characteristics 47

3.10 Summary of the comparisons 48 
CONTENTS

4 Social role concepts underlying the instrument 49

$\begin{array}{lll}4.1 & \text { Introduction } & 49\end{array}$

4.2 Role concepts $\quad 50$

4.2.1 Symbolic interactionism 51

4.2.2 Social conflict 51

4.2.3 Structural functionalism $\quad 52$

4.3 The theory of Uta Gerhardt; a meta analysis 52

4.3.1 Definition of role $\quad 52$

4.3.2 Status roles $\quad 53$

4.3.3 Position roles $\quad 54$

4.3.4 Situation roles $\quad 55$

4.4 The different levels and the freedom of action 55

4.5 Operationalization of the role concept in the current study 56

4.6 The concept of role and the socialization process 56

$4.7 \quad$ Life cycles $\quad 58$

4.8 Role performance domains $\quad 60$

4.9 Discussion and conclusion $\quad 62$

5 A comparative review of current instruments $\quad 67$

$\begin{array}{lll}5.1 & \text { A review of the state of the art } & 67\end{array}$

$\begin{array}{ll}\text { 5.1.1 A focus on functional assessment } & 67\end{array}$

$\begin{array}{lll}5.1 .2 & \text { Judgement criteria } & 68\end{array}$

$\begin{array}{lll}5.2 & \text { Evaluation } & 69\end{array}$

5.2.1 The state of the art $\quad 69$

$\begin{array}{lll}5.2 .2 & \text { The update } & 72\end{array}$

$\begin{array}{lll}5.3 & \text { Conclusion } & 72\end{array}$

$6 \quad$ Item selection and operationalization $\quad 73$

$6.1 \quad$ Selection procedures 73

6.1.1 A brief recapitulation of important aims 73

$\begin{array}{lll}6.1 .2 & \text { Gable } & 74\end{array}$

$\begin{array}{lll}6.2 & \text { The pilots } & 75\end{array}$

6.3 Findings on the basis of Gable's procedure 77

$6.4 \quad$ The most important changes $\quad 78$

6.5 Composition of the final operational draft $\quad 80$

6.5.1 Two versions containing the same items 80

6.5.2 The first part: what did the individual achieve $\quad 80$

6.5.3 The second part: role performance in five domains $\quad 83$

$\begin{array}{lll}6.6 & \text { Conclusion } & 86\end{array}$

$\begin{array}{llr}\text { PART } 3 & \text { TESTING THE INSTRUMENT } & \mathbf{8 7}\end{array}$

$\begin{array}{llr}7 & \text { Design and objectives of the main study } & 89\end{array}$

$\begin{array}{lll}7.1 & \text { Focus of the analyses } & 89\end{array}$

7.2 Design and methods $\quad 90$

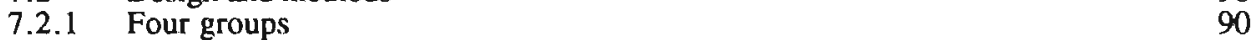

7.2.2 Composition of the groups 91

$\begin{array}{lll}7.2 .3 & \text { Two versions and subsequent drafts } & 92\end{array}$

7.2.4 Calculation of the score 93

7.2.5 A step-by -step analysis 94

7.3 Limitation by the number of subjects: a power analysis 94

7.4 Specification of methods of analysis 95

7.4.1 The reproducability of the ratings 96

7.4.2 The construct validity: dimensionality and internal consistency 96

7.4.3 The validity of the instrument: interjudge agreement 97

$\begin{array}{ll}\text { 7.4.4 Criterion oriented validity } & 97\end{array}$

$\begin{array}{lll}7.4 .5 & \text { Discriminative value and outcome } & 98\end{array}$

$\begin{array}{ll}\text { 7.4.6 Description on case level. } & 99\end{array}$

7.4.7 Comparison with a normal reference group 99 


\section{CONTENTS}

8 Reproducability of the ratings

8.1 Procedure

8.2 Present performance

8.3 Past performance

8.4 Assumptions on outcome and important questions 103

8.5 Results 104

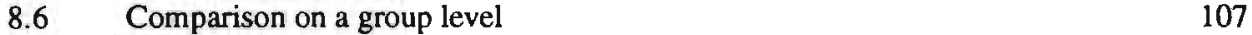

8.7 Summary

9 Internal consistency and dimensionality 109

9.1 Questions related to consistency 109

9.2 Completeness of the data: missing values $\quad 110$

9.2.1 Effects of the missing values $\quad 110$

9.2.2 Treatment of the missing values $\quad 111$

9.3 Procedures 111

9.3.1 Internal consistency: measuring differences 111

9.3.2 Internal consistency: coherence within the domains 111

9.3.3 Dimensionality: the distinction between the domains 112

9.3.4 Some comments on the statistical power 113

9.3.5 Step- by-step analysis of internal consistency and dimensionality $\quad 114$

9.4 Results $\quad 114$

9.4.1 The percentage positive scores $\quad 114$

$\begin{array}{lll}\text { 9.4.2 Internal consistency } & 115\end{array}$

9.4.3 Position of Sexuality within the theoretical construct 117

9.4.4 LISREL confirmatory factor analysis: defining the model 118

9.4.5 LISREL contirmatory factor analysis: professionals judgment 119

9.4.6 LISREL confirmatory factor analysis: patients information 120

9.4.7 LISREL confirmatory factor analysis: correlations between factors 121

$\begin{array}{llr}9.5 & \text { Discussion } & 122\end{array}$

9.6 Summary 123

10 Interjudge agreement $\quad 125$

10.1 Procedure 125

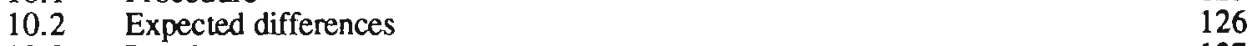

$\begin{array}{lll}10.3 & \text { Results } & 127\end{array}$

$\begin{array}{lll}\text { 10.3.1 Interjudge agreement on group level } & 127\end{array}$

$\begin{array}{ll}\text { 10.3.2 Interjudge agreement - response tendency } & 129\end{array}$

$\begin{array}{ll}\text { 10.3.3 Interjudge agreement - past performance } & 129\end{array}$

10.3.4 Interjudge agreement - differences between young and old 130

$\begin{array}{lll}10.4 & \text { Discussion } & 131\end{array}$

10.4.1 Interjudge agreement on group level 131

10.4.2 Interjudge agreement - response tendencies 132

$\begin{array}{ll}\text { 10.4.3 Interjudge agreement - retrospective information } & 132\end{array}$

10.4.4 Interjudge agreement - determination of agreement by specific 132

10.4.5 Current literature on judgement of social behavior 133

$\begin{array}{llr}10.5 & \text { Summary } & 134\end{array}$

PART 4 ASPECTS OF VALIDITY 135

11 Concurrent validity 137

$\begin{array}{lll}11.1 & \text { Procedure } & 137\end{array}$

$\begin{array}{ll}\text { 11.1.1 The issue of concurrent validity } & 137\end{array}$

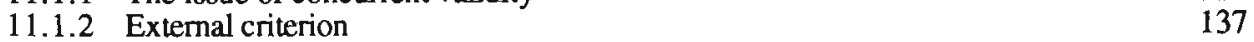

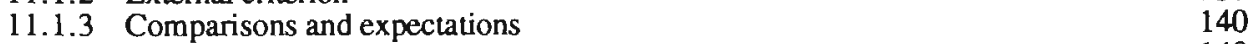

$\begin{array}{lll}11.2 & \text { Important questions } & 140\end{array}$

$\begin{array}{lll}11.3 & \text { Results } & 141\end{array}$

11.3.1 Frequencies - sensitivity of the Sickness Impact Profile 141

11.3.2 Concurrent validity - comparison with the Sickness Impact Profile

$\begin{array}{lll}11.4 & \text { Summary } & 142\end{array}$ 
12 Differences between groups 143

12.1 Procedure 143

12.2 Assumptions on outcome and important questions $\quad 145$

12.3 Results 146

12.3.1 Differences in the professional's judgment 146

12.3.2 Differences in the patients information 147

$\begin{array}{lll}12.4 & \text { Summary } & 148\end{array}$

13 Clinical validity: the case reports, feedback and data 149

13.1 Questions related to clinical validity 149

13.2 Role performance and achievement of position roles $\quad 150$

13.3 Topics of interest in the feedback 150

13.4 Operationalization and data, a recapitulation 151

13.5 Case reports 152

13.5.1 The young and unmarried men at onset 152

13.5.2 The young and unmarried women at onset 156

13.5.3 The older married men at onset 160

13.5.4 The older married women at onset $\quad 162$

$\begin{array}{lll}13.6 & \text { Summary } & 165\end{array}$

14 Measuring deviation: a matched comparison with a reference group 167

14.1 Hypothesis on differences between patients and references 167

14.2 Selection procedure $\quad 169$

$\begin{array}{lll}14.3 & \text { Comparisons } & 170\end{array}$

14.4 Results 171

14.4.1 Outcome of the matching procedure 171

14.4.2 Cases and controls: comparison in role performance 172

14.4.3 Cases and controls: variability of position roles 173

14.4.4 Cases and controls: network variability 173

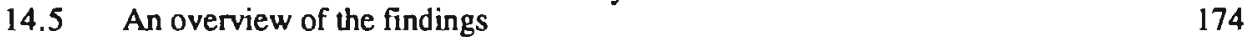

$\begin{array}{lll}14.6 & \text { Summary } & 175\end{array}$

$\begin{array}{lr}\text { PART V CONCLUSION } & 177\end{array}$

15 Summary and conclusions 179

15.1 A summary of the instrument development 179

15.1.1 Preliminaries: Chapter 1 and Chapter 2 179

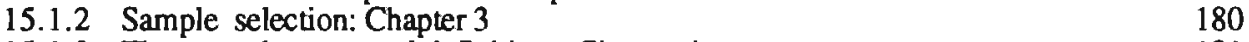

15.1.3 Theory and conceptual definitions: Chapter 4 181

15.1.4 The need for a new instrument: Chapter 5 181

$\begin{array}{ll}\text { 15.1.5 Item selection procedure: Chapter } 6 & 181\end{array}$

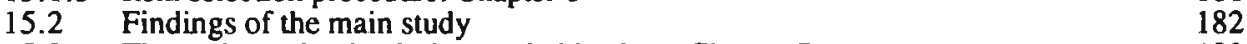

15.2.1 The main study, the design and objectives: Chapter 7 182

15.2.2 Reproducibility of the ratings: Chapter $8 \quad 182$

15.2.3 Construct and content validity: Chapter 9 and $10 \quad 183$

15.2.4 More complex aspects of validity: Chapters 11,12,13 and 14

15.3 Methodological problems encountered in the study 185

$\begin{array}{lll}15.4 & \text { Conclusions } & 185\end{array}$

16 Samenvatting en conclusies $\quad 187$

16.1 Een samenvatting van de instrumentontwikkeling 187

16.1 De voorstudies: Hoofdstuk 1 en Hoofdstuk 2 187

16.1.2 Selectie van de onderzoeksgroepen: hoofdstuk $3 \quad 189$

16.1.3 Theorie en conceptuele defenities: hoofdstuk 4 189

16.1.4 Literatuur overzicht: hoofdstuk 5 190

$\begin{array}{ll}\text { 16.1.5 Item selectie procedure: hoofdstuk } 6 & 190\end{array}$

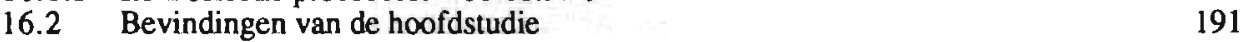

16.2.1 De hoofdstudie, ontwerp en doelen: hoofdstuk $7 \quad 191$

16.2.2 Reproduceerbaarheid van de coderingen: Hoofdstuk 8 


\section{CONTENTS}

16.2.3 Construct en inhoudsvaliditeit: hoofdstuk 9 en hoofdstuk 10

16.2.4 Meer complexe kenmerken van validiteit: de hoofdstukken 11, 12, 13 \& 14

16.3 Methodologische problemen die we in de studie tegenkwamen

16.4 Conclusies

References

APPENDIXES

I Group differentiation (groepenindeling)

II Manual (in dutch)

III The Questionnaire items (in dutch)

IV Case report

V Tablebook

VI Formal mathematical representation lisrel model

VII The corrected item sumtotal correlation

VIIA The correlation matrix

VIII Calculation of the minimum size

IX The standardized cronbach's $\alpha$ 



\section{PART 1}

\section{Introduction}

The first part of this book consists of two introductory chapters which are devoted to the background of the study. Chapter 1 presents the general perspectives, deals with the philosophical and historical background and also presents the results of some preliminary qualitative studies. Chapter 2 describes the practical application of the instrument we developed to measure social role development. A single case history is presented (Noorthoorn et al., 1991 and Noorthoorn et al., submitted 1992).

This part presents what the study is about. Those readers mainly interested in the mental health care aspects of the study should read Chapter 2, which contains a description of the practical application of the instrument. 
1 Y739 


\section{CHAPTER 1}

\section{Introduction and history}

\subsection{The aims and scope of this thesis}

The aim of this thesis is to describe and measure the degree of social integration of a socially less adapted population of the chronic mentally ill. The study resulted in an instrument to measure social role fulfillment and its development: the Social Role Performance and Development Inventory (SRPDI, Noorthoorn et al., 1991). Current research and knowledge in psychiatry provides abundant information relating the disorder to the direct effect on the social position of the individual (for an overview, de Jong, 1991). Only recently have efforts been aimed at the implementation of research instruments in the daily practice of mental health care (for an overview Anthony \& Liberman, 1986; for the Dutch setting: Baars et al., 1990; de Jong \& v.d. Lubbe, 1991). Few - theoretically substantiated - efforts have been made to develop instruments relating the social position of the individual to the long-term, lifetime development of the chronic mental illness (Hill, 1989; Häfner et al., 1992). This study describes one of these efforts. Some sociological concepts are translated in such a way that professionals are provided with an operational questionnaire covering the difficult process of the development of social integration. The focus of this study is threefold:

1 to develop an instrument which relates the current degree of social integration to the lifetime development of social adaptation;

2. to fit this instrument into a simple and understandable theoretical framework;

3. to construct the instrument in such a way that less extensively trained professionals may be encouraged to apply it in their daily practice in the resocialization of the chronic mentally ill in ambulatory care.

This chapter deals with the general theoretical perspective and the main questions of this study. The current study is embedded in a line of research. We first present some background information of this line of research $(\$ 1.2$, and $\S 1.3$ ), followed by a short review of the state of the art in rehabilitation research and care $(\$ 1.4$ and $\S 1.5)$. We then present our frame of reference $(\S 1.6)$, followed by the general perspectives and the main questions of this study $(\S 1.7$ and $\S 1.8)$.

\subsection{Following a tradition}

The study presented here is a project in a line of research which is focused on the chronic mentally ill (Escher et al., 1987; Romme et al., 1987; Baars \& 
Uffing, 1987, 1988; Honig, 1989; Noorthoorn et al., 1991). The department of Social Psychiatry of the University of Limburg, in cooperation with the Community Mental Health Services of Maastricht, the Netherlands, is engaged in different studies aimed at professionalization of care. These studies all deal with various levels of functioning of the chronic mentally ill. The research program, focused on the chronically mentally ill, was based on a global inventory (Romme et al., 1981; Honig et al., 1987). A number of studies were performed. Of these, we will describe two pilot studies leading to this specific study. In this paragraph we will describe the global inventory and in paragraph 1.3 the two pilot studies that preceded the current study.

In a study carried out between 1982 and 1984 (Radstake, 1985) and aimed at the development of health care for the chronic mentally ill, 100 extensive problem analyses (P.A.) were constituted following a semi-structured inventory covering 3 main aspects:

1. the patient's psychiatric history;

2. the patient's 4 levels of functioning: the somatic level, the individual level, the micro social level and the meso social level;

3. the patient's competence.

The P.A. has been designed as a practical treatment-oriented instrument. Its manageability by all workers in a multi-disciplinary psychiatric team was one of the major goals. It is neither a research instrument nor a rating scale but serves as an inventory with open-ended questions, to be completed within the first three months of regular patient care. The somatic level covers physical disease and complaints. The individual level covers the individual's problems in terms of the DSM-III and refers to possible psychological developmental disorders. It is accompanied by a guideline for taking a biographical history following the stages described by Erickson (1963). The micro social level goes into a description of the problems in the interaction of the patient with his social network. It contains not only an overview of the number of social contacts or of difficulties within social contacts, but also an extensive analysis of the functional characteristics of the network (Baars et al., 1990). The meso social level covers the level of integration of the individual within society (for example, vocational history, coping with institutions, living up to expectations). In effect, this level covers the particular position of the individual within society.

The organization of the four levels (Figure 1.1) is developed from the more intricate and differentiated, but less practical taxonomic hierarchy of Cooper (1981), and follows concepts similar to those of von Bertalanffy (1950). Level 1 of the P.A. covers the first three ranks defined by Cooper: the anatomy, the physiological homeostasis and neurological functions and physiologically steered behavior as eating, drinking, sexual arousal, etc. Level 2 covers the 4 th rank defined by Cooper, the control of the individual over his direct environment, as well as his response to the direct environment. Level 3 covers 
Cooper's 5th rank, over the dyadic relations with the direct environment. Level 4 covers Cooper's 6th through 8th rank; the roles and expectations within a small group and affiliation to social and cultural groups. Cooper's 9th rank, the metaphysical, is left out of analysis. Level 1 of the P.A. has been investigated by Honig (1989). Level 3 of the P.A. is under investigation by Baars \& Uffing $(1988,1990)$.

Figure 1.1 The system-theoretical model (Honig et al., 1987).

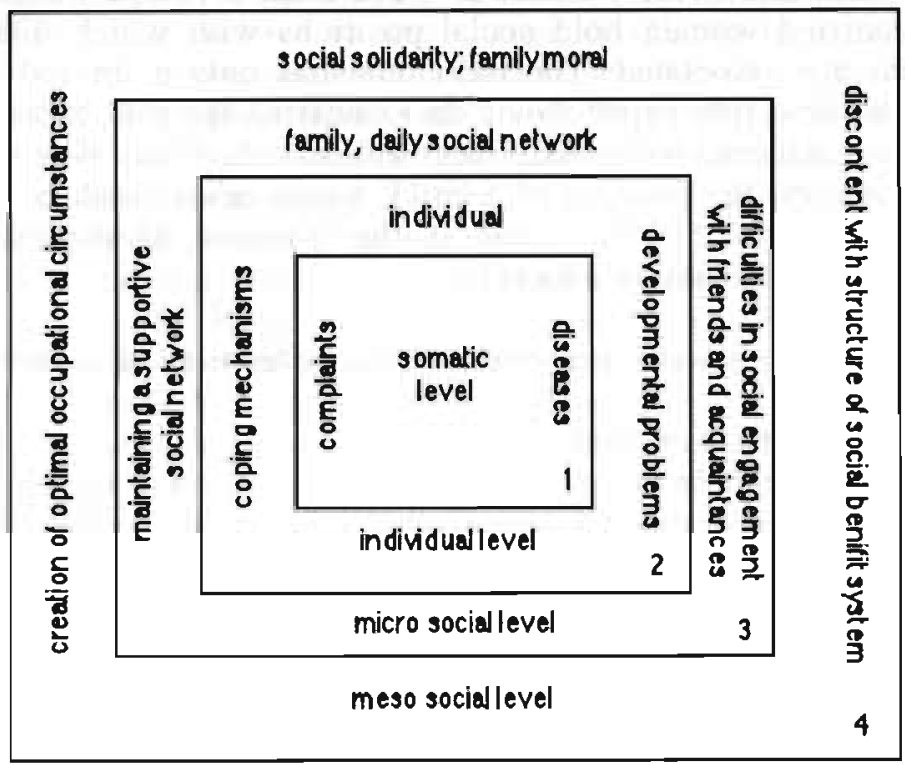

This thesis focuses on a development of level four of the P.A. Prior to the current study a number of efforts were made to systematize the information gathered in level 4 (Romme, 1987). After these preliminary studies, we chose to operationalize the fourth level of the P.A. into a practicable instrument to be used by mental health professionals in their analysis of the patient's social integration in terms of social roles and living up to expectations. In the next paragraphs we will present the results of these preliminary studies. In the paragraphs thereafter we will explain why we made the effort to develop a new instrument, instead of relying on current instruments.

\subsection{Preliminary studies}

In 1986 and 1987 two pilot studies were performed to systematically evaluate information gathered on level four of the P.A. These were qualitative studies aimed at identifying similarities between groups of patients (Romme, 1987). 


\subsubsection{First effort}

The first effort on the fourth level concerned the systematization of the information gathered by means of 100 problem analysis protocols (Honig et al., 1987). That study covered a random selection of 541 patients in care in 1982-1984 (Escher et al., 1987). One of the studies following that study was directed at the development of a classification of diagnostic categories according to social position. A qualitative description of the information gathered on level four of the problem analysis inventory was made. The cases were categorized according to marital status and gender. It was assumed that unmarried men, unmarried women, divorced men, divorced women, married men and married women hold social positions with which different role expectations are associated. The individual has only a limited amount of influence on these role expectations. In evaluating the role expectations the social position achieved by the individual was described first. Was it, in respect of responsibilities, the position of a child, young adult, adult or elderly? In respect of vocational status, was it the position of director, middle management, subordinate, or patient?

The case descriptions were then evaluated on differences or resemblances the following aspects:

1. age and phase of life at onset;

2. difficulties in keeping or gaining a rewarding position in society after onset of care, for example in work, as a spouse, as a parent, or otherwise;

3. dependence on care.

After evaluating the achieved social position, difficulties in achievement were related to type and chronicity of the psychiatric behavior. 13 groups were distinguished (appendix no. I). Comparison of the different groups made it clear that in fact certain social roles are associated with the patient's social position, and that the fulfillment of these roles is related to age and phase of life at onset of mental health care. One of the groups comprises the unmarried men. Romme et al. (1987) observed that patients in this group mainly have difficulties in the developmental transition from either child or young adult to adult. As a psychotic or a neurotic having been labeled mentally ill, many of this group have never had a successful partner relationship. They only partly succeeded in their professional career and often barely seem able to function independently in social situations.

\subsubsection{Second effort}

In a second pilot, the implications of the group differentiation in terms of need for care (as identified by the professionals; c.f. Stevens, 1986) was studied. 108 descriptions of case histories of newly referred clients, in care for a period of between half a year and a year, were made and compared with the groups distinguished above. Inclusion criteria were formulated for each group. 
The research procedure consisted of the following steps:

1. Into which group can a specific case be categorized on the basis of age, sex and marital status at onset of patient career?

2. To which extent does the case history fit the inclusion criteria as formulated in the group descriptions?

3. To which extent does the case history differ from these criteria?

4. To which extent are the criteria clearly formulated, and do they have any relevance in distinguishing groups on according to their treatment needs?

81 patients were considered to fit in the criteria. 15 of the 27 patients who not fit were diagnosed manic depressives. In most of these cases, the psychiatric disorder could not be related to any change or relapse in achieved social position. In fact, the illness had led to a chronic dependence on medication and an infrequent primarily preventive contact with the professional only to cover the threat of backlash and to evaluate the effect of the medication. Of the 81 patients, 59 could be consistently placed into a specific group. The following groups were regarded as most recognizable:

1. a group of unmarried men at onset, who had a psychotic decompensation in adolescence $(n=15)$. These men never succeeded in establishing an intimate relationship with a girl or in becoming intimate sexually;

2. a group of married men at onset, exhibiting somatic fixation as their primary complaint $(n=16)$. This fixation is interwoven with long-standing work-related problems. Loss of work being embedded in an increasing complex process of negative interrelations between task fulfillment and somatic complaints;

3. a group of unmarried women at onset $(n=8)$, with a history of difficulties emerging around puberty. Coming from problem families, they experienced many conflicts at an early age, left home when they were young, or reacted with withdrawal within their context. Having had a chaotic youth, they display a high energy level and an impulsive personality, moderately structured and hardly functional in work, sports, or community service;

4. married women at onset, who no longer can or are willing to comply with the expectations that are part of the loving, caring role attributed to the married woman $(n=11)$. These women experience little satisfaction in the intimate relationship with their husband, the marriage is also burdened by external or internal stressors, and the women can rarely compensate for the experienced burden within their lives. They subsequently react with a depression or develop a paranoia;

5 . elderly single women at onset of illness, either widow or never married $(n=9)$. These women have had a fulfilling professional or family life in the past, but now encounter total isolation. Having lost all contact with any external environment, they withdraw in paranoia or delusion, they only reluctantly accept supportive care and they show a behavior which sparsely can be influenced. 


\subsubsection{Conclusion of the preliminaries}

These preliminary investigations led to the conclusion that role performance and achieved social position are important factors in dependency on care and the development of a relapse. An important finding is that similarities between patients can predominantly be found in similar patterns of social functioning. Within each group, we observed a rather limited range of psychopathology. The main conclusion was that the process of deterioration was comparable between members of a given group. This finding determined the choice to develop an instrument with which the process of social development in particular can be described in a reliable and valid way and which takes retrospective distortion into account.

\subsection{The state of the art}

Within the last several decades, a consensus has developed about what constitutes a conceptual model for rehabilitation and its underlying philosophy, as well as what constitutes appropriate rehabilitation practice. The conceptual model was introduced by leaders in physical medicine and rehabilitation and later extended for the mental health disciplines (Anthony, 1980, 1982). Both physically and psychiatrically disabled persons exhibit disabilities in social functioning; handicaps in role performance; needs for a wide range of services, often for a long period of time; and frequent failure to experience total recovery. Rehabilitation of psychiatric disorders, as with physical illnesses, begins when the pathology and the impairments of the acute stage stabilize. In cardiac rehabilitation, intervention begins after the myocardial infarction and the associated pain and stress have been resolved. Similarly, rehabilitation of schizophrenia begins when the acute and florid psychotic symptoms recede or stabilize. Even if the symptoms persist, rehabilitation can proceed within the limits of the individual's capacity to respond to training and supportive interventions (Anthony et al., 1983). The classification and consequently the research models in physical medicine are built upon three central concepts, impairment, disability and handicap (Figure 1.2).

Figure 1.2 Causal sequence of the ICDIH - model

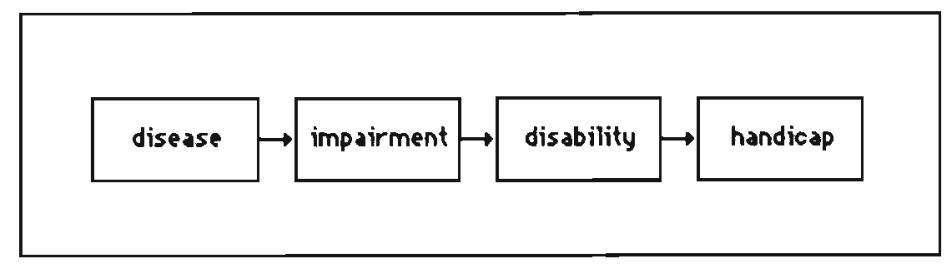


If an impairment is not cured or corrected, and the individual does not return to what may be regarded as normal, a disability is the outcome. Disability refers to the restrictions in the individual's ability to perform a function. The disability may or may not limit the ability to perform a social role. The disability, thus, leads to the level of "handicap": the social disadvantage which may arise from disability. When we translate this model to psychiatry, some problems arise. For most of the disorders, the pathology is unknown. The impairment, defined within the criteria of a specified syndrome diagnosis of the DSM-III, refers to a combination of (a number of) behavioral deficits with a specific course. Especially at the levels of "disability" and "handicaps", recent studies in the field of social psychiatry question whether the simple linear model provided in the International Classification of Disabilities, Impairments and Handicaps may be applied in psychiatry (Wiersma, 1986; Häfner et al., 1992; for an overview, de Jong, 1991).

A conceptual problem is that deviant behavior relates to all three levels of this model. The negative symptoms of schizophrenia indicate the incapacity to communicate, and may be caused by lesions at a neuroreceptive level. The negative symptoms determine the definition of the disease schizophrenia. However, the negative symptoms are in fact a disability: the absence of communicative behavior. In the meanwhile, the real cause of the impairment is unknown. Several question marks arise (Figure 1.3).

Figure 1.3 Unclarified relationships in the ICDIH - model

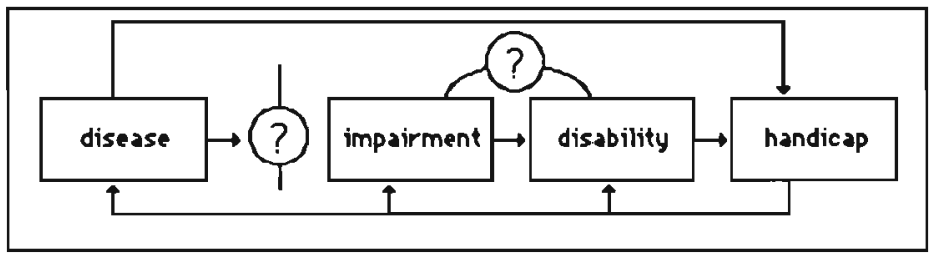

In effect, the same observation defines both an impairment and a disability. At the same time, we do not know what really determines our observation. In the course of mental illness cause and effect shift to and fro. Causal relations may well be the other way around. The handicap (social isolation) may in fact cause the disorder. We may indeed ask ourselves whether we can expect the DSM-III and the ICDIH, or their offspring, to provide a full and detailed model separating the cause clearly from the effect of the disorder in terms of social functioning. Developed as global tools for classification, and based on a nontheoretical consensus between expert professionals in the field of medicine and psychiatry over the course as well as the individual behavioral effects of the 
disorder, these instruments are not necessarily concerned with a description of everyday human social functioning. They follow a psychiatric frame of reference, which is focused on the observable behavior of the individual. Consequently, interventions usually focus on idiosyncratic behavioral targets, targets which are then monitored for decisions to continue, change or terminate the interventions (Anthony \& Liberman, 1986).

Recent developments in psychiatry stress the need to integrate other frames of reference, relating behavior to the social context (De Vries, 1992) and socialization processes (Grob, 1981; Galligher, 1987; Hill, 1989), and to develop a theory on the judgment of social behavior (Wykes, 1986; Wiersma et al., 1988; Wing, 1989). Concerning the chronic mentally ill, a number of current studies advocate the importance of understanding when and how the disorder really begins. Retrospective assessment of longer time intervals has been the goal of recently developed instruments for the lifetime assessment of psychopatholgy such as the 'Schedule for Affective Disorders and Schizophrenia', SADS (Endicott \& Spitzer, 1978), the 'Past and Present State Examination' (McGuffin et al., 1986) and the 'Composit International Diagnostic interview', CIDI (Robins, 1985). Two instruments focus on lifetime development of psychopathology as well as on social adjustment or social role performance: the Adult Personality Functioning Assessment (Hill, 1989) and the Interview for Retrospective Assessment of the Onset of Schizophrenia, IROAS (Häfner, 1992). Studies on the reliability and validity of time-oriented items in these instruments indicate that the retrospective evaluation of major life events, psychiatric symptoms and social effects is possible and show a satisfactory reliability.

Information from people who are important in their life, and pinpointing change to significant moments in life, such as the death of a family member or the beginning of occupational training, optimizes the quality of the assessment (Wittchen et al., 1989). Häfner's study (1992) shows a powerful reliability on several indicators of social adjustment, irrespective of the time gap between interview and remission. However, these instruments have little practicability for mental health professionals, being highly complex (upto 240 and 168 items), and needing psychiatric expertise and extensive training. These instruments have little flexibility in relating the interview to the particular individual's circumstances, as they are highly prestructured (Patton, 1987).

Until now, a systematic and practical inventory assessing the main problem areas in the daily life of the chronic mental patient has not been available. The two most important instruments in this domain (the Social Role Performance schedule, SRP, Hurry \& Sturt, 1981; the Groningen Social Disability Schedule, GSDS, Wiersma et al., 1988) focus on the assessment of current behavior. Other instruments which trace the development of social functioning in psychiatric patients on an individual level (e.g. Strauss, 1981) require a timeconsuming and often inefficient assessment. 
Reviewing the instruments at the starting point of this study in 1988, with our objectives in mind, we concluded:

1. insofar as the instruments covered aspects of lifetime development, they were not simple and understandable and did not relate to any theory on socialization or normal human development. Most of the instruments focused on the social impact of specific disorders;

2. insofar as the instruments covered aspects of social integration they did not cover aspects of lifetime development;

3. none of the instruments provided a practical framework for professionals.

Next to these problems we also encountered problems related to the level of detail of the information gathered and the coding systems applied in these instruments. A full overview of these comments is presented in Chapter 5. To clarify some choices we made in the current study, we will discuss our frame of reference after reviewing the frame of reference currently applied by most professionals.

\subsection{The professional's options - a need for systematic inventories}

In clinical psychiatry, releaving symptoms is the main goal. Rehabilitation medicine, and in effect its psychiatric offspring, the care of the chronic mentally ill (either ambulatory or inpatient), aims at something essentially different. It aims at normalization and optimalization of functional disabilities given the impairment (de Witte, 1991). This is not brought about by a single focus on the disorder and symptomatology, but requires a more extensive evaluation of the individual's capacities in relation to the facilitation of initiative and social interaction in the personal environment. The main problems of the chronic mentally ill are related to ongoing difficulties in interaction, preserved and not relieved by care focused on remission of deviance instead of on use and facilitation of talents and capacities within the patient (Bachrach, 1980). These ongoing difficulties in interaction are such that the patient himself, or the social environment, feels a need to present the problems to a person outside this environment. A need is felt to visit a professional problemsolver, consequently a mental health professional. The professional subsequently translates the problems into his own frame of reference, mostly in terms of the extent of deviant behavior, a diagnostic category or individualized psychological explanations of the behavior. He combines this with often chaotic presentation of the history and needs by the patient and thus formulates a therapeutic plan. The core of the therapeutic plan is what the professional regards as relevant does not necessarily relate to the problems experienced by the patient (Rotteveel \& Uffing, 1988).

In dealing with the chronic mentally ill, on the one hand the complexity of the presented problems and a "therapeutic immunity" may lead to staff burnout (Lamb, 1979a, 1979b), while on the other hand simple and effective interventions may remain unused, notwithstanding extensive psychotherapy (Baars \& Romme, 1984). Diagnostic instruments such as the DSM-III or its 
offspring rarely focus on difficulties in interaction but focus on (dis)behavior as a symptom, an effect of a disorder. The medical frame of reference remains the focus of attention: a disorder emerges, the disorder leads to difficulties, medication relieves effects of the disorder, and cure is brought about by changing the cause of the disorder. However, in the chronic mentally ill, especially in ambulatory care, therapeutic action lies almost entirely within the domain of social interaction with others.

Honig (1989) therefore argues that loss of information using this main "Classic medical" frame of reference is too large to be either effective or practicable in ambulatory care. In a hospital setting, this classical frame of reference seems to have more effect. But then the patient is isolated from the environment causing most of his problems: his own natural setting. After discharge, patients quite show a relapse. The risk of this relapse is quite often a burden for the institutional psychiatrist, causing reluctance in resocialization efforts (Haveman, 1982). For inpatient and ambulatory care, new tools need to be developed, with a focus on the integration of the individual in his own environment (Anthony \& Liberman, 1986).

\subsection{Frame of reference: social homeostasis}

The philosophical basis of this thesis is the relationship between cause and effect in psychiatry. It is derived from what Querido (1956) has described as the social homeostasis mechanism. This mechanism describes how the equilibrium between an individual and society is influenced. Querido states:

"Between environment and individual, society intervenes. Therefore the individual has to find an equilibrium between himself and the forces acting in society. Society came into being because its members are willing to pay with individual dependence, to sacrifice freedom for security. If for the individual the social pressure becomes too heavy, he has no feedback to readjust society. His only means to maintain the equilibrium is to readjust himself. His other choice is to give up his membership of society, to place himself outside society, either as a criminal or as a sick or insane person, or as a marginally living individual. If, however, the individual in the circumstances mentioned above succeeds in making use of the same mechanisms that brought society into being, if he succeeds in uniting his individual tendencies with those of others, then it is possible to create a feedback-force which is strong enough to influence the social forces and which therefore may change the social equilibrium in such a way that it becomes more acceptable to him and his group. This mechanism is: social homeostasis".

In the social homeostasis theory the model of a circular causality is for the first time introduced in social psychiatric thinking. Querido applied the principles of homeostasis, known from physiology, to the interactions of the individual and his environment. In the interaction with the environment, the individual and the environment always seek an equilibrium, in a physical, a psychological, or a social sense. Disruption of the equilibrium always induces a compensatory mechanism. The mechanism is at first regulative within the 
individual's own perceptions; when these are insufficient, the regulation is imposed on by the environment.

The environmental regulation can be complementary (supportive and caring) or non-complementary (repulsive or rejectory). Psychiatric illness is then regarded as displacement of social integration. According to Querido, when people are unable or do not want to meet other's expectations over a prolonged period of time, they place themselves outside society. Since the individual is not capable of changing the society to which he belongs, his only choice is either to adapt to that society or to give up his membership in it. The implication of Querido's concept of illness as a displacement of social integration is that, in dealing with patients, professionals have to realize the limitations imposed by the means they try to apply in therapy. A change in behavior may indeed be brought about in the therapeutical setting, but is by no means successful if it cannot be brought into effect in daily life. Social rehabilitation in this way therefore has two options:

1. either to change the patient in such a way that he is able to take up his membership in society;

2. or to change the forces that forced him to give up his membership.

The consequence of this philosophical point of view is that health may be conceived as a special state of an unstable equilibrium between the individual and society. The disorder, seen in this way, becomes an interactive result of this state. The disorder can be seen as a displacement of social integration. According to the social homeostasis mechanism, the causal relationships should be adjusted as following (Figure 1.4).

Figure 1.4 Circular dependecies in the disability-impairment-handicap model.

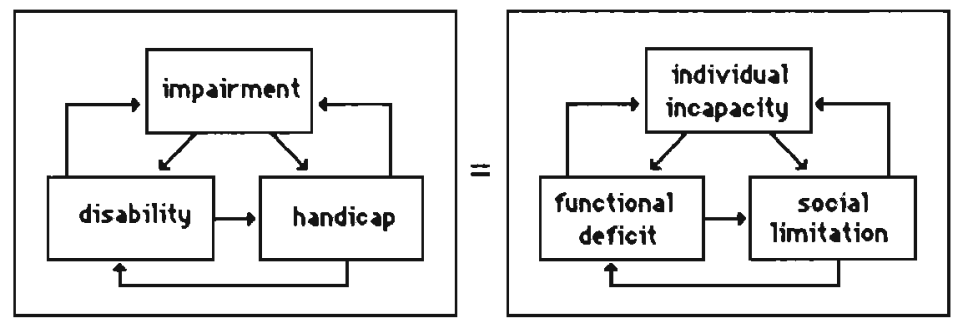

This way of reasoning makes it important to connect rehabilitation with social integration in a more differentiated way. In the above model, the individual incapacity - the impairment - determines both the societal limitations (reactions in the environment) as expressed in the handicap, as well as the functional deficit (the observable performance) as expressed in the disability. The variables in the model are interdependent. The functional deficits are 
determined by social integration. The social integration is determined by the functional deficit. In the development of an instrument relating social integration to lifetime development we will have to focus on an operationalization of the development of the functional deficit and a description of the social integration. In the next paragraph we present a summary of our perspectives

\subsection{General perspectives}

This thesis focuses on a more detailed development of level four of the Problem Analysis (Honig et al., 1987): the evaluation of the interaction of the patient with society by professionals. The degree to which a patient is able to function in his community depends not only on the social problems he has, but also on his particular social position. In level four, special attention is focused on the possibility of compensating for losses (often the loss of work and the loss of structure and meaning in one's life) and on the possibility of promoting the social interests of the patient. In the chronic mentally ill, the current social position is the endpoint of a development over many years. To understand the achieved social position we need an assessment which relates this to the social development. As already formulated in $\$ 1.1$, the first objective of this study is to develop an instrument which relates the current degree of social integration to lifetime development of social adaptation. In the chronic mentally ill, the number of social positions is limited and has become less after the onset of mental illness (Greunberg, 1967). The individual only partly succeeds in living up to the demands of society. The performance measured at a specific moment in time is the residual of lifetime development. For rehabilitation purposes, it is necessary to know when deterioration first occurred and how the process of deterioration developed later on (Shepherd, 1989).

Social integration relates to two general concepts (Murphy, 1981). Firstly, it is related to the degree of social integration in the direct environment and in society. What does the individual have in terms of a social network (Adams, 1967; Speck \& Atteneave, 1973; Erikson, 1984) and in terms of social positions within behavioral settings (Barker, 1963)? Secondly, social integration is related to the activities and initiatives which the individual undertakes in the relationships with others in his direct environment. How does the individual function and succeed in gaining the appreciation which he needs in order to adapt? Everyday life is composed of a sequence of behavioral settings, where the individual is either alone or (inter)acts with others within a social context. Behavioral settings place demands on behavior. Human beings are social beings dependent on others in daily life. Living with others indicates an adaptation to the demands and expectations set by society and by the direct social environment. An adaptation necessary to fulfill the demands at work, within the family, with friends, or in social clubs or other behavioral settings. Some demands are clear-cut and explicit, such as job expectations specified in a work contract. Others may be implicit and relate to subcultural setting, to age, sex or the individual's phase of life. 
The first dimension of social integration < what does the individual have > implies a description of the number and variability of social positions which the individual fulfills at the moment of assessment. For the second dimension < how does the individual function $>$ we selected the concept of social role performance, as this concept relates performance to expectations set by the environment. Our second objective was to fit this instrument into an understandable framework. This objective is the reason we formulated an extensive theoretical fundament for these two dimensions (Chapter 4 ). The third objective was to construct the instrument in such a way that less trained professionals can use it. Because of this objective, we collaborated closely with mental health professionals throughout various phases of the research (Chapter 6). We chose for a semistructured, interview-based questionnaire. This method of assessment fits into our requirements of flexibility and reproducibility at a case level.

\subsection{Research questions of the current study}

The decision to develop an instrument led to the following conceptual questions:

- Concerning the first objective, the development of an instrument:

1. how can social integration be operationalized?

2. how can social role performance best be described in terms of a developmental process?

- Concerning the second objective, the development of an understandable framework:

3. which theoretical model can be applied in respect of the development of conceptual and operational definitions relevant in the description of social role development?

4. how can development of social functioning be operationalized in a way which is practical for mental health professionals?

The first question concerns a description of the current role fulfillment. The second question relates to assumptions on coherence within social roles both current and in respect of development, and to assumptions on cause and effect in the developmental process. Dimensions in social behavioral development need to be identified. For this question we applied the socialization theory of Hurrelmann (1983). These two questions will be addressed in greater detail in Chapter 2. For the third question the role theory of Gerhardt (1971) is applied and operationalized. In her monograph "Rollenanalyse als kritische Soziologie" she distinguishes different types of roles according to their permanence. The theories of Querido, Gerhardt and Hurrelmann are applied to describe certain aspects of social integration, socialization and lifetime development beyond childhood. The fourth and final question is dealt with by developing the instrument in a continuous interaction with the mental health professionals 
collaborating in the study. The instrument has been developed in a sequence of small steps following the procedure of Gable (1987) in which a list of 116 items was reduced and edited to a coherent instrument covering role development within five domains of social functioning (Chapter 6).

\subsection{The structure of the book}

This first chapter highlighted the preliminaries and philosophical background of the study. Following this introduction, Chapter 2 clarifies in greater detail some theoretical and philosophical fundamentals of the study by means of a case history. An effort is made to identify a coherent method in the analysis of social role development and performance.

The second part of this book describes the theoretical and practical process of instrument development and presents a characterization and an overview of the samples. A global overview of literature on the identification of chronicity in mental health is presented in Chapter 3. It also offers an insight in the research protocol in different stages of the study and describes the demographic and diagnostic characteristics of the different samples. Non-response and dropouts are described. It finishes off with a selected set of findings regarding characteristics of the samples which are relevant to the conclusions to be made in the following chapters. So much for the scientific rituals for identification of population. Chapter 4 more extensively highlights the theoretical presumptions of the instrument. Chapter 5 offers a full overview of current instruments in this field of research. Chapter 6 provides a global insight in aspects of content validity.

The third part describes the most important analyses of the main study. Chapter 7 presents the main requirements of the instrument and briefly recapitulates what we are interested in, with respect to aspects of instrumental utility, reliability and validity. Chapter 8 describes the reproducibility of the scoring of the items of the instrument in terms of interrater agreement. Chapter 9 describes the construct validity of the instrument in terms of the dimensionality and internal consitency. Chapter 10 goes into aspects of content validity by comparing.

The fourth part deals more extensively with several aspects of validity. Chapter 11 presents the criterion validity of the instrument by comparing the findings with another similar instrument measuring social functioning. Chapter 12 investigates the discriminative power of the instrument by looking at univariate comparisons between various selection groups participating in the main study. Chapter 13 summarizes the implications of the study for the daily practice of the rehabilitation of the chronic mentally ill. Chapter 14 compares the results obtained from patients with results obtained from a reference population.

The fifth part contains the summaries. Chapter 15 covers the main conclusions as well as an overview of the previous chapters. This chapter is repeated in Dutch in Chapter 16. 


\section{Presenting an effort}

This chapter provides a first effort to present our ideas on the development of the Social Role Performance and Development Inventory (SRPDI) ${ }^{1}$. The need for a more systematic social interactionistic approach to chronic mental patients is discussed by means of a single case report.

\subsection{Abstract}

Successful rehabilitation of the chronic mentally ill quite often depends on interventions in the social environment (Shepherd, 1989). Improvement of social functioning by enhancement of existing social roles can only be realized in a productive environment in which the individual can flourish (Bennett, 1978). A thorough and systematic analysis of social role fulfillment means not only determining the achieved social position of the individual, but also analyzing the lifetime social development. Especially in the chronic mentally ill, behavior is a result of long-term interaction with the direct environment (Adler, 1984). This article shows how the development of social role fulfillment can be analyzed in daily practice, using a single case history. It explains the main features and theoretical basis of an instrument to be used in the diagnostic phase by case managers in the confrontation with patients whose long-term claim for help has quite often led to staff burnout (Lamb, 1979b) and whose level of functioning displays the remnants of hospitalization effects in combination with extensive social isolation. The method discussed has been used in the analysis of 107 ambulatory chronic mentally ill, patients in the care of the Social Psychiatric Service of the Community Mental Health Center, Maastricht. In a next article, the authors will go into aspects of validity and reliability of the instrument.

\subsection{Context of the study}

Handling the chronic mentally ill, especially in the outpatient setting, has been the subject of extensive study (for reviews, Bachrach, 1980; 1982). Most of the American studies deal exclusively with organizational aspects of care. Some studies indeed focus on social adaptation, but only in patients under highly experimental conditions. In the far denser Dutch Mental Health Care system, a variety of specialized services, both inpatient and outpatient, are responsible for the care of the chronic mentally ill. The methods applied in the distinct

Previously printed in Dutch in The Dutch Journal of Psychiatry (Noorthoom, 1991) and submittled in a different format for publication in English in The International Joumal of Social Psychiatry, 1993. 
settings differ widely and depend mainly on the training of the professional (Henkelmann, 1987). Inpatient care focuses mainly on two aspects: firstly, the normalization of symptomatology, using medication and inflicting social sanctions; and secondly, the self-conception of the individual's reactions or motivations using various psychotherapeutic methods of which behavioral training is the most important (Baars \& Romme, 1986). Inpatient care is dominated by the medical point of view, aimed at cure and provided within a hierarchical structure with the psychiatrist on top. If cure is not possible, protection is provided in the form of sheltered housing, sheltered work and a controlled environment. Dutch outpatient care focuses more on the individual's residual possibilities for functioning within a personal, social and vocational context (van Weeghel \& Zeelen, 1987). Outpatient care is concerned with the interaction and interrelations between the individual and his natural setting. Interventions do not only focus on the individual, but also try to mold the context (Romme, 1991).

In order to professionalize the outpatient care of the chronic mentally ill, the Department of Social Psychiatry of the University of Limburg is collaborating with the Community Mental Health Center of Maastricht in a number of studies on patient careers, need of care, social network and social role fulfillment. This article focuses on an instrument for analyzing the social role development of the chronic mentally ill in their natural context: the outpatient setting. An effort has been made to develop an instrument to be used as a tool in the evaluation of the social adaptation of outpatients who have been in care for more than one year. After an evaluation of current instruments, the proposed method will be explained in further detail using an individual case history. Also, the selection of the variables and definition of categories will be highlighted.

\subsection{Evaluation of current diagnostic instruments in psychiatry}

Social adaptation is the main field of intervention in the chronic mentally ill (Jablenski et al., 1980). Few instruments have, however, been developed to systematically monitor and evaluate such interventions. Currently, the main diagnostic instrument is the DSM-III (APA, 1987). As an instrument for professional communication and consensus, the DSM-III is highly sophisticated. Though offering an extensive differentiation of diagnostic categories, the DSM-III lacks theoretical presuppositions (Vaillant, 1982). It also lacks a more sophisticated linkage with the degree of social integration. For the minor fluctuations of importance in the rehabilitative process, the DSM-III and its siblings - for example the Present State Examination (Wing et al., 1973), or the Diagnostic Interview Schedule (Robins et al., 1981) - are of little help (Bennett, 1983). Moreover, because the DSM-III denies theoretical coherence, it is inadequate for making decisions in therapy (Vaillant, 1984). Every linkage between etiology, symptomatology and daily performance as an effect is omitted (De Jong, 1986; 1991). Therefore, it has little value in the daily practice of care for the chronic mentally ill. Instruments recommended 
for measurement of functioning in psychiatric patients, such as the Groningen Social Disabilities Schedule (Wiersma et al., 1988), the Social Adjustment Schedule (Weissmann et al., 1978), the Disability Assessment Schedule (WH0, 1988), the Past History and Sociodemographic Description Schedule (Jablenski et al., 1980) or the Standard Social Interview (Clare \& Cairns, 1978), are indeed more specific than the Global Assessment Scale (APA, 1976) of the DSM-III. But in these instruments, too, measurement is cross-sectional, leaving no room for interpretation and analysis of development. Most of the above instruments are only sensitive to major changes and are insufficiently intricate to reflect the slight changes to be observed in the chronic mentally ill.

Studies on the prognosis of the major psychiatric disturbances show a large variation in degree of social adjustment, as well as in the degree of remission. Remission seems to be more dependent on premorbid factors as job stability, the ability to maintain social contacts, or the communicative structure of the family. This statement is valid not only for the schizophrenic (Bleuer, 1972; Ciompi \& Miller, 1976; Huber et al., 1979; Strauss et al., 1977; Wiersma et al., 1983 \& 1984; Leff, 1982) but also for the depressive patient (Brown \& Harris 1978; Levinson, 1978). Preliminary studies in this respect (Nijhoff, 1980; Radstake et al., 1985; Escher et al., 1987; Romme et al., 1987) show that the degree of social integration and social role fulfillment at onset is an important factor in the persistence of the mental disorder. Description of the problems of the chronic mentally ill in terms of development of social functioning and integration could be a useful alternative for current instruments. Especially in the determination of rehabilitative goals, a detailed and systematic knowledge of the resources of the individual is essential.

\subsection{Objectives and important questions}

The most important choice in the development of the instrument we propose is to begin with normal human functioning as a starting point. In contrast to the current view in most instruments, we do not focus on the disturbance, i.e. the abnormality, but on the degree of normality. What is the social position the individual has in fact accomplished? Which social roles are fulfilled? To what extent does the fulfillment of the social roles contribute to the achievement of a social position? To define what could be called "normal" a number of important sociological concepts on role fulfillment were studied. The theories relevant for a description of the degree of social integration and the main areas of social role fulfillment were compared and applied in so far as they fit into the goals of the instrument. In the following, some main concepts will be explained in further detail, before going into the theoretical principles and the outline of the instrument.

\subsection{Social isolation as a developmental circular process}

Behavioral dysfunctioning quite often is accompanied by isolation and social rejection (Rosenfield, 1982; Dohrenwerd \& Dohrenwerd, 1969). Social 
problems are consequently individualized, especially in the mentally ill (Nijhoff, 1980). Being difficult to handle and showing adverse behavior, the mentally ill are rejected by society and lose their jobs as well as many of their social contacts. Especially in the USA, society has no interest in maintaining the mentally ill. The social effects of loss of position are direct and severe, especially in the mentally ill (Bachrach, 1980). In European society, the social security system leads to less severe personal consequences, but basically the social processes accompaning social rejection in the mentally ill are the same. In a number of West European societies, with the Netherlands up front, job competition has been increasing in recent years, accompanied by alienation, especially in the cities (Mackenbach \& van der Maas, 1987). Social demands increase, making it virtually impossible to maintain a daily obligation, even in protected work settings. At the same time, family bonds decrease in these societies (Killian, 1991).

Because of social rejection and isolation, the psychiatric patient loses the normative guidance of a social context. In the (chronic) mentally ill, a social dynamic is set into motion, impairing the individual's freedom of action. Isolation becomes an effect as well as a cause of behavioral dysfunctioning. A self-enforcing process is set into motion. The findings of Faulkner (1984) show that this process is not so much dependent on the kind and degree of psychiatric disturbance, but much more on the tolerance of the direct social environment. Faulkner's ideas can be set into a sociological context within the framework of Weber's social action theory (1947).

Weber argues that each individual participates in social action by means of social role fulfillment. To fulfill a social role the individual needs social skills. The positive, or negative, appraisal by the direct environment is imperative for the development of these social skills. By "doing" the individual learns. Skills can be taught, but implementation of the skills in practice depends on the flexibility of the environment. Fulfillment of a social role is always limited by the degrees of freedom left to the individual. This concept of limitation of role fulfillment led Weber to define the sociological concept of "handlungsraum", which can best be translated as "the actor's span of control" (Kahn, 1978). In lifetime social development, the span of control increases, together with the variability and complexity of the roles the individual fulfills.

Within the stratification of society, Weber (1947) reasons different rules, motives and predispositions are applied. Each individual has his or her own framework within which the motivational level is in balance with the expectations of the direct environment, i.e. a subculture. Consequently, the mentally ill rejected by society are either placed apart, or seek for themselves shelter within a subculture. With respect to the chronic mentally ill, it can be observed, for example, that many "young chronics" are quite often homeless or drug addicts (as reported by Bachrach, 1982; Kaplan et al., 1990).

Social isolation therefore depends on a number of factors: firstly, the 
individual's capacities and social skills; secondly, the interaction with the current direct environment; but thirdly and most importantly, the social demands to be met in work and social contact. Socially isolated people encounter few situations in which their actions are subject to criticism or social sanctions. Due to a lack of either quality or quantity in their social interactions, both role fulfillment and role development remain inadequate, or perhaps even become increasingly insufficient. A circular, and in many patients, irreversible process can be described. Skills learned in the past can be lost. Demands once met or roles once fulfilled are abandoned. As the span of control diminishes, the patient becomes inversely dependent on care (Figure 2.1).

Figure 2.1 Diminishing span of control

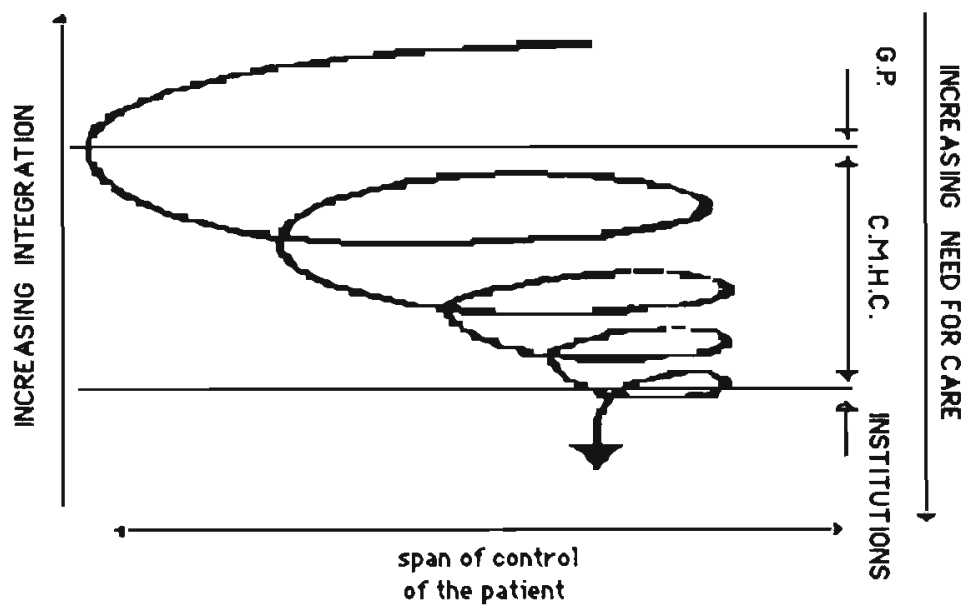

In the above process of social isolation, most of the chronic mentally ill not only lose their grip on their direct environment, but they also fall down the social ladder. Social role is a dynamic concept, as roles and role expectations change over time and are related to the developmental phase of the individual (Krauss-Whitborne, 1982). Successful role fulfillment in a specific area can have a positive effect on another area. The effect can be direct, as in personal appraisal or material reward. Or it may be indirect, as successful roles make new roles more accessible. Failed role fulfillment affects other roles in a negative way (Bruhn, 1977). Following this reasoning, the phase of life in which the first full scale rejection occurs is of importance to the residual level of functioning faced by the professional at the end of the line. The earlier the rejection, the more the deficiencies in role fulfillment are extensive and widespread over different areas. The later the rejection, the better the prognosis. A rejection occurring in later life implies a certain degree of achievement. In the latter case, deficiencies are of a temporary and lacunary 
order. Yet, in the case of an onset in later life, if remission does not occur within a reasonable time frame, the deficiencies can spread. As time passes, a residual level of functioning can be observed, in which cause and effect are difficult to determine.

Development of social skills, therefore, does not always imply enhancement of social roles. In our opinion, the span of control is a major problem in psychiatric rehabilitation. Studies in this domain show that modeling programs within mental hospitals are inefficient in treating the severely disordered mentally ill, as many chronic mentally ill people do not maintain skills after finishing the program (Farkas et al., 1988). Providing the behavioral settings in a natural social context may be more effective. Resources need to be developed by modeling the context. New social roles have to be acquired despite conflict and criticism. Renewal of "old", i.e. former roles is seen to be motivational in the process of role-acquisition due to positive appraisal from the environment within which the individual has to prove himself.

\subsection{A rehabilitation model aimed at development and integration}

An integrated care model should not only have medical and psychological objectives, but should also focus on the social span of control, thus limiting the downward involution of social isolation. Inadequate role fulfillment enforced by periods of relative decline in various areas of social role fulfillment is typical for chronic mentally ill. Psychiatric and also somatic symptomatology may sometimes be the cause but are mostly the effect of this decline. They are at least a major factor in the process. This opinion implies a choice for rehabilitation methods, as advocated by Bennett (1978). In Bennett's interpretation, rehabilitation needs a comprehensive evaluation: to look for lost individual capacities and to enforce existing reserves from both individual and environment (Zeelen, 1988). Bennett emphasizes a careful and systematic assessment of present social, psychological and somatic functions in relation to the past. Bennett defined rehabilitation as the process in which the mentally or physically impaired individual is stimulated to optimize the use of remaining capacities. Optimalization of these capacities is only possible in an environment which sets limited demands, but is comparable to the environment in which the individual finally lives.

Success of rehabilitation can only be evaluated after a considerable time span and can be measured by the extent of participation in work, family and social life. Rehabilitation consequently implies a comprehensive and coherent enforcement of different social roles (Shepherd, 1989). The contrast between this objective and the viewpoint as formulated by the WHO (Jablenski, 1980) lies in the emphasis on development and the principle of a circular relationship between cause and effect. This "classic" rehabilitation model of the WHO follows the principles of the medical model (Engel, 1978): a disturbance is the cause of a functional impairment, which leads to a handicap. In this concept, the mental disease (Fabrega, 1982) is a physical entity. This physical entity 
leads to abnormal behavior. The abnormal behavior leads, finally, to a restriction of social functioning. The core of this concept is the definition of disease as a problem of the individual. Assessment focuses on current dysfunctions and treatment is aimed at the effect of the disease and deals with short-term goals. The past is only briefly covered. Based on this model, the approach as formulated by Anthony and Libermann (1986) indeed shows different factors leading to variations in outcome; it does not explain the coherence and interrelations between each of the separate factors (Figure 2.2).

Figure 2.2 The vulnerability, stress, coping and competence model (Anthony \& Libermann, 1986)

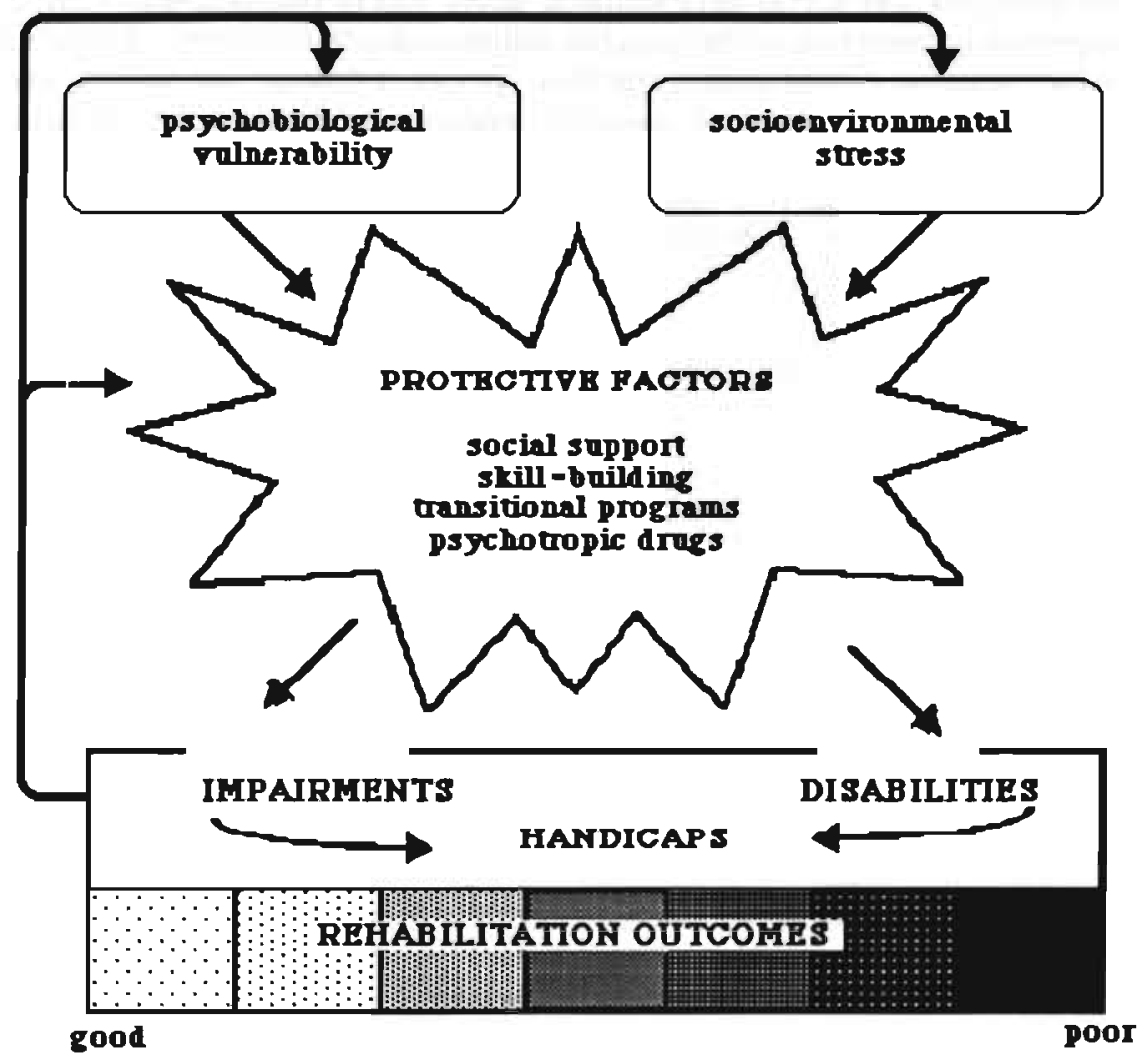

In their view, therapy provides protective factors such as social support or skills as well as personality training and psycho-inductive medication. These factors are a buffer, partly protective, but also elusive. Each factor is seen as a separate component of treatment which can be influenced separately. The medical "disease-oriented" model of mental disorder assumes that the etiology 
of mental disorders resides in a disordered biological substrate. When the disorder develops, it is assumed that it must take a clear course with recognizable and predictable symptoms.

This perspective ignores the obvious fact that any behavior is subsequently modified by events which follow its occurrence. The final presentation of (any) problem is always a function of formative factors, precipitate factors, exacerbating factors and maintaining factors. Because the model defines disease as an entity, it presumes a linear relation between vulnerability, outward pressure and sanctions and the individual's coping mechanisms. Though the model acknowledges a reciprocal effect of the handicap on vulnerability and coping ability, it offers no insight into development in its implementation and practical application. Current abilities are not related to lifetime personal and social development. More recent interactional models of psychopathology emphasize the psychobiological representations of externally occurring experiences and events and thus provide a linkage for relating socioenvironmental phenomena to internal events. Interdependencies across different categories of variables as well as their simultaneous interactive properties lead to elaborate diagrams stressing the complexity of mental disorders (e.g. Marsella, 1982, Figure 2.3).

Figure 2.3 Marsella: Complexity of interdependencies.

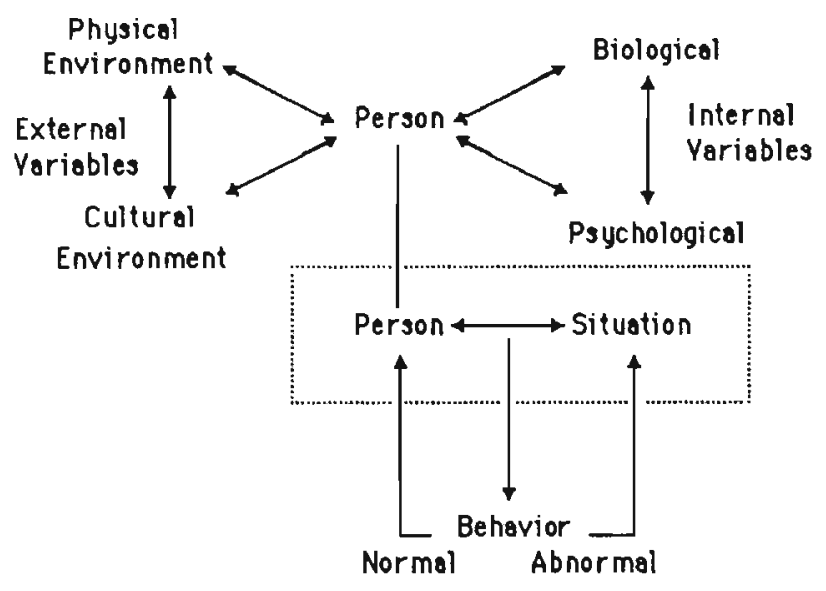

Bennett's approach also acknowledges circular interdependencies. He also applies, but from a practitioner's view, the same model as Marsella. Dysfunctional behavior is in his view both cause and effect of mental disorder. Bennett's approach implies a careful analysis of individual development in terms of social role enactment. In the description of development, special attention must be given to the relationship between past and present role 
enactment. This relationship implies a qualitative and interpretative analysis of development. The development should be related to the expectations placed upon the individual in the different stages of his or her life. Each individual undergoes a unique developmental role sequence (Rodgers, 1962) in which the individual is confronted with the norms and values set by the direct environment and to a lesser extent also by society. Following the findings of Duvall (1967) and Rodgers (ref. above \& 1964), Hurrelmann (1983) defined five different areas in daily life, within which social roles develop coherently. Hurrelmann's conclusions have been used in the definition of the five main areas of social role development used in our instrument.

\subsection{Arrangement of roles in main areas of daily functioning}

The social roles are described using five main areas of daily life in which they develop coherently. The operational definitions of these five main areas are based on the socialization theory of Hurrelmann (1983) who defines these areas as distinct socialization settings within which behavior develops. These main areas are:

1. Material self-care and care for others; in "taking care".

2. Supportive, family and kinship roles, such as relationships with children, parents and other kin, but also relations with important non-kin; in "support".

3. Sexuality and intimacy roles; in "sexuality".

4. Vocational roles, either in a formal or a non-formal setting, if a responsibility has to be carried; in "daily obligations".

5. Social roles, covering activities without an obligatory function, in relation to kin or non-kin, but also within an organizational setting or social clubs; in "sociai activities".

In our instrument, current social functioning is assessed using three to eight items in these five areas. If the functioning on these items is insufficient the development is assessed using important developmental moments as a guideline. Lost capacities of the individual can thus be compared in a global way. The case histories show breaking points mainly in the transitory periods between the different lifetime phases (defined by Krauss-Whitborne, 1982). The main objective of the assessment is not to look at disabilities in current functioning, but to track down patterns and developmental processes leading up to the disabilities. This objective is the main reason to choose theoretically distinct areas and to not follow the more empirical role definitions proposed by Wiersma et al. (1984) or Jablenski et al. (1980) in the WHO studies. Following the concepts of Duvall and Hurrelmann, coherence in respect of development can be expected between empiricaly distinct roles. Regarding the items of importance for the roles defined by Wiersma et al. (1984), a slight redundancy can indeed be observed ${ }^{2}$. Behavior defined within different roles 
can be expected to be caused by the same trait; for example, the capacity to give support has consequences for both the family and the parental role, but also for the social role. In our instrument these redundancies were avoided when possible.

\subsection{A single case history}

The following case history illustrates how problems of mental illness might arise in transitory periods of life, leading to a decline of social functioning. It shows how systematic assessment may unravel the deadlock, so typical for the chronic mentally ill.

\subsubsection{Background information}

Mrs. P., a 27 - year-old married woman, has been in ambulatory care for nine years since 1983. In 1982 she had her first panic aftack, at night, shortly after the birth of her first child. Following the birth of her child she suffered from apathy and felt totally inept. Using psychoinductive medication, she tried to control these complaints. Over the years, use of medication increased to $12 \mathrm{mg}$. Rohypnol a day and to $60 \mathrm{mg}$. Librium a day. An impressive history of care at different mental health care institutions started, beginning with a year in the outpatient service of a mental hospital. Subsequently, she was referred to a team specialized in anxiety disorders. After terminating this treatment, she was referred to the outpatient service of a county hospital mental department. She followed the treatment intermittently, because she felt little benefit. Three years lator, she was roferred back to her general practitioner. She became increasingly dependent on medication, being terrified of a return of the panic attacks. Finally she was admitted into hospital to detoxify. From the detoxification unit she was referred to our rehabilitation service.

What happened? Why did this case turn chronic? Extra information on the development of her social span of control shows an important changing point just prior to the onset of her dependency of care, related to major changes in her social context .

\subsubsection{Social span of control}

Mrs. $P$. is the fitth child in a family of six. She describes her youth as carefree, cosy, playful and pleasant. In her youth she had little responsibility for herself, and was spoiled by her parents and older sisters. At age 18, she married her husband who was 10 years her senior. After her marriage, little changed in this carefree existence. Her husband took over most of the responsibilities in the organization of their life. Her daily activities were organized for her. She was busy moving and furnishing, working daytime and always had a full agenda. Self-care, care of others, personal support, sexual activity, her work and her social activities were embedded in a clear structure, for which she had little responsibility. Due to this confluent organization of her daily life by her environment, she had little opportunity to learn to give support. She always received support and also had little opportunity to develop her own social life.

Her problems started shortly after the birth of her child. The birth of her child had important consequences for her daily life. A number of changes can be 
observed. Beforehand, she always was busy. After childbirth, her day was suddenly focused only on her child. Confronted with this responsibility, she became insecure in her maternal role. At a moment when society expects a mother to give support and to assume the role of mother by intuition, her claim for support increased. Suddenly, many activities in daily life, in her job and in her social life were replaced entirely by a role in which she felt insecure and inadequate. From the moment she had to organize her own day and had to be responsible she fell short. Financial problems arose due to a lack of planning. Her husband criticized her, enforcing her insecurity. Her panic disorder may be viewed as a reaction to a threatening position: she feels she functions insufficiently, but she doesn't know how to change this.

\subsubsection{Evaluation of her span of control}

What is important in this developmental history is the sudden limitation of her scope. In the first years of her marriage, she led an active and fulfilling life. She had a job, was an active participant in a municipal association, and all time off was completely taken by organizing and rebuilding her house. After the onset of pregnancy, her daily activities changed completely. She stopped working and participating in associations and had to focus all her attention on her family and, after childbirth, more specifically on her child. The social roles in respect to both daily obligations and social activities and leisure were suddenly restricted almost exclusively to the family. Regarding the core roles (Walker et al., 1977; Staal et al., 1989) such as "taking care", "support" and "partnership", it is important to notice the increasing deterioration after the onset of treatment.

\subsubsection{Five areas of role performance}

In the first area of role performance, taking care of her family, she increasingly relies on her mother. She is supported in the organization of her housekeeping, her money and the shopping. In all her activities she depends on her husband and her mother. In the second area of role performance, support, she can not express warmth either to her husband or to her child, while on the other hand she feels a need to receive warmth. Problems and conflicts remain unresolved. In the third area of role performance, sexuality, we observe that the commitment to a sexual or intimate relationship is limited by various factors. The expression of intimacy is disturbed due to marital quarrels and the frequent presence of her mother in her house. Finally, with respect to the last two domains of role performance, she remains completely inept both in her daily obligations and in her social activities, she takes no initiatives, does nothing, goes nowhere. All her responsibilities are met by her mother. She has no resposibilities for herself.

\subsubsection{Evaluation of role performance}

Her role performance within all five domains ("taking care", "support", "sexuality", "daily obligations" and "social activities") deteriorated soon after the moment she had to comply with expectations set in her social position as a married woman with a young child. She failed in meeting two fundamental expectations: taking initiative and giving support. Her reaction is fear and withdrawal. Parallel with this change in her social position, she loses contact 
with her social life and her work. She can only rely on a domestic existence. As an effect, she feels a continuous and increasing pressure because her family leaves her no space for any relaxation. Thus, her symptoms lead to a stressed interaction within her family, whereas on the other hand the relation with her family induced her symptoms. Her recognition of her dependency and the feeling of failure to live up to expectations, leads to disappointment in her own achievement, and subsequently to a passive attitude, which in itself enforces her dependence - a circular deadlock typical in the chronic mentally ill.

\subsubsection{Implications for treatment}

Psychotherapy given for the panic disorder actually stabilized her downfall instead of inducing any relief or change in her position within her social context. In order to relieve her symptoms, family therapy was directed at enforcing the support by her environment, thus inducing a decrease of her responsibilities and putting her further away from remission. Current treatment is focused on developing her daily activities and changing of her position within her family by inducing changes in the limitations set by her family. At the same time she puts the expectations set by her environment into perspective by exploring her own ideas on her role as a housewife and comparing these ideas with the expectations set by her environment as well as by herself. She is stimulated to seek support from other women in her neighborhood and to lessen the symbiosis with her mother. Not the panic disorder, but the supportive network - so carefully preserving the disorder - is thus treated. This is not done by leaving her to her own resources, but by carefully providing situations in which she can function, independent of the support network. An example is volunteer work in a kindergarten. After a period of time, she becomes embedded in her environment in a more independent position. At the moment of this report she has contact of a preventive nature with her case manager once every two months, to avoid renewed dependence on either medication or other people in her personal environment.

\subsection{Epilogue}

This case history describes how a deadlock may be induced in the treatment of a chronic mentally ill person. It is shown that relief of the deadlock can indeed be brought about if both development of social role performance and span of control are carefully analyzed and not only the psychological development is taken into account. The differentiation between the domains applied in this case history is based on the socialization theory of Hurrelmann et al. (1983). This approach is based on the theoretical concept of an interdependence of role performance and human development. Therefore, it differs to a certain extent from the current more empirical differentiations of role performance applied in various instruments in psychiatry (Jablenski et al., 1980; Hurry \& Sturt, 1980; Wiersma et al., 1984; 1990). 
This article presents an arrangement of developmental role performance into five main domains of daily life, illustrated by a single case history. The same arrangement has been used in an instrument to be used by mental health professionals in their analysis of social role development of the chronic mentally ill. A subsequent article will go into the results of a reliability study carried out on a sample of 56 chronic mentally ill people. 


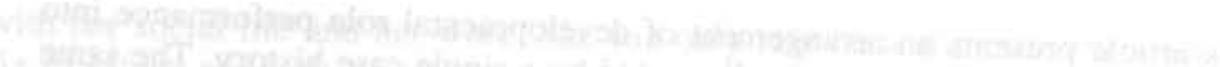

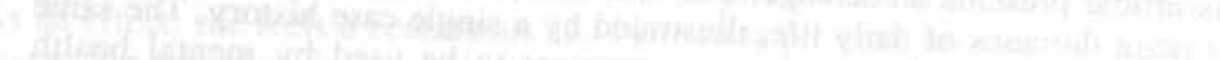

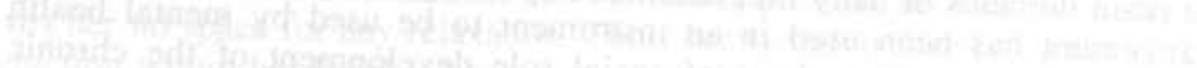

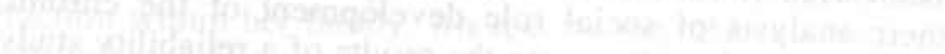

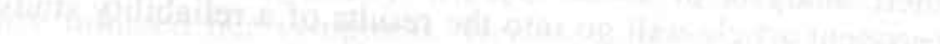

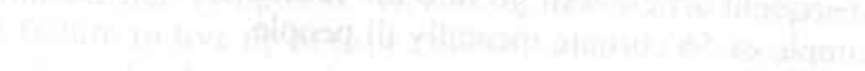




\section{PART 2}

\section{Sample description and instrument development}

This part is concerned with the first phase of the research: the identification of the population and the development of the instrument in various steps. First theoretically, then practically. Chapter 3 identifies the population. It contains a review of literature on the definition of chronic mental illness. This chapter also contains a description of the patients involved in the various stages of this study in relation to the population referred to the Community Mental Health Center where the study was carried out. Chapter 4 contains an extensive review of the theoretical background of the instrument. Chapter 5 provides a review of current instruments in the domain of judgment and assessment of social behavior in psychiatry. Chapter 6 goes into methodological and practical aspects of the instrument development in different phases of the study.

Readers mainly interested in health care aspects of the study may really skip chapter 6 as it contains a meticulous though boring description of the strenuous process of operationalization and item selection. Chapter 5 contains a global overview of the state of the art in current instruments and may be interesting for measurement freaks. Chapter 4 , is, however, more interesting. In this chapter we made an effort to translate the abstract concepts of sociological theory into a theoretical model for the rehabilitation of chronic mentally ill. Those interested in methodological aspects as generalizability of the samples or who want to know how "sick" or "healthy" the studied groups are, may turn to chapter 3 . 
S TYIAC 


\section{CHAPTER 3}

\section{Defining chronicity within the samples}

The previous chapter clarified how social role development can be analyzed by means of a single case history. In this chapter different views on chronicity will be discussed and related to the definition of chronicity we apply in this study. The study was carried out in two small pilots, which focused on instrument development (also Chapter 6), and a main study concerned with testing the instrument on aspects of reliability and validity (Chapter 7, and part III and IV of this thesis). After a discussion on the definition of chronicity the present chapter describes the sociodemographic characteristics of the chronic mentally ill in general, and relates this to the sociodemographic as well as the diagnostic characteristics of the samples participating in the various phases of the current study. We want to know whether we selected a fair representation of the chronic mentally ill in care at the specialized service of the Community Mental Health Center (CMHC) in Maastricht. First, we describe the criteria for accepting referrals to the rehabilitation team of the CMHC. A short review of literature on chronicity follows, in order to put our definition of chronicity into perspective. Then we look into the general characteristics of the population of the rehabilitation service of the CMHC. What are the characteristics of this population? Do they meet the criteria we formulated? To what extent does the referred population differ from the population of the district? Finally, the subjects participating in the various samples of the study are compared with the referred population.

\subsection{The rehabilitation service of the Maastricht CMHC}

The Maastricht CMHC has divided its services into special task services with teams for long-term and short-term psychotherapy, child guidance and geriatric services, prevention, and a rehabilitation service for the chronic mentally ill. The rehabilitation service, where this study was carried out, is concerned with the care and resocialization of the ambulatory chronic mentally ill. The team is more oriented on care than cure. The rehabilitation service's criteria for accepting referrals are (van Marrelo, 1986):

1. a severe psychiatric disorder;

2. a history of long-term mental illness;

3. dysfunctions in more than one domain of life.

Referrals are made either from the mental hospital (concerning aftercare), or from other teams within the CMHC (concerning cases presenting the above mentioned criteria). Some cases are also referred to the team by general practitioners and psychiatrists in private practice. Because the team has no 
waiting list, it treats to a certain extent the overflow of the short-term treatment team. Due to this organizational interplay, a minority of the case load consists of patients who are not really (or not yet) chronic mentally ill. However, the patients of the service predominantly have a history of various hospitalizations or long-term psychotherapy in the past, and can indeed be labeled as chronic mentally ill living in the community. Needing a sound definition of which patients can be regarded as "chronic mentally ill", we looked at some important studies on this issue. A short review follows, before we present a detailed description of the subjects and the several subpopulations they were drawn from.

\subsection{Chronicity in psychiatry: a short review of literature}

\subsubsection{Various views concerning chronicity}

When we look at the abundant literature on chronicity, it is striking how few authors provide sound definitions that cover the target population sufficiently. Literature reveals a number of qualitative characteristics to cover the term chronic mental illness. Dependent on the focus of the article, notions such as severely disrupted problem-solving capacity, dependence on the environment, a subjectively distorted perception of environment leading to isolation, or threatening outward behavior are combined with often unclear definitions of duration of the mental illness. Sometimes chronicity is associated with the course of specific psychiatric disorders. In the American literature, with its focus on de-institutionalization and organizational aspects of care, the term "chronic mentally ill" is to a great extent synonymous with the diagnosis schizophrenia. Others provide criteria restricted to the duration of mental health care, irrespective of the severity of the disorder, the degree of social dysfunctioning, or other characteristics of the individual. In short, five main types of criteria may be distinguished, each with their own focus, relating chronic mental illness to:

1. a specific psychiatric disorder, predominately schizophrenia, and in some instances severe personality disorders or manic depressive disorders;

2. length of treatment, or in fact admission to a hospital;

3. dependency on and consumption of care;

4. combinations of the above views;

5 . loss of social integration.

In the next paragraphs, we will present some of the representatives of the different views, and relate these to our own point of view.

\subsubsection{Chronicity related to schizophrenia}

First and most commonly, authors (Ciompi, 1976; Bleuler, 1972; Giel, 1978; Richartz, 1981) relate the term chronic mental illness to the course of specific psychiatric disorders. They focus their attention especially on schizophrenia. 
Chronic mental illness has been synonymous with schizophrenia since the days of Kraeplin (1897; 1913), who reported grim results of only thirteen percent remission in patients with "dementia praecox". This pessimistic view was enforced by Eugene Bleuler (1911), who conceived the concept of schizophrenia. In his concept of schizophrenia he distinguishes the primary symptoms ${ }^{3}$, representing causal factors, and secondary symptoms ${ }^{4}$, representing the psychological spin-off of the changes caused by the primary symptoms. In his view, the primary symptoms may be viewed as present in all phases of schizophrenia, and he emphasizes this defeatism with his conclusion on the schizophrenic disorders as "a group of psychoses, with a sometimes chronic or otherwise inter-current progression, at times a relapse and at times again short remissions, but with no complete restitutio ad integrim".

These views dominated psychiatry up to the sixties, apart from a single exception (Meyer, 1936; Sullivan, 1940; 1953; 1973). In the seventies, the studies of Manfred Bleuler (1972), Ciompi \& Müller (1976), and Huber et al. (1979), as well as (in the Dutch setting) Wenniger \& Romme (1978), spread the first doubt on this view. However, the first prospective empirical study was performed by Strauss and Carpenter $(1972,1974)$. This study led to the conclusion that the course of schizophrenia is by no means always chronic, but that a wide range of possibilities remain open after first onset. They extracted the following factors as main predictors of a chronic course of schizophrenia:

1. the length of previous admissions to psychiatric institutions;

2. the frequency of social contacts;

3. having a job;

4. symptomatology.

Their conclusion was, however, that these factors were relatively independent. This indicates that severe symptoms do not necessarily lead to major impairments in work or social contacts. In a follow-up performed by Strauss et al. (1977), two years is regarded as a cut off point, after which the prognosis becomes less promising. These findings are confirmed by a number of studies of Häfner et al. $(1982,1983,1984,1985)$, which show a stabilization in the dependency on mental institutions in schizophrenics after a period of 18 months. His data show a stabilization and partial remission of primary symptoms of $17 \%$ in a hospital setting and of $63 \%$ in an ambulatory setting. A complete remission occurs in only $20 \%$ of the cases. A conclusion of these studies is that a schizophrenic disorder with a course of primary symptoms exceeding two years may be evaluated as chronic.

\subsubsection{Chronicity and length of treatment: the number of years after onset of treatment}

Secondly, we can distinguish the authors who predominately relate chronic mental illness to the number of years after onset of treatment. The main body

"Akzessorische Symptome" 
of literature (e.g. Mendell \& Rapport, 1969; Marx et al., 1973; Test \& Stein, 1980; Goldman, 1981; Giel, 1983; Talbott, 1981; Haveman, 1980; 1987; Lynch \& Kruzich, 1986; etc.) acknowledges two years as a cutoff point, as dismissal from the institutions occurs in $95 \%$ of the cases within two years. The chance that patients admitted for longer than five years ever leave the mental institution is regarded by some authors as nearly zero (van Andel \& van Dutterloo, 1986; Scholte \& Uffing, 1981). However, all these studies are concerned with patients in inpatient services. Only a few, more recent, case register studies cover outpatient's data (Wing et al., 1982; Häfner et al., 1982; 1984; 1987; Tansella, 1986; 1989; Hamers \& Driessen, 1985; 1986; Escher et al., 1987; Schreurs \& Wiersma, 1992). Our study concerns only outpatients. In these patients the number of years after onset of treatment is an insufficient criterion to cover chronicity, because it has no relationship with duration of mental illness. We shall have to formulate our definition of chronicity using more specific data on patterns of mental health care consumption. For a good definition, we will have to include a notion on the dependency on care.

\subsubsection{Chronicity and dependency on care}

A number of studies relate chronicity to dependency on care in terms of consumption of psychiatric services. Tansella (1986), using outpatient's data found, in accordance with Wykes (1982) and Lavik (1983), an increased risk of becoming chronically dependent after a period of one year. In his comprehensive study Tansella relates care consumption to the period of time in care and discerns four different types of dependency:

1. long-term continuous dependency: patients who visit the services frequently over a long period of time;

2. long-term discontinuous dependency: patients who despite long-term derangement do not visit the services very often;

3. short term continuous dependency: patients who are highly dependent on the services for a short period of time;

4. the short-term discontinuous dependency: patients not fitting in the above groups, consequently those who use the services incidentally.

One of Tansella's most important findings is that approximately $10 \%$ of the patients use more than $85 \%$ of the care and belong to the long-term continuously dependent. About $65 \%$ of this group is also at risk of staying in care. We also focus our attention on this group in the current study. Tansella's definition of one year continuous care, with a discontinuation of no more than three months, is applied in our study. We will use this criterion as a minimum boundary of dependency on care in our own sample.

\subsubsection{Multi-axial definitions and descriptions of chronicity}

Also important but fewer in number are the authors who try to combine aspects of the above criteria. A more precise definition would require a specification of chronicity both in terms of duration and in terms of 
invariability and relate to a typology of the way the mentally ill interact with their direct environment. Gruenberg (1967) fulfills this requirement with his description of the Social Breakdown Syndrome. As characteristics of chronicity, he mentions:

1. a strong identification with the role of someone who needs help, which is expressed through these people's dependence on others in their daily needs;

2. comparatively severe manifestations of psychopathology elicited by relatively little stress;

3. stereotypical patterns of interaction with the environment in which the patient often shows an ambivalent attitude of wanting to be cared for and, at the same time, rejection;

4. an impoverished, marginal functioning in the domain of living, working, leisure and intimate relations.

However, these criteria remain relatively vague and provide a mere sketch of some of the problems mental health professionals are confronted with in dealing with the chronic mentally ill. Current research demands more precise criteria to define this population. In a more recent study, Gruenberg identified four criteria in his definition of chronic mental illness (Gruenberg \& Pepper, 1985):

1. there has to be a mental illness within the criteria of axis one or two of the DSM-III R (APA, 1987);

2. only if the case is treated by doctor or a mental health professional, is the label "patient" applicable;

3. there have to be one or more impairments, as defined by the ICDIH (WHO, 1980);

4. illness is indeed chronic, and continuously apparent.

The above criteria were applied and extended for the Dutch ambulatory setting in a recent study by Schreurs et al. (1992), with a few refinements which cover the definition of chronicity in outpatients. In that study, the next criteria were applied:

1. a minimum of two years of professional care, minus intermissions of more than half a year;

2. a diagnosis within the criteria of axis one or two of the DSM-III R;

3. a chronic course of the disease: either (a) progressive; (b) stable at a pathological level; or (c) intermittent, with recurrent episodes of remission and illness;

4. the psychiatric disorder is related to a disability in social functioning, for example in work or housekeeping.

In ambulatory care, both the first and the fourth criterion of Greunberg cannot always be operationalized. Especially in the Dutch setting, professionals direct their interventions in outpatient care more towards improvement of experienced handicaps. A precise diagnosis is, consequently, regarded as less important (Rotteveel \& Uffing, 1988). In our data a conclusive diagnosis is 
given in only $56 \%$ of the cases. Furthermore, it is perhaps questionable whether this strictly time and illness-oriented view is useful in the outpatient setting, as it implicates a unity in course and prognosis contradictive to the daily practice in care (Henkelmann, 1987). Severely impaired mentally ill patients quite often withdraw from treatment for a longer period of time, to return into care after perhaps years of severe dysfunctioning. A definition stressing level of functioning, irrespective of the dependency on care, is more sensible. Honig et al. (1987) mention, following Adler (1984), as a minimum criterion that a disorder must affect two of the four levels of functioning: the somatic level, the individual level, the microsocial level and the mesosocial level and combines this with a time span of one year dependency on care. This view leaves more room for an important characteristic of outpatient care: discontinuity.

\subsubsection{Chronicity related to society and social integration}

None of the above researchers, however, consider the restricting influence of society on the chronicity of disease. It is not only the psychiatric disorder which determines prognosis and chronicity. Integration in work and the quality of the social context is a far more powerful indicator than diagnosis (Dohrenwerd \& Dohrenwerd, 1969). Society sanctions dysfunctional behavior severely when the individual does not live up to expectations especially within a vocational setting, and to a lesser extent within an educational setting (Nijhof, 1989). Organizations dictate the working conditions. People who do not fit are labeled ill. Eventually they become labeled as incapacitated and are doomed to remain rejected. Within the vocational setting, the organization determines the norms, which some people cannot meet. Once rejection has occurred, reintegration is difficult (Nijhuis \& Soeters, 1982).

It is not only outrageous behavior (for example during a manic psychosis) which can lead to rejection. More often people lose their work after a gradual process of being unable to cope with stressful working conditions. Dutch legislation on work disability insurance has an reinforcing effect on this process of losing a position. In an attempt to restore the individual's ability to work, social security legislation focuses on health care and rehabilitation facilities rather than on working conditions. Inability to function in a stressful working situation has always been regarded as an effect of the individual's incapacities. In this way the legislation allows employers to misuse the system by getting rid of the employee and leaving stressful working conditions unchanged (Romme \& Noorthoorn, 1991).

Within a period of one year, the employer is obliged to re-employ the employee. Within a period of two years, the employee still has a good chance to return after a renewed assessment by health authorities. After a period of two years, disability is confirmed. A way back is often impossible. Subsequently, the patient grows increasingly dependent on care and may become an incapacitated chronic (mental) patient. The same period of time is 
found in research on long-term unemployment. Again we see a cut-off point after two years, after which re-employment is highly unlikely (v.d. Horst, 1988). One year, therefore, may well be regarded as a period of time within which a way back still is possible, whereas two years may be regarded as the period of time after which a way back becomes unlikely. A period of two years may be regarded as the time after which chronicity becomes irreversible.

\subsection{Definition of chronicity in this study}

In this study we tried to combine several of the above criteria into a clear-cut definition. Our definition had to be pragmatic and to fit the ambulatory situation. The cases were selected through medical dossier research. We therefore chose not to use the psychiatric disorder as a criterion, because we could not fully operationalize this definition. For practical reasons, we used the Problem Analysis (P.A.) as a measure (Honig et al., 1987). Secondly, we used the history of care as a measure. All the dossiers of the patients in care longer than half a year contained a summary of problems ordered according to the P.A.. In the P.A. four levels of functioning can be distinguished - the somatic level, the individual level, the microsocial level and the mesosocial level. Patients were included only when they had a disorder in more than two levels of functioning and when they had a history of care longer than one or two years, with an interuption of no longer than three months (following Wykes, 1982; Lavik, 1983; Adler, 1984; and Tansella, 1986). With these criteria, we chose to distinguish two kinds of chronic mental patients, as following:

1. those not yet, but at risk of becoming chronic, having had a history of care longer than one year and shorter than two years, with a disorder in more than two levels of the four levels of functioning according to the P.A.;

2. those definitely chronic, having had a history of care longer than two years, and a disorder in more than two levels of the four levels of functioning according to the P.A.

\subsection{Demographic and patient career characteristics of the chronic population}

Considering the abundant literature on factors precipitating and prolonging mental illness, it is striking how few authors really have described the demographic characteristics of the chronic mentally ill population. Community studies in psychiatric epidemiology mainly focus on incidence and prevalence of mental illness (Talbott, 1984a, 1984b; Murabi et al, 1984) or on aspects such as case finding (Ormel, 1980; Goldberg \& Huxley, 1981; Wing et al., 1981; Ormel et al., 1983; Sturt \& Wykes, 1987), without making any distinction in respect of length of treatment. 
Studies on need for care, though giving a rich and often colorful description of main characteristics of the mentally ill, have little foundation in empirical data (Bachrach, 1980). Some other studies indeed go into the sociodemographic characteristics of diagnostic categories important within the chronic mentally ill population, as e.g. in the studies of Ciompi \& Miller on schizophrenia (1976), Brown \& Harris on depression (1978) or of Wiersma et al. (1983; 1984) on functional psychosis, but do not take length of treatment sufficiently into consideration. A major handicap in gathering data on the chronic population as a whole, and especially on the outpatient population, is the case detection (Bebbington et al., 1981; Talbott, 1984b; Brook \& Hamers, 1985). Most more empirical studies focus on aspects of definition of chronicity or patterns of care without providing insight into other characteristics of the population (Tansella, 1986; Lavik, 1983). A further problem is that few researchers have sufficient access to the outpatient group. Even when access has been provided, most studies until now have been preliminary pilots.

The study of Schreurs et al. (1992) covered all chronic mentally ill patients $(n=181)$, in care for a period longer than two years in a circumscribed predominately rural area. This community sample of inpatient and outpatient chronic mentally ill showed the following main characteristics:

1. an over-representation of the unmarried and the divorced;

2. an over-representation of single people living alone;

3. an under-representation of young men and women between 20 and 30 years of age.

A study in a fully urban community sample at the CMHC of Maastricht $(n=541)$ (Escher et al., 1987) provided a similar picture, with some slight differences. This study mentioned (among others) the following main demographic characteristics of the chronic mentally ill:

1. an over-representation of divorced women and unmarried men and women;

2. many living alone or with parents;

3. few having a job (both men and women);

4. finally, contrary to the study by Schreurs et al., an over-representation of young men and women between 20 and 30 years of age and women in the age of 40 to 50 years.

As we drew our samples from the same population, we may expect the several samples to have the same main characteristics as in the last study.

\subsection{The different samples}

The study this book reports on was carried out in the rehabilitation service of the Maastricht CMHC in two phases. The first phase of the study focused on instrument development in collaboration with the mental health professionals. No patients were interviewed in this phase, so we were less concerned with 
non-response 5 . The second phase was concerned with several studies on aspects of reliability and validity. In this phase we interviewed both patients and professionals, and we had to deal with substantial non-response. In Figure 3.1 we present a flow chart of the selection procedure in various phases of the research.

Figure 3.1 Selection procedure in the various phases of the research

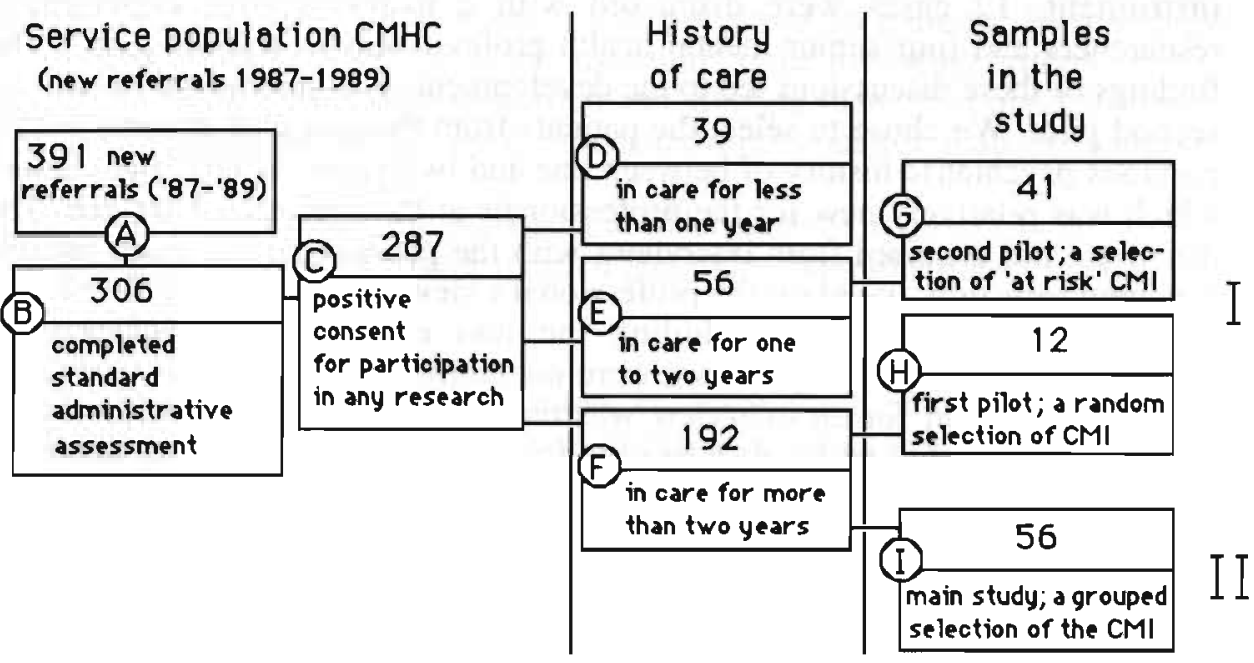

The first phase (I), carried out in October 1988, consisted of two pilot samples. One sample contained 12 patients $(\mathrm{H})$, a second sample contained 41 patients (G). In the second phase (II), the main study which was carried out in 1990, a sample of 56 patients participated (I). All of the patients came into care between January 1987 and and June 1989. In this time frame the rehabilitation service received 391 referrals (A). Of these, 306 remained in care long enough to complete a standard assessment (B). 287 patients consented (C) to participate in research projects at the CMHC. 19 patients refused participation (B - C). From the 287 we obtained data concerning a number of indicators (described in \$3.7). Of these 287 consenting patients, 39 remained in care for a period of less than one year (D), and will be left out of the comparative analyses. The first cohort of 56 had been in care for one to two years (E). The second cohort of 192 had been in care for more than two years (F). The first pilot sample $(n=12 ; H)$ as well as the main study sample $(n=56$; I) was drawn from the cohort of patients defined as definitely chronic $(n=192$; 
F). The second pilot sample $(n=41 ; G)$ was drawn from the patients defined as not yet, but at risk of becoming, chronic mentally ill $(n=56 ; E)$. For each phase a different selection procedure was followed, as each phase of the study had its own goals. In the following, we describe the selection procedures of the various phases in greater detail.

\subsubsection{Phase 1 - pilots}

In the first phase the items relevant for the instrument were selected. Two small pilots were carried out. After a conceptual development of the instrument, 12 cases were discussed with a panel of four experienced researchers and four senior mental health professionals in a small pilot ${ }^{6}$. The findings of these discussions led to the development of an instrument tested in a second pilot. We chose to select the patients from the group of patients with a previous psychiatric history of between one and two years, as this was a group which was relatively new for the professionals at the specialized service. The data were not acquired from interviews with the patients, as the main interest was item selection, based on the professional's view (Chapter 5). In the second pilot the full team, also including the less experienced professionals, participated. In these two pilots we were not confronted with non-response, as no patient consent for an interview was required. The only limitation was if the patient refused to let his data be used for scientific goals. We did, however, stop the sampling after having discussed four cases per professional. The sample then contained 41 cases.

Figure 3.2 Main study: target groups sampling

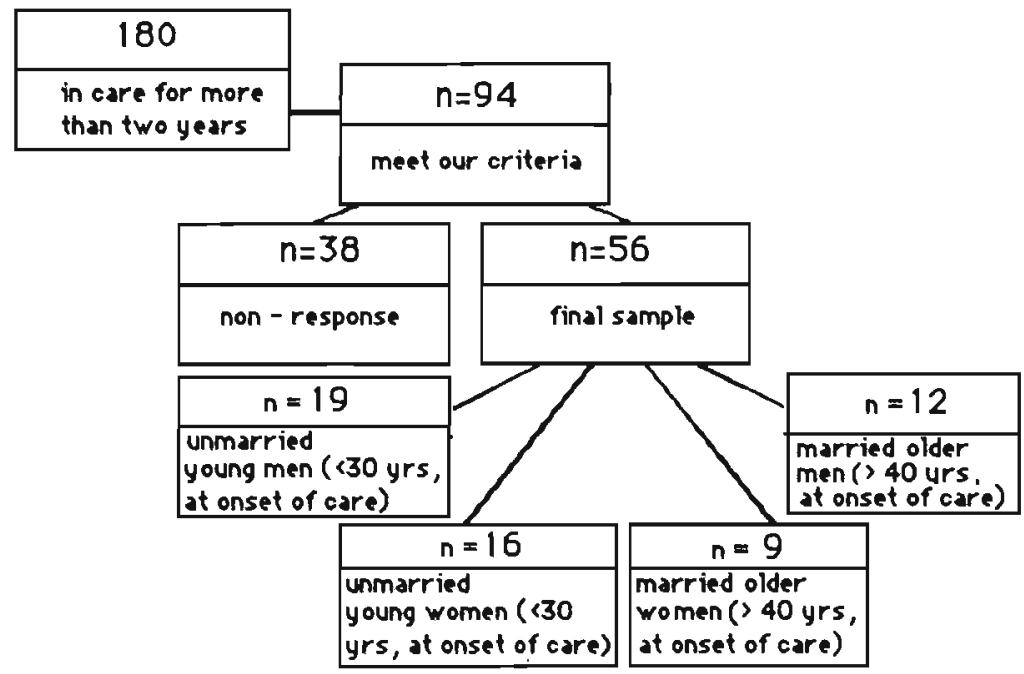

The data of these patients are not included in the comparative analyses described in \$3.8, as we selected this group of patients predominately to discuss the composition of the instrument. 


\subsubsection{Phase 2 - target groups sampling}

In Figure 3.2 we describe the selection procedure of the main study. In the main study we looked at the reliability and the validity of the instrument in a sample of 56 definitely chronic mentally ill, having a preceding history of at least two years (also, Chapter 7). The 12 cases used in the first pilot were excluded, leaving a population of 180 , before the selection. Specific target groups were selected to ensure data acquisition in homogeneous groups of chronic mentally ill according to their social position at onset of mental health care. 94 patients met the selection criteria. 38 did not consent for an interview or were not interviewable, leaving a final sample of 56 patients. Four groups of ambulatory patients were selected according to the following criteria:

1. a group of men who were unmarried and younger than 30 at onset $(n=19)$;

2. a group of women who were unmarried and younger than 30 at onset $(n=16)$;

3. a group of men who were married and older than 40 at onset $(n=9)$;

4. a group of women who were married and older than 40 at onset $(n=12)$.

\subsection{Non-response}

As described in the previous paragraph, we were confronted with significant non-response only in the second phase of the study. The procedure was to ask the therapist to ask the patient for consent, in order to avoid a conflict of interest between research and treatment. Consequently, the non-response was an effect of either the refusal of the patient or because the professional concluded the patient was at that moment not fit for an interview. The nonresponse is summarized in Table 3.1. 94 patients met the selection criteria. 72 were asked to participate 7 . Of these $60(83 \%)$ consented to an interview.

\section{Table 3.1 Reasons for non response by target group in the main study}

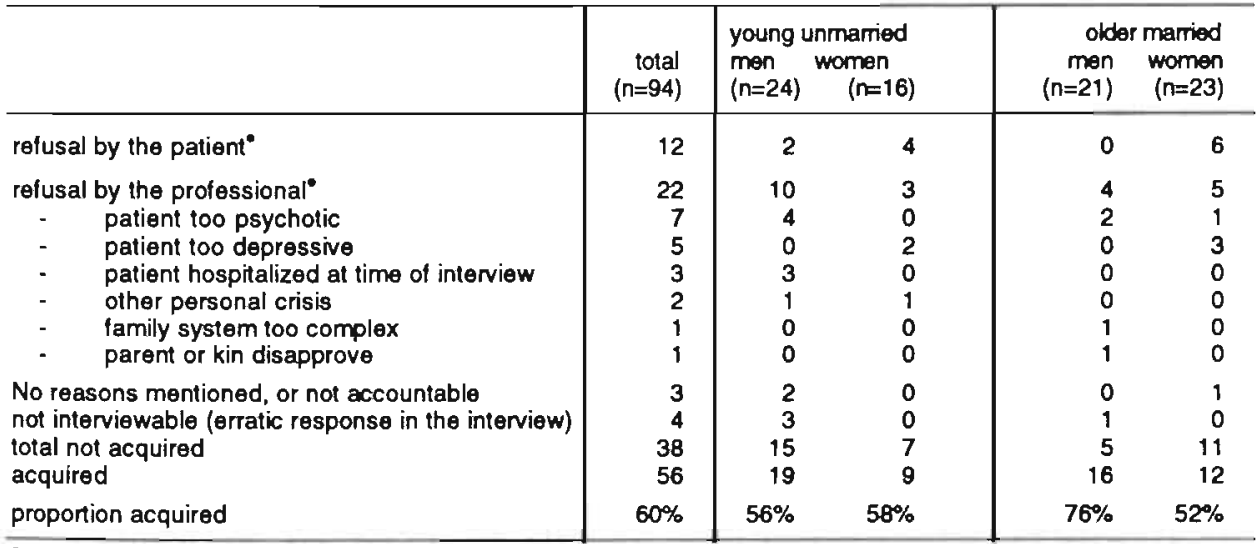

- N.B. $12=31 \%$ of the total refusal were due to the patient, while $69 \%$ were due to the professional

4 patients did not finish the interview sessions before we could finish the assessment. 
Reliable data were acquired from 56 patients. It is important to notice that the majority $(65 \%)$ of the refusals were due to the therapist. Almost always, this was due to a crisis or acute exacerbation of mental illness. This could lead to a "healthy patient effect" in the sample. In the group of married women refusal was more frequently due to the patient. Only $52 \%$ of this group was acquired. The risk of a healthy patient bias, or other selection bias will be addressed in the discussion of the comparison between the different samples $(\$ 3.9)$.

\subsection{Comparison of the chronic population with the population of the district}

In Table 3.2 we present an overview of the sociodemographic characteristics of our population. To understand the selectivity of our response we shall first have to know more about the population we drew the samples from. We are

Table 3.2 Sociodemographic characteristics of the chronic mental patient cohorts at the rehabilitation service of the CMHC Maastricht, compared with the demographic key figures in the population of the district

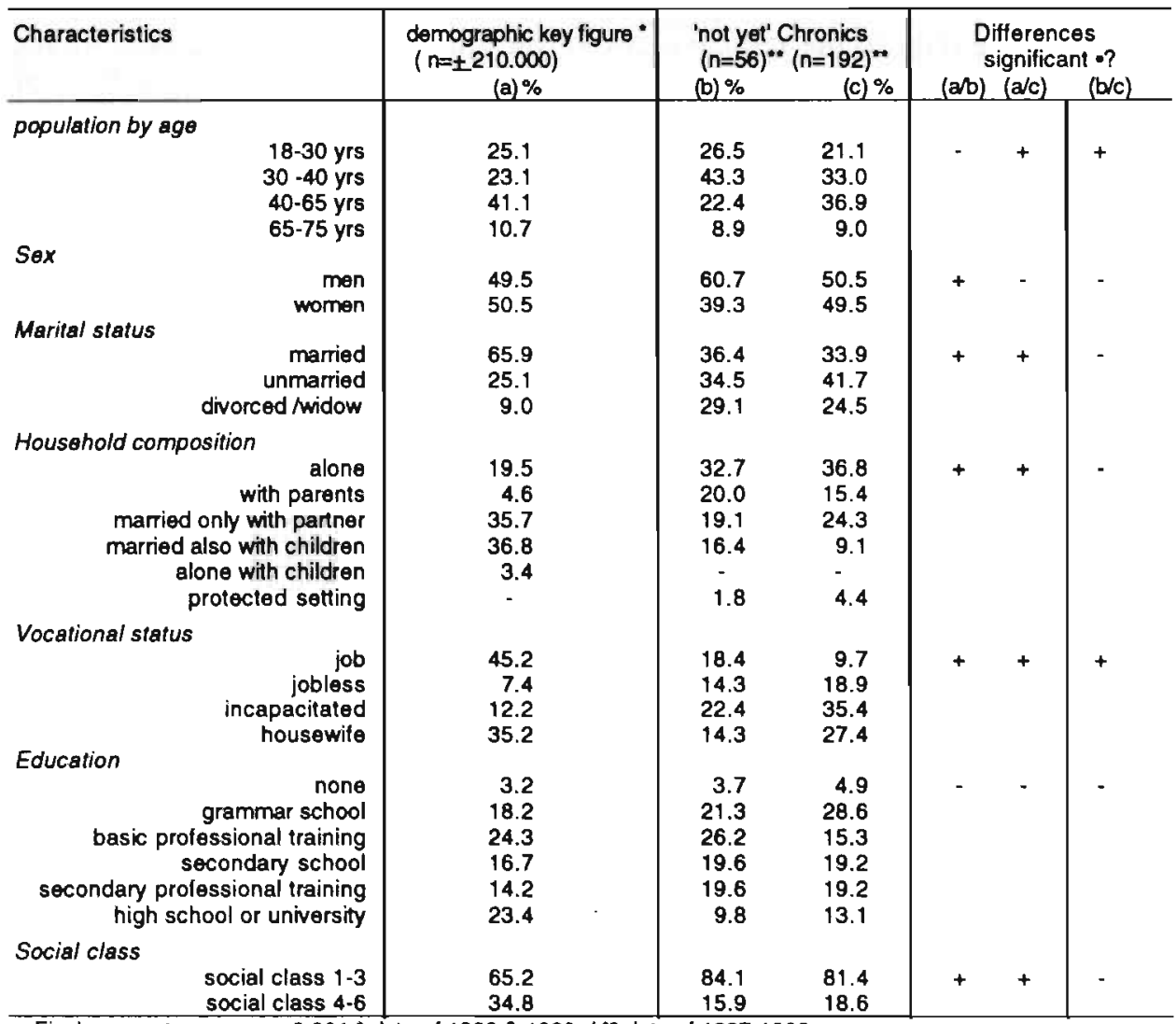

- Fischer exact z score, $\mathrm{p}<0.001^{\circ}$ data of $1989 \& 1990 /{ }^{* *}$ data of 1987-1989 
interested in the specific characteristics of the patients in care at this specialized service. We therefore compared the two patient cohorts "not yet" and "definitely" chronic with demographic key Figures of the district of the CMHC. These key figures were obtained from the Dutch Central Bureau of Social Statistics (CBS, 1990; 1991a). We used these data as a baseline, to get an impression of which demographic characteristics are related to chronicity in our population. The comparison focuses on the variables age, sex, marital status, household composition, vocational status and social class. Though the demographic key figures represent only data for 1989 and 1990 and the described population concerns data over the years 1987-1989, it is quite safe to compare these, as no major changes in the variables represented here have occurred over this time period (CBS, 1991b).

When we compare the demographic key figures of the district with the two patient cohorts we may observe quite a number of differences. Both patient populations show an over-representation of the age group 30-40 years and an under-representation of the age group 40-65 years. The data on marital status, household composition, vocational status and social class underline the vulnerable and socially marginal position of the chronic mentally ill. Both patient cohorts show a powerful underrepresentation of the married (twice as few as in the regional population), and over-representation of the unmarried and the divorced (up to twice as many as in the regional population). In both patient cohorts, a relatively large percentage live either alone or with their parents. Also, relatively large percentages are either jobless or incapacitated. Concerning educational level, the comparison is influenced by the fact that Maastricht is a University city with a relatively large percentage of highly educated people. When we compare the two cohorts with each other we may observe some slight differences. The cohort 'at risk, but not yet' contains more patients in the age group 30-40, more men, more patients still living with their parents, but less incapacitated or jobless.

\subsection{Comparison of the samples with the patient cohorts}

\subsubsection{Sociodemographic data}

In Table 3.3, the samples are compared with the patient cohorts 'not yet' and 'definitely' chronic. The first sample was extracted from the not yet chronic. A large proportion of this group $(75 \%)$ was entered in our sample. The data show no important differences between the cohort and this sample. The second sample is a homogenous grouped selection of the patients in care for a period longer than two years. This sample was a very specific selection. Consequently, it may be expected that the sample has certain specific characteristics, which may be significantly different from the group it was selected from: the definitely chronic. The apparent, and statistically also significant, differences - as for example the larger proportion of unmarried,and the larger proportion of patients younger than thirty in the 
Table 3.3 Sociodemographic characteristics of both samples compared with the patient cohorts at the rehabilitation service of the CMHC Maastricht

\begin{tabular}{|c|c|c|c|c|}
\hline $\begin{array}{l}\text { Characteristics } \\
n=\end{array}$ & $\begin{array}{c}\text { Not yet } \\
\text { chronics } \\
56\end{array}$ & $\begin{array}{c}\text { Sample } 1 \\
\text { (second pilot) } \\
41\end{array}$ & $\begin{array}{c}\text { Chronics } \\
192 \\
\end{array}$ & $\begin{array}{l}\text { Sample } 2 \\
\text { (main study) } \\
56\end{array}$ \\
\hline \multicolumn{5}{|l|}{ Age } \\
\hline $\begin{array}{l}18-30 \text { yrs } \\
30-40 \text { yrs } \\
40-65 \text { yrs } \\
65-75 \text { yrs }\end{array}$ & $\begin{array}{r}21.5 \\
39.3 \\
21.4 \\
8.9\end{array}$ & $\begin{array}{r}18.2 \\
41.7 \\
32.0 \\
8.1\end{array}$ & $\begin{array}{r}18.7 \\
33.3 \\
26.0 \\
7.3\end{array}$ & $\begin{array}{r}27.8 \\
33.3 \\
33.4 \\
9.3\end{array}$ \\
\hline \multicolumn{5}{|l|}{ Sex } \\
\hline $\begin{array}{r}\text { men } \\
\text { women }\end{array}$ & $\begin{array}{l}60.7 \\
39.3\end{array}$ & $\begin{array}{l}48.6 \\
51.4\end{array}$ & $\begin{array}{l}50.5 \\
49.5\end{array}$ & $\begin{array}{l}51.7 \\
48.3\end{array}$ \\
\hline \multicolumn{5}{|l|}{ Marital status } \\
\hline $\begin{array}{r}\text { married } \\
\text { unmarried } \\
\text { divorced /widow }\end{array}$ & $\begin{array}{l}36.4 \\
34.5 \\
29.1\end{array}$ & $\begin{array}{l}38.9 \\
27.8 \\
33.3\end{array}$ & $\begin{array}{l}33.9 \\
41.7 \\
24.5\end{array}$ & $\begin{array}{l}24.2 \\
56.9 \\
18.9\end{array}$ \\
\hline \multicolumn{5}{|l|}{ Household composition } \\
\hline $\begin{array}{r}\text { alone } \\
\text { with parents } \\
\text { married or with partner } \\
\text { protected setting }\end{array}$ & $\begin{array}{r}32.7 \\
20.0 \\
45.5 \\
1.8\end{array}$ & $\begin{array}{r}41.7 \\
11.1 \\
44.4 \\
2.8\end{array}$ & $\begin{array}{r}36.8 \\
15.4 \\
43.4 \\
4.4\end{array}$ & $\begin{array}{l}48.2 \\
23.2 \\
28.6 \\
-\end{array}$ \\
\hline \multicolumn{5}{|l|}{ Vocational stalus } \\
\hline $\begin{array}{r}\text { job } \\
\text { jobless } \\
\text { incapacitated } \\
\text { housewife }\end{array}$ & $\begin{array}{l}18.4 \\
14.3 \\
22.4 \\
14.3\end{array}$ & $\begin{array}{l}19.4 \\
19.4 \\
35.5 \\
25.9\end{array}$ & $\begin{array}{r}9.7 \\
18.9 \\
35.4 \\
27.4\end{array}$ & $\begin{array}{l}17.3 \\
15.4 \\
38.5 \\
17.3\end{array}$ \\
\hline \multicolumn{5}{|l|}{ Education } \\
\hline $\begin{array}{r}\text { none } \\
\text { grammar school }\end{array}$ & $\begin{array}{r}3.7 \\
21.3\end{array}$ & 32.4 & $\begin{array}{r}4.9 \\
28.6\end{array}$ & $\begin{array}{l}7.3 \bullet \\
14.5\end{array}$ \\
\hline basic protessional training & 26.2 & 23.5 & 15.3 & 29.1 \\
\hline secondary school & 19.6 & 20.6 & 19.2 & 16.4 \\
\hline secondary professional training & 19.6 & 20.6 & 19.2 & 12.7 \\
\hline high school or university & 9.8 & 2.9 & 13.1 & 20.0 \\
\hline \multicolumn{5}{|l|}{ Social class } \\
\hline $\begin{array}{l}\text { social class } 1-3 \\
\text { social class } 4-6\end{array}$ & $\begin{array}{l}84.1 \\
15.9\end{array}$ & $\begin{array}{l}82.7 \\
17.3\end{array}$ & $\begin{array}{l}81.4 \\
18.6\end{array}$ & $\begin{array}{l}81.1 \\
18.9\end{array}$ \\
\hline
\end{tabular}

- Fischer exact Z score, significant differences, $p<0.05$

second sample - are an effect of the choices made in the selection procedure. Also the higher proportion of better-educated in the second sample is an effect of the selection, as relatively more younger patients were sampled.

\subsubsection{Investigation of selection bias}

Apart from the choice to select homogeneous groups, the sample in the second phase of the study was slightly biased as an effect of a selective response. Only $62 \%$ of the patients fitting our criteria were interviewed. Elderly patients consented less often for an interview. Only half of the elderly women were interviewed. The professionals regarded a substantial amount of the young unmarried men as not fit enough for an interview. Consequently, some concern in respect of a selection bias in the main study sample is warranted. To investigate this concern, we compared the samples of the second pilot and the main study with the patient cohorts in terms of diagnostic characteristics 
Table 3.4 Diagnostic categories of both samples and of the patient cohorts at the rehabilitation service of the CMHC Maastricht

\begin{tabular}{l|c|c|c|c}
\hline $\begin{array}{l}\text { Characteristics } \\
\mathrm{n}=\end{array}$ & $\begin{array}{c}\text { Not yet Chronics } \\
\mathbf{5 6}\end{array}$ & $\begin{array}{c}\text { Sample 1 } \\
\mathbf{4 1}\end{array}$ & $\begin{array}{c}\text { Chronics } \\
\mathbf{1 9 2}\end{array}$ & $\begin{array}{c}\text { Sample 2 } \\
\mathbf{5 6}\end{array}$ \\
\hline Diagnostic category & & & & \\
psychotic disorder & $21 \%$ & $24 \%$ & $20 \%$ & $20 \%$ \\
affective disorder & $16 \%$ & $24 \%$ & $21 \%$ & $25 \%$ \\
anxiety disorder & $10 \%$ & $16 \%$ & $10 \%$ & $3 \%$ \\
deferred diagnosis & $17 \%$ & $9 \%$ & $9 \%$ & $8 \%$ \\
personality disorder & $25 \%$ & $29 \%$ & $30 \%$ & $32 \%$ \\
BPRS (mean score) & 11.1 & 10.4 & 12.6 & 15.3 \\
BPRS - Schizothymic index score & 4.3 & 4.6 & 5.2 & 8.2 \\
BPRS - Depressive index score & 4.3 & 3.7 & 5.6 & 6.7 \\
Foulds index & 2.3 & 2.2 & 2.1 & 2.1 \\
SFCL & 21.2 & 22.3 & 22.5 & 22.1 \\
\hline
\end{tabular}

- Fischer exact $z$ score, significant differences, $p<0.05$

and patient career characteristics. Table 3.4 shows that we need not worry about a healthy patient selection effect. These data show that the last sample in particular contains more severe cases, as the B.P.R.S. as well as the schizothymic and depressive index scores are significantly higher than that of the cohort they were drawn from. With respect to the diagnostic categories no major differences were detected. The high schizothymic index score in the second sample may be due to the selection of more young chronics.

\subsubsection{Patient career characteristics}

Also concerning global indices concerning patient characteristics such as current age, age at onset and years in care, no significant differences were observed (Table 3.5). Only the second sample showed a somewhat lower mean duration of care, again perhaps an effect of the over-representation of the younger groups.

Table 3.5 Patient career in the samples compared with the patient cohorts at the rehabilitation service of the CMHC*

\begin{tabular}{l|cccc}
\hline $\begin{array}{l}\text { Characteristics } \\
n=\end{array}$ & $\begin{array}{c}\text { Not yet Chronics } \\
56\end{array}$ & $\begin{array}{c}\text { Sample 1 } \\
41\end{array}$ & $\begin{array}{c}\text { Chronics } \\
192\end{array}$ & $\begin{array}{c}\text { Sample 2 } \\
56\end{array}$ \\
\hline current age (mean) & 37 & 40 & 41 & 38 \\
age at onset (mean) & 36 & 33 & 28 & 30 \\
duration of care (mean yrs) & 1.5 & 1.3 & 10.3 & 7.9 \\
\hline
\end{tabular}

Student $\mathrm{t}$-test, differences between means 


\subsection{Summary of the comparisons}

In this chapter we discussed our decision to distinguish two patient cohorts among the population referred to a specialized rehabilitation service for the chronic mentally ill. First a group of 'at risk, but not yet' chronic mentally ill, in care for longer than one, but less than two years. Second a group of 'definitely' chronic mentally ill in care for more than two years. These patient cohorts were compared to the population of the district on a number of sociodemographic characteristics. The patients at the service are relatively young, most often without a partner - unmarried or divorced, living either alone or with their parents - and almost always without any daily obligations, being either jobless, incapacitated or ill. Relatively few have children of their own. Many still live with their parents, despite being in their mid-thirties. The social class of the patients is low, despite a sometimes good education or background. When we look at the comparison between the samples we studied and the patient cohorts, fewer differences are apparent. Most of the differences, especially in the second sample, can be explained by the specific choices we made in respect of the selection criteria. In the first phase of the study, when we discussed a number of patients with the mental health professionals, the main goal of the assessment was item selection and obtaining a professional's opinion on the feasibility of the instrument. In this phase we were not confronted with non-response nor were we concerned with this issue. In the second phase, non-response was considerable. However, the data show that the response group is not a healthy patient selection. On the contrary, in respect of symptomatology assessed within three months after intake, data show that the group we interviewed actually contained the more severe cases. We therefore may conclude that the group we sampled is a fairly good representation of the population we wanted to select. 


\section{Social role concepts underlying the instrument}

The present chapter highlights the theoretical background of the conceptual definitions underlying the instrument. It presents a historical review of the role concept. Different theories are compared. These are not regarded as mutually exclusive, but as complementary (Gerhardt, 1971). An effort is made to combine the different concepts in a single theoretical framework for the description of social role development. This framework is finally related to social integration and social disintegration in the chronic mentally ill. This chapter relates to the first two objectives presented on page 1 of this thesis:

1. to develop an instrument which relates the current degree of social integration to the lifetime development of social adaptation;

2. to fit this instrument into a simple and understandable theoretical framework;

\subsection{Introduction}

Ambulatory care of the chronic mentally ill is focused on the functioning of the individual within the natural setting, the patient's own social context. Social psychiatric research contributes to professionalization of mental health care by focusing on the understanding and analysis of the social dynamics precipitating mental illness (Romme, 1991). In order to professionalize the outpatient care of the chronic mentally ill, the Department of Social Psychiatry of the University of Limburg is collaborating with the Community Mental Health Center of Maastricht in a number of studies on patient careers, need of care, social network and social role fulfillment (Radstake et al., 1985; Hamers, 1987; Romme et al., 1987; Baars et al., 1990). In these studies the social dynamics precipitating mental illness are interpreted following the ideas first presented by the Dutch psychiatrist Querido (1956) as the "theory of social homeostasis". Querido applied the physiological principles of homeostasis for the description of the social dynamics of a mental illness. In his view (mental) illness replaces socially integrated functioning. If illness is long-term, the (mentally) ill lose their integration in society. Following his line of reasoning, the diagnostic process implies a biographical description of the social position of the individual, clarifying which part of the social functioning was replaced by illness, and which social dynamics have influenced the process of replacement.

However, Querido did not explain how to operationalize his ideas. How can an abstract concept like integration into society be operationalized? What is "socially integrated functioning"? Socially integrated functioning implies two 
sub-dimensions. First the degree of social integration in the direct environment and in society. Secondly, the activities and initiatives which the individual undertakes in the relationships with others in his direct environment. (Social) action leads to adaptation and integration if the individual lives up to expectations set by the direct environment. Living up to expectations means an adequate fulfillment and performance of social roles (Weber, 1947). To describe the degree of social integration in the direct environment, we chose to apply the theoretical framework provided by Gerhardt (1971). In her monograph "Rollenanalyse als kritische Soziologie", she presents a framework in which she distinguishes three different types of roles in terms of their permanence. Thus, her theoretical framework is useful for the description of the positions achieved by the individual in society. She based her ideas on a number of theoretical predecessors, the main features of which we shall also highlight. For the description of the second dimension, the development of the activities and initiatives which the individual undertakes, we will review a selection of literature on socialization, both in youth (Erickson, 1963) and in adulthood (Krauss-Whitborne, 1979; 1982; Erickson, 1974; Levinson, 1978; Hurrelmann, 1983). This chapter first presents a historical review of role theory and the ideas of Gerhardt. Her ideas are then combined with the findings of different authors on socialization, leading to a framework for description of social role development and acquisition of a position in society. We will conclude with a description of the relevance of this theoretical framework for the rehabilitation of chronic mentally ill.

\subsection{Role concepts}

The concept of role is by no means clearly defined. Many sociologists have presented their own role theories each with a different set of definitions and its own terminology. Quite often, different words cover the same concept, whereas different concepts are covered by the same words. An example is the term 'position'. Linton (1936) uses this term to describe the position achieved by the individual in society, whereas the same concept is covered by Dahrendorf using the term 'status'. Depending on the source, a role may be conceived as (Biddle, 1979):

- a position differentiated in terms of a given social structure (Levy, 1952);

- what the actor does in his relations with others........within the context of his functional relation with the other(Parsons, 1951);

- what individuals do as occupants of a defined social position (Newcomb, 1950);

- an internally consistent series of conditioned responses (Cotrell, 1942);

- (an) integrated or related subset of social norms" (Bates, 1956);

- the sum of cultural patterns associated with a particular status. It thus includes attitudes, values and behavior ascribed by the society (Linton, 1945).

No matter what the role theory, when you apply the concepts it covers, you have to make explicit which theory and which concepts are used. Only then, 
will the application of the terms be understandable and the operationalizations controllable.

\subsubsection{Symbolic interactionism}

In sociology, various theoreticians describe social interaction in terms of role fulfillment. One of the best known theoretical descriptions is that of the symbolic interactionists. In their view, role is defined as the subjective perception of the direct interaction. The perception of the role the other plays in the interaction is interpreted as a means of action toward one another. Human beings interpret and appraise each other's actions instead of merely reacting to each other's actions. Behavior is regarded as the individual's interpretation and handling of stimuli, and group action as an effect of fitting together individual lines of action (Stryker, 1957). The individual's response is based on the meaning attached to certain actions. Interaction is mediated by the use of symbols, by interpretation, or by ascertaining the meaning of one another's actions (Mead 1934). The symbolic interactionists regard selfconsciousness and the continuous interpretation of the actions of others as the motive of human action. In their view, social roles are fulfilled in the direct contact with other people, thus description and interpretation of interaction is the focus of study at a micro-social level (interactionist role concept, Visser et al., 1983).

\subsubsection{Social conflict}

Another important theory, the theory of social conflict, focuses on the personal interests of individuals participating in a social interaction, on their motives, incentives and division of power. The description of relations and positions between individuals on the organizational and group level is the focus of study at a meso-social level (the "personal role concept", Visser et al., 1983). Human society is determined by differences in positions, power and rebellion against power, and the threat of sanctions. In this theory, antagonism and incompatibility within society are the incentive for human action. An example is Dahrendorf (1958a, p. 190-205), who distinguishes three kinds of expectations, each bringing about a different kind of sanction: "Muß-", "Soll-" and "Kann-erwartungen". In "Muß-erwartungen" the sanctions are explicit, either by law or by a professional code. In "Soll-erwartungen" the sanctions are ethically determined within a cultural or subcultural context and sanctioned by an implicit rejection. "Kann-erwartungen" are sanctioned by positive reinforcement, consent and approbation (e.g. by superiors in a hierarchical organization). The impact of sanctions determines the actions of the individual: the stronger the sanctions, the clearer the expected behavior. Conflict theory regards prescribed norms and power structures as the determinants of human behavior. Within each social organization, positions with control over other positions can be distinguished. Social roles are determined by sanctions and norms. Consequently, the positions and relationships between individuals at a meso-social level is the focus of study. 


\subsubsection{Structural functionalism}

The third theory, the theory of structural functionalism, describes the conditions and prerequisites for keeping the social structure together. Description of cultural and societal norms and expectations is the focus of study at a macro-social level (the "structural role concept", Visser, 1983). Structural functionalism connects the elements of the individual's actions by relating these actions to an integrated structure of society. Human's actions are always determined by rules and prescriptions (Linton, 1945). These prescriptions limit the individual's span of control over his own actions, engendering a structure of explicit expectations.

\subsection{The theory of Uta Gerhardt; a meta analysis}

\subsubsection{Definition of role}

These three different levels of analysis and interpretation, the micro-social level as described by the symbolic interactionists, the meso-social as described in the theory of social conflict and the macro-social level as described in the theory of structural functionalism, were combined by Gerhardt into a comprehensive theoretical framework. Gerhardt combined the main features of these apparently conflicting theories in an effort to relate the actions of the individual to the structure of society. The predominately structural role concept of Uta Gerhardt is useful for the analysis of the chronic mentally ill because it describes the position of the individual in terms of roles with a more or less important impact and permanence in daily life. She uses the following definition of role:

Roles are the result of a typology of prescriptions based on behaviors, traits, performances and task fulfillments of individuals having a similar position or rank (Gerhardt, 1971, p. 226).

In her theory, she refers to the three main sociological views mentioned above. In her view each of these views reflects a different organizational principle of social order at a different level:

1. The theory of normative integration, i.e. structural functionalism, focuses on normative consensus and the adjustment of the individual to the societal structure. Society is built upon a set of rules and expectations. The individual must adjust in order to participate. Interaction and collaboration are consequently defined by these rules and expectations, whether explicit or not. In the process of socialization, the individual internalizes these expectations. Thus, the individual knows what to do and how to behave in a specific social position.

2. In the theory of conflict, society is built upon the division of power. It is not consensus and adjustment, but power and sanctions which determine the position of the individual within society. The individual is obliged to adjust and comply and is threatened by rejection and sanctions. 
3. In the theory of symbolic interaction, society is viewed as a process of ongoing activity and interactions, not as a relatively static system, structure or organization (Stone, 1962). The individual forms and aligns his own actions on the basis of his interpretation of the acts of others.

Whereas most of the representatives of the different views reject the other opinions, Gerhardt reasons that they are in fact complementary, each focusing on a different level of societal structure (Gerhardt, 1971, p. 291). Within each level, she distinguishes different types of social roles, each with a different impact on the position of the individual in society. On the highest level she distinguishes the status roles, on the middle level the position roles, and on the lowest level the situation roles. In Gerhardt's construct, the theory of normative integration focuses on the highest level, the status roles. The theory of social conflict focuses on the middle level, the position roles. The theory of symbolic interaction, finally, focuses on the lowest level, the situation roles. The division between the various types of roles is gradual. The status role represents what is ascribed by others to a person, because of age, sex and social class. Position roles give a structure to daily life. They are a representation of the position of the individual in society and are gained through achievement. The situation roles reflect the direct interactional roles the individual shares with others in daily life.

\subsubsection{Status roles}

Status roles reflect behavioral expectations which the individual has to live up to as a member of society with specific universally applicable characteristics, such as sex, phase of life, religion and social class. When you are a young man, society expects you to have a job. When you are an older woman, society expects you to have responsibilities within your family. The expectations accompanying the status roles are implicit, but well known. They are shared by a major part of a (sub)culture (van Gelooven, 1990). For each cultural group in society, these expectations differ. For example, as a woman you are expected to marry and raise children, but you are allowed to have your own career if you organize it adequately. However, as a woman of an ethnic minority you are not allowed to have your own career and you have to focus all your activities on domestic responsibilities.

The status role is ascriptive: an individual has little influence over obtaining the role and either does or does not assimilate the characteristics. The individual grows into the status role. Expectations related to status roles change over different periods of life. A child is not expected to perform in the same way as a young adult is, just as the expectations for young adults are other than those for older adults. An individual fulfills the expectations of a status role by showing behavior which is expected of everybody of a certain age, sex, social class and with a certain position in society. An adult who behaves like a child does not fulfill his status role. To assume a status role, the individual has to win respect and authority from his environment. Personality, 
abilities, and experience, among other factors, determine whether an individual can meet the expectations. Because the societal expectations are abstract and implicit and not determined by the individual's abilities but by what he is, role fulfillment at this level is difficult to learn or change. However, deficiencies in living up to the expectations of the status roles are severely sanctioned. Falling short is mostly due to a severe dysfunctioning. Consequently, deficiencies are difficult to compensate for.

\subsubsection{Position roles}

A position role is a compilation of expectations and rules set by the direct environment according to the position the individual has within a distinct social network, for example within a family, a business, or a club (Knibbe, 1981; 1982). Position roles are obtained through accomplishment at home, at work or at leisure. They have to be gained, an individual has to show certain abilities. Examples of position roles are the role of husband or wife, the role of leader, the role of foreman or the role of scholar. A position role represents the placement of the individual within a social substructure. Each person takes a number of positions at the same time. Some are short-lived, others are more important and require certain abilities. These roles give a structure to daily life, because they require meeting expectations regularly. Through the fulfillment of different position roles, an individual becomes hierarchically placed within social relationships. Position roles represent the rank order of the individual within a limited and definable social context. The expectations are explicit and less abstract than the expectations set to status roles. In the short and the long term, daily life is composed of different positions within various interpersonal relationships. In a position role responsibilities have to be met, expectations in respect of tasks are set and the individual has to perform to a minimum standard in order to keep the position.

The position role is acquired by complying to social norms and rules, for example within a job, within a marriage, or within social clubs. Skills, professional training and personal abilities determine the achievement of position roles. The expectations set to position roles are sanctioned, misbehavior or inadequate performance leads to loss of or rejection from the role. However, if the role is well established, for example because the individual has performed well for a long time in the past, the sanctions are difficult to impose. In organizations, inadequate performance by employees who have worked for a longer period of time mostly leads to long-standing conflicts which quite often remain unresolved, because both parties have few alternatives (Kahn, 1974). Consequently, position roles held for a longer period of time provide security since loss of the role is less likely.

\subsubsection{Situation roles}

Situation roles are determined by expectations of adequate behavior within incidental situations. The expectations regulate interaction within limited 
situations, for example in traffic, at parties, at a meeting, or in a pub. Examples of situation roles are leader, group participants, visitor or speaker. Situation roles have little impact. For example, when an individual has led a meeting with a certain success, he may be asked to become chairman, i.e. a position role. Situation roles are temporary. They are limited to a particular time, place and situation, and are restricted to the direct interaction with others. An individual can easily withdraw from a situational setting. The sanctions for inadequate performance are short-lived and experienced as less important. They have little or no effect on the social position of the individual in the long term. Situation roles are changeable and interchangeable: in a certain situation a person may have a role of major importance, while he may be subordinate in another situation. Situation roles, thus, offer an opportunity for training abilities and behavior necessary to acquire position roles.

\subsection{The different levels and the freedom of action}

According to Rommeviet (1955), roles can be placed in a continuum with an increasing degree of structure imposed by rules and expectations and an increasing number of sanctions. By combining the ideas of Rommeviet and Gerhardt, it becomes clear that functioning in a situation role leaves the individual with a large degree of personal liberty, while in a position role the individual has to comply to more fixed norms (Figure 4.1).

Figure 4.1 Role components: personal and cultural

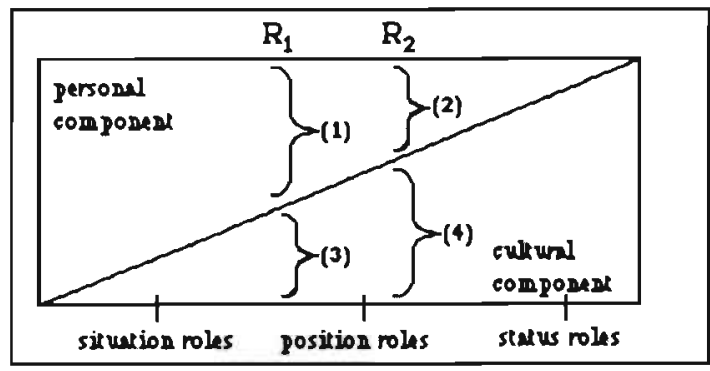

$\mathrm{R} 1$ is the situation role of the individual in his circle of friends. The personal component (1), i.e. the freedom to behave is much larger than the cultural component (2). The sanctions are less, but the impact and continuity of the role are also less. R2 is the position role of the actor in a vocational setting. The personal component (3) is now much less; the cultural component (2) as well as the sanctions are in inverse proportion more important, and the impact and continuity of the role are consequently also greater. 


\subsection{Operationalization of the role concept in the current study}

To describe the fulfillment of role, two main dimensions are important: what did the individual achieve, and how was this achieved. "What" can be described by means of the status and position roles the individual has achieved: the place the individual has acquired in society (cf. Gerhardt, see the previous paragraphs). "How" can be described by means of the assessment of the social role performance and the social role development within a number of relevant domains. In most observational instruments dealing with the judgment of social behavior and social functioning, assessment is dependent on the interpretations, norms and expectations of the observer.

To obtain a certain degree of objectivity, we defined the concept of role performance as the factually observable behavior within a clearly defined interaction with other people. In short, we are interested in what the individual indeed does. What aspects of social role are observable ${ }^{8}$ ? In our definition of role performance we follow Visser (1983):

A social role is the combination of expectations with respect to behavior within a circumscribed position and the activity of the actor in that position.

In Visser's operationalization, role is more than a set of expectations: it is what the individual does in fact. Subsequently, in the assessment of role performance, obtaining information from the environment is essential, either through an informant or through a careful assessment of experienced problems. The main question concerns the extent to which the behavior of the patient meets the demands of the direct environment. These demands can be fitted into a limited number of domains. In our study we defined these domains as role performance areas, areas of human functioning within which behavior is linked. Because we want to relate current functioning to past functioning, the choice we made in defining the domains is based on assumptions of dimensions in human development: the process of socialization, not only in youth, but also in later life. In the following paragraphs we will address the theoretical foundations of the five role performance areas we chose for the description of role development. Beforehand, the relationship of certain concepts of socialization theory to certain specific characteristics in the social development of the chronic mentally ill will be clarified in order to explain our choice of five distinct areas of social role performance.

\subsection{The concept of role and the socialization process}

A typical feature in the development of social adjustment in the chronic mentally ill is the preponderance of an inadequate role performance accompanied by periods characterized by a downward spiral of deterioration 
in several areas of daily life. Nijhoff (1980) shows that social problems are often individualized, and followed by social rejection. The social dynamics he describes make it clear that people with problems, especially psychiatric patients, have an increasingly diminishing span of social control. Quite often the process is irreversible if the problems become chronic. Consequently it is important to identify the phase of life in which social rejection first took place. The earlier it occurred, the more widespread the dysfunction. The earlier the relapse, the more widespread the role impairment in areas of daily life. The later the relapse, the better the chance of a circumscribed role dysfunction. Especially after a long period of time, the impairment may have spread to so many areas of daily functioning that cause and effect are impossible to trace.

In the description of social role performance in the chronic mentally ill, it is important to relate current performance with development. In human social development, socialization is a process in which a child, and later an adult, learns to adapt to the norms and values set by the direct environment either at home, with peers or in a vocational or school setting. Socialization may be described as: "learning in which situation which norm has to be applied, but also having an opinion as to which norm is appropriate" (Knibbe, 1981). Knowing which norm is appropriate means internalizing the expectations, thus making it a part of your personality. According to Baumrind (1980), socialization in the child is an adult-initiated process by which children, through insight, training and initiation, acquire the habits and values congruent with adaptation to their culture. According to Kreppener (1982), this process of socialization does not stop after adulthood. Then, however, the expectations are more complex and less explicit. By acknowledging the positive or negative reinforcements of the environment, an individual acquires the possibility of adjusting his behavior. By meeting expectations, the individual acquires an increasing degree of independence and power in the fulfillment of roles in daily life. Each change in status and position roles requires socialization to a certain extent, as for example in a new job, in marriage, in the raising of children, after retirement. Functioning in new, more complex position roles requires an increasing degree of differentiation and specialization, especially in the current over-organized society.

To develop oneself in new position roles, and to acquire new and more complex roles, skills are required which can be learned at different moments in life. Some skills have to be a part of your personality. You can't develop them at an older age; however, they may be felt as indispensable in the new role. Role strain and dysfunctioning will follow. The freedom provided by the context determines the extent to which role strain develops. This freedom also determines the possibilities of learning and adapting to a new position. In this view, personal development is a continuous process in the interaction with the direct environment and the social and the vocational context. An example is adaptation within work. If there are certain expectations in respect to personal hygiene in the vocational setting, role fulfillment in terms of self-care and self- 
presentation may be expected to be optimal. The individual knows how to behave. The same observation may be made with regard to behavior within social clubs. To be accepted, the individual has to comply with the rules of the club, and show a minimum standard of self-presentation. A role hierarchy may be assumed to exist; to fulfill the more complex roles within organizations or at work or in social clubs, the individual has to perform well in less complex roles. This hierarchy in role performance has been empirically confirmed in different studies in normal, in physically ill and mentally ill individuals (Biddle, 1979; Gerhardt, 1986; de Jong, 1987; de Jong \& Molenaar, 1987).

\subsection{Life cycles}

According to Kohli (1983), three developemental cycles in wich the individual learns and requires new roles can be distinguished in human society. Each cycle consists of a number of subsequent phases. Certain roles are achieved, carried out, and perhaps lost in a later period of life. Functioning in daily life is determined by at least one of these three cycles: the family cycle, the social cycle and the vocational cycle. Each cycle is of importance at different moments of life. They may be represented as undulations with ups and downs at various phases of life, as follows:

1. The family cycle. At home in the family, each child learns how to behave. The security and the feeling of basic trust provided by the parents offer the child the opportunity of bonding (Bowlby, 1969). This ability to bond and express a feeling of togetherness may be brought into effect at a later phase of life, for example in partnership relations. At home, values are learnt in respect of the care of oneself and others, and in respect of personal interest in others. In early youth, early adolescence, and when the individual starts his or her own family in early adulthood, the family is a major aspect of daily life, and consequently a major aspect of identity. When the child becomes older, or, later on, when his or her own children become older, family life becomes less important. The children move their focus to a peer group and the parents develop activities in the neighborhood or in social clubs. For the parents, social contacts and leisure become more important again.

2. The social cycle. In childhood, an individual learns to adopt socially desirable behavior in a peer group. Later on, this behavior is brought into effect in social clubs, organizations and friendships. The social context becomes more important in later adolescence, and when one's own children leave home in later adulthood. In those phases of life when the family is important, social life becomes less important, and vice versa.

3. The vocational cycle. In education, and later, in a job, the individual has to perform according to demands laid down by the setting. Skills and abilities lead to appreciation in the form of better position and income. The individual achieves, develops and maintains a position until reaching the summit of his abilities. In early adulthood most people start a career, which is either consolidated or abandoned in the mid-thirties. 
In the midlife crisis, an evaluation of achievements takes place, and sometimes a reorientation. After midlife, either a decline or a further stabilization may take place (Levinson et al., 1974).

A new phase in a cycle is quite often marked by an important event (Glick, 1978) such as partnership, marriage, childbirth, leaving home or the decease of a partner or child. In each cycle a sequence can inevitably be recognized. Whenever a change occurs in the normative content of the role, i.e. the role expectations, a new role in the sequence emerges (Rodgers, 1964). The role of father of a toddler is not the same as the role of father of a schoolboy, an adolescent or a young adult. In each phase, different positions are taken together with different combinations of position roles. In a longitudinal or retrospective study on role performance, these combinations of positions and relationships have to be taken into account. When an individual assumes a role, this leads to integration and balance within the social context. If the individual does not succeed in fulfilling the basic expectations of a new role in a sequence, this may lead to a lack of integration, the experience of pressure or sanctions, and difficulties in assuming subsequent roles in the sequence. Typical patterns of development are presented in Table 4.1 (Erickson, 1974).

Table 4.1 Typical patterns of major life events in adulthood

\begin{tabular}{|c|c|c|c|}
\hline $\begin{array}{l}\text { Developmental } \\
\text { phase }\end{array}$ & $\begin{array}{l}\text { Personal } \\
\text { characteristics }\end{array}$ & Family & Career \\
\hline Early adulthood & $\begin{array}{l}\text { Firming adult identity } \\
\text { Productive and ener- } \\
\text { getic orientation } \\
\text { Defining a set of goals }\end{array}$ & $\begin{array}{l}\text { Becoming independent } \\
\text { Search for mate } \\
\text { followed by establish- } \\
\text { ment of own family }\end{array}$ & $\begin{array}{l}\text { Exploration and tentative } \\
\text { choices followed by } \\
\text { commitment to career } \\
\text { Finding a "mentor" }\end{array}$ \\
\hline $\begin{array}{l}\text { Middle adulthood } \\
\text { (30-45 years) }\end{array}$ & $\begin{array}{l}\text { Continued definition of } \\
\text { identity } \\
\text { Peak in productivity } \\
\text { and active seeking } \\
\text { of life goals }\end{array}$ & $\begin{array}{l}\text { Involvement in child- } \\
\text { rearing and settling } \\
\text { down into family life }\end{array}$ & $\begin{array}{l}\text { Settling down into career } \\
\text { and seeking career } \\
\text { goals } \\
\text { Breaking with mentor } \\
\text { Settling in own } \\
\text { independent position }\end{array}$ \\
\hline $\begin{array}{l}\text { Midlife crisis } \\
\text { (optional) } \\
\text { (42-45 years) }\end{array}$ & $\begin{array}{l}\text { Questioning identity } \\
\text { Concern over morta- } \\
\text { lity }\end{array}$ & $\begin{array}{l}\text { Discontent with } \\
\text { marital relationship } \\
\text { concern over children } \\
\text { leaving home }\end{array}$ & $\begin{array}{l}\text { Dissatisfaction with } \\
\text { career accomplishments }\end{array}$ \\
\hline $\begin{array}{l}\text { Later middle } \\
\text { adulthood } \\
\text { ( } 45-60 \text { years) }\end{array}$ & $\begin{array}{l}\text { Personality integra- } \\
\text { tion } \\
\text { Relaxation and relativ } \\
\text { ization of conflicts }\end{array}$ & $\begin{array}{l}\text { Preparation of children } \\
\text { for maturity } \\
\text { Redefinition of marital } \\
\text { relationship }\end{array}$ & $\begin{array}{l}\text { Final effort to achieve } \\
\text { career before retirement } \\
\text { Slowing down of career } \\
\text { activity }\end{array}$ \\
\hline
\end{tabular}

Depending on the phase of life in which the individual can be placed, the requirements and expectations vary. Erikson $(1963,1974)$ was the first to describe some main features in the expectations typical of the different phases of life. Following Erickson, Krauss-Whitborne (1982) described adult 
development in greater detail and distinguished a number of developmental phases, each with its own specific features, which we follow in our study. When an individual has to assimilate several changes at the same time in different areas of life this may induce a decompensation. Consequently, the transitionary periods between phases of life are essential in the assimilation of new roles. These are the moments when the individual acquires new roles in relation to his performance and abilities. At these moments the individual meets the challenges of life. In these transitory periods not only role transition, but also role conflict and stress occur. A relapse or a stagnation in development can be the result of unsuccessful role transitions between different phases of life. At each moment of life several basic expectations may be defined which the individual has to meet. These expectations are the minimum prerequisites for adjustment in a specific phase of life. When an individual does not succeed in meeting the expectations, stagnation or downfall may occur, sometimes accompanied by mental illness.

\subsection{Role performance domains}

The basic prerequisites for adjustment can be clustered within five domains of social role performance. In this study we based the choice and the operational definitions of these five domains on the socialization theory of Hurrelmann (1983), who identifies these areas as distinct settings of socialization within which behavior develops. These five areas are delineated as follows:

1. Material self-care and care for others; in "taking care".

2. Supportive, family and kinship roles, with specified expectations, such as relationships with children, parents and other kin, but also relations with important non-kin; in "support".

3. Sexuality and intimacy roles; in "sexuality".

4. Vocational roles, either in a formal or a non-formal setting, if a responsibility has to be carried; in "daily obligations".

5. Social roles, covering activities without an obligatory function, in relation to kin or non-kin, but also within an organizational setting, or social clubs; in "social activities".

These role performance domains may be seen as functional prerequisites (Duvall, 1967), functions which necessarily have to be performed for the individual to keep his position. In this arrangement, the five basic human needs of Maslow (1970) can be recognized: physiological needs, comfort, love, esteem and accomplishment of values. Physiological needs are fulfilled in taking care. Comfort is realized through support. Love is realized within a intimate relationship. Esteem is realized through a professional career, or in the establishment of a family. Finally, most of the values are realized either in a career or in social life. In the current study, we assume the above roleperformance areas develop independently of each other within the various phases of life. Support, for example, develops in early youth with the feeling of basic trust and may be expressed to a partner and children in early adulthood. The vocational roles develop in adolescence and are established in 
arly or middle adulthood. The next paragraph will describe the different roleperformance areas in greater detail, and we will go into how they develop and when and how they are brought into effect. In the definition and distinction of the different role-performance areas, we are primarily interested in current performance. For the description of current performance, we applied the operational definitions as described by Ivan Nye in his study (1976),"Role structure and analysis of the family", complemented with sub-dimensions relevant for the assessment of development. Selection of the items was based on the dimensions and items he describes in his study, though not all domains were used and they were also arranged in a different way?.

In the "taking care" role-performance domain we distinguish self-care and care of others. This domain is developed in early youth and is quite often a source of conflict in child rearing. Especially in young adulthood, a stagnation or relapse in development may occur.

In the "supportive" role performance domain (the therapeutic role c.f. Ivan Nye, 1976) we distinguish three sub-dimensions: bonding (the ability to establish an emotional relationship); practical support; and the ability to resolve interpersonal problems and conflicts. These three sub-dimensions may be regarded as features of an affective bond within family life or with important friends. The dimensions of this domain can be expressed in family relations, but also in the relation with an elderly neighbor, for example. Support first develops in early youth by the basic trust experience. Subsequently, in puberty and adolescence, the child is trained in solving problems and conflicts, an ability which it needs for the establishment of its own family (Bowlby, 1969).

The third role performance domain is "intimacy and sexuality". In this domain we distinguish the choice of a sexual preference, the establishment of sexual and intimate relationships, the choice of a partner, and the determination of his or her own position and input in a relationship, as well as the recognition of the other's wishes. In early life a child already learns gender-specific behavior. In the puberal years the sexual identity is further developed. In adolescence one's own preferences and choices are shaped. Especially in adolescence, the individual may be preoccupied with uncertainty and insecurities in this domain. Self-awareness and individual choices in this domain are mainly established in early or middle adulthood.

The fourth role performance domain is the "vocational" role domain. We chose not only to evaluate performance in a job, but broadened this concept to include working in a structured or semi-structured environment within which the individual has a certain responsibility but not necessarily an income. Subdimensions of this role domain are practical task fulfillment, interaction with 
others, both at the same level and on higher or lower levels, and the coping with problems and personal conflicts in work. In adolescence, when in school, the sanctions may be of little impact and work less important, but especially in early and middle adulthood work is an important source of identity and selfesteem. Levinson et al. (1974) distinguished four different phases in the professional career, within which the responsibilities increase. First, a construction phase: under supervision of a mentor an individual assumes increasing responsibilities. Then, a phase of establishment. In this phase the individual has his or her own responsibilities related to experience and these responsibilities are expanded gradually, though still in the same subordinate position. In middle adulthood the career develops and the individual functions at the top of his abilities. If the individual does not succeed in keeping his position, stagnation or rejection occurs, which in Dutch society quite often leads to incapacitation. The final period is, of course, retirement.

The fifth role performance domain is the domain of "social activities". This domain covers those activities not bound by obligations or expectations which are aimed at leisure, personal development or informal interactions with friends or kin (recreative and socialization role, cf. Ivan Nye, 1976). This domain includes interactions and activities, but also the possibility drawing on friends, relatives, acquaintances, or social clubs. It does not include relationships with close friends, which is covered by support. Leisure may be a source of a social network and a support network. The way leisure time is spent, either entirely alone or (more frequently) with others, is an indication of the quality of the social interactions. Another indicator is the mutuality within social relationships. A third indicator of the quality of social relations is initiative and the extent to which initiatives lead to activities at home or outside. In early youth and adolescence, social activities and a social network may be quite unstable. In early adulthood, a stable network and social life within social clubs is generally established. This network and the social activities tend to decrease when family life becomes more important. Later on, when the children leave home, the social activities tend to increase again.

Each role domain has consequently a specific developmental pattern throughout lifetime. Each new phase of life sets new demands. New and more complex roles have to be learned. What is learned in early youth and puberty is tested first in adolescence. In early adulthood the individual acquires a place in society, and perhaps starts his or her own family. Middle adulthood is a period of consolidation, both in work and family life. In mid-life, reevaluation of achievements may lead to a crisis. For example, marriage may be experienced as a routine, leading to divorce: the professional career is reevaluated, leading to change or loss of work. In later adulthood, the achieved position is either consolidated or deterioration starts.

\subsection{Discussion and conclusion}

In his theory of social homeostasis, Querido stated that a person in the 
interaction with his environment is always subject to mechanisms of equilibrium, physically, mentally and socially. Disruption of the equilibrium always leads to a compensation. The compensation is either from within the person or imposed by the environment. When the person falls short in any way, this disturbs the social environment and a regulatory impulse occurs. This impulse may be complementary and supportive, or non-complementary and rejective. Figure 4.2 presents a model showing the interdependencies.

Figure 4.2 Relationship between social roles, social integration and rehabilitation.

DEVELOPMENT

ANALYSIS

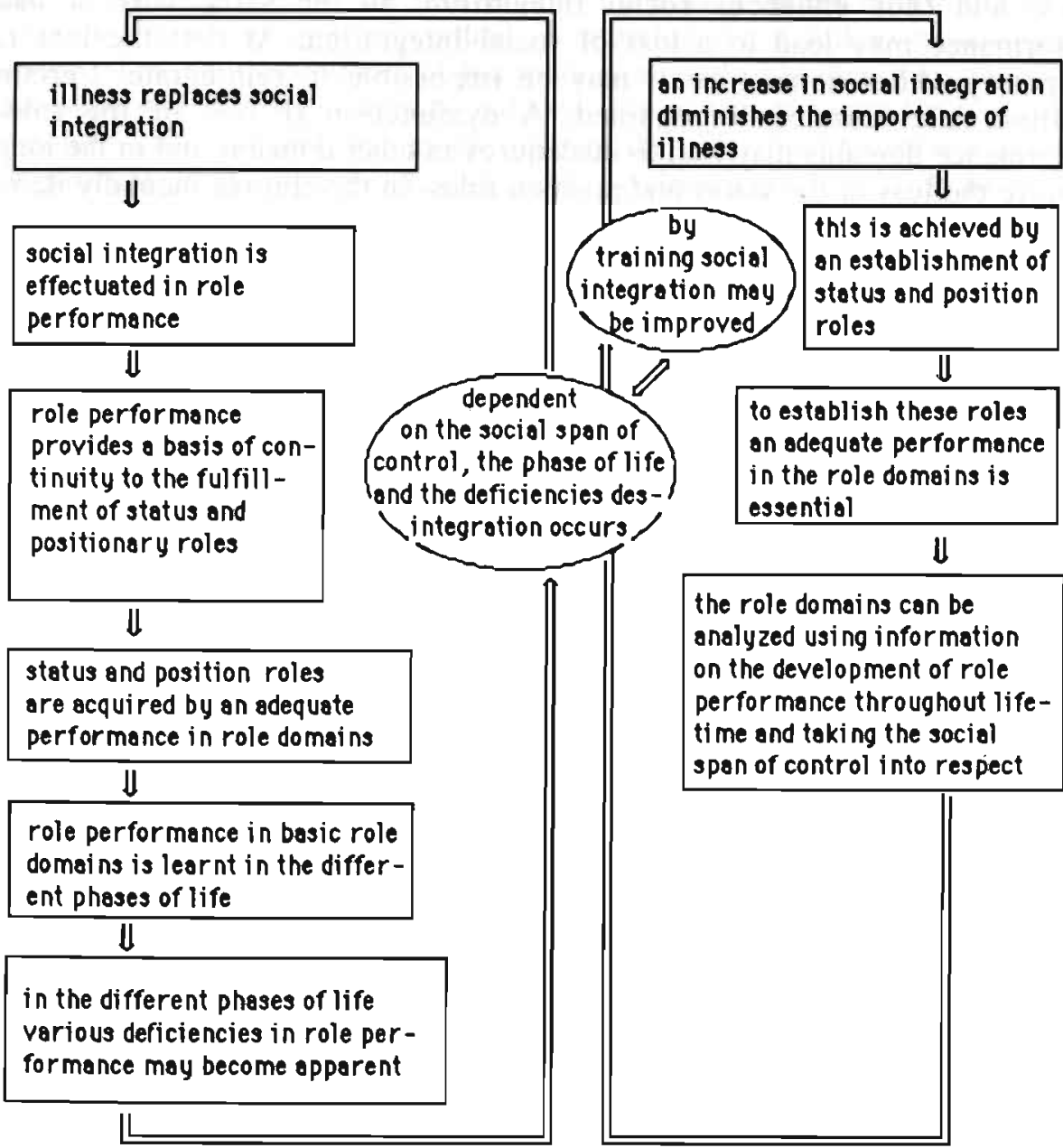


In this model, social behavior is gradually replaced by psychiatric illness. When the equilibrium is disrupted for a longer period of time, the patient loses his grip on his environment, and the illness replaces social integration. The patient has no opportunity to fulfill the required position roles. Following the theoretical framwork presented in this chapter, social integration is operationalized in role performance and the achievement of a social position through the fulfillment of status roles and position roles. Role performance concerns to what extent the individual lives up to the demands he meets. A good performance indicates that the individual meets demands in a number of domains in daily life, concerning his personal hygiene (in taking care), concerning important relationships (in support), concerning the intimate relationship with a partner (in sexuality) concerning his job (in daily activities), and concerning his social context (in social activities).

A good performance also determines the fulfillment of status and position roles, and thus enhances social integration. In the same way, a bad performance may lead to a loss of social integration. At first the loss is temporary. After some time it may be impossible to reintegrate. Certain position roles cannot be regained. A dysfunction in one of the roleperformance domains may lead to inadequacy in other domains and in the long term, to the loss of the status and position roles. In the chronic mentally il, an important feature is the failure to maintain even the simplest of the daily life roles. By being a father, a mother, having a job, being a partner, taking care of others and giving support, one belongs to others. To belong within a social context an individual has to actively perform social roles and take some initiative. If an individual stays a child, is taken care of, is supported without giving any support, doesn't solve problems or conflicts or have any contacts outside the family, the individual hardly belongs anywhere and becomes socially disintegrated.

Roles give stability in daily life. By occupying a number of roles you have something to do and you know what to do. You have your goals and expectations to meet. Looking at the biographies of chronic mentally ill patients (Romme, 1987), it is important to notice that especially transition to more complex roles is accompanied by relapse, either in early adulthood or at moments when responsibilities in family life or job change. The desintegration process can be described by following the development in the five domains of role performance. The performance in these five domains is learned during different phases of life. Though deficiencies may be apparent in earlier phases of life, they may not necessarily lead immediately to disintegration. Only when major discrepancies between performance and expectations occur in a way which is not acceptable to by the direct environment do they lead to social rejection and disintegration. The inability to fulfill a certain position role or to live up to the expectations attached to a status role can always lead to a dysfunction in one of the role domains. By comparing role performance with the expectations the individual has to meet and relating this to the span of control, i.e. the degrees of freedom, set by the direct environment, it is 
possible to analyze which aspects of role performance can be trained with a certain chance of success.

The instrument whose theoretical background has been described in this chapter is applied as follows ${ }^{10}$. First, a short description of the biography of the patient is made. Then the current status and position roles are assessed. These are compared with an estimation of the status and position roles at onset of mental illness. Subsequently, role performance and development in the five main domains is assessed. The main objective is to understand why the individual does not succeed in maintaining the position roles required in the social position achieved. For example why does an individual not succeed in maintaining a position as an adult or a parent? Or why does an individual not succeed in keeping various position roles in work or social relationships?

Through analysis of role performance, it is possible to ascertain what impairs the social integration of the individual. Information on the development, and also on the social span of control, is essential for a full examination and appraisal of the possibilities of the individual, and only then it is possible to ascertain which changes may be induced. The psychiatric care for the chronic mentally ill is focused too much only on the individual's performance and adjustment. In the daily practice of social psychiatry and especially in the care of the chronic mentally ill, the main objective is not to cure the illness but to optimize the conditions. This is more important than a transient change of behavior or an improvement of psychopathology. More essential is the removal of factors impairing the social integration or the personal development of the patient (Romme, 1991). Role theory provides an insight in the factors limiting the social context in which the individual has to live. The value of role theory in the care of the chronic mentally ill lies in the assessment of what may be achieved, given the impairment relative to the social span of control and the social position of the patient. A framework is provided to assess the adaptation of the individual to his social context.

In Chapter 5, we describe the operationalization of the instrument in detail. In the appendix no IV as well as in chapter 13 some case reports are presented to illustrate the practical application. 


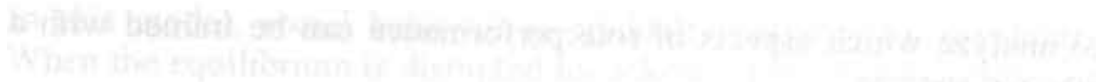

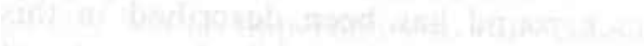

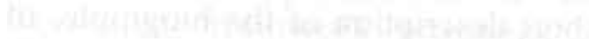




\section{A comparative review of current instruments}

The previous chapter highlighted some theoretical concepts concerning the choice of the domains of interest within the Social Role Performance and Development Inventory (SRDPI). This chapter presents an overview of the most important instruments used in the assessment of social behavior in psychiatric rehabilitation practice. The main question of this chapter is: to what extent do current instruments meet the theoretical and practical conditions of the instrument we want to develop? In Chapter 4 we presented an outline of the main theoretical concepts of our instrument. We introduced two main concepts of role: status roles and position roles. We used these concepts to describe social integration. Secondly, we identified five domains of social role performance. Our choice concerning the domains of role performance was based on socialisation theory, contrary to the predominately empirical construction of most current instruments. In this chapter we compare our ideas with the charcteristics of current instruments. In $\S 2.3$ a very brief critique on current instruments was presented. Here, we present a more comprehensive overview.

\subsection{A review of the state of the art}

\subsubsection{A focus on functional assessment}

In this chapter, the content, format and psychometric charcteristics of the most important instruments in the domain of functional assessment in psychiatry are compared with the choices we have made in creating our own instrument. The purpose of this review is to summarize the advantages and disadvantages of current instruments and relate these to our ideas on assessment of the ambulatory chronic mentally ill. Table 5.1 summarizes the major characteristics of the instruments to be reviewed (Gathered by means of a medline \& psychlit. search on the key words psychiatry, rehabilitation and social over 1980 up to 1993 , together with a snowball search through their references and updated to January 1993). We exclude from this review instruments primarily developed to assess psychopathology, such as the 'Inpatient Multidimensional Psychiatric Scale' (IMPS, Lorr \& Klett, 1967), the 'Mental Status Examination record' (MSE, Endicott et al., 1975), the 'Schedule for Affective Disorders and Schizophrenia', (SADS, Endicott \& Spitzer, 1978), the 'Past and Present State Examination' (PPSE, McGuffin et al., 1986), the 'Composit International Diagnostic Interview', (CIDI, Wittchen et al., 1991) and the Brief Psychiatric Rating Scale (BPRS, Overall \& Gorham, 1962; 
Dingemans, 1986). We also exclude instruments, constructed for use in a particular treatment setting such as the Behavior on Ward Scale (BWS, Rostow \& Smith, 1975).

\subsubsection{Judgement criteria}

We formulated two theoretical criteria and three practical criteria for the instrument we need (see also Table 5.1):

\section{Theoretically, the instruments}

1. have to relate current social position to a theory on the development of social role performance; i.e. the instruments have to provide a comprehensive description of (a) achieved social position, (b) social role performance and (c) social role development;

2. have to clarify the equilibrium between the individual and his environment; i.e. the items have to be formulated in such a way that they assess the manner in which the patient interacts with his social context;

\section{Practically, the instruments}

3. have to provide an interview schedule containing open-ended questions to be used by professionals to obtain idiographic information from the patient;

4. have to be concise and understandable enough to suit the daily practice of mental health care;

5. have to provide a practical framework for professional's assessment of social role performance by professionals not only based on their evaluation of the patients, but also focused on the rehabilitation efforts.

The first two criteria involve a comparison with our own theoretical framework. For this comparison, we evaluated the instruments on their contents. We evaluated their operationalization of the concept of role with respect to the choice of domains as well as in respect of their coding instruction. The last three criteria concern the demands set by the daily practice of mental health care. Of these, the most important criterion concerns the format: it had to be a semi-structured interview containing open-ended questions, making it possible to tailor the assessment to the specific history of the patient. The choice for this format is deliberate, as other methods of assessment can be ruled out because of a limited validity in the chronic mentally ill. Self report questionaires are known to have a very limited validity, especially in the severely mentally ill (John \& Weissmann, 1987). However, using the patient as the only source of information is also tricky (Weissmann \& Bothwell, 1976), while the use of informants either may be influenced by too much emotional involvement (e.g. family members), or too little (other than family members) (Katschnig, 1983). Secondly, many patients have no relatives or others who may serve as informants. To remain practical, the assessment has to focus on a limited number of items. Reliability and 
validity of the information has to be established by means of probing, focusing, feedback and other interview techniques (Liberman, 1988). Only semistructured interview methods leave room for such open communication with the patient. With respect to practicability, our second concern was that the instrument had to be concise and understandable. The concepts underlying the instrument may be complex and intricate, but the operationalization has to be clear and understandable. In this overview we present instruments developed before we started our own research (the state of the art) and after (an update).

In the comparison, we have to keep in mind the purpose for which the various instruments were designed. Some instruments were developed to evaluate psychiatric disorders (such as the Psychiatric Status Schedule (PSS) or the Katz Adjustment Schedule (KAS)). Items are selected to evaluate behavior in terms of symptomatology. Scoring criteria follow the DSM-III criteria. Designed to monitor change in symptomatology, these instruments provide only a global insight on the level of social functioning. Other instruments were developed to evaluate behavior related to success of treatment within a hospital setting (such as the Independent living Skills Interview (ISI) and the Rehabilitation Evaluation (REHAB)). The items in these instruments were selected in relation to the daily activities in a psychiatric ward and have only a limited value for the ambulatory setting.

\subsection{Evaluation}

\subsubsection{The state of the art}

When we look at Table 5.1, we find only a few instruments which meet our practical criteria. We also find only a few instruments which incorporate all our theoretical propositions. The Social Behavior \& Adjustment Schedule (SBAS), the Current and Past Psychopathology Scale (CAPPS), the Past History and Socio-Demographic Schedule (PHSD), the Social Stress and Functioning Inventory (SSFI) and the Community Adapation Scedule (CAS) are simply too long and require too much expertise to be practical for mental health professionals. These instruments are highly prestructured rating scales developed to measure change within specified research goals, rather than providing a judgement framework for professionals. Other instruments are far too global to provide a measurement of social behavior sensitive enough to reflect the subtle inadequacies in the performance of the chronic mentally ill (the Global Assessment Scale (GAS) and the Social Functioning Schedule (SFS)). The GAS is a very short and very global inventory of social functioning, combining many domains of daily life. The SFS is a less global inventory covering interpersonal performance.It reflects a number of problems in social interaction but it does not relate this to a level of performance nor does it relate performance to the demands set by the environment or to a concept of social development. 
Table 5.1 Major characteristics of current instruments

\begin{tabular}{|c|c|c|c|c|}
\hline Instrument & $\begin{array}{l}\text { Aroas } \\
\text { assessed }\end{array}$ & $\begin{array}{l}\text { Time frame } \\
\text { of assessment }\end{array}$ & $\begin{array}{l}\text { Data collectlon } \\
\text { method }\end{array}$ & $\begin{array}{l}\text { Criterla } \\
\text { mot }\end{array}$ \\
\hline $\begin{array}{l}\text { Katz Adjust- } \\
\text { ment Scale } \\
\text { (KAS) } \\
\text { Katz \& Lyerty. } 1963\end{array}$ & $\begin{array}{l}\text { symploms } \\
\text { expected } \\
\text { activity recreation } \\
\text { leisure activity }\end{array}$ & Past few weeks & $\begin{array}{l}\text { Form } \mathrm{R} 205 \text { iterns } \\
\text { completed by intormant } \\
\text { Form } \$ 138 \text { items } \\
\text { completed by patient } \\
\text { (self report rating scales) }\end{array}$ & none \\
\hline $\begin{array}{l}\text { Social } \\
\text { Behavior } \\
\text { \& Adjustment } \\
\text { Schedule (SBAS), } \\
\text { Platt et al., 1980 }\end{array}$ & $\begin{array}{l}\text { Symptoms } \\
\text { Role perfor- } \\
\text { mance, objective } \\
\text { burden household } \\
\text { distress }\end{array}$ & Past month & $\begin{array}{l}79 \text { items } \\
\text { by staff } \\
\text { (judgement rating scale) }\end{array}$ & none \\
\hline $\begin{array}{l}\text { Psychiatric } \\
\text { Status Schedule, } \\
\text { (PSS), } \\
\text { Spitzer et al, } 1970\end{array}$ & $\begin{array}{l}\text { Symptorns } \\
\text { instrumental } \\
\text { role performance }\end{array}$ & $\begin{array}{l}\text { Past week } \\
\text { (symptoms) } \\
\text { Past month } \\
\text { (role performance) }\end{array}$ & $\begin{array}{l}321 \text { items } \\
\text { by interviewer/ professional } \\
\text { (researcher rating scale) }\end{array}$ & none \\
\hline $\begin{array}{l}\text { Cument and Past Psy- } \\
\text { chopathology Scale } \\
\text { (CAPPS) } \\
\text { Endicott \& Spitzer, } \\
1972\end{array}$ & $\begin{array}{l}\text { Symptoms } \\
\text { instrumental } \\
\text { role performance } \\
\text { past adjustment } \\
\& \text { personality }\end{array}$ & $\begin{array}{l}\text { Past week } \\
\text { (symptoms) } \\
\text { Past month } \\
\text { (role performance) }\end{array}$ & $\begin{array}{l}173 \text { items } \\
\text { by interviewer/ professional } \\
\text { (researcher rating scale) }\end{array}$ & $1 b, 2$ \\
\hline $\begin{array}{l}\text { Past History and } \\
\text { Sociodemographic } \\
\text { Schedule (PHSD) } \\
\text { WHO, } 1973\end{array}$ & $\begin{array}{l}\text { instrumental } \\
\text { role performance } \\
\text { past adjustment } \\
\text { subjective burden }\end{array}$ & $\begin{array}{l}\text { Past week } \\
\text { (symptoms) } \\
\text { Past month } \\
\text { (role performance) }\end{array}$ & $\begin{array}{l}120 \text { items } \\
\text { by interviewer/ professional } \\
\text { (researcher rating scale) }\end{array}$ & $1 b, 2$ \\
\hline $\begin{array}{l}\text { Psychiatric and } \\
\text { Personal } \\
\text { History } \\
\text { Schedule (PPHS) } \\
\text { WHO, } 1978\end{array}$ & $\begin{array}{l}\text { Symptoms } \\
\text { instrumental } \\
\text { role performance } \\
\text { past adjustment } \\
\text { subjective burden }\end{array}$ & $\begin{array}{l}\text { Past week } \\
\text { (symptoms) } \\
\text { Past month } \\
\text { (role pertormance) }\end{array}$ & $\begin{array}{l}248 \text { items } \\
\text { by interviewer/ protessional } \\
\text { (researcher rating scale) }\end{array}$ & $1 b, 2$ \\
\hline $\begin{array}{l}\text { Social Stress and } \\
\text { Functioning Inventory } \\
\text { (SSFI) } \\
\text { Seran, } 1978\end{array}$ & $\begin{array}{l}\text { Perlormance \& } \\
\text { Stress in } 21 \\
\text { areas of } \\
\text { community living }\end{array}$ & Not reported & $\begin{array}{l}174 \text { performance } \\
\text { and } 130 \text { stress items } \\
\text { by interviewer/ professional } \\
\text { (researcher rating scale) }\end{array}$ & none \\
\hline $\begin{array}{l}\text { Community Adaptation } \\
\text { Schedule } \\
\text { (CAS) } \\
\text { Bumes \& Roen, } 1967\end{array}$ & $\begin{array}{l}\text { Behavior, affect } \\
\text { and desire for } \\
\text { change in } 34 \\
\text { areas of } \\
\text { functioning }\end{array}$ & current & $\begin{array}{l}212 \text { iterns } \\
\text { completed by the patient } \\
\text { (self report rating scale) }\end{array}$ & none \\
\hline $\begin{array}{l}\text { Rehabilitation } \\
\text { Evaluation } \\
\text { (REHAB) } \\
\text { Baker \& Hall, } 1983\end{array}$ & $\begin{array}{l}\text { Deviant be- } \\
\text { havior } \& \\
\text { general } \\
\text { behavior }\end{array}$ & past week & $\begin{array}{l}22 \text { items } \\
\text { completed by staff } \\
\text { judgement rating scale) }\end{array}$ & $1 b, 5$ \\
\hline $\begin{array}{l}\text { Independent Living } \\
\text { Skills Interview } \\
\text { (ISI). } \\
\text { Libermann et al., } 1986\end{array}$ & $\begin{array}{l}\text { Ward skills, } \\
\text { job skills } \\
\text { role pertormance } \\
\text { coping strategies }\end{array}$ & past month & $\begin{array}{l}121 \text { items } \\
\text { completed by staff } \\
\text { (judgement rating scale) }\end{array}$ & $1 b, 5$ \\
\hline $\begin{array}{l}\text { Social Interview } \\
\text { Schedule (SIS) } \\
\text { Faltermaier et al., } 1985\end{array}$ & $\begin{array}{l}\text { maladjustment } \\
\text { role performance } \\
\text { and satisfaction }\end{array}$ & past month & $\begin{array}{l}39 \text { items, } \\
\text { by the patient } \\
\text { as well as by stafi } \\
\text { (self report \& } \\
\text { judgement rating scales) }\end{array}$ & $1 b, 2,4$ \\
\hline $\begin{array}{l}\text { Social Adjustment } \\
\text { Schedule } \\
\text { (SAS) } \\
\text { Weissman et al., } 1981\end{array}$ & $\begin{array}{l}\text { General \& } \\
\text { interpersonal } \\
\text { performance } \\
\text { and satisfaction } \\
\text { in } 6 \text { roles }\end{array}$ & Past month & $\begin{array}{l}42 \text { items, } 3 \text { versions } \\
\text { informant, } \\
\text { acute patients } \\
\text { chronic patients } \\
\text { (judgement rating scale) }\end{array}$ & $1 b, 2,4,5$ \\
\hline
\end{tabular}


Table 5.1 Major characteristics of current instruments

\begin{tabular}{|c|c|c|c|c|}
\hline Instrument & $\begin{array}{l}\text { Areas } \\
\text { assessed }\end{array}$ & $\begin{array}{l}\text { Time frame } \\
\text { of assessment }\end{array}$ & $\begin{array}{l}\text { Data collection } \\
\text { method }\end{array}$ & $\begin{array}{l}\text { Criterla } \\
\text { met }\end{array}$ \\
\hline $\begin{array}{l}\text { Global Assessment } \\
\text { Scale (GAS) } \\
\text { APA, } 1976\end{array}$ & $\begin{array}{l}\text { General } \\
\text { pertormance }\end{array}$ & Last week & $\begin{array}{l}10 \text { rating points } \\
\text { (judgement rating scale) }\end{array}$ & none \\
\hline $\begin{array}{l}\text { Disability Assessment } \\
\text { Schedule } \\
\text { (DAS) } \\
\text { WHO, } 1988\end{array}$ & $\begin{array}{l}\text { role perfor- } \\
\text { mance } \\
\text { in } 7 \text { roles }\end{array}$ & Past month & $\begin{array}{l}21 \text { items } \\
\text { (researcher rating scale) }\end{array}$ & $1 b, 3,5$ \\
\hline $\begin{array}{l}\text { Social Functioning } \\
\text { Schedule } \\
\text { (SFS) } \\
\text { Remmington \& Tryer, } \\
1979\end{array}$ & $\begin{array}{l}\text { social mal- } \\
\text { adjustment } \\
\text { behavioral } \\
\text { items } \\
\text { no roles }\end{array}$ & Past month & $\begin{array}{l}41 \text { items } \\
\text { (researcher rating scale) }\end{array}$ & $1 b, 3,5$ \\
\hline $\begin{array}{l}\text { Groningen Disability } \\
\text { Schedule (GSB) } \\
\text { Wiersma et al., 1984, } \\
1990\end{array}$ & $\begin{array}{l}\text { role pertor- } \\
\text { mance } \\
\text { in } 8 \text { roles }\end{array}$ & Past month & $\begin{array}{l}24 \text { items } \\
\text { (semistructured interview, } \\
\text { researcher rating scale) }\end{array}$ & $1 b, 3,4,5$ \\
\hline $\begin{array}{l}\text { Social Role } \\
\text { Performance } \\
\text { Schedule } \\
\text { (SRP) } \\
\text { Hurry \& Stur, } 1981\end{array}$ & $\begin{array}{l}\text { role perfor- } \\
\text { mance } \\
5 \text { roles }\end{array}$ & Past month & $\begin{array}{l}20 \text { items } \\
\text { (semistructured interview, } \\
\text { researcher rating scale) }\end{array}$ & $1 b, 3,4,5$ \\
\hline $\begin{array}{l}\text { The Morningside } \\
\text { Rehabilitation } \\
\text { Status scale } \\
\text { Affleck \& Mcguire, } \\
1984\end{array}$ & $\begin{array}{l}\text { performance in } \\
4 \text { relevant } \\
\text { domains of } \\
\text { functioning }\end{array}$ & Past month & $\begin{array}{l}4 \text { rating scales, } \\
\text { Likert-type, global measure } \\
\text { of participation completed } \\
\text { by staff } \\
\text { (judgement rating scale) }\end{array}$ & $1 b, 3$ \\
\hline \multicolumn{5}{|l|}{ (recent developments) } \\
\hline $\begin{array}{l}\text { Adult Personality } \\
\text { Functioning } \\
\text { Assessment } \\
\text { (APFA) Hill, } 1991\end{array}$ & $\begin{array}{l}\text { Symptoms } \\
\text { Personality disorder } \\
\text { role performance } \\
7 \text { roles }\end{array}$ & Past month & $\begin{array}{l}168 \text { items, } 84 \text { current } \\
\text { B4 retrospective } \\
\text { (prestructured interview, } \\
\text { researcher rating scale) }\end{array}$ & $1 b, 2,4,5$ \\
\hline $\begin{array}{l}\text { Instrument for Retro- } \\
\text { spective Assessment } \\
\text { of the Onset of } \\
\text { Schizophrenia } \\
\text { (IRAOS), } \\
\text { Häfner et al., } 1992\end{array}$ & $\begin{array}{l}\text { Symptoms } \\
\text { Social } \\
\text { Impairments } \\
\text { related to } \\
\text { Schizophrenia } \\
\text { (retrospective) }\end{array}$ & $\begin{array}{l}\text { Past month } \\
\text { related to onset }\end{array}$ & $\begin{array}{l}240 \text { items } \\
\text { (prestructured interview, } \\
\text { researcher rating scale) }\end{array}$ & $1 b, 1 c, 2$ \\
\hline
\end{tabular}

The most important and widespread intstruments dealing with the assessment of social behavior are the Disability Assessment Scedule (DAS), the Groningen Disability Schedule (GDS, or GSB -in Dutch), the Social Interview Scedule (SIS) and the Social Role Performance schedule (SRP). These instruments indeed relate the performance of the individual to the demands set by the environment. They also combine an open idiographic interview format with global scoring instructions, but they leave out an essential feature for the chronic mentally ill: an assessment of the patients' possibilities. They focus on shortcomings rather than on abilities. As we want to formulate rehabilitation aims with the information gathered in the assessment, we shall have to cover the 'abilities' as well as the 'disabilities'. 


\subsubsection{The update}

In recent years, two instruments were developed which relate actual role performance to development: the Adult Personality Functioning Assessment (APFA) and the Instrument for Retrospective Assessment of Onset of Schizofrenia (IRAOS). Both instruments are long, complex interview schedules. The APFA does not relate role performance to demands, nor was it developed for an assessment by means of patient interviews. It provides a rating scale based on the global judgement of current and past role performance by the professional. The IRAOS incorporates features of the DAS and indeed meets most of our requirements. However, this instrument is extremely complex and needs extensive expertise. It is by no means simple and practical nor does it provide a framework for rehabilitation.

\subsection{Conclusion}

Although we encountered a vast body of literature on the characteristics of the chronic mentally ill as well as on the impact of mental disorder on social adaptation, we succeeded in identifying only a few initiatives dealing with the application of this body of knowledge in the daily practice of mental health care. Most current instruments are prestructured, nomothetic item-based rating scales. Few of them provide idiographic information. All of the above instruments either look at the effects of behavior in terms of what the patient 'does not do' or examine the hindrance the patient experiences due to the mental disorder. At the time we started the development of our own instrument, none of the instruments fully met our first criterion: the assessment of role based on a theoretical concept of social development.

In Chapter 2 we extensively discussed the neccesity of relating current functioning to past possibilities in the chronic mentally ill. Especially in these patients, the observed behavior is an end-point of (abnormal) development throughout many years. Therefore, a retrospective assessment starting from 'normality', rather than focusing on 'abnormality' expressed in the level of impairment should provide more relevant information for the professional.

So, we went back to the drawing board to construct a concise, simple, practical and reliable instrument, which to a certain extent would be valid for its purpose. In the construction of our instrument, we combined theoretical concepts on social integration, social role theory and socialization theory with the practical input of a panel of experts. In the present chapter we compared the characteristics of the most important instruments in our field with a number of criteria we set prior to the development of the SRPDI. In the next chapter, we present our item selection procedure as performed in a number of consecutive pilot studies. 


\section{Item selection and operationalization}

The previous chapter presented a review of the mainstream instruments which have been developed to assess social functioning in psychiatry. We formulated a need for an interview-based assessment instrument relating social role performance to social development. This chapter describes the operational definitions and the procedure applied in selecting the items in our instrument, the Social Role Performance and Development Inventory (S.R.P.D.I.). We wanted to develop an instrument to measure current role performance and relate this to lifetime development and the achievement of a position in society. The instrument also had to be designed in such a way that less extensively trained professionals could be interested in applying this instrument in their daily practice in the resocialization of the chronic mentally ill in ambulatory care (page 1 of this thesis). For the above reason, we constructed our instrument following a predominately qualitative procedure based on expert opinion (Gable, 1987). The procedure was carried out in two small pilot studies in collaboration with a panel of experts. These pilot studies are the focus of the current chapter.

\subsection{Selection procedures}

\subsubsection{A brief recapitulation of the most important aims}

The instrument we have developed in the course of this study aims at the judgement of social role performance in a developmental perspective. The background hypothesis of the study is that different groups of patients can be distinguished according to typical patterns of development of social role performance. The instrument has been designed to distinguish these groups. The long-term objective of the study is a classification of groups requiring a specific treatment plan with regard to their achieved social position and history of social role performance. The achieved social position was operationalized in the first part of the instrument, which consists of a description of the status and position roles. The history of role performance was operationalized in the second part of the instrument, which covers the development of lifetime role performance. To meet this objective, an instrument had to be developed which can measure and distinguish different patterns of social role performance and development in a reliable and valid way. The instrument had to have practical and clinical utility for the daily practice of mental health care. We will first present an overview of the selection procedure before presenting the final draft of the instrument. 


\subsubsection{Gable}

We chose an item selection procedure which stresses practical utility and relies predominately on the judgment of a panel of experts. In developing our instrument we followed the steps Gable (1987) proposes for the development of psychometric instruments:

1. The development of conceptual definitions

2. The development of operational definitions

3. The selection of a scaling technique within a specific domain

4. The selection of a response format per item

5 . The development of a response instruction

6. Judgment of the items by a panel of experts

7. Testing the instrument in a small pilot

8. Composition of the final draft of the instrument

9. Testing the instrument in a larger pilot

10. Applying the instrument in the target population.

The instrument was developed in two subsequent pilots covering a number of these steps at a time. Then the instrument was tested in the main study. The theoretical preparations together with the first pilot covered the first five steps. The second pilot covered the next four steps. The main study covers, of course, the last step. Not all steps were followed rigorously. We tried to apply the most important aspects of the procedure proposed by Gable. After the development of the conceptual definitions, the first drafts of the instrument were tested and adjusted in continuous collaboration with four senior researchers and four experienced mental health professionals. With regard to the operational definitions, the most important choice was to focus our questions on actual performance: What does the patient really do?

In this research, the third step in Gable's procedure (the selection of a scaling technique within a specific domain) is especially important when specific questions are designed to differentiate between hypothetically distinct groups. The items were selected to distinguish performance between different groups. They were not primarily selected in order to construct perfect scales. However, if the level of functioning between groups differs, it may be reflected in a scale of some kind. It should be kept in mind, however, that it is not our objective to develop another rating scale but an instrument to be used by professionals in the daily practice of mental health care. Scaling of the items is therefore secondary. The internal consistency of the different role performance domains is more important. We have to know whether the instrument adequately distinguishes between different groups and whether the questions designed to distinguish between the groups are coherent enough. Thus, questions within a certain domain have to correlate quite well, whereas questions in different domains should not correlate too much. This will be tested with the data of the main study. 
The fourth step in Gable's procedure is concerned with the response format. We tried to fit the precoded items as far as possible into a dichotomous format. In the categorization of the open questions we also tried to dichotomize as often as possible. In our analysis we are primarily interested in the reliability of the information. For the analysis of reliability using Cohen's Kappa we shall have to rely on dichotomous codes, because we are dealing with small samples. In a too small sample size, intraclass correlation coefficients on multicategorical variables are difficult to evaluate, as we don't know what a positive or negative result indicates. Furthermore, apart from being unpractical in respect of statistical analysis, categorization into many categories is also theoretically unadvisable because it yields an irrelevant differentiation of the variables under investigation.

The fifth step, the response instruction, is extensively defined in the manual (appendix no II; in Dutch). Each item is defined in terms of its observable effect: how often is the defined behavior shown, and how do other people appraise the behavior of the patient? Is the specific behavior or action an effect of the patient's own initiative or does he need stimulation from others or support to perform the behavior? Because it is not feasible to look endlessly into the manual while conducting the interview in daily practice, the formulation of the items and the response format are designed in such a way that the same routine is always followed. To increase the reliability of the results and of the method we are developing, we used trained interviewers and independent raters. In each phase of the study, the instrument, the manual and the code book were adjusted.

\subsection{The pilots}

As we described briefly in $\$ 3.5$ and in the previous paragraph, the study was carried out in two phases. The first consisted of two pilot studies. In the first pilot the instrument was developed and screened on its utility characteristics by a panel of experts consisting of four senior researchers and four professionals. In this pilot we were primarily interested in the structure of the questionnaire and the formulation of the different questions in the five role performance domains. Were the questions clear, open to a single interpretation only, and thus unambiguous? Were the questions relevant for the specific domain? Did the questions fit into the theoretical definition of the domain? Twelve cases were subsequently discussed using different test versions of the instrument. The utility was then discussed with the senior researchers and the mental health professionals. An amended version was tested on a single patient and subsequently adjusted, re-tested and adjusted again. After repeating these steps for improvement three times, the second draft of the instrument was presented in the second pilot to ten professionals (Figure 6.1). 
Figure 6.1 The panel adjustment sequences in the two pilots

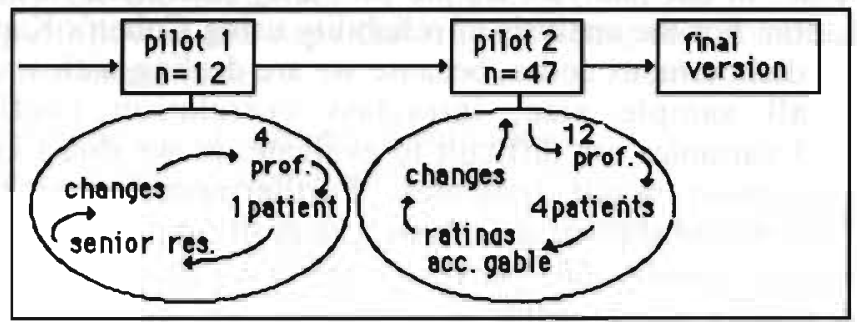

In the second pilot we were interested in the relevance of the questions in the five role performance domains with the aim of reducing the questionnaire to a practical format and improving those parts which remained unclear. In the second pilot phase the instrument was adjusted only in a single round, but following an extensive discussion with a larger forum of professionals. In this phase we followed a step-by-step procedure. With 12 mental health professionals, the different cases were discussed in three steps (the instrumental utility validation procedure according to Gable) as follows:

1. An introduction and explanation of the instrument for those professionals not yet acquainted with the S.R.P.D.I.

2. Rating of two cases by the professionals on their own, followed by an extensive discussion in which the professionals criticized and pointed out ambiguities in both instrument and manual. Different aspects of content validity were rated and categorized on the basis of taped discussions on the contents of the instrument. In the discussions on the contents, we looked at the relevance of the item with respect to the specific domain, the clarity of the item definitions, the way the questions were posed, the response format, and also the relevance of the items in respect of mental health care. Each item and role performance domain was given a rating " 3 " if no changes had to be made, a " 2 " if the item was not unequivocal, and finally a " 1 " if the item was found to be redundant or superfluous. A score of 1 meant that the item needed serious reconsideration or had to be deleted (Table 6.1, next page).

3. The two previous steps were followed by a feedback interview with each of the professionals, in which case reports compiled from the assessments were discussed and compared with the coded information gathered in the instrument. These discussions were summarized in a brief report and presented to two panels of six professionals each: 2 registered psychiatrists, a social worker, a psychiatric nurse, and 2 psychiatric interns. Along with the ratings, the remarks made in the panel discussions were used in the instrument development. 
The judgment of the panel in the first pilot focused especially on the distinction and the definition of the different domains of social role performance and the way in which we investigated the development. In collaboration with the panel of experts, the assessment criteria were formulated more specifically in respect of whether the patient performs according to a defined criterion and whether the environment has to compensate for shortcomings. In this way we tried to include the expectations of the environment in the assessment criteria.

\subsection{Findings on the basis of Gable's procedure}

The instrument was adjusted on the basis of the critical remarks and the ratings made during the procedure described above. The findings of the ratings concerning instrumental utility were compared with information gathered about the patients from open questions and in discussions of the case reports. Flaws and shortcomings could be assessed in various ways. In total we analyzed 920 different answers and 173 different comments concerning the open-ended questions. These data derived from a total of 41 patients. To give an impression, the utility ratings on the different items and domains are presented in Table 6.1. The results show marked differences in the ratings. Especially support and social activities show lower ratings.

Table 6.1 Mean ratings on item practicability of twelve professionals according to Gable's procedure*

\begin{tabular}{llccccc}
\hline ratings & $\begin{array}{l}\text { self- } \\
\text { care }\end{array}$ & $\begin{array}{l}\text { care for } \\
\text { others }\end{array}$ & support & sex & $\begin{array}{c}\text { daily } \\
\text { obligations }\end{array}$ & $\begin{array}{c}\text { social } \\
\text { activities }\end{array}$ \\
\hline open questions & 2.5 & 2.4 & 2.7 & 2.1 & 2.4 & 2.7 \\
item 1 & 2.4 & 1.4 & 1.6 & 2.3 & 2.3 & 2.2 \\
item 2 & 2.5 & 1.3 & 1.7 & 2.1 & 2.2 & 1.3 \\
item 3 & 1.4 & 1.5 & 2.4 & 1.3 & 1.4 & 1.3 \\
item 4 & 1.5 & 1.6 & 1.4 & 1.2 & 1.3 & 1.5 \\
item 5 & 2.4 & 1.4 & 2.5 & - & 2.3 & 1.3 \\
item 6 & 2.2 & 1.5 & 1.3 & - & 2.4 & 1.8 \\
item 7 & 2.1 & - & 2.6 & - & - & - \\
item 8 & 1.7 & - & 1.5 & - & - & - \\
item 9 & 2.1 & - & - & - & - & - \\
- onset of care & 2.5 & 2.2 & 1.3 & 1.3 & 2.4 & 2.2 \\
- stagnation & 2.4 & 1.4 & 1.4 & 2.0 & 2.1 & 1.6 \\
- phase of life & 2.2 & 2.2 & 2.3 & 2.2 & 2.2 & 2.3 \\
\hline
\end{tabular}

"note: 1 = must be deleted 2 = needs adjustments 3 = okay, no problems

A mean rating of less than 1.4 meant a majority of the professionals judged the item to be irrelevant or superfluous. A mean score of more than 2.4 meant that a majority of the professionals judged that no changes were necessary. The conclusion from this procedure is that especially the domains "care for others", "support", "sexuality" and "social activities" needed major changes, and that the domains "self care" and "daily obligations" needed a few changes. 
Changes were based on an index of the comments provided by the professionals. The main study was carried out with the adjusted version of the instrument. From the previous discussion, it will be clear that the method we followed is primarily qualitative and tentative. The opinions gathered in the different phases were always presented to the different panels of researchers and mental health professionals. The conclusions and the decisions made in the procedure during the pilot phase are summarized in the next paragraph. In the main study, the efficiency of the procedure was investigated by testing the internal consistency and several aspects of validity. This will be discussed in Chapter 8 and in part IV of this book.

\subsection{The most important changes}

In Table 6.2 we presented a brief overview of the selection process. In the first pilot we focused on the development of the response format. We also deleted a large number of too vague open questions in the various domains. The rigorously precoded items covering role performance were, on the other hand, reformulated in a more open way. Some items were deleted as they were felt to be redundant or covered by comparable questions. Other items were added, using information gathered in feedback discussions with the separate professionals. After the second pilot we developed the two different versions for the patient and the professionals. Now the patient's version contained only a few precoded questions. Coding and categorization was performed after the interview by means of the manual (Appendix II). In the second pilot the professionals judged that three of the nine items in the domain of self-care actually investigated almost the same behavior. These items were deleted. Four items were not changed, and two items were combined into one. Subsequently, the domain consisted of the items "washing", "clothing", "cleaning the environment", "short term planning" and "long term planning".

The two separate subdomains "self-care" and "care for others" were summarized in a single domain. The mean score on the subdomain "care for others" was 1.4, indicating that most of the professionals judged that a majority of the questions in this domain had to be deleted. The main difficulty was that the distinction between whether somebody did a specific action only for himself or whether he also did it for other members of the family was difficult to judge.

Often, the professionals were not informed, at item level, about the division of tasks in the family setting and whether this had led to conflicts between family members. The entire subdomain was, however, judged to be relevant, so we redesigned the domain in respect of household task items according to the family role in the Groningen Social Disability Schedule (Wiersma et al., 1984). In the domain of support the main problem was the choice of the response format. It also appeared impossible to judge past functioning in this domain unless the professional had been acquainted with the patient since the 
Table 6.2 Decisions on item selection in the various phases of the study

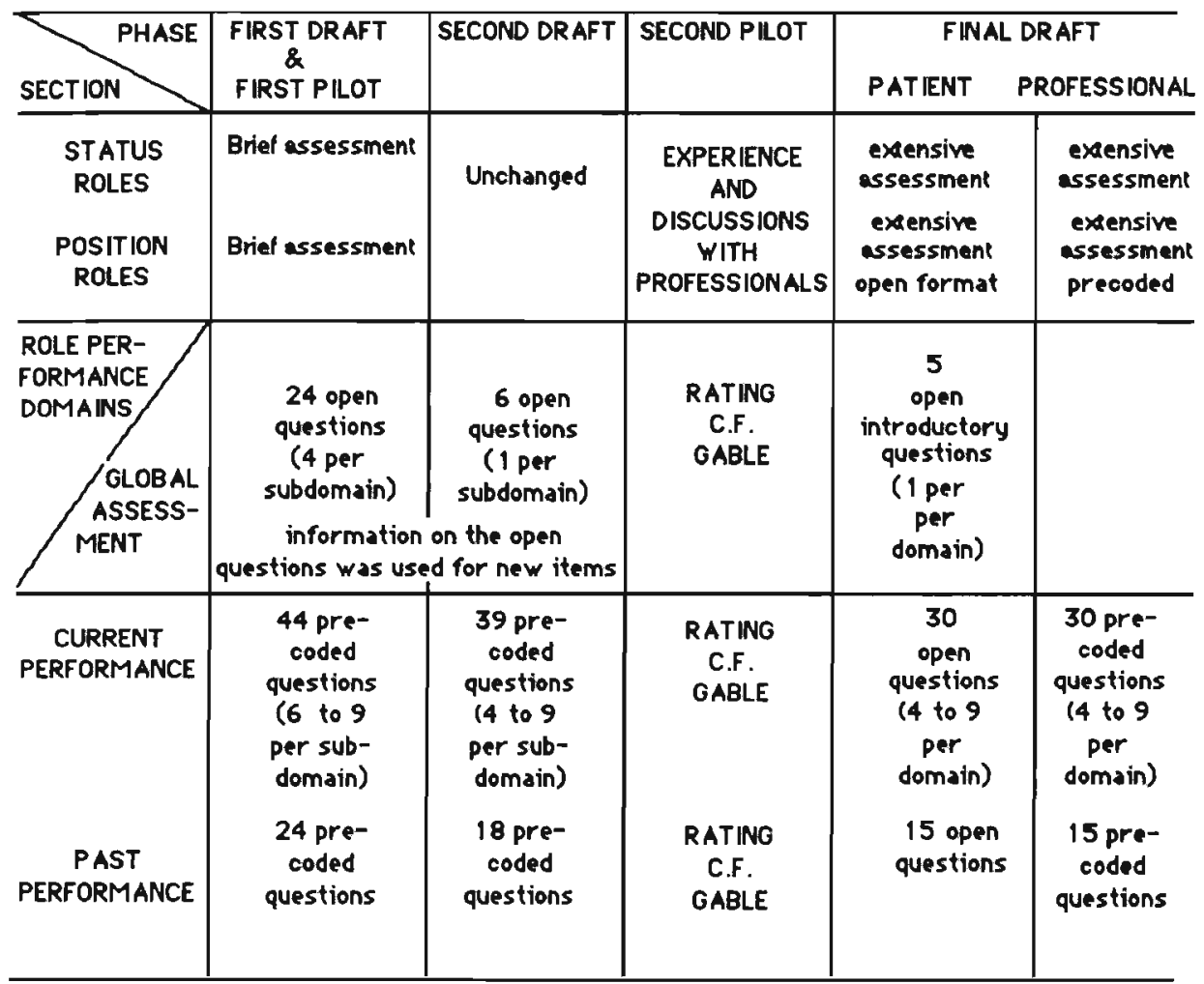

onset of care. Assessment of past role performance in this domain requires such specific knowledge of family life and personal relationships that it could only be provided adequately if the professional had known and treated the patient since the onset of care.

Regarding the response format, we chose to formulate open questions in this domain, asking for a description of the performance of the patient on the five items "practical support", "passive bonding", "active bonding", "problem solving" and "conflict solving". Using the manual, the responses are rated on a scale varying from "often shows the behavior" to "never shows the behavior". If a professional was not informed about the past, only a global impression was assessed. In the domain of sexuality, the professional knew very little in a number of cases. Despite this, the questions posed were judged to be very unclear. Using information gathered in the open questions and in the discussion of the case reports, four items were composed: the choice of interest with respect to the gender of the partner, the existence of an intimate relationship, 
the practice of sexuality and intimacy, and finally the problems experienced. The items in the domain of daily obligations were judged to be clear. They were, however, judged to be too little concerned with not having a paid job. Because a majority of the patients does not have a paid job, some open questions were added investigating both the impact of not having a job in daily life, and the manner in which and extent to which the day was planned. Finally, the items concerning the social activities were judged to be vague, not clearly formulated and insufficiently concerned with the way leisure and social contacts were maintained. This domain was also adjusted, by selecting six items: boredom, passive activities, active activities, task-oriented interaction, person-oriented interaction and mutual interaction. Apart from these items, we added the items initiative and outreach character of personal contacts. The questions investigating the development in all domains were judged to be too detailed. Only in clear-cut domains such as self-care, sexuality and daily obligations, were they judged to reflect performance rather than educated guesses. These were replaced by three open questions in the patients' version and three precoded questions in the professional's version.

\subsection{Composition of the final operational draft}

\subsubsection{Two versions containing the same items}

In the main study two versions of the instrument were developed. The first version was designed for an interview with the mental health professional. The second was designed for an interview with the patient ${ }^{11}$. We used these two versions in order to test differences and especially similarities between the professional's judgment and the patient's answers. The patient's version consists of open questions, which are coded after the interview. The professional's version consists of partly precoded and partly open questions. To a very large extent, both instruments contain the same questions. In the patient's version we are interested in factual information, while in the professional's version we are interested in a judgment. We have to keep in mind that in both versions the information is blurred by interpretation. In the patient's version this is caused by interview-related factors such as selective memory, introspection, and the clarity of the question. In the professional's version bias may be introduced from what the professional knows of the patient, or from his own degree of selfawareness, as wel as from the simple fact that the professional does not always know what we ask because he considers it to be irrelevant.

\subsubsection{The first part: what did the individual achieve}

The Social Role Performance and Development inventory consists of two parts. In both versions the assessment starts off with a short investigation of the most important personal data. Then, the first part of the instrument 
describes what the individual has achieved in terms of the status and position roles (Gerhardt, 1971; Knibbe, 1982; van Gelooven, 1990). This part of the instrument contains the assessment of factual information: which position roles does the patient fulfill in daily life, and with which people did the patient have contact in the last month? With respect to social role performance it is important to know what the patient has achieved in terms of the fulfillment of status and position roles. By means of a listed chart we first assess the potential status and position roles. For each status and position role, we assess the expectations the individual has to meet to keep his social position. A detailed description of these concepts may be found in Chapter $4, \S 4.3$. Here, we present the factual operationalization. The first variable which determines status is gender. A second variable is the patient's phase of life. Together with social class, these two variables determine the expectations society sets in terms of role fulfillment. In a semi-structured way, we investigate the extent to which the patient lives up to the expectations set by society and the direct environment. When a person has achieved a specific status role, he is expected to fulfill a certain number of position roles. In turn, these position roles require a degree of role performance. When a person cannot live up to the expectations within several roles, we identify role conflicts and discrepancies. We are interested in a description of the discrepancies between the achieved status and position roles on the one hand and role performance within the five role performance domains (Chapter $4, \S 4.8$ ) on the other hand. For example, one expects adults to maintain good personal hygiene and to be able to take care of themselves. This is not always expected of a child. Some adults, however, perform as children. The fulfillment of the status and the discrepancies between expectations and performance is judged by the professional and the interviewer respectively. In the status roles, the following distinctions may be made:

1. man - woman

2. child - adolescent - young adulthood - middle adulthood - elderly

In the main study, a homogeneous selection was made of the most important groups with respect to the above differentiation in status roles. Secondly, we made a distinction in marital status, as this is an important predictor of the achieved position roles. The position roles are assessed by presenting a chart on which the patient or the professional indicates the fulfilled roles (Figure 6.2). As stated elsewhere ( $\$ 4.3$ ), a position role is a compilation of expectations set by the direct environment regarding the position the individual has within a distinct social network, for example within the family, within a business, or within a club (Knibbe, 1982). Examples are teacher, researcher, housewife, chairman of the board, director, etc. In the evaluation of position roles it is important to ascertain the extent to which responsibilities and expectations are met. The position roles are assessed by asking what kinds of positions the patient has in the relationship with others in various social contexts:- what "is" the patient in the relationships with others? In the assessment of the position roles, we not only assess which roles are fulfilled, 
Figure 6.2 Position roles

\begin{tabular}{|l|l|l|l|}
\hline \begin{tabular}{l|l} 
FAMILY \\
ROLES
\end{tabular} & $\begin{array}{l}\text { FRIEND } \\
\text { ROLES }\end{array}$ & $\begin{array}{l}\text { WORK } \\
\text { ROLES }\end{array}$ & $\begin{array}{l}\text { LEISURE } \\
\text { ROLES }\end{array}$ \\
\hline $\begin{array}{l}\text { partner } \\
\text { parent } \\
\text { child } \\
\text { brother or } \\
\text { sister } \\
\text { brother-in-law } \\
\text { sister-in-law } \\
\text { grandfather } \\
\text { grandmother } \\
\text { niece or nephew } \\
\text { other member of } \\
\text { the family }\end{array}$ & $\begin{array}{l}\text { friend } \\
\text { acquaintance } \\
\text { neighbor } \\
\text { befriended } \\
\text { collague } \\
\text { befriended } \\
\text { (ex }- \text { patient } \\
\text { housemate }\end{array}$ & $\begin{array}{l}\text { employee } \\
\text { employer } \\
\text { colleague } \\
\text { voluntary } \\
\text { worker } \\
\text { apprentice } \\
\text { housewife }\end{array}$ & $\begin{array}{l}\text { member of a } \\
\text { club } \\
\text { member of a } \\
\text { board } \\
\text { member of a } \\
\text { political } \\
\text { organization }\end{array}$ \\
\hline
\end{tabular}

but also the extent to which the patient fails to meet expectations set for the position roles. We ascertain how much time an individual puts into a specific role, how important the role is for the individual, whether conflicts in fulfilling the role are encountered, and the extent to which the individual succeeds in meeting the expectations by himself. In this way we assess which roles are inadequately fulfilled. As stated in Chapter 4 , insufficient role development may lead to many discrepancies in the fulfillment of current position roles and in meeting status role expectations. These discrepancies are assessed in the first part of the instrument.

This assessment can be regarded as a measurement of outcome. After assessing current status and position roles, we ask when the first contact with mental health care took place. Then we assess in a global way which status and position roles were fulfilled at onset of mental illness and compare them with the current roles (flow chart, Figure 6.3, next page). In short, the first part of the instrument is concerned with a description of what the patient has achieved in terms of the structural characteristics of the social network and in terms of the status and position roles. One of the objectives of the first part is to determine the difficulties which the patient encounters in the fulfillment of his status and position roles. With this information it is possible to understand the extent to which a discrepancy exists between role performance and the expectations which any individual of the same age, sex, social class, or social position has to meet. Because no clearly defined norms exist for these expectations, we defined a discrepancy on the basis of consensus with either the therapist or the patient. In rehabilitation, the therapist will have to evaluate what the patient would have achieved if he or she had not been a patient, and the extent to which the discrepancy in role performance may be reduced by rehabilitative effort. 
Figure 6.3 Consecutive questions on the status and position roles

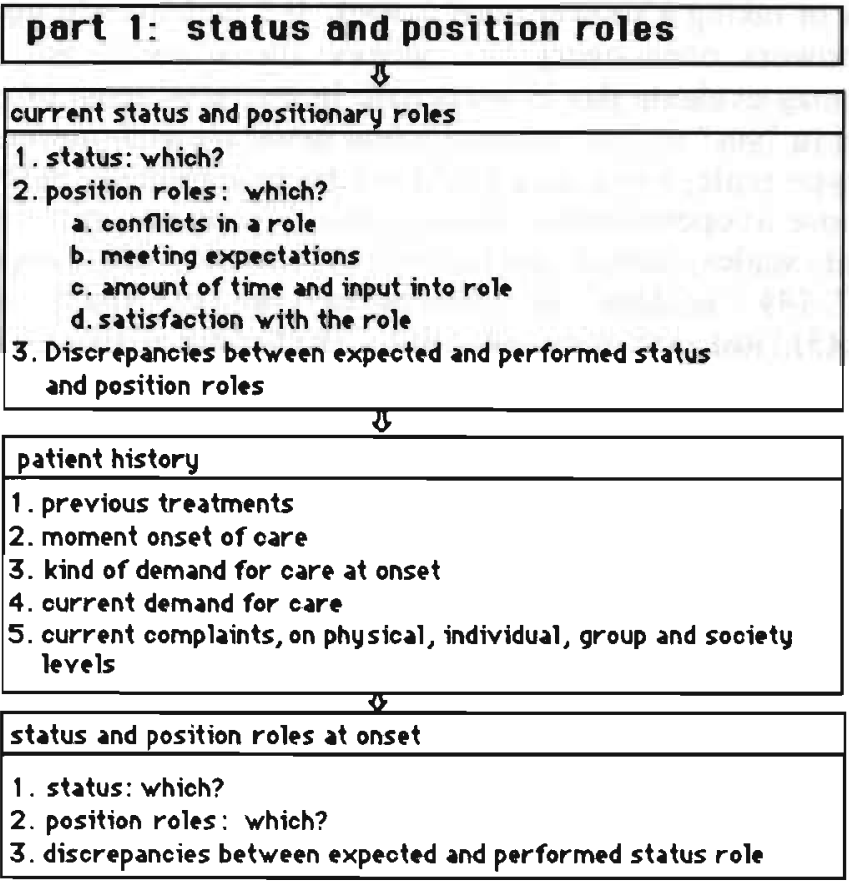

Consequently, the interviewers evaluated together with therapists or patients what the patient had achieved and assessed the extent to which this differed from what may be expected, given the status role of the patient. No substantive conclusions with respect to any hypotheses were drawn from this assessment, whose purpose was mainly to provide feedback for the professional and the patient.

\subsubsection{The second part: role performance in five domains}

In the second part of the instrument, the current and past role performance is discussed whithin five domains (also Chapter $4, \S 4.8$ and chapter $2, \S 2.7$ ). Each role domain is described using three to eight items, as indicated in Figure 6.4 (next page). Role performance then is discussed by means of five to ten open questions, which are coded afterwards by means of a coding instruction (also in the manual, appendix no. II). A score "yes" or "positive" is given when the patient performs according to a minimum criterion. A score "no" or "negative" is given when this criterion is not met. In both versions of the instrument, we try to assess actual performance. We are not interested in the patient's possible performance. We are also not really interested in the details 
of the problems the patient meets when not performing sufficiently. The only point we are interested in is the patient's actual performance on the specific item. An example is the item "washing": the minimal criterion is washing four times a week or taking a shower once a week. If a patient only washes twice a week, or showers once every two weeks, the score is no, even if the professional may evaluate this as sufficient. In this way, most of the items are dichotomized in "yes" or "no" scores. A few items are trichotomized or scored on a Likert-type scale, when they could not be so rigorously defined within a norm. We chose to operationalize these kinds of items into two different types of five-point scales, either performs (1) "often", (2) "regularly", (3) "sometimes" (4) "seldom" or (5) "never" or (1) "much", (2) "fairly adequately", (3) "just sufficient", (4) "little" or (5) "not at all".

Figure 6.4 The items in the domains of social role performance (final draft).

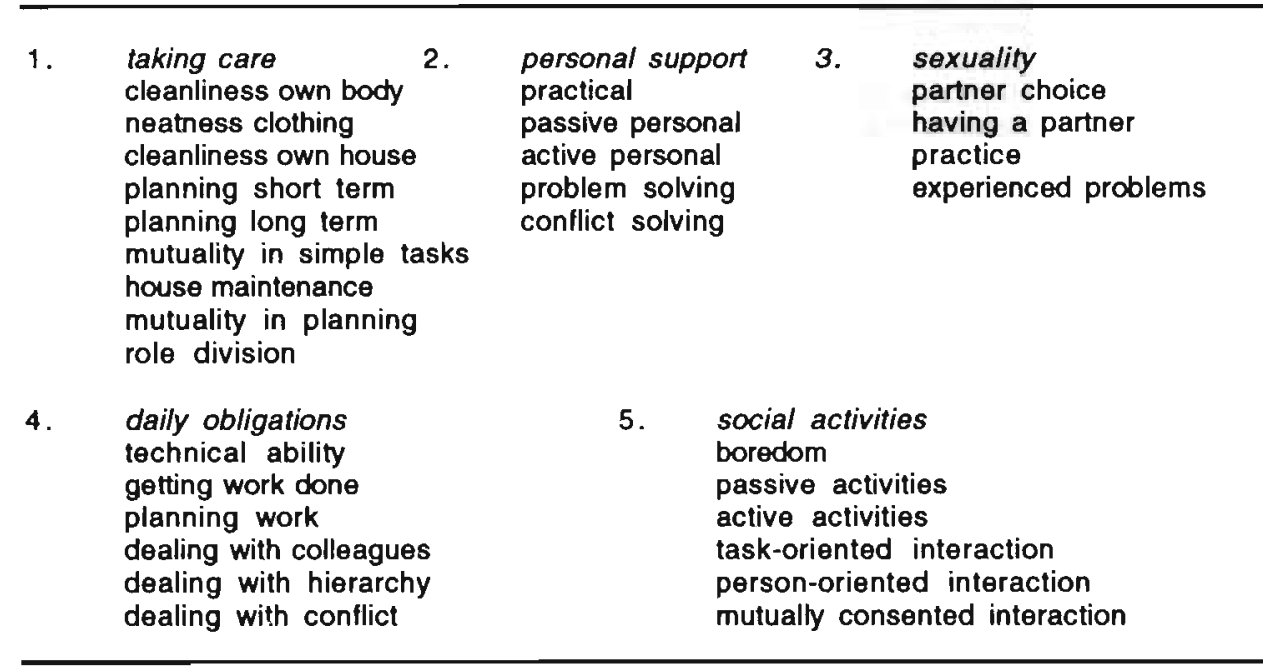

After discussing the items in each domain, the development in the domain is assessed. Current functioning is compared with functioning at onset by asking detailed questions about role performance at onset. Two to six months before the first contact with mental health care is the baseline period. In this way, the development is discussed according to a specific routine. The patient is asked to recall a moment some two to six months before the first contact with mental health care. Social functioning in this period of time is discussed. The interviewer estimates whether role performance was less than, equal to or better than current performance. Then an estimate of the pattern of relapse is established. In the development of role performance, different patterns may be assumed. First, the development may be normal. Next, there may be insufficient development, stagnation. When the development is initially normal 
but subsequently deteriorates this is defined as a relapse. Such a relapse may be short-lived, with few consequences for long-term role performance. The relapse may also be more enduring, with significant consequences for the level of performance.

Apart from the way in which deterioration occurred, we also explore when, why and how insufficient performance had perhaps not been learnt or lost. At what stage was the development when deterioration started? At what age or period of life did it start (rated c.f. Häfner, 1984)? Finally, we ask whether the relapse followed an important life event or occured at an important point in life, such as after a divorce, or when the children left home. We ask whether the relapse is related to any major event or change in the social span of control. In each role domain, we further pose a number of extra questions to understand the process of role performance development (Figure 6.5).

Figure 6.5 A pathway through the structure of the instrument

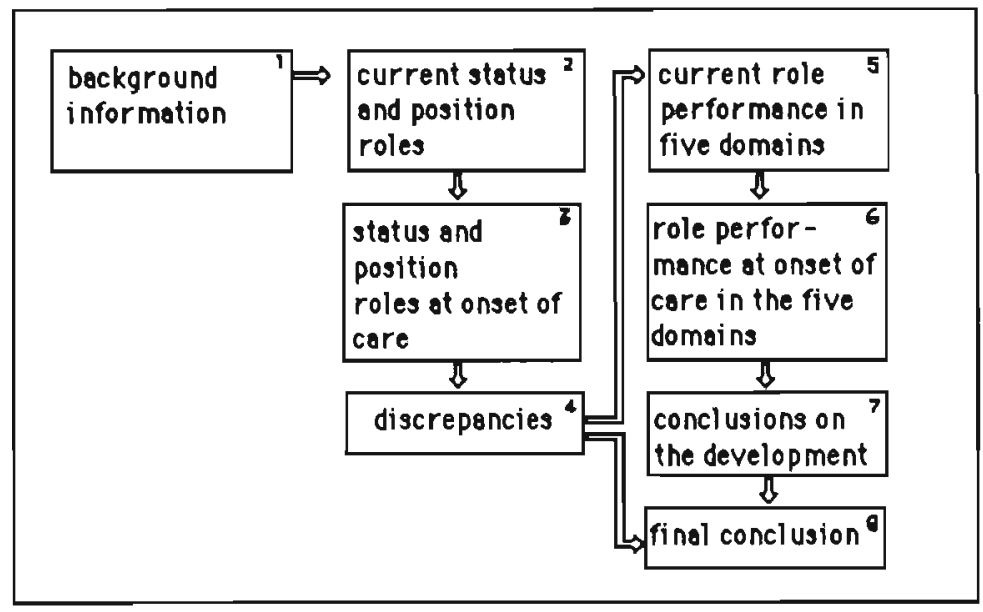

For example, conflict solving. Initially this is learnt in puberty. Did the parents give enough freedom, did the patient experience many conflicts, or are there other explanations why current performance is insufficient? In the interview with the professional, we are interested in a judgment of the role performance. Unlike the patient's version, we ask the professional what he or she thinks are the most important deficiencies in a specific domain. This question is followed by a global rating of the entire domain: is the level of functioning better or worse than may be expected? Then the various more specific items covering role performance follow. The same questions put to the patients are also judged by the professional, in exactly the same order. 
After the discussion of the relapse, for instance, the interpretation of the professional on the causes of this relapse are discussed. Each domain is concluded by a global judgment and a summary of performance and development, followed by a short indication of the specific interventions the professional may have undertaken in the specific role domain. Chapters two and thirteen show by means of case histories how this is done in daily practice.

\subsection{Conclusion}

In a number of panel judgement rounds, the instrument was reduced in three steps from 68 to 45 and then 30 items concerning current performance in the five role performance domains. In the final draft, 20 questions concerning the background information, as well as the the status and position roles were added, in order to gain more detailed information on the position roles in particular, which were the outcome variables. In the main study, the second part of the instrument was further reduced and adjusted with empirical data. In the following chapters this will be addressed in greater detail. 


\section{PART 3}

\section{Testing the instrument}

This part contains four chapters dealing with the primary concerns of instrument development, such as reliability, consistency and validity. Chapter 7 briefly recapitulates what we are interested in regarding the objectives of the instrument. An outline of what follows in the next chapters is presented. We chose to perform the various analyses in a logic step-by-step order, fitting the conclusions of each analysis into the next analysis. Chapter 8 deals with interrater agreement. Chapter 9 deals with the internal consistency of the instrument. Chapter 10, finally, presents the results on the study of the interjudgment agreement between mental health professionals and one of the two independent raters ${ }^{12}$.

Chapter 7 is essential for any reader, as it contains a summary of the research questions in the main study. Fast readers should also not miss Chapter 9, as it goes into what professionals really know of their patient's social role development. The fast readers can miss the Chapters 8 and 10: Chapter 8 contains a neccesary but dry investigation of the interrater agreement while Chapter 10 deals with the statistically tough process of understanding the internal consistency. Please note the summary in every chapter. In these summaries we clarify step-by-step the choices we made after completing each analysis and relate them to the following analysis.

The results presented in these chapters were also submitted for publication as: Noorthoorn, E.O., M.A.J. Romme, H. Philipsen, W. Krol, Reliability of social role analysis in a community sample of the chronic mentally ill. and as Noorthoorn, E.O., Romme, M.A.J., Philipsen H., Buiks, A.G.G.M.., Levensloop en sociale rolvervulling bij chronisch psychiatrische patiēnten: betrouwbaarheid, validiteit en toepasbaarheid van een interviewschema. 


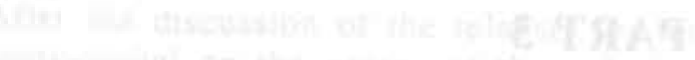

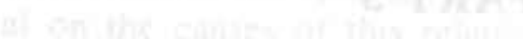




\section{Design and objectives of the main study}

In this study our main interest is to develop an instrument for the description of the development of social role performance of outpatient chronic mentally ill, the Social Role Performance and Development Inventory. The previous two chapters described the theoretical background, the construction and the operationalization of the instrument. In the present chapter we will summarize the questions we want to investigate in the main study and relate them to the research design. An overview of the analyses is presented.

\subsection{Focus of the analyses}

The main study focuses on the last step in the Gable's procedure, the application of the instrument in the sample of the main study. The first part of the instrument assesses the current status and position roles as well as the status and position roles at onset of mental health care. This part contains factual information on what the patient has achieved in daily life, at the moment of assessment as well as at onset of mental health care. This part provides a global insight into the domains of daily life in which the patient currently fulfills specific roles. The second part is concerned with an item-based judgment of the level of role performance. Concerning this part we have to know what a specific score indicates and we have to gather information on several psychometric characteristics. In the main study we investigated the reliability and validity of the measurement of role performance and as well as the retrospective assessment in the second part of the instrument.

We did not focus on the reliability and the validity of the first part of the instrument for several, mostly pragmatic, reasons. First when we started our assessment we had only a general idea as to how we could operationalize the abstract concept of fulfillment of position roles. Second, this part of the instrument could not be translated into scalable measures representing severity of social isolation or degree of social integration. Most of the gathered information was idiographic, descriptive at case level and dependent on the individual's subjective interpretations and perceptions. Throughout the main study we further developed and adjusted this assessment, using some recent developments in our field of research. In a recent follow-up study (Noorthoorn et al., 1992) we follow the operational definitions proposed by Stephens (1991), who identifies a number of steps at case description level, such as the personal appraisal of role expectations and the choice of priorities and coping strategies to deal with role strain and role conflict. In this way each of the position roles is investigated and rated. However, we had no access to 
this information at the time we started the current study. When we started the main study we did not know in what way the number, the variability or the quality of the performed roles reflected the quality of social integration. Therefore, we performed some comparative analyses with these data (Chapter 12 and 13 ).

The second part of the instrument provides an explanatory framework relating the current level of role performance to the development of role performance. Concerning the content validity of the information, we are interested in how a specific score is related to experienced impairments in social performance. Concerning the clinical validity, we have to know to what extent the information relates to the daily practice of mental health care. The research questions of the main study, therefore, concern the utility characteristics of the second part of the instrument, the assessment of current role performance and the assessment of the development of role performance. In this part of the study, further item selection is performed, now on empirical evidence rather than qualitative estimates as in the "expert-panel" procedure presented in Chapter 6. In $\S 7.4$ we will discuss these analyses in greater detail.

But first we present the design of the study. When we conducted the main study, we did not succeed in gathering sufficient patients in the various selection groups. We dealt with this practical limitation by performing a number of power analyses. Therefore, we present an overview of the mathematical procedure for obtaining a score on current role performance. With this information, we performed the power analyses, to assess the minimum number of cases necessary in the following analyses.

\subsection{Design and Methods}

\subsubsection{Four groups}

The main study focuses on the reliability and validity of the instrument. Since analyses on reliability may be influenced by a too large variance of the data, a reasonably homogeneous sample had to be selected. We needed a minimum number of patients with a comparable response within the various role domains. However, the chronic mentally ill are a highly differentiated group of patients (Henkelman, 1989). In the main study, we chose to select four groups homogenized according to age, sex and marital status at onset of the mental illness. The preliminary study we reported in Chapter 1 (Romme et al., 1987) led to the conclusion that these three data are associated with comparable difficulties in lifetime social role performance. We chose to select the four groups we identified in the preliminary studies. The qualitative information gathered in the preliminary studies gave a reasonable estimate of those patients who encountered comparable problems in role performance. To ensure the inclusion of only the chronic mentally ill, the first criterion for selection was a history of care for a period of time longer than two years (also Chapter 3). 
The following four groups were selected according to their age and marital status at onset of care:

1. unmarried men, younger than $30(n=20)$;

2. unmarried women, younger than $30(n=16)$;

3. married men, older than $40(n=9)$;

4. married women, older than $40(n=11)$.

\subsubsection{Composition of the groups}

In Table 7.1 we present a description of the four selected groups with respect to their main characteristics: patient career, diagnosis, education and vocational status. Some features warrant attention (noted with a $\Leftarrow$, the arrow points in the direction of the majority).

Table 7.1 Comparison between the sociodemographic and diagnostic characteristics of the four groups selected in the main study

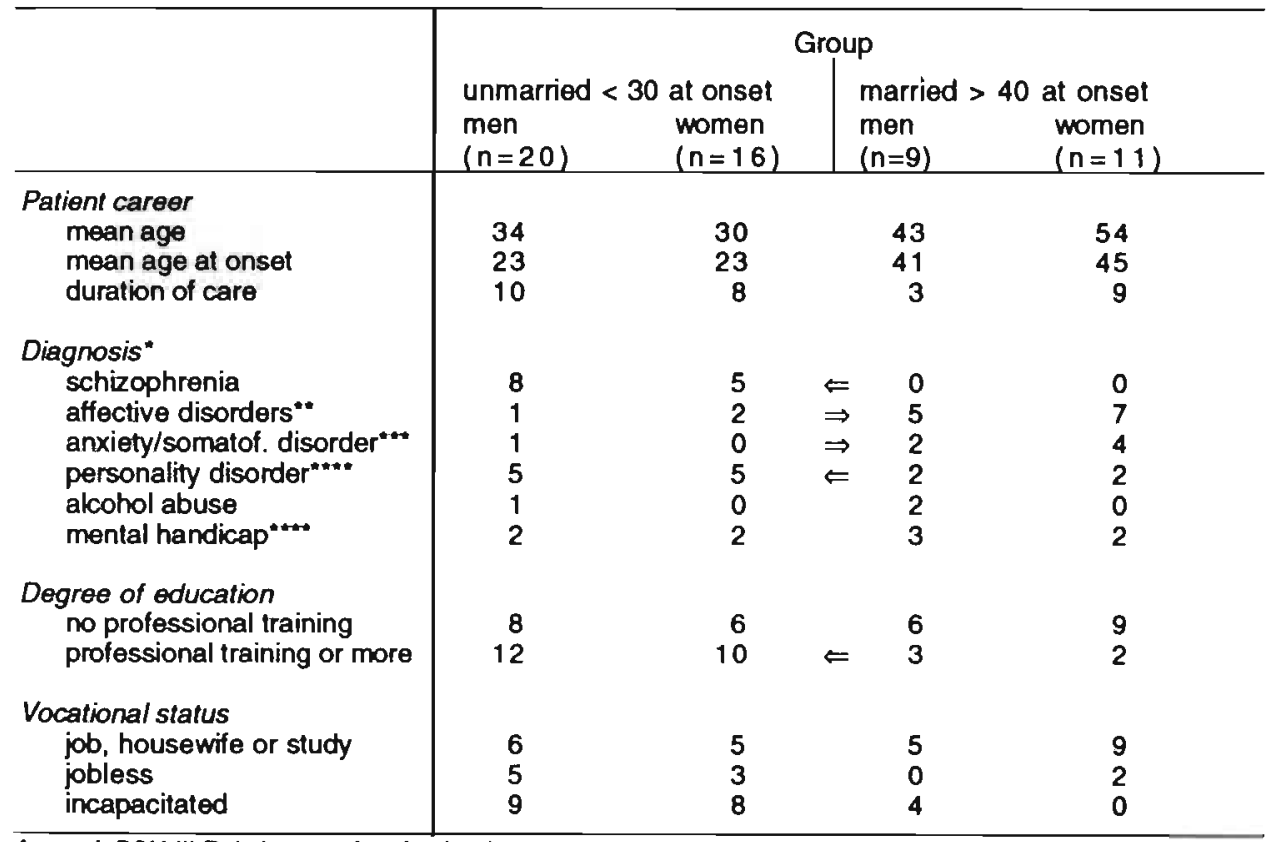

- c.f. DSM-III-R, judgment of professionals

- all being major depressions or bipolar disorders

... two panic disorders, one social phobia

*... this diagnosis always together with other diagnoses

The first difference is the diagnostic category. The groups with an early age of onset of mental health care were dominated by psychotic and personality disorders. The two groups of married and somewhat older men and women at onset, were dominated by depression, alcohol abuse or somatoform disorder. 
Another important feature is the large proportion of younger respondents who are either jobless or incapable of working despite a better education.

\subsubsection{Two versions and subsequent drafts}

As we stated in Chapter 6, two versions of the instrument were constructed. The first, used in the interviews with the patients, contained open-ended questions, categorized and rated after the interview. The second version was used in the interviews with the mental health professionals and contained mostly precoded questions, along with some open-ended questions. The information was gathered by two independent interviewers who were trained in using the manual and the instrument. The patient's data were recoded by another independent rater. A graphic representation of this design is presented in Figure 7.1.

Figure 7.1

The design of the main study: interviewers, subjects and data

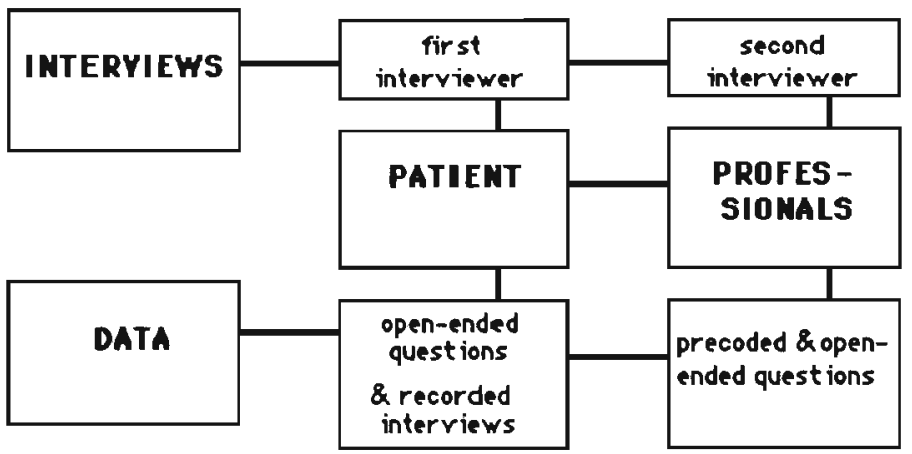

In the patient's version we tried to obtain the factual information $<$ what does the patient really do? $>$, whereas in the version for the professional's interview we tried to obtain a judgment about what the patient really does. The interviews with the patients were tape-recorded in order to register the response to the various open-ended questions in a more precise way. Directly after the interview a case report was composed for the purpose of feedback, using information obtained from both professional and patient. This information was presented to professional and patient, sometimes separately, sometimes together. Three to five months after the interviews, both the interviewer and an independent rater rated the open-ended interview questions (following the coding instruction in the manual). These ratings were used to determine interrater agreement. A third, independent rater rated the professional's interviews. 
With these data, various comparisons and analyses related to the validity of the instrument were made. Each of these analyses concerns a different aspect of the study and is related to different research questions. In each phase specific items or domains were left out of further analysis, as they were found to be either too irrelevant, unreliable or insufficiently valid.

\subsubsection{Calculation of the score}

The instrument follows the next mathematical procedure. Each item is dichotomized and obtains a score of zero or one. In the first version, 26 items in five domains are used, and more than 2 items per domain may be regarded as a deviation from normal performance. In the various consecutive analyses discussed throughout this chapter, several items were deleted. In the final version, 21 items in four domains are used to compute the overal instrumental score. Table 7.2 presents the calculation of the sum score in the first and the final version.

Table 7.2 Score calculation in the first and the final version of the Social Role Performance and Development Inventory

\begin{tabular}{|c|c|c|c|}
\hline Domalns & Items* & $\begin{array}{l}\text { liret } \\
\text { draft } \\
\text { range }\end{array}$ & $\begin{array}{l}\text { final } \\
\text { draft } \\
\text { range }\end{array}$ \\
\hline Taklng care & $\begin{array}{l}\text { cleanliness+clothing+cleanliness own house+ } \\
\text { planning short term+planning long term } \\
\text { +mutuality in tasks+mutuality in house maintenance+ } \\
\text { mutuality in planning+mutuality in management+role division }\end{array}$ & $0-5$ & - \\
\hline Support & $\begin{array}{l}\text { practical support+passive personal support } \\
\text { +octive personal support+problem solving } \\
\text { +conflict solving }\end{array}$ & $0-5$ & 0.5 \\
\hline Soxuality & $\begin{array}{l}\text { which interest+intimate relation+practice+experienced } \\
\text { problems }\end{array}$ & 0.4 & - \\
\hline Daily obl & $\begin{array}{l}\text { tochnical ability+getting work done+planning work+ } \\
\text { dealing with colleagues+dealing with hierarchy+ } \\
\text { dealing with conflict }\end{array}$ & $0-6$ & $0-5$ \\
\hline Social act & $\begin{array}{l}\text { boredom + passive activitles+active activitios+ } \\
\text { task-oriented int.act.+person-oriented int.act.+ } \\
\text { mutually consented int.act. }\end{array}$ & $0-6$ & $0-6$ \\
\hline Total & & $0-31$ & $0-21$ \\
\hline
\end{tabular}

- The remaining items which compose the final construct are indicated bold 


\subsubsection{A step-by-step analysis}

We chose to do the analyses in a specific logical order. Each step in the consecutive analyses will be dealt with in different chapters of this book. First we determined to what extent the items could be interpreted by determining the interrater agreement. After this first analysis, certain items were left out of further analysis. This is described in Chapter 8 . Then we looked at the internal consistency, to determine whether the domains are coherent and whether they represent scalable dimensions. Again, certain items were left out of analysis. The results of this analysis is described in Chapter 9. In Chapter 10, we present the interjudge agreement between the professional and the researcher, in order to determine the validity of the gathered information. After this phase, no items were left out of analysis. As a last step in the evaluation of instrumental utility, we looked at the discriminative value of the instrument by performing univariate comparisons between various contrast groups and by comparing our data with data obtained from the Sickness Impact Scale (Carter et al., 1976). We present this in the Chapters 11 and 12. Finally, in Chapter 13 we present some typical case histories. In Chapter 14 we compare the patients of two groups with matched normals.

\subsection{Limitation by the number of subjects: a power analysis}

It is obvious that the number of patients we succeeded in gathering for the main study is relatively small. Within the limits of the current study no more could be sampled. To investigate the effect of the number of patients on our analyses, we performed a hypothetical power analysis ${ }^{13}$ to obtain some basic information on what the minimum size for the most important analyses should be. In the judgement of statistical test results we are interested in the rejection or acceptance of an assumption, the null-hypothesis. The probability of a false rejection is expressed as $\beta$, while the probability of a false acceptation is expressed as $\alpha$. The power analysis showed that most of the univariate and bivariate analyses could be perfomed under the usual conditions of a $\alpha$ of 0.05 and a $\beta$ of 0.90 . Only in a few analyses, especially the multivariate analyses an $\alpha$ of 0.05 and a $\beta$ of 0.80 had to be accepted.

The values of the power vary for the various statistics we applied. In a matched sample using a correlational measure such as Cohen's Kappa, we need a sample of 106 observations for a $90 \%$ power at a significance level of 0.05 . For example, 53 patients are sufficient for an analysis of the interrater agreement. In most of the univariate comparisons we have the same power. Only in some of the multivariate analyses, we shall have to accept a $80 \%$, or even less. However, when several different kinds of analyses - approaching the same construct from changing viewpoints - are applied to investigate psychometric characteristics, as in the current study, Kreamer \& Thieman (1987) proved that the sample size may be reduced impressively. 


\subsection{Specification of methods of analysis}

In Table 7.3 we present a short overview of the various analyses applied in this study, with a short reference to the chapter in which the results are discussed.

\section{Table 7.3}

\section{A specification of the analyses on instrumental utility in this study}

\begin{tabular}{|c|c|c|c|c|}
\hline Issue & $\begin{array}{l}\text { Statistic or } \\
\text { method } \\
\text { used }\end{array}$ & $\begin{array}{l}\text { Data obtained from } \\
\text { patient (subj.) or } \\
\text { professional (prof.) }\end{array}$ & $\begin{array}{l}\text { I ntended } \\
\text { S tudied } \\
\text { A nalyzed } \\
\text { D escribed }\end{array}$ & $\begin{array}{l}\text { described in } \\
\text { chapter .. }\end{array}$ \\
\hline $\begin{array}{l}\text { Interpretation of } \\
\text { the items } \\
\text { interrater agreement }\end{array}$ & Kappa & subj. & S, A, D & Chapter 8 \\
\hline $\begin{array}{l}\text { Construction of } \\
\text { the domains } \\
\text { content validity }\end{array}$ & Description of literature & - & S, D & $\begin{array}{l}\text { Chepter } 4 \\
\text { Chapter } 5\end{array}$ \\
\hline content validity & Qualitative panel study & - & S, A, D & Chapter 6 \\
\hline reliability of scale & $\begin{array}{l}\text { Item sum total corr. } \\
\text { within scales } \\
\text { Cronbach's alpha }\end{array}$ & subj. + prof. & S, A, D & Chapter 9 \\
\hline $\begin{array}{l}\text { independence of } \\
\text { domains }\end{array}$ & $\begin{array}{l}\text { Lisrel confirmatory } \\
\text { factor analysis }\end{array}$ & subj. + prof. & S, A, D & Chapter 9 \\
\hline & $\begin{array}{l}\text { Exploratory factor } \\
\text { analysis }\end{array}$ & subj. + prof. & I, S, A & Chepter 9 \\
\hline $\begin{array}{l}\text { Value of the } \\
\text { instrument } \\
\text { intersubjectivity }\end{array}$ & $\begin{array}{l}\text { Percenlage agreement } \\
\text { Pearson corr. between } \\
\text { patients and profes- } \\
\text { sionals }\end{array}$ & $\begin{array}{l}\text { subj. + prof. } \\
\text { subj. + prof. }\end{array}$ & $\begin{array}{l}\text { S, A, D } \\
\text { S, A, D }\end{array}$ & $\begin{array}{l}\text { Chapter } 10 \\
\text { Chapter } 10\end{array}$ \\
\hline & $\begin{array}{l}\text { Kendall's rank order W } \\
\text { Qualitative description } \\
\text { of case histories }\end{array}$ & subj. + prof. & $\begin{array}{l}\text { S, A, D } \\
\text { S,D }\end{array}$ & $\begin{array}{l}\text { Chapter } 10 \\
\text { Chapter } 13\end{array}$ \\
\hline $\begin{array}{l}\text { discriminative } \\
\text { power of the } \\
\text { instrument }\end{array}$ & $\begin{array}{l}\text { Mann- Whitney U, } \\
\text { T-test comparisons } \\
\text { between groups } \\
\text { Discriminant analysis }\end{array}$ & $\begin{array}{l}\text { subj. + prof } \\
\text { subj. + prof }\end{array}$ & $\begin{array}{l}\text { S, A, D } \\
\text { I, S, A }\end{array}$ & $\begin{array}{l}\text { Chapter } 12 \\
\text { Chapter } 12\end{array}$ \\
\hline concurrent validity & $\begin{array}{l}\text { Spearman rank order } \\
\text { correlation with S.I.P. }\end{array}$ & subj & S, A, D & Chapter 11 \\
\hline $\begin{array}{l}\text { criterion-oriented } \\
\text { discriminatory validity }\end{array}$ & $\begin{array}{l}\text { Comparison with normal } \\
\text { reference group } \\
\text { (known groups tech- } \\
\text { nique) Mann- Whitney U, } \\
\text { T-test comparisons } \\
\text { between groups }\end{array}$ & prol. & S, A, D & Chapter 14 \\
\hline $\begin{array}{l}\text { Outcome } \\
\text { relationship between } \\
\text { dependent variables } \\
\text { (social role perfor- } \\
\text { mance) and indepen- } \\
\text { dent variables such as } \\
\text { diagnosis, achieved } \\
\text { roles, etc. }\end{array}$ & $\begin{array}{l}\text { Mann- Whitney U, } \\
\text { T-test comparisons } \\
\text { between groups } \\
\text { Discriminant analysis }\end{array}$ & $\begin{array}{l}\text { subj. + prof. } \\
\text { subj. + prof. }\end{array}$ & $\begin{array}{l}\text { S, A, D } \\
\text { I, S, A }\end{array}$ & $\begin{array}{l}\text { Chapter } 12 \\
\text { Chapter } 12\end{array}$ \\
\hline
\end{tabular}

- when underlined, the analyses of either professionals or subjects may be regarded as the most important 


\subsubsection{The reproducibility of the ratings}

In the process of developing the instrument we were initially interested in the extent to which interpretations of the items could be reproduced in a reliable way. The information gathered in the patient version was rated by the interviewer and by an independent rater. The agreement between these raters was determined with Cohen's Kappa (Cohen, 1968). The results were used to detect which items or perhaps role performance domains were difficult to reproduce or even irrelevant. These results will be discussed in Chapter 8 . The following questions are important:

1. Are there specific items which provide information that can hardly be rated in the same way? These items have to be deleted.

2. Is there a specific domain which provides information that can hardly be rated in this sample as an effect of non-variability? Are there differences with respect to the rating of the items between the groups? Some ratings may be easier to ascertain in one group than in another. Whatever the finding, does the domain have to be deleted or do items need correction?

3. How do the above aspects contribute to the overall reproducibility of the ratings of the instrument and is this, as we may hope, sufficient?

\subsubsection{The construct validity: dimensionality and internal consistency}

Following the study on interrater agreement, we tested the internal consistency, in order to avoid the inclusion of items not fitting into the construct of the instrument in the further analysis. In this phase we used the following measures to determine the internal consistency:

1. Simple frequencies and p-values.

2. The correlation between the item and a sum score on a scale, within each domain.

3. Cronbach's alpha (Cronbach, 1951) and Mokken scale analyses (Mokken, 1971), both relating the means of the correlates between the items on a scale with the number of items in that scale. The first as a measure of cohesion, the second as indication of the discriminative power.

The above measures investigate the coherence between the items within a specific role performance domain. However, in testing the construction of the questionnaire, we shall also have to know whether the domains are indeed independent. To investigate this, we performed a LISREL confirmatory factor analysis and determined various correlations, e.g. between the item of one scale and the sum score of another scale, between the different domains, and also the correlations between the sum scores of different domains. Concerning these measures, significant agreements or an insufficient fit may give rise to suspicion and reconsideration of the chosen construct. The results of this part of the study will be discussed in Chapter 9 . 


\subsubsection{The validity of the instrument: interjudge agreement}

With the thus reduced instrument, the information from the patient interviews ${ }^{14}$ was compared with the judgment of the mental health care professionals. This is the core of our analysis. Interjudge agreement was firstly determined with Pearson's correlation (r) (Pearson, 1967), by comparing the following scores:

1. The ratings on the open-ended questions in the patient version of the instrument. These scores represent the judgment of one of the researchers based on factual information, gathered from the patient.

2. The ratings on the precoded questions in the professional's version of the instrument. These scores represent the judgment of the professional based on what the professional knows about the patient.

Secondly, we compared the response tendency of professionals and patients by means of Kendall's W coefficient of concordance (Kendall, 1948). Both a quantitative as well as a qualitative study into the various reasons for differences between patients and professionals was done (see also Chapter 12). With respect to the interpretation of the comparison between the judgment of mental health professionals and the ratings of the patient information, several factors influence the outcome of the data. The different domains in the questionnaire investigate information which is at times easy but also quite often difficult to interpret. Sometimes, the professional will not know enough to provide consistent answers. In other cases, the patient will not always present a clear response. Consequently, in some domains patients will tend to underestimate their own possibilities, while in other domains professionals will perhaps know too little or tend to overestimate. The results of this part of the study will be discussed in Chapter 10. With regard to the comparison, the next questions are important:

1. How much does the professional know about the patient? Does this differ in respect of the different professionals, or in respect of the various kinds of patients?

2. Are there differences between the degree of knowledge of the patients, and does this differ between the groups, and to what extent does this influence the findings?

3. What does the patient know about himself?

4. Do some patients have a better insight into their own performance than others and how does this influence the findings?

5. How may these findings be evaluated when we compare them with current literature on the judgment of social behavior?

\subsubsection{Criterion-oriented validity}

To test the extent to which the questionnaire indeed reflects different levels of

14 We compared the data obtained from the first coder with the data obtained from the professional, check the tablebook, appendix no $V$ for the simple frequencies. 
social functioning, we compared the outcome in the various domains of role performance with comparable scores obtained on the Sickness Impact Profile (S.I.P., Bergner et al., 1976) by means of a Spearman rank order coefficient (Spearman, 1910). The S.I.P. is a self-report questionnaire. It measures the extent to which daily behavior is limited by the subjective appraisal of either mental or physical health. In the S.I.P., a score is given when an individual experiences a limitation due to mental illness or physical impairment. In our instrument, a positive score is given when an individual is judged to display expected behavior. A negative score is given when the behavior is not displayed. Consequently, the role domains should correlate inversely with the comparable domains on the S.I.P. Questions related to this issue are:

1. Which domains on the S.I.P. are comparable with which domains on our own instrument?

2. Does a high score in a category or a construct of categories on the S.I.P. correlate with a high score in a comparable domain of social role performance?

This issue is related to aspects of convergent and divergent validity of the measured traits in the S.R.P.D.I. We may hope that aspects of taking care, support or social activities judged by the professionals correlate inversely with aspects of taking care, support or social activities represented in the S.I.P. These analyses will be discussed in Chapter 11 .

\subsubsection{Discriminative value and outcome}

In $\$ 7.1$ we described the selection of four homogeneous groups. We postulated that these groups would differ in their role performance. To test the discriminative power of the instrument, we tested to what extent the four groups indeed yielded different patterns of role development. As we need a minimum of 20 patients in each group to perform any statistical analysis, we grouped the four groups into various contrast groups. First, we compared the patients with an early onset with those with a late onset. Second, we compared the men with the women. The third comparison was between the patients with or without a partner. The final comparison was drawn between patients with few and with many discrepancies between the expectations set in the status and position roles and their actual role performance.

This last comparison may be regarded as a measure of outcome. In Chapter 4, we distinguished two dimensions in role concepts. In the first, ("what"), the status and position roles cover what has been achieved by an individual. In the second ("how"), the role performance deals with how the individual has achieved the above status and position roles. In this way, the status and position roles may be seen as variables determining the outcome, consequently as independent variables, while the current role performance illustrates the differences in outcome, and can thus be valued as a dependent variable. A low role performance together with an early onset of the mental disorder may be expected to correlate with the achievement of few status and position roles, 
while a high role performance should correlate with the achievement of more status and position roles.

Next to the differences in current role performance, we also tested differences in certain structural characteristics of the social network and in the number of position roles. We tested these differences using simple statistics for the evaluation of group differences. With respect to the number of established social contacts within the social network and the number of achieved position roles, we used the Student t-test (Fisher, 1934) to measure the differences between the various contrast groups. With respect to the comparison of the scores on the various scales we used the Mann - Whitney U univariate nonparametric test (Mann \& Whitney, 1947). The results of these analyses will be discussed in Chapter 12. Questions related to this issue are:

1. To what extent do the various contrast groups differ?

2. Does the instrument discriminate between the four groups?

\subsubsection{Description on case level}

Apart from an extensive description of the data on item and group level, we will illustrate the data with a number of case reports in Chapter 13 to show how the instrument may be used in daily practice. In Chapter 13 we shall address the differences between the various groups at case level and indicate some implications for the daily practice in the care of the chronic mentally ill. We are interested in clinical validity at face value. Do obvious differences at case level result in distinctions as measured with the instrument? Questions related to this issue are:

1. Are obvious observable differences reflected by clear distinctions in the data provided by the instrument?

2. Is the instrument sensitive enough to measure change?

3. Are the various differentiations in developmental patterns reflected by the data?

4. Which parts of the instrument provides the most sensitive information?

\subsubsection{Comparison with a normal reference group}

We finally looked at the comparison between a subset of our sample with a normal reference group. This population was obtained from a registered healthy population of three general practitioners. First criterion of selection was that the reference group had no current complaints, either physical or psychological. Second, we selected the reference group by means of paired matching on a number of demographic characteristics, to secure comparability. In the comparison with the reference group, we were interested in three topics: the number and variability of the personal network, the number and variability of social roles and finally the impairments measured in the four domains of social role performance.

Between these topics, we may assume a certain interplay. Roles, and more 
specifically position roles, may be regarded as one of the most important determinants of interpersonal relationships, and it in effect determines the composition of the personal network (Janssen, 1992). Through his actions within certain roles the individual manipulates his network of social relationships. By initiating a new role, the individual may establish several new relationships; by ending a role he may free himself of old roles (Boissevian \& Mitchell, 1973). When a person suffers a (mental) health deviation he will no longer be able to perform several roles. The severity and duration of the deviation determines the impact on role performance. We may assume that the individual suffering a health deviation, for example as an effect of a psychiatric disorder, loses many of his situation roles and an increasing number of his position roles and finally may have difficulties in meeting the expectations related to maintaining his status roles. The composition of the personal network also changes, as the individual relies on fewer people, predominately in the network sectors "kin" and "formal non-kin". Role performance may be expected to be impaired in more than one domain.

With respect to the comparison between patients and references we may formulate the following hypotheses concerning the difference between the patients and the reference groups. Patients may be expected to have more impairments in role performance, limiting the number and the variability of the social roles and leading to less balanced and more unstable personal networks. These hypotheses are tested in Chapter 14. 


\section{Reproducibility of the ratings}

The first question to be answered in the main study concerns the reproducibility of the information we gathered. Before considering the consistency or aspects of validity of the Social Role Performance and Development Inventory, we have to know to what extent different raters interpret the information in the same way. The answers on open-ended questions in the patient's version of the instrument were rated by two independent raters. The agreement between these two raters was calculated.

\subsection{Procedure}

To determine the agreement between raters and the interrater reliability of an instrument, many measures may be used, as for example Cohen's Kappa, weighed Kappa, the Maxwell random error coefficient, the intra-class correlation coefficient, the Yule's y, and many others. A distinction between reliability and agreement has to be made. Agreement is when different raters try to provide the same rating scores at item level. Reliability of an instrument concerns a more relative measure of agreement at scale level. It represents the degree to which the ratings of different judges are proportional when expressed as deviations of their means at scale level (Tinsley \& Weiss, 1975). In this chapter we will look at the reproducibility of the absolute ratings, i.e. the agreement between raters. To correct for coincidence we applied Cohens' unweighed Kappa (Cohen, 1951). As the Kappa is a very strict measure, providing a correction of the percentage of agreement by chance, we will also discuss the percentage of agreement on the items.

The agreement between raters was determined in the patient version of the questionnaire. All items concerning the current role performance and the development of role performance, i.e. part two of the questionnaire, were analyzed. In this part of the questionnaire each domain begins with a number of scalable items, representing a level of functioning. The questions were posed in an open format: "What do you do with .......". The open format facilitates a dialogue on the content of the performance. Trained interviewers and a detailed response instruction were used to ensure reliability. Items were scored only if the individual performed the behavior in question, as our main interest was performance. Probable capacities - interpretations of what the patient perhaps "could have done, if not ..." - were thus avoided as far as possible. Two independent raters generated the data by coding and categorizing these questions. When $\kappa$ has a value of 1.0 , agreement is perfect; when zero, agreement is no better than chance. In the evaluation of our results 
we used the criteria given by Laundis and Koch (1977, p. 265), who define a kappa exceeding 0.61 as substantial. Because we are dealing with concise information and have to rely on a small number of items, we used this as a minimum criterion. Extreme skewness is known to influence the $\mathrm{K}$ substantially, but also influences the interpretation of many other analyses (Boomsma, 1983). Consequently, items with a $\kappa<0.60$ or a skewness with a $p$ value equal to or larger than 0.90 or smaller than 0.10 will be discarded from further analysis.

With regard to the data, it should be taken into account that the first rater was the same individual who interviewed the patient and who also provided feedback to mental health professional and patient. To ensure a certain degree of anonymity, only the identification number was left on the questionnaire when it was coded and the coding was performed en masse, some three to five months after the interviews took place. The second rater was a student psychulogist, having absolutely no prior information but with training in conducting interviews and in using our instrument's manual. By carrying out the rating some time after gathering the data, and by training the raters, we tried to improve the rater's objectivity.

\subsection{Present performance}

In the coding manual we defined a number of different response formats, as the required performances differed. With respect to the domains "self care", "daily obligations", and "social activities", the items are dichotomous: either the patient shows the behavior or not. The items in the sub-domain "care for others" are trichotomous, the behavior being either overzealous, normal or less than expected. The items in the domain "support" were scored on a Likert - type rating, varying from frequent to infrequent performance on the required item. Most sexuality items are nominal, in contrast to all other items which are ordinal. Only the item "sexual practice" is defined on an ordinal scale, varying from none at all to fulfillment of mutually consented sexual desire. Cohens' Kappa was determined after dichotomizing all data on current performance, mostly into the categories "does" or "does not" perform the behavior. We chose this dichotomization for a number of pragmatic reasons. First, it relates to our concept of role performance: we are interested in what the patient in fact does, how he performs within observable criteria. Second, the power of the analysis decreases with the number of categories. With 60 patients a power of more than $90 \%$ can be obtained with dichotome variables. When the variables are trichotome, we have to accept a power of less than $70 \%$, while for items with five catogories the power may be less than $50 \%$. So, we do not know what a low kappa indicates. Finally, in most items the response format was selected on behalf of consensus with the professionals. It had to relate to their concepts in the judgement of behavior, which not always can be forced into a yes or no format. 


\subsection{Past performance}

In the schedule, current role performance in each area is always related to performance before onset of illness. If problems do occur in current functioning, additional questions are posed in order to gain information on the comparison with functioning at the onset of the mental illness and, in a broader sense, on the development of the defined area of social role performance. First we asked whether role performance was either better, the same or less than before onset of mental illness. On these items interrater reliability was determined. It has to be stressed, however, that a comparison at item level has very little clinical relevance. For the evaluation of current possibilities it is interesting to know whether the patient previously functioned at a higher level, how long ago, and in which context deterioration took place.

The details of functioning at onset are of less importance and in our instrument served as a means to stimulate discussion on the pattern of the deterioration, not as information as such. Regarding development, different patterns are assumed in the schedule. Firstly, a normal development is assumed if no problems are encountered at the current level of functioning. Secondly, stagnation is assumed when development has always been seen as insufficient. Thirdly, a relapse is assumed when the development has followed a normal course and insufficiencies have developed later on. Finally, two kinds of relapse are distinguished. The relapse may be short-term, showing few consequences for social role fulfillment. The relapse can also be long-term, with persistent consequences for social role fulfillment (cf. Häfner, 1985; 1992). These patterns were only compared using Pearsons $r$, as the data could not be dichotomized in a sensible way without too great a loss of information.

\subsection{Assumptions on outcome and important questions}

Regarding interrater reliability, we are interested in the following questions:

1. Are there specific items which provide information that can hardly be rated in a reproducible way? These items have to be deleted.

2. Is there a specific domain which provides information that can hardly obtain a satisfactory agreement between raters? If so, does the domain have to be deleted or do the items again need correction? Or can the domain be interpreted as an independent variable with no relation whatsoever to the other domains within the instrument?

3. Are there differences in respect of rating agreement between the groups? As may be expected, the answers to certain questions may be easier to ascertain in one group than in another.

4. How do the various aspects mentioned above contribute to the overall rating agreement of the instrument and is this agreement, as we hope, sufficient?

With respect to the interpretation of these questions, it is obvious that the domains differ in the extent to which items can be coded in a reproducibleway. "Self care" consists of clear and well defined items, leaving little room for 
interpretation. A trained interviewer with enough experience in the questionnaire and the manual can be expected to obtain highly reliable information. The domain of "support", however, consists of items such as "Do you show your personal emotions to other people?", which require a certain amount of acknowledgment of one's own personal feelings, both on the part of the interviewer and the interviewee. Some answers are clear, others are definitely vague, such as the response of case number 11 : "I' $m$ not sure, I do feel myself connected to my boyfriend, though we almost never talk about feelings." Even after inquiring more extensively, it remained unclear if the patient indeed ever showed her personal feelings to anyone. So this domain may provide less clear information. The domain of sexuality, on the other hand, contains items the respondent may be reluctant to answer. Thus, no information at all was obtained from some patients. Some of the data in this domain were obtained from only 28 patients, exactly half of the response group. The domain of daily activities contains clear items such as "Can you finish the work or the goals you have set for a day?", but also some items on personal interactions, for example "Do you make contact with colleagues or superiors?". The first may not produce difficulties in interpretation, whereas the latter may indeed leave room for interpretation differences. The domain of social activities, finally, contains to a great extent very well defined and clear items. A second important factor determining the interrater agreement is the number of patients a certain domain may be relevant for. "Self care", "support" and "social activities" are relevant for all patients. In the domain of "sexuality", 14 patients declined to provide any information; we thus obtained information from 42 patients. The domain of "daily obligations" is relevant for only 33 patients. Six patients did solitary work, consequently rendering items such as contact with superiors irrelevant. "Care for others" was relevant to only 21 patients of the 56 .

\subsection{Results}

The interrater agreement on the schedule was determined by computing the percentage of agreement and Cohen's $\kappa$ between two independent raters on the items covering current functioning and on retrospective items covering the social functioning in the past. In Table 8.1 we present the results of the analysis. We first present the results on current functioning, then the results on past functioning, both on item level. In the first column, the mean rated percentage of people responding with a positive answer to the item is given, as an extreme skewness may diminish the Kappa severely. In the second and third column we show the percentage agreement and the Kappa. Within the domains we also present, in italics, the weighted totals over all the items composing a domain, when computable. In the fourth column we present the percentage of respondents who indicate that their level of functioning on the specific item was worse at the onset of mental health care. The fifth and sixth column show the percentage agreement and the Kappa for the items representing the level of functioning at onset of mental health care. The 
number of valid responses is presented in the final column, also in italics. All items were dichotomized for this analysis only. The results show that all Kappa's are considerably better than chance; however, current functioning was more consistent than past functioning. In the presentation and the discussion of the results we will discuss each domain separately.

Table 8.1 The interrater agreement on the open-ended questions posed to the patients and rated by two independent raters with Cohen's Kappa*

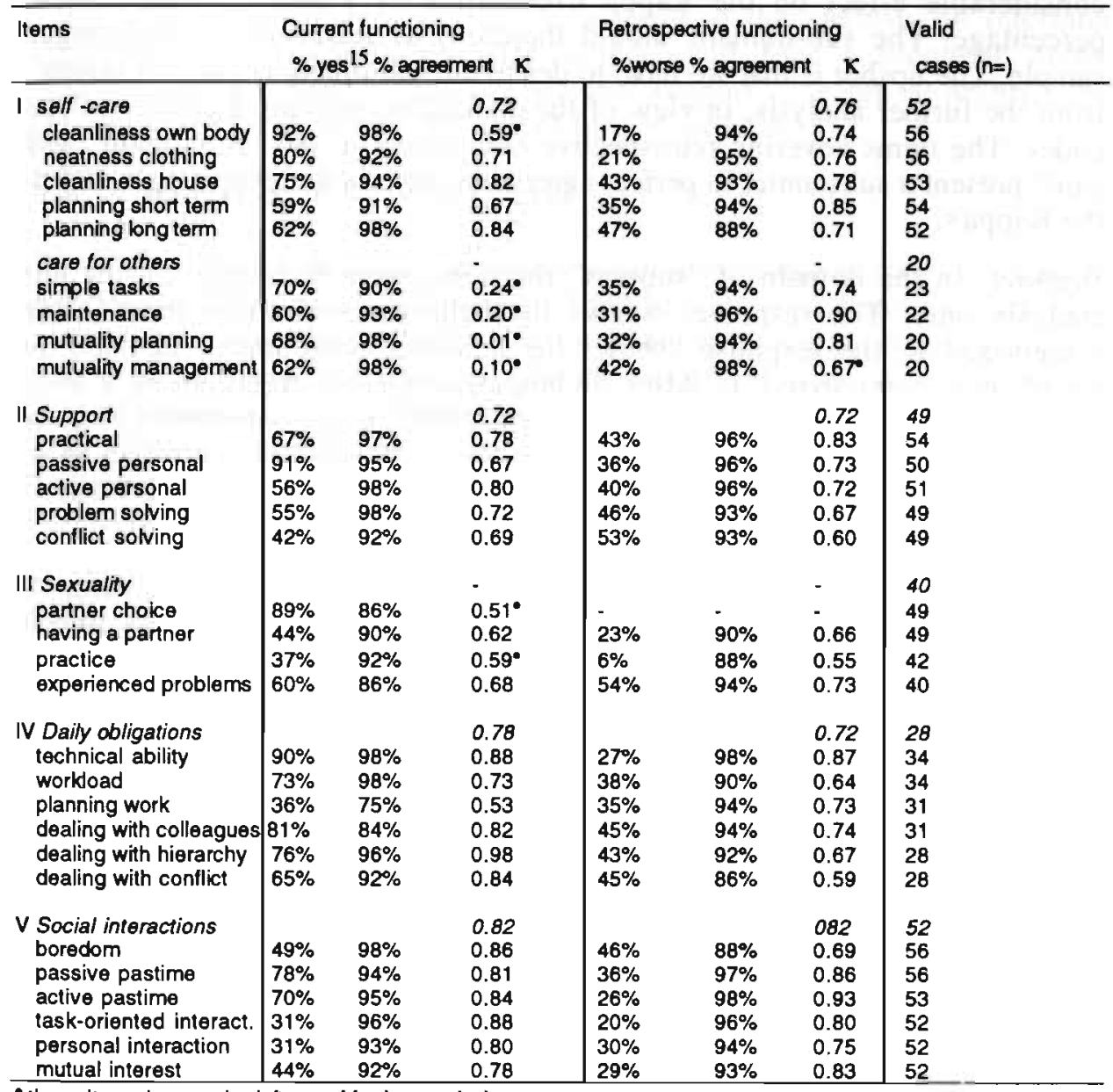

- these items have to be left out of further analysis

- Criteria Laundis \& Koch : $\quad k<.00=$ poor,

$0.00<k<0.20=$ slight .

$0.41<k<0.60=$ moderate,

$0.21<k<0.40=$ lair,

$0.61-0.80=$ substantial,

$>0.81=$ good 
Self-care and care for others. In the domain of self-care, the agreement between raters may be regarded as quite good, with the exception of the item "cleanliness own body". However, this item exhibits very extreme skewness ( $p$ - value $\geq 0.90$ ), and should preferably be omitted from further analysis as it provides no distinctive information about our sample. It might be sensible to test an item like this in a population of hospitalized patients, comparing them with patients in ambulatory care. The sub-domain "care for others" shows poor to slight Kappa's. However, we do not know how to evaluate this result, because only a limited number of patients responded. A single case may have a considerable effect on the Kappa irrespective of a sufficient agreement percentage. The sub-domain should therefore be tested in a much larger sample. The upshot is that we have to delete the sub-domain "care for others" from the further analysis, in view of the difficulties in reproducibility of the codes. The items covering retrospective functioning in the sub-domain "self care" present a substantial to perfect agreement, both in the percentages and in the Kappa's.

Support. In the domain of "support" the items were dichotomized for this analysis only. The response "shows the behavior seldom or never" was categorized 0 ; the response "shows the behavior sometimes, regularly or often" was categorized 1. After dichotomization, all items show a high percentage of agreement (between 92\% and 99\%), and a substantial to good Kappa. Only the item "passive personal support" will be ommitted from further analysis due to extreme skewness. Regarding the retrospective items, agreement was somewhat lower.

Sexuality. In this domain, nominal variables on both current functioning as well as level of functioning at onset of illness were dichotomized into a positive - negative categorization. All items, whenever a positive response was given, were categorized 1. This operation incurred considerable loss of information. A second problem was that an important number of patients produced unclear or rejective answers to the items "sexual practice" and "experienced problems", incurring a variable number of missing values on these two items. When we look at the percentage of agreement (based on the nominal categories) both on current as well as past functioning, the agreement may be regarded as good. The Kappas, both on current functioning and on level of functioning in the past, vary between moderate and substantial. A Pearson correlation was determined on the undichotomized items revealing results between 0.42 and 0.68 , which is quite good. The insufficient Kappas, consequently, may be regarded as an artifact of the dichotomization. So, despite these results, we decided not to delete any of these items from further analyses for reasons of poor reproducibility.

Daily obligations. In this domain, the items "technical ability" and "planning of work" need to be omitted from further analysis, the first because of an extreme skewness ( $p$ - value $\geq 0.90$ ) and the latter because of a low Kappa ( $\kappa$ $\leq 0.60$ ). When we look at the response pattern on the last item, it is salient that 
this is one of the few items with a negative response tendency. Quite often different problems in this item were mentioned, and categorization was sometimes arbitrary. With respect to past functioning, the Kappa's were lower, but also agreeable, with a fairly good median percentage of agreement.

Social interactions. In the domain of social interactions, both the current and the retrospective items show a satisfactory to good Kappa. In this domain the information gathered from the patients is of good quality and, again, no items needed to be deleted.

Conclusion for further analysis. As a result of the analysis on interrater agreement the domain "care for others" and four subsequent items, "cleanliness own body", "passive personal support", "technical ability" and "planning of work", will be left out of further analysis.

\subsection{Comparison on a group level}

To be sure that the accuracy of the information is independent of the kind of patients we interviewed, we compared the Kappa's within the four selection groups. We expected that the data of the younger unmarried men and women would be less reproducible than the data of older married people, as the former contain a large number of schizophrenics. Acquisition of information in schizophrenics is known to be difficult, as they tend to be erratic in their responses to interviews (v.d. Bosch, 1982). A summary of the data is given in Table 8.2. The mean Kappas on the domains are presented.

Table 8.2 A groupwise comparison of the interrater agreement with Cohen's Kappa

\begin{tabular}{|c|c|c|c|c|}
\hline domain & $\begin{array}{l}\text { grc } \\
\text { at onset unmarried } \\
\text { men and women }\end{array}$ & $\begin{array}{l}\text { at onset married } \\
\text { men and women }\end{array}$ & men & women \\
\hline $\begin{array}{l}\mathrm{n}= \\
\text { self-care } \\
\quad \text { current functioning } \\
\text { past functioning } \\
\text { development pattern } \\
\text { social activities } \\
\text { current functioning } \\
\text { past functioning } \\
\text { development pattern }\end{array}$ & $\begin{array}{l}26 \\
0.65 \\
0.55 \\
0.83\end{array}$ & $\begin{array}{l}20 \\
0.76 \\
0.52\end{array}$ & $\begin{array}{l}29 \\
0.61 \\
0.65 \\
0.82\end{array}$ & $\begin{array}{l}27 \\
0.73 \\
0.61 \\
0.84\end{array}$ \\
\hline
\end{tabular}

- too little data available for analysis

We only compared data on self-care and social activities, as the data were gathered from enough patients to make the comparison worthwhile. First, we 
compared those who came into care early, i.e. the young unmarried men and women, with the older married men and women. Second, we compared the men and the women. In these data no major differences arise. The young show indeed slightly lower Kappas than older people in the domain of "self care". The data on the domain of "social activities" show no differences at all. We may conclude that the characteristics of the specific groups do not determine the interrater agreement.

\subsection{Summary}

In Chapter 7 we argued that the first step in the analysis of instrumental utility is the interrater agreement. The main objective was to determine which items provide information which may be reproduced by a second rater. We set the criterion that the items at least had to have a Kappa higher than 0.61 , or a skewness with a p - value smaller than 0.10 or larger than 0.90 . As a result, eight items had to be omitted from further analysis. We deleted the entire sub domain "care for others". In the domain of "self care", the item "cleanliness own body" was left out. In the domain of support the item "passive personal support" was left out. Finally, in the domain of "daily obligations" the items "technical ability" and "planning of work" were omitted. In the domain of "social activities" no items were discarded.

The data in this chapter show that especially the domains "care for others" and "sexuality" provide low Kappas and less impressive percentages of agreement. The main cause of the poor results in the domains "care for others" and "sexuality" is the low response rate. Only a minority of the patients live with others; thus the domain "care for others" quite often generated irrelevant information. Secondly, many patients are reluctant to provide information on their experience of sexuality. The only other item showing a low Kappa despite a normal skewness and a reasonable response rate is the item "planning of work". This item shows one of the lowest percentages of agreement between raters.

When we evaluated whether specific group characteristics determine reproducibility, we found no major differences. The Kappas were only slightly, but not significantly lower in the two younger groups. 


\section{CHAPTER 9}

\section{Internal consistency and dimensionality}

The present chapter addresses the exploration of our theoretical assumptions concerning the construction of the instrument. In the Chapters 4 and 6 we distinguished five main domains in which socialization occurs, social behavior develops and social role performance may be observed: the domains of selfcare and care for others, support, sexuality and partnership, daily obligations and social activities. This chapter investigates whether the item selection procedure presented in the two chapters above resulted in a sensible construct. We are primarily interested in the coverage and the homogeneity of the different domains, and in some aspects of scalability. We investigated this in both versions of the instrument. Because our focus is on the judgment of the professional, we address the professional's view first in the presentation of the results, and compare it with the results obtained from the patients. In this chapter the subdomain care for others, and the items cleanliness body, passive personal support, technical ability and planning of work are left out of the analysis, as decided in the conclusion of Chapter 8.

\subsection{Questions related to consistency}

This chapter focuses on construct validity. In the investigation of the construction of our instrument the following main questions arise:

1. Before we look at consistency we first have to know to what extent our data are complete. To what extent are we hampered by missing data in the interpretation of internal consistency?

2. Concerning the consistency, we first have to know if we do indeed measure differences. Is there a difference between easily performed items and more difficult items?

3. We then have to know to what extent the distinct domains are coherent. Do the items within a single domain indeed represent aspects of the same kind of behavior, and is the sum of these items a reliable representation of the whole domain?

4. Finally, concerning the dimensionality, we have to know whether we measure different dimensions of behavior in the different domains. Do the items within different domains indeed compose distinct factors, or is there a certain overlap between the domains?

In each analysis we will compare the results obtained from the professional's judgments data with the patient's self-report data. Consistency and coherency of the response may be related to which person we ask. Patient's answers may be more accurate and detailed, but also subject to fluctuation of mood or self- 
perception. Professional views may be less accurate on details, but more consistent in a global way. Sometimes, however, professionals may know too little to respond.

\subsection{Completeness of the data: missing values}

\subsubsection{Effects of the missing values}

An important problem disturbing the interpretation of the multivariate analyses in particular is the considerable number of missing values, especially in the domain of daily obligations, but also in the domains support and sexuality. The main reason for coding a missing value was the absence of a context to relate the item to. So especially the domains support, sexuality and daily obligations were affected. A small number of patients $(n=6)$ had few to no contacts at all, apart from the mental health professional. Items such as practical support, showing overt personal support, and problem or conflict solving could not be judged, as the patient, lacking a social context, had no opportunity to perform these items.

As many as 13 patients refused to provide information in the domain of sexuality, apart from simply stating whether or not they were engaged in a relationship. In as many as 21 cases the professional knew too little of the patient to provide information on several items in this domain. Finally, many patients had no vocational setting, and no obligations whatsoever $(65 \% \quad(n=37)$ was either jobless or incapacitated, $44 \%(n=25)$ had no structured daily occupation). Role performance in the domain of daily obligations of 19 patients $(31 \%)$ could not be judged. $23 \%$ of the professional's judgment data consisted of missing values, as did $18 \%$ of the data obtained from the patients.

Furthermore, we may expect the psychiatric disorder to influence the accuracy of the assessment, in a way we cannot correct for. Accuracy may be impaired especially when items cover behavior requiring a certain selfinsight, as most of the items in the domain of support and some of the items in the domain of social activities. This effect may be expected to be stronger in the groups containing the most schizophrenics, as with for example the young and unmarried at onset. It is less likely to occur in the groups of the older and married at onset. In the presentation of the analyses on the coherence of the instrument the reader may note the number of cases the domain applied to. In the evaluation of the results of the multivariate analysis a bias also has to be considered, as the missing values concern an important part of the data matrix and we often had to decide to replace a missing value by a probable score.

\subsubsection{Treatment of the missing values}

The simple analyses concerning the differences in difficulty of the items and the coherence within the domains were carried out on a database with missing values. To avoid a severe reduction of the data matrix, the multivariate 
analyses ${ }^{16}$ were performed on a "purified" data matrix. We excluded the items which proved to be highly inconsistent with the domains. For the other items we recoded the missing values according to the tendency provided by the other items within a specific domain in a specific case. So, when an item revealed a missing value in a specific case, we looked at the median of the other three or four items in the domain and recoded the item according to the median of the other items.

In some cases this rule could not be applied. When the number of missing items in a scale was more than 2 , we applied a second consideration concerning the next assumption on the most probable score. Most of the missing values occur within the domains "support" and "daily obligations". In both domains it is reasonable on theoretical grounds to assume that a missing value indicates absence of performed behavior and should thus be coded zero. In the domain of support most of the missing values are an effect of the fact that some patients have too few personal contacts to allow a reasonable evaluation of the items. In the domain of daily obligations, some patients simply do not have anything to do, so it is difficult to judge how they would deal with colleagues or superiors. To sum up, when indicated we either chose the median or a zero.

\subsection{Procedures}

\subsubsection{Internal consistency: measuring differences}

The first question concerning internal consistency of the domains is: Do we indeed measure differences? Within the domains "self-care", "support", "daily obligations" and "social activities" we selected items representing a hierarchy. A simple and tangible way to check the expected hierarchy is by comparing the percentage of positive scores on the items within a domain and to see whether the probability of either passing or failing an item decreases in the lower ranked items of the domain.

\subsubsection{Internal consistency: coherence within domains}

The most simple way to look at the coherence within a domain is by calculating the correlation between the score on one item and the overall sum of the other items on that specific role domain (the corrected item-sumtotal correlation). However, good correlations are only an indication of the consistency of the separate items with the domain. A more important measure, dealing with the scale reliability as a whole, is the Cronbach's $\alpha$ (Cronbach, 1951). A high Cronbach's $\alpha$ (above 0.70) indicates that the items cover a single trait, and that the sum score of that specific domain is reliable. The procedure makes it possible to identify items which do not fit into a scale. The discriminative power of the scale is a prelimiting condition for a high 
Cronbach's $\alpha$. To assess the discriminative power of the scales, Mokken analysis was also performed (Mokken, 1971). Mokken provides two measures, the scalability coefficient $\mathrm{H}$, and the reliability coefficient rho (roughly the same as the $\alpha$ ). When $H$ is less than 0.3 , the scale is not regarded as a scale, when it is less than 0.4 it is regarded as a weak discriminatory scale, and only when it is more than 0.5 is it regarded as a powerful discriminatory scale. In the evaluation of the Cronbach's $\alpha$ and Mokken, the completeness of the data set has to be taken into account. A domain containing many missing values may be expected to be less consistent and show a less impressive scale reliability. Slight inconsistencies in single cases may have important effects on both the item-sumtotal correlation and the Cronbach's $\alpha$. We therefore present the number of valid cases for each scale.

\subsubsection{Dimensionality : the distinction between domains}

A next topic of interest concerns the distinction between the domains. Are the various domains indeed reasonably independent while still composing a single construct? Do the different domains really represent distinct dimensions of role performance? And do items within one role domain elicit information about only that role domain? These are this chapter's most important questions, as they support our assumption regarding the division of role performance into 5 domains. Exploratory factor analysis seems to be the analysis of first choice to address these questions. However, exploratory factor analysis, though commonly (but inadequately) used for the confirmation of theory has (especially in this mis-use) a number of not so widely known risks. An important recent view is eloquently formulated by Tabachnick \& Fidell (1989, p. 599):

"One of the problems is that there is no criterion beyond interpretability to test the solution. A second problem with exploratory factor analysis is that, after extraction, there are infinite numbers of rotations available, all accounting for the same amount of variance in the original data, but with factors defined slightly differently. A third problem is that the very power of exploratory factor analyses to create apparant order from what actually is real chaos contributes to their somewhat tamished reputations as scientific tools. Confirmatory Factor Analysis (CFA) is a much more sophisticated technique used in the advanced stages of the research process to test a theory about latent processes. Variables are carefully and specifically chosen to reveal underlying processes. A number of comparisons between the pattern of loadings from theory and loadings from sample data can be conducted."

Therefore, we addressed these questions with a CFA following the LISREL procedure (Jöreskog, 1978). We chose to perform a LISREL analysis as we were interested in a rigorous exploration of the theoretical assumptions underlying the construct of the instrument. Contrary to relying solely upon the exploratory factor analysis, the researcher can by the use of a LISREL model define substantially motivated constraints. 
The LISREL analysis provides the possibility of testing hypotheses concerning:

1. the number of factors underlying the item set;

2. the correlations between the factors;

3. the loadings of the items on the various factors.

Statistical tests can be performed to determine whether the sample data are consistent with the imposed constraints, or in other words whether the data fit the substantively generated model. In the LISREL output, different measures provide information on the probability of the model. In the interpretation of LISREL analysis, three indicators are important to notice:

1. the maximum modification index, indicating which items (or variables) need adjustment in order to improve the goodness of fit;

2. the adjusted goodness of fit index, an indicator of the appropriateness of the model;

3. the percentage of normalized residual covariances smaller than -1 or larger than 1 , indicating the percentage of items that poorly fit into the model.

The most important is the chi-square goodness of fit test. With the chi-square the proposed model is tested against an alternative model with no structure or restrictions. With this procedure the researcher obtains information on the appropriateness of the fixed model and obtains an unambiguous single mathematical solution of the structure imposed on the data by means of the fixed model ${ }^{17}$. An important reason to use LISREL is its robustness for a small data set and non - normal skewed items (Boomsma, 1983), as in the current study. Especially in the case of small data sets, it is hard to obtain a fitting model (Saris \& Stronkhorst, 1984). When the model is not rejected in either of the data sets, we may regard this as a good indication of our model.

\subsubsection{Some comments on the statistical power}

In the analyses on internal consistency, the critical effect size (Chapter 7, p. 90 ) is determined by comparing the total number of items in a scale with the number of items we regard as an indication of deviance. For each scale, different values of the main power analysis parameters - effect size, power and level of significance - have to be taken into account. "Self-care" is covered by five items. More than one zero score may be regarded as deviant. The critical effect size is $2: 5=0.4$. We need 36 cases for a power of $80 \%$ and a level of significance of 0.05 . For "support" the same calculation can be made. "Sexuality" contains four items, with a critical effect size of 0.25 , thus needing 105 cases for a power of $80 \%$ and a level of significance of 0.05 . The 56 cases included in the study provide for this scale a power only slightly above $50 \%$. "Daily obligations" and "social activities" both contain six items, with a

Exploratory factor analysis was also performed, but provided consistent with Tabachnick views, inconsistent and contradictory information, several strategies and tests showing conflicting conclusions. For example, with a GL method five factors provided an eigenvalue larger than 1,0, with a M L method the chi-square test of goodness of fit gave a solution of three factors, but using a simple varimax rotation only the four factor solution provided a satisfactory proportion of unexplained residuals $(<20 \%)$. So, much confusion and no solution. 
critical effect size of 0.33 , needing approximately 70 cases for the same power and level of significance. For the last two scales we have to accept a power of $70 \%$. The calculation of the power of the Lisrel analysis, largely the same as the reliability analysis (also the example in Chapter 7). In both cases we are dealing with a critical effect size of 0.24 , a power of $80 \%$ and a level of significance of 0.05 , and data of two independent, but related samples: the sample containing the data of the patients and the sample containing the data of the professionals. Again, the minimum number is approximately 50 cases.

\subsubsection{Step-by-step analysis of internal consistency and dimensionality}

Each of the analyses mentioned represents a step in the testing of the internal consistency and the dimensionality. Three steps deal with the internal consistency. The first step, looking at the distinction between the items, is investigated by simply comparing the probabilities to fail or pass of the various items in a domain. In the domains self-care, support, daily obligations and social activities, we expect a hierarchy in the items, some items being performed by many patients, others performed by few patients. The second step, the item-sumtotal correlation within the domains, provides information on how coherent the domains are. It shows, more specifically, which items fit badly in the domain and should be left out of further analysis. The third step, determining the height of the Cronbach's $\alpha$, provides information, not only on the coherence of the scale, but also on the discriminative value and the reliability of the sum score. The fourth step, which deals with the dimensionality and concerns the LISREL procedure, addresses the distinction between the domains and tests the validity of our choice of items and domains.

\subsection{Results}

\subsubsection{The percentage positive scores}

In Table 9.1 we present the precentage positive scores of the items in the various domains using the data provided by the professionals.

Table 9.1 The percentage positive scores in the domains "selfcare", "support", "daily obligations" and "social activities" with the data obtained from the professional's judgments

\begin{tabular}{|c|c|c|c|c|c|c|c|}
\hline sell care & $n=52$ & support & $n=52$ & daily obligations & $=28$ & social activities & $n=43$ \\
\hline $\begin{array}{l}\text { clothing } \\
\text { cleaning } \\
\text { planning weok } \\
\text { planning day }\end{array}$ & $\begin{array}{l}92 \% \\
86 \% \\
82 \% \\
75 \%\end{array}$ & $\begin{array}{l}\text { practical } \\
\text { active personal } \\
\text { problem solving } \\
\text { conflict solving }\end{array}$ & $\begin{array}{l}60 \% \\
57 \% \\
32 \% \\
18 \%\end{array}$ & $\begin{array}{l}\text { work load } \\
\text { dealing with colleagues } \\
\text { dealing with hierarchy } \\
\text { dealing with conflicts }\end{array}$ & $\begin{array}{l}68 \% \\
63 \% \\
58 \% \\
48 \%\end{array}$ & $\begin{array}{l}\text { boredom } \\
\text { mutual interest } \\
\text { task-oriented activity } \\
\text { person-oriented activity } \\
\text { active pastime } \\
\text { passive pastime }\end{array}$ & $\begin{array}{l}43 \% \\
69 \% \\
68 \% \\
71 \% \\
84 \% \\
92 \%\end{array}$ \\
\hline
\end{tabular}

Sexuality was not computed, as the items are neither formulated in a scale construct nor expected to represent a hierarchy. These results show clearly that the items in the domains "support" and "daily obligations" cover a 
satisfactory range. It is important to notice the slant skewness of the items in the domain of self-care, which may have effects on multivariate analyses reported elsewhere. In the domain of social activities we notice that the expected hierarchy is not fully supported, and that the differences in difficulty between a number of items are less impressive.

Table 9.2 The percentage positive scores of the items in the domains "selfcare" "support", "daily obligations" and "social activities" with the data obtained from the patient's self-reports

\begin{tabular}{ll|ll|ll|ll}
\hline seff care & $n=52$ & support & $n=52$ & daily obligations & $n=28$ & social activities & \\
\hline clothing & $77 \%$ & practical & $42 \%$ & work load & $85 \%$ & task-oriented activity & $31 \%$ \\
cleaning & $73 \%$ & active personal & $59 \%$ & dealing with colleagues & $74 \%$ & person-oriented activity & $29 \%$ \\
planning day & $64 \%$ & problem solving & $54 \%$ & dealing with hierarchy & $73 \%$ & boredom & $49 \%$ \\
planning week & $60 \%$ & conflict solving & $42 \%$ & dealing with conflicts & $64 \%$ & mutual interest & $43 \%$ \\
& & & & & & active pastime & $69 \%$ \\
& & & & & & passive pastime & $78 \%$ \\
\hline
\end{tabular}

In Table 9.2 we present the results on the patient's self-reports: We may also notice the slightly less impressive results in the domains "self-care" and "daily obligations" in the data from the professionals. The clear cumulative percentages observed in table 9.1 now disappear from all domains except "support". However, the domains do cover a sufficient range. This supports the findings on the coherence of the professional's judgements presented later this chapter.

\subsubsection{Internal consistency}

In Table 9.3 (next page) we briefly summarize the corrected item-sumtotal correlation, the Cronbach's $\alpha^{18}$ and the Mokken analysis measures of the five domains using the data obtained from the professional's. When we look at the responses of the professionals we see that all domains, except of course sexuality, have a good to excellent $\alpha$. These $\alpha$ 's decrease impressively when we include the items we deleted in the previous chapter. Addition of the item planning work to the analysis decreases the $\alpha$ of daily obligations to 0.41 . Addition of "passive personal support" decreases the $\alpha$ of support also as far as 0.36 . When we look more specifically at the data from the professionals, only a few items show low correlates with the sumtotal (i.e. less than 0.30). The first two domains, "self-care" and "support" show fairly satisfying correlations, ranging from 0.49 to 0.78 . The Mokken analysis supports the discriminatory power of most of the scales, however, in the domain of social activities two items are rejected by the procedure; boredom and passive pastime. The exclusion of these items is disputable, but may very well be an effect of a large variance in item difficulty. When we look at the contribution 
Table 9.3 The item-sumtotal correlation and Cronbachs $\alpha$ and Mokken analyses within the domains with the data obtained from the professional's judgments

\begin{tabular}{|c|c|c|c|c|c|c|c|c|}
\hline self-care & support & sexuality & & daily obligati & tions & social activities & & total $\alpha$ \\
\hline $\begin{array}{lr}\text { clothing } & 0.49 \\
\text { cleaning } & 0.72 \\
\text { planning day } & 0.57 \\
\text { planning weok } & 0.70\end{array}$ & $\begin{array}{cc}\text { practical supp. } & 0.68 \\
\text { active support } & 0.59 \\
\text { problem solving } & 0.78 \\
\text { conflict solving } & 0.68\end{array}$ & $\begin{array}{l}\text { partner choice } \\
\text { having a partner } \\
\text { sexual practice } \\
\text { sexual problems }\end{array}$ & $\begin{array}{l}0.32 \\
0.24 \\
0.67 \\
0.17\end{array}$ & $\begin{array}{l}\text { work load } 0 \\
\text { colleagues } 0 \\
\text { superiors } \\
\text { conflicts }\end{array}$ & $\begin{array}{l}0.20 \\
0.76 \\
0.59 \\
0.71\end{array}$ & $\begin{array}{l}\text { boredom } \\
\text { passive pastime } \\
\text { active pastime } \\
\text { task oriented } \\
\text { person oriented } \\
\text { mutual interest }\end{array}$ & $\begin{array}{l}0.75 \\
0.17 \\
0.55 \\
0.64 \\
0.69 \\
0.63\end{array}$ & \\
\hline Cronbach's $\alpha \quad 0.83$ & 0.86 & & 0.47 & & 0.77 & & 0.61 & 0.75 \\
\hline $\begin{array}{l}\text { Mokken } \\
\text { coeffcient } h=0.58 \\
\text { reliability } h o=0.82\end{array}$ & $\begin{array}{l}0.53 \\
0.73\end{array}$ & & - & & $\begin{array}{l}0.49 \\
0.74\end{array}$ & & $\begin{array}{l}0.47 \\
0.67\end{array}$ & \\
\hline$n=\quad 52$ & 52 & & 31 & & 28 & & 43 & \\
\hline
\end{tabular}

- items less consistent with the domain $(p<0.05) \cdots$ Mokken analyses showed no substantive results in the domain of sexuality

of specific items to the $\alpha$ 's of the various domains, only the deletion of items "work load" and "boredom" lead to slight increase in the $\alpha$ of the domain.

In Table 9.4 we present the results obtained from the patients. When we compare the data obtained from the professionals with the response from the patients, it is clear at first glance that the patients show less consistent responses in the domains "self-care", "support" and "social activities". In the domain of "sexuality", the consistency is somewhat less than in the professional's data. Apart from the item "sexual practice" the correlations are low. In the domain of daily obligations the consistency is even better than in the professional's data. In these data, apart from the domains "social activities" and, again, "sexuality" the Cronbach $\alpha$ 's are satisfying. In the response of the patient, daily fluctuations, mood and many other situation bound factors may be expected to influence the results. Total instrumental $\alpha$ decreases, however,

Table 9.4 The item-sumtotal correlation and Cronbach's $\alpha$ with the data obtained from the patient's self-reports

\begin{tabular}{|c|c|c|c|c|c|c|c|c|c|c|}
\hline self care & & support & & sexuality & & daily obligat & tions & social activities & 10 & stal $\alpha$ \\
\hline $\begin{array}{l}\text { clothing } \\
\text { cleaning } \\
\text { planning day } \\
\text { planning weok }\end{array}$ & $\begin{array}{l}0.42 \\
0.38 \\
0.33 \\
0.31\end{array}$ & $\begin{array}{l}\text { practical supp } \\
\text { active bond } \\
\text { problem solving } \\
\text { conflict solving }\end{array}$ & $\begin{array}{l}0.37 \\
0.21 \\
0.53 \\
0.51\end{array}$ & $\begin{array}{l}\text { partner choice } \\
\text { having a partner } \\
\text { sexual practice } \\
\text { sexual problems }\end{array}$ & $\begin{array}{l}0.21 \\
0.39 \\
0.71 \\
0.21\end{array}$ & $\begin{array}{l}\text { work load } \\
\text { colleagues } \\
\text { superiors } \\
\text { conflicts }\end{array}$ & $\begin{array}{l}0.45 \\
0.77 \\
0.77 \\
0.74\end{array}$ & $\begin{array}{l}\text { boredom } \\
\text { passive pastime } \\
\text { active pastime } \\
\text { task-oriented } \\
\text { person-oriented } \\
\text { mutual interest }\end{array}$ & $\begin{array}{l}0.31 \\
0.46 \\
0.35 \\
0.52 \\
0.63 \\
0.71\end{array}$ & \\
\hline Cronbach's $\alpha$ & 0.60 & & 0.66 & & 0.34 & & & & 0.85 & 0.43 \\
\hline $\begin{array}{l}\text { Mokkene } \\
\text { coeffcient } h= \\
\text { reliability rho= }\end{array}$ & $\begin{array}{l}0.38 \\
0.67\end{array}$ & $\begin{array}{r}0.47 \\
0.72\end{array}$ & & - & & & $\begin{array}{l}0.86 \\
0.94\end{array}$ & $\begin{array}{l}0.47 / 0 \\
0.61 / 0\end{array}$ & $\begin{array}{l}0.52 \\
0.69\end{array}$ & \\
\hline$n=$ & 52 & & 52 & & 39 & & 28 & & 52 & \\
\hline
\end{tabular}

- items less consistent with the domain $(p<0.05) \cdots$ Mokken analyses showed no substantive results in the domain of sexuality 
after any deletion, both in the professional's and in the patient's data. So we can conclude that our sample does not allow any further reduction of the items. When we look at the Mokken analysis, we observe that the coefficient $\mathrm{H}$ is not on all scales lower than we saw in the response from the professionals. Most of the scales do remain intact, except "social activities", which now clearly falls apart into two self-coherent subdimensions. The conclusion is that the response tendency is largely the same in both data sources, confirming our hypothesis on increasing difficulty of the items. With regard to the scale on social activities, we are not sure whether it represents one or two underlying traits. The Confirmatory Factor Analysis may provide more on this point. Finally, these results show that the items we selected for the domain of sexuality could not really be analyzed as scale. Regarding the formulation of the items in this domain, the only item with any discriminating value may perhaps be the item sexual practice. The items partner choice, having a partner and experienced problems in sexuality may actually be regarded as independent predictors, rather than dependent outcome variables. Though the items may have some clinical validity, they do not constitute a single trait.

\subsubsection{Position of sexuality within the theoretical construct}

In the previous paragraph we saw that the items in the domain of sexuality proved to be independent of each other and did not constitute a scale. When we look at the meaning of the items in more detail, we can see that three items - "partner choice" and "having a partner" and "problems in sexuality" actually may be regarded as independent rather than as a dependent variable ${ }^{19}$. The item "sexual practice" is the only item representing a level of functioning, as it is formulated as a ordinal scale (no activity to mutually consented activity). So we will have to know the extent to which this item is either dependent or independent from the sum scores of the other domains and the extent to which this item may be fitted as either a dependent or an independent variable in the final construct on social role performance. To test this we first determined the item - sumtotal correlation between this item and the sum scores of the various domains as well as with the sum score of the four other domains together. In Table 9.5 we present the results of these analyses.

Table 9.5 Pearson correlation between sexual practice and the sums of other domains

\begin{tabular}{l|cc}
\hline \multicolumn{1}{c|}{ sum scores } & professional & patient \\
\hline self-care & .07 & .08 \\
support & -.13 & .01 \\
daily obligations & .11 &. .04 \\
social activities & .25 & $.32^{*}$ \\
total instrumental score & .10 & .16 \\
total instrumental alpha after including the item "sexual practice" & .62 & .69 \\
\hline
\end{tabular}

significant correlate, $p<0.05$ 
The results show that, especially with respect to the judgment of the professionals, the item sexual practice is independent from the other domains, and independent from the total score. The data provided by the patients support this finding. The only significant correlation is with the domain "social activities". Consequently, we regard the domain to be independent of other domains and of the over-all score. We conclude that our construct of social role performance is not related to the item "sexual practice". We may, however, analyze these items at item level, but not as part of a scale construct. The extent to which having a partner and having made a partner choice, as well as experiencing sexual problems is related to good social role performance, is still an interesting question. Secondly, it remains important to know how little or how much the professional knows about the patient's difficulties in this domain. In the Chapters 10 and 11 we address this in greater detail.

\subsubsection{LISREL confirmatory factor analysis: defining the model}

After performing the internal consistency analyses, we turned to look at the independence of the different domains. LISREL analysis provides a tentative answer to this issue. In the definition of our LISREL model, we assumed that the items of the four domains "self-care", "support", "daily obligations" and "social activities" constituted coherent factors. A graphic representation is presented in figure 9.1 . The observed variables, the item scores, are given as squares. The latent factors $\left(\xi_{\mathrm{i}}\right)$ and the unique variances $(\delta)$ are presented as circles. The correlations between the factors are represented by $\left(\Phi_{i}\right)$, and the loadings of the items on the factors by $\left(\lambda_{i}\right)$. The correlations between the unique components of each item are given as $(\Theta i, j)$.

Figure 9.1 LISREL model of social role performance

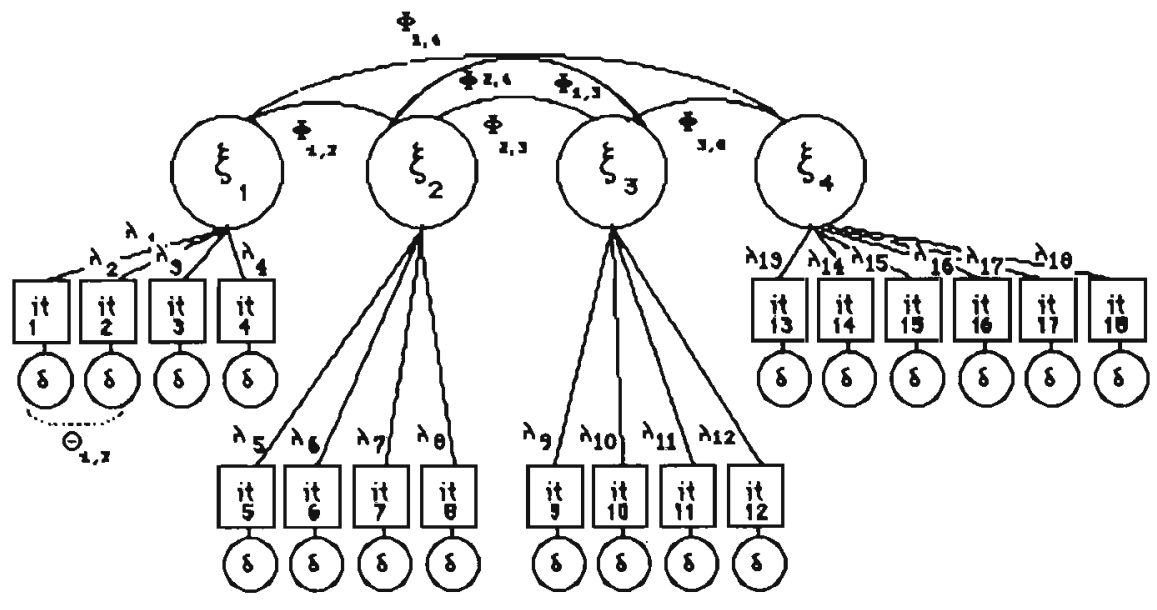


A simple check of the detailed correlation matrixes (appendix no VII), already shows that all items correlate more with the sumscore of their own domain than with other domains. Using LISREL we tested the assumption of one factor for each domain, that is four factors in total, with each item loading on one factor (a full representation of the model is presented in the appendix no VI, pp. 197). In addition, the correlations between these factors were estimated, in order to evaluate the (in) dependence between the four domains. Consequently, two constraints were imposed on the model. Firstly, we assumed that each item loaded on only one factor. Secondly, we assumed that each domain corresponded to one factor, thus no underlying trait determined all of the four domains. We did not assume the factors to be independent, as we are interested in the degree of their (in)dependence.

\subsubsection{LISREL confirmatory factor analysis: professional judgment}

We first did the analysis on the data obtained from the professional judgments (Table 9.6$)^{20}$, using the maximum likelihood method of estimation.

Table 9.6 The LISREL CFA using the maximum likelihood procedure with the data obtained from the professional's judgments

\begin{tabular}{|c|c|c|c|c|}
\hline $\begin{array}{l}\text { VARIABLE LABEL FACTOR LOADINGS } \\
\text { 1. clothing } \\
\text { 2. cleaning } \\
\text { 3. planning day } \\
\text { 4. planning week }\end{array}$ & $\begin{array}{l}\text { self-care } \\
0.18 \\
0.31 \\
0.31 \\
0.34\end{array}$ & support & daity obl. & socis \\
\hline $\begin{array}{l}\text { 5. practical support } \\
\text { 6. active personal } \\
\text { 7. problem solving } \\
\text { 8. conflict solving }\end{array}$ & & $\begin{array}{l}0.71 \\
0.64 \\
1.00 \\
0.89\end{array}$ & & \\
\hline $\begin{array}{l}\text { 9. finishing work } \\
\text { 10. dealing with colleagues } \\
\text { 11. dealing with superiors } \\
\text { 12. dealing with conflicts }\end{array}$ & & & $\begin{array}{l}0.19 \\
0.42 \\
0.40 \\
0.36\end{array}$ & \\
\hline $\begin{array}{l}\text { 13. boredom " } \\
\text { 14. passive pastime }{ }^{\infty} \\
\text { 15. active pastime } \\
\text { 16. task-oriented interaction } \\
\text { 17. person-oriented interaction } \\
\text { 18. mutual social interaction }\end{array}$ & & 0.19 & & $\begin{array}{l}0.19 \\
0.05 \\
0.13 \\
0.25 \\
0.34 \\
0.32\end{array}$ \\
\hline $\begin{array}{l}\text { Indicators of fit } \\
\text { 1. MAXIMUM MODIFICATION INDEX } \\
\text { 2. CHI SQUARE } \\
\text { 2. ADJUSTED GOODNESS OF FIT INDEX }\end{array}$ & & & & $\begin{array}{r}10.38 \\
162.27 \\
0.265\end{array}$ \\
\hline \multicolumn{2}{|c|}{ 3. \% NORMALIZED RESIDUAL COVARIANCE( $\Theta)$} & $\begin{array}{l}>1.0 \text { or }<-1.0= \\
>2.0 \text { or }<-2.0=\end{array}$ & & $\begin{array}{r}12 \% \\
2 \%\end{array}$ \\
\hline
\end{tabular}

"INVERSELY CODED “ RELAXED FAOM MODEL N.B.: noto that variable 14 loeds more on 'support" than on 'social activities".

The results show that the model does fit reasonably well providing a high coefficient of determination (consequently a reasonably low unexplained variance), as well as a low percentage of unexplained normalized residual 
covariance. This indicates that most items fit well into the model. However, the adjusted goodness of fit index is quite small, while the maximum modification index ${ }^{21}$ is high, indicating that the model is not completely perfect. With these data, LISREL analysis did not reject the structure we imposed after relaxing the item "passive solitary activities" from the model (i.e. $\lambda_{14,1} \neq 0, \lambda_{14,2} \neq 0 \& \lambda_{14,3} \neq 0$ ). The item subsequently loaded on the factor "support". This is not contrary to the theoretical construct since this item may be expected to be (inversely) coherent with items such as "practical support" and "active bonding".

\subsubsection{LISREL confirmatory factor analysis: patient's information}

The above model was roughly supported by the data provided by the patients (Table 9.7). When we look at the results in more detail, we can see that most of the loadings $\left(\lambda_{\mathrm{i}, \mathrm{j}}\right)$ are roughly the same as in the results of the professional judgment presented in table 9.6. A puzzling finding is that the item "boredom" shows a very low loading. The loading of the item "mutual social activities" to "self-care" indicates that we have to assume a link between these two domains.

Table 9.7

The LISREL CFA using the maximum likelihood procedure with the data obtained from patients

\begin{tabular}{|c|c|c|c|c|c|}
\hline $\begin{array}{l}\text { VARIABLE LABEL } \\
\text { 1. clothing } \\
\text { 2. cleaning } \\
\text { 3. planning day } \\
\text { 4. planning woek }\end{array}$ & FACTOR LOADINGS & $\begin{array}{l}\text { self care } \\
0.29 \\
0.29 \\
0.13 \\
0.15\end{array}$ & support & daily obl. & social act. \\
\hline $\begin{array}{l}\text { 5. practical support } \\
\text { 6. active bonding } \\
\text { 7. problem solving } \\
\text { 8. conflict solving }\end{array}$ & & & $\begin{array}{l}0.60 \\
0.34 \\
0.97 \\
0.89\end{array}$ & & \\
\hline $\begin{array}{l}\text { 9. finishing work } \\
\text { 10. dealing with coll } \\
\text { 11. dealing with sup } \\
\text { 12. dealing with con }\end{array}$ & $\begin{array}{l}\text { jues } \\
\text { ors } \\
\text { is }\end{array}$ & & & $\begin{array}{l}0.36 \\
0.42 \\
0.47 \\
0.42\end{array}$ & \\
\hline $\begin{array}{l}\text { 13. boredom " } \\
\text { 14. passive pastime } \\
\text { 15. active pastime }\end{array}$ & & & & & $\begin{array}{l}0.01 \\
0.08 \\
0.17\end{array}$ \\
\hline $\begin{array}{l}\text { 16. lask-oriented in } \\
\text { 17. person-oriented }\end{array}$ & eraction & & & 0.133 & $\begin{array}{l}0.31 \\
0.31\end{array}$ \\
\hline 18. mutual social int & ietion ${ }^{\infty}$ & 0.28 & & & 0.29 \\
\hline \multicolumn{6}{|c|}{ Indicators of fit } \\
\hline $\begin{array}{l}\text { 1. MAXIMUM MOD } \\
\text { 2. CHI SQUARE } \\
\text { 2. ADJ. GOODNES }\end{array}$ & $\begin{array}{l}\text { CATION INDEX } \\
\text { DF FIT INDEX }\end{array}$ & & & & $\begin{array}{r}9.83 \\
142.53 \\
0.35\end{array}$ \\
\hline \multicolumn{3}{|c|}{$3 . \%$ NORMALIZED RESIDUAL COVARIANCE $(\theta)$} & $\begin{array}{l}>1.0 \text { or }<-1.0= \\
>2.0 \text { or }<-2.0=\end{array}$ & & $\begin{array}{r}15 \% \\
3 \%\end{array}$ \\
\hline
\end{tabular}

- Inversely coded "a Relaxed trom the model 


\subsubsection{LISREL confirmatory factor analysis: correlation between factors}

In the definition of our model, we did not fix the dependency of the domains, as we were interested in their correlations. In Table 9.8 we present the correlations (i.e. the $\Phi$ estimates). The correlation estimates indicate substantially different interdependencies. A major difference is the greater interdependency in the professional's data, especially between the domain "social activities" and the other domains, but also between the domains "support" and "daily obligations". In the data of the patients the factor "support" correlates highly with the factor "self-care", while the two other factors appear to be reasonably independent.

Table 9.8

The LISREL Estimates of correlation between the factors $(\Phi)$ in the data provided by professionals and in the data provided by patients

DATA PROFESSIONALS

FACTOR 1 (SELF-CARE) FACTOR 2 (SUPPORT)

FACTOR 3 (DALY OBL)

FACTOR 4 (SOCIAL ACT.)
SELF-CARE

SUPPORT

DAILY OBL.

SOCIAL ACT.
0.25

0.20

0.61

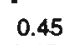

0.45

0.35

\section{DATA PATIENTS}

FACTOR 1 (SELF-CARE)

FACTOR 2 (SUPPORT)

FACTOR 3 (DAILY OBL.)

FACTOR 4 ( SOCIAL ACT.)

\subsection{7 \\ 0.03 \\ 0.20}

0.12

0.04
0.08

The $\chi^{2}$ statistics as well as inspection of the normalized residuals (= the unexplained inter-item covariance) show an acceptable fit of the four factor model, with the restriction of correlated factors, and after a few adjustments. The unexplained inter-item covariance for both data sources less than $15 \%$, the maximum modification of the $\chi^{2}$ by deletion of an item remains also less than $7 \%$. Four items, all in the domain of "social activities" needed an adjustment. We had to let the item "passive social activities" load on support (i.e. $\lambda_{14,2} \neq 0$ ) in the first model based on the professional judgments.

In the second model based on the patient's interviews, we had to let the items "task-oriented interaction" and "mutual interaction" load on "daily obligations" and "self-care" (i.e. $\lambda_{16,3}$ and $\lambda_{16,1 \neq 0}$ ). With these adjustments, only 6 items provide a modification index larger than $3.82(=\chi$ crit, DF $=1)$. With 127 , respectively 126 , fixed parameters, a $5 \%(=6.5)$ excess may be expected, so a type I error - i.e. an unjust confirmation of our hypothesis - is unlikely. In short, these results do support the model has reasonable fit. Thus, theoretically, it is unlikely that a larger sample would provide a completely different structure. 


\subsection{Discussion}

The present chapter described some analyses on the construct validity of the instrument. The main question was whether our assumptions on the division of the instrument into five domains could be supported empirically, and whether these domains were internally consistent. In the interpretation of the results in this chapter, we have to keep in mind that the often fairly harsh statistical restrictions of some procedures simply were not met by the data. Secondly, we have to keep in mind that we are dealing with a small sample size, containing a considerable number of missing values.

Concerning the internal consistency, we first looked at the percentage of positive scores. The results showed that the items indeed had different probabilities, i.e. that the difficulties of the items varied satisfactorily. The most important statistic measuring consistency is Cronbach's $\alpha$. The $\alpha$ varied from satisfactory to high, indicating that the items within a given domain were satisfactorily coherent. The domains proved to be reasonably reliable scales. Both analyses thereby support our a priori assumption that the items represent different levels of functioning. Especially the items in the domains "self-care", "support" and "daily obligations" proved to compose good scales. "Social activities" proved to be reasonably consistent. The domain of "sexuality" proved to be inconsistent. Its position in the construct was therefore investigated in greater detail. "Sexuality" proved to be independent of all other domains. In the theoretical construct the items in this domain may be regarded as discriminators between the chance to perform well or less well, rather than a measure representing a sub domain of social role performance. The domain was therefore discarded from further multivariate analyses.

We repeated all analyses on the patient's material as well. Some differences in consistency arose. With regard to the domains "self-care", "support" and "social activities", the patients provided somewhat less consistent responses. Especially in the domains "self-care" and "support" we might have expected this finding, as some of the questions require reflection on one's own behavior. It is well known that self-report data are biased, influenced by the mood of the day, by a not necessarily consistent self-concept, and - more specifically in the mentally ill - perhaps by a self awareness not fitting to the norm. Though the information the patients gave could indeed be analyzed as such, we do not yet know its accuracy. This is a question our data will never answer, as the only sources of information are either the patient or the professional, the comparison being always the outcome of a subjective judgment on arbitrary criteria, thus leaving the "true value" somewhere in the middle.

Although showing several minor inconsistencies, the LISREL analysis are indeed consistent with the four factorial model we postulated as a result of the internal consistency analyses. The finding that the correlations between some 
domains are of slight significance, does not oppose our assumption on dimensionality, because we may expect that an individual who performs well in one domain, also performs well in another domain. Furthermore, an inspection of the whole correlation matrix shows that all items always correlate more with their own domain than with the sumscores of other domains. In LISREL, a small sample size enhances the chance of a high goodness of fit, leaving some room for a type I error in respect of an unjust confirmation of our hypothesis. However, a fitting model is hard to get with few data, because of the multiple checks performed in the procedures computations. An opposing problem is the slant distribution of some items and sum scores, which enhances the chance of a type II error of an unjust rejection of our hypothesis. Summarizing, we may conclude that the LISREL analysis does not reject our assumptions, but that this finding needs support from future larger sample studies or multiple clinical trials on the feasibility of the instrument. In the other analyses the cases containing missing values in a specific domain were discarded. It would still be promising to find two relatively independent data sets fitting the same model.

\subsection{Summary}

The main conclusion of this chapter regarding further analysis is that the four factorial model was not rejected. It supported our assumption that the domains "self-care", "support", "daily obligations" and "social activities" are independent subdomains of a theoretical construct representing social role performance. The domain of "sexuality" proved to be independent. If we want to apply sum scores or use the instrument to differentiate between groups, this domain has to be left out of analysis. The remaining four domains proved to be satisfactorily coherent, as well as discriminative, as they provided a satisfactory to good Cronbach's $\alpha$. A minor adjustment has to be made in respect of the domain of "social activities", which perhaps consists of two separate sub dimensions. However, the evidence is not powerful enough to justify a major change of the construct.

The most important conclusion is that, using LISREL confirmatory factor analysis, most of our expectations on the construction of the instrument were not rejected by our data. We may safely conclude that the four domains selfcare, support, daily obligations and social activities consist of reliable and discriminating scales, representing a reasonably consistent measure of social role performance. Some items have to be looked at with scrutiny and need reconsideration, as they show very low correlations with the sumtotal of the domain. In further multivariate analysis in a follow-up study, we may have to consider discarding or replacing these items. 


\section{CHAPTER 10}

\section{Interjudge agreement}

In the previous two chapters we determined the items which could be interpreted in a reliable way and which fit into the theoretical construct of the Social Role Performance and Development Inventory. The present chapter deals with an entirely different aspect of instrumental utility, the value of the gathered information. It deals with intersubjectivity as an aspect of clinical validity: does the judgment of the professional represent aproximately the same information as the interviewer obtained from the patient? We looked at intersubjectivity not only to gather information on instrumental validity. Especially in the outpatient chronic mentally ill, the validity of the assessment of role performance is relevant (Anthony \& Liberman, 1986). As role strain and role conflict are an important source of social relapse it is in our view important to know the extent to which professionals agree with the patient's self report. Consequently, we are specifically interested in the differences and what they indicate, and not necessarily interested in perfect agreement. In which domains does the professional perhaps underestimate or overestimate the patients functioning? We know beforehand that we will find some differences, because we compare two essentially different viewpoints.

\subsection{Procedure}

We will present the comparison between:

a. The ratings on the open-ended questions in the patient's version of the instrument, and

b. the ratings on the precoded questions in the professional's version of the instrument.

The scores on the open-ended questions in the patient's version represent the judgment of the researchers based on factual information gathered from the patient and interpreted according to the manual. The scores on the precoded questions in the professional's version represent the professional's judgment. We made this comparison using the percentage of agreement and Pearson's correlation ( $r$ ), both fairly robust measures. The percentage of agreement investigates whether several judges respond in the same way. The correlation coefficient reflects the degree of agreement, correcting for coincidence. Both measures are presented, because theoretically a perfect correlation may occur even when there is a complete disagreement. We selected these two measures because they allowed us to compare our findings with other studies on the judgment of social behavior. Because the main body of literature on the judgment of social behavior or personality traits favors the use of Pearson's $r$ 
as a measure of interjudge agreement, we are able to compare our findings with a large body of literature on the interpretation and judgment of social behavior. Another more practical consideration concerns the skew of the items. A number of the items have an extreme positive or negative skew. This skew was built into the instrument because we wanted items of a varying difficulty in order to discriminate between groups. The Pearson correlation coefficient is a rather robust measure, which is less affected by an extreme skew.

On the level of the scales, we also compared the scores of the professionals with those of the independent raters, using Kendall's rank order coefficient, $\tau$ (Kendall, 1947). Kendall's $\tau$ was determined on the four coherent scales we constructed and discussed in Chapter 8 . Kendall's $\tau$ is a measure which investigates whether two raters follow the same order of positive responses within a scale or a number of independent variables.

The calculation of the power of the interjudge agreement is largely the same as the analysis on reproducibility of the ratings. Again, we are dealing with a critical effect size of 0.50 , a power of $90 \%$ and a level of significance of 0.05 , and data of two independent but related samples: the sample containing the patient's data and the sample containing the professional's data. As we observed in Chapter 8 , the minimum number of cases is approximately 25 .

\subsection{Expected differences}

In the presentation of the results, we will focus on several issues. Where do we see differences? Where do patients and professionals provide the same response tendency within the various scales? What do the differences indicate? Is there any tendency of the professionals to overestimate or underestimate as compared with the patients? As already discussed in Chapter 8, several factors influence the outcome of a comparison between different judges. In this study, we compare the judgment of a researcher based on (not necessarily coherent) information provided by the patient with a more distant view of the professional. In fact, two essentially different viewpoints are compared. The patient's point of view could perhaps be more accurate, but this point of view is influenced by the degree of self-awareness. The patient may tend to give socially desirable answers or skip difficult topics, merely by providing a positive answer. Some domains, as "sexuality", but also "social activities", concern private information the patient may be reluctant to discuss with a researcher who is a virtual stranger. Finally, this information can be influenced by the willingness of the patient open up to the interviewer. This depends on the degree of confidentiality the interviewer succeeds to establish in the interview: the research alliance.

The professional, on the other hand, may be not informed in detail or perhaps may never have discussed a certain topic. These factors may be expected to vary not only within the five domains of the instrument, but also in respect to 
the different groups of patients we investigated. We may expect the professional's knowledge to vary between the various selection groups, as the groups differ in respect to diagnosis, vocational status, dependency on care and presentation of demand. The older groups present mostly marital problems, or problems in their jobs, whereas the younger have problems of social integration, in obtaining either a job or a relationship and in home maintenance. So we may expect the professionals to be better informed on various areas of daily life in respect of the younger population than in the older. Finally, we may observe differences between men and women. As we know from the literature (Dohrenwerd et al., 1980), women in the chronic mentally ill population tend to function better than men. When we interpret the results, all these factors have to be kept in mind.

\subsection{Results}

\subsubsection{Interjudge agreement at group level}

Interjudge agreement was first determined with Pearson's $r$ and the percentage of agreement. The results of the comparisons on current role performance are presented in Table 10.1 (next page). We first present the percentage of agreement of each item. Then we present the correlations between patients and professionals on the items and on sumscores of the various domains. To determine the direction of the difference, we present the percentage positive responses on the various items in the different response groups. Concerning social behavior we may regard an interjudge agreement expressed in a Pearson correlation of less than 0.20 as poor, a correlation between 0.20 and 0.30 as moderate, between 0.30 to 0.40 as reasonable, and of more than 0.40 as good (Funder and Ozer, 1983). When we look at the results of the percentage of agreement, a percentage of $50 \%$ may be regarded as poor, a percentage of $60 \%$ as sufficient, and a percentage of more than $80 \%$ as good (again, Funder and Ozer, 1983).

As we are dealing with two totally different viewpoints - judgment and selfreport - we should expect a large variability in the correlations. Some of the judgments may be expected to diverge or even be contradictory, reflecting a disagreement in opinion (Evers, 1989). Taking the differences of perspective into account, a Pearson above 0.60 may even be regarded as suspiciously high. The majority of the correlations exceed 0.30 , and the overall mean is 0.38 , indicating a reasonable concurrence at group level. The correlations of the sum scores in the domains "self-care", "support" and "social activities" are good, and the correlation of the sum score in the domain of "daily obligations" is reasonable. If we take the patient's word for granted and use it as a starting point, we see a sufficient to good percentage of agreement in four of the five items in the domain of "self-care". In this domain the professionals overestimate the level of functioning of the patient in all but one item. In the domain of "support" this difference is less clear, though again a tendency of overestimation is observed. In the domain of "sexuality" the professionals 
Table 10.1 Interjudge agreement between professionals and researchers, determined with Pearson's r

\begin{tabular}{|c|c|c|c|c|c|}
\hline \multicolumn{2}{|c|}{$\%$ agreement } & \multirow{2}{*}{$\begin{array}{c}\text { Pearson } \\
0.62\end{array}$} & \multirow[t]{2}{*}{$\begin{array}{l}\text { frequencies } \\
\% \text { yes professional }\end{array}$} & \multirow{2}{*}{$\begin{array}{c}\text { Direction of" } \\
\text { the difference }\end{array}$} & \multirow{2}{*}{$\begin{array}{l}\text { frequencies } \\
\% \text { yes patient } \\
\text { - }\end{array}$} \\
\hline Self care & - & & & & \\
\hline neatness clothing & $78 \%$ & $0.49^{\circ}$ & $92 \%$ & $\Rightarrow$ & $77 \%$ \\
\hline cleaning & $75 \%$ & $0.49^{\circ}$ & $86 \%$ & $\Rightarrow$ & $73 \%$ \\
\hline planning day & $86 \%$ & $0.37^{\circ}$ & $75 \%$ & $\Rightarrow$ & $64 \%$ \\
\hline planning week & $48 \%$ & - & $82 \%$ & $\Rightarrow$ & $60 \%$ \\
\hline Support & - & $0.55^{-}$ & - & & - \\
\hline practical & $76 \%$ & $0.38^{\circ}$ & $76 \%$ & $\Rightarrow$ & $66 \%$ \\
\hline active bond & $69 \%$ & - & $70 \%$ & & $58 \%$ \\
\hline $\begin{array}{l}\text { problem-solving } \\
\text { conflict-solving }\end{array}$ & $\begin{array}{l}72 \% \\
92 \%\end{array}$ & $\begin{array}{l}0.35^{\circ} \\
0.55^{\circ}\end{array}$ & $\begin{array}{l}53 \% \\
53 \%\end{array}$ & $\Rightarrow$ & $\begin{array}{l}53 \% \\
58 \%\end{array}$ \\
\hline $\begin{array}{l}\text { Sexuality } \\
\text { partner choice } \\
\text { relationship }\end{array}$ & $\begin{array}{l}- \\
81 \% \\
86 \%\end{array}$ & $\begin{array}{l}- \\
0.42^{\infty} \\
0.54^{-\infty}\end{array}$ & $\begin{array}{l}- \\
89 \% \\
49 \%\end{array}$ & & $\begin{array}{l}- \\
81 \% \\
44 \%\end{array}$ \\
\hline sexual pract. & $0 \%$ & - & $34 \%$ & $\Leftarrow$ & $64 \%$ \\
\hline problems & $0 \%$ & - & $17 \%$ & $\Rightarrow$ & $40 \%$ \\
\hline Dally obligations & - & $0.36^{\circ}$ & - & & - \\
\hline work load & $88 \%$ & $0.56^{\circ 00}$ & $58 \%$ & $\Leftarrow$ & $73 \%$ \\
\hline dealing with colleagues & $76 \%$ & $0.39^{\bullet}$ & $63 \%$ & $\Leftarrow$ & $85 \%$ \\
\hline dealing with hierarchy & $65 \%$ & $0.29^{\prime}$ & $58 \%$ & $\Leftarrow$ & $74 \%$ \\
\hline dealing with conflict & $0 \%$ & - & $44 \%$ & $=$ & $64 \%$ \\
\hline $\begin{array}{l}\text { Social activities } \\
\text { boredom }\end{array}$ & $\overline{70 \%}$ & $\begin{array}{l}0.42^{\circ} \\
0.31^{\circ}\end{array}$ & $43 \%$ & & $49 \%$ \\
\hline passive pastime & $64 \%$ & - & $92 \%$ & $\Rightarrow$ & $78 \%$ \\
\hline active pastime & $71 \%$ & $0.28^{\circ}$ & $75 \%$ & $\Rightarrow$ & $69 \%$ \\
\hline task-oriented & $52 \%$ & - & $68 \%$ & $\Rightarrow$ & $31 \%$ \\
\hline person-oriented & $56 \%$ & - & $71 \%$ & $\Rightarrow$ & $29 \%$ \\
\hline mutual interest & $73 \%$ & $0.28^{\circ}$ & $69 \%$ & $\Rightarrow$ & $43 \%$ \\
\hline
\end{tabular}

Correlations not significant at a level of $p<0.05$ are left out; "sign., $p<0.05{ }^{*}$ sign., $p<0.01$, ${ }^{\infty}$ sign., $p<0.001$

- $\Leftrightarrow$ ) points in the direction of the lowest level of functioning, n.b: having more sexual problems is interpreted as a lower level of functioning. The figures in italics represent the correlation of the sumscores.

estimate the choice of partnership and the existence of a relationship quite accurately, but tend to know very little of how the patient deals with his or her "sexuality" or whether a patient experiences problems in this domain. In the domain of "daily obligations" the professional underestimates all items except "planning"22. In the domain of "social activities", we find, contrary to what we expected, a consequent overestimation. Important differences may be noticed on the items concerning the quality of the interaction with others. Inspection of the questionaires revealed that patients reported few interactions, and often 
could not provide a clear differentiation between task-oriented and personoriented interaction ${ }^{23}$.

\subsubsection{Interjudge agreement - response tendency}

We were not only interested whether the patients and professionals agreed at item level, but also whether they responded in the same way in respect of the scalable domains. To test this, we used Kendall's $\tau$ rank order coefficient.

Table 10.2 Tendency of response: interjudge agreement with Kendall's $\tau$

\begin{tabular}{l|c|c|c|c}
\hline & self care & support & daily obligations & social activities \\
\hline$n=$ & 51 & 41 & 29 & 51 \\
$\tau$ & 0.33 & 0.59 & 0.26 & 0.39 \\
sign. $(p=)$ & 0.001 & 0.000 & 0.01 & 0.001 \\
\hline
\end{tabular}

Kendall's $\tau$ tests if the rank order given by two different judges tends to point in the same direction. Kendall's $\tau$ may be between 0.0 and 1.0 , with 1.0 showing a perfect rank order agreement and 0.0 showing no agreement. Significance of the coefficient is related with Kendall's z-score to the sample size (Siegel, 1956). These results show that the agreement on a more global level is reasonable, which underlines the findings of the correlation of the sum scores and the items presented in Table 10.1. We may safely conclude that both patients and professionals give responses following a comparable order.

\subsubsection{Interjudge agreement - past performance}

We also looked at the correlations on past performance. In the investigation of past performance (for the operational definitions, Chapter 6, p. 84) we first attempted to compare the current level of functioning with the level of functioning at the onset of mental health care, at item level. We then discussed whether the subsequent level of functioning either deteriorated, stayed the same, or improved. The pattern of development was operationalized in three global codes. First, stagnation, meaning that the patient never functioned at a sufficient level. Second, relapse, meaning that the patient once functioned at a better level. Third, no dysfunction. Apart from this global rating, a more specific rating in six ordinal categories, varying from short relapse to stagnation at an insufficient level, was also given. Finally, we compared the information on the phase of life in which stagnation or relapse occurred. In the interview with the professional, we asked for a judgment of the pattern of development. In the interview with the patient the researcher made this judgment. Table 10.3 (next page) presents a summary of the results of these analyses. 


\begin{tabular}{|c|c|c|c|c|c|}
\hline Domain & self-care & support & sexuality & daily obligations & social activities \\
\hline $\begin{array}{l}\text { past performance (detailed) } \\
\text { item range } \\
\text { scale mean }\end{array}$ & $\begin{array}{l}0.25-0.42 \\
0.35\end{array}$ & $\begin{array}{l}0.29-0.48 \\
0.41\end{array}$ & $\begin{array}{l}0.36-0.41 \\
0.38\end{array}$ & $\begin{array}{l}0.47-0.68 \\
0.56\end{array}$ & $\begin{array}{l}0.31-0.43 \\
0.34\end{array}$ \\
\hline $\begin{array}{l}\text { past performance (global) } \\
\text { global pattern } \\
\text { of development } \\
\text { more specified pattern } \\
\text { of development } \\
\text { phase of life when the } \\
\text { first relapse occured }\end{array}$ & $\begin{array}{l}0.64 \\
0.05 \\
0.71\end{array}$ & $\begin{array}{l}0.68 \\
0.12 \\
0.78\end{array}$ & $\begin{array}{l}0.72 \\
0.21 \\
0.82\end{array}$ & $\begin{array}{l}0.66 \\
0.15 \\
0.76\end{array}$ & $\begin{array}{l}0.72 \\
0.28 \\
0.82\end{array}$ \\
\hline
\end{tabular}

- significance level of $p<0.05$ with a correlation of $<.30 ; p<0.01$, with a correlation of $<0.42$, otherwise, $p<0.001$

First we summarize the data by presenting the item range of the several correlations in the domains, then we present the global rating, the specific rating and finally the phase of life. This analysis shows that the item-level agreement between patients and professionals on past functioning is neither greater nor less than on current functioning. This confirms the findings in Chapter 8 , i.e. that information on the level of functioning around the onset of mental health care can be determined quite reliably. When categorized in three global codes, the agreement on the pattern of development was quite good. Categorization of the pattern of development into more specific categories proved to be highly unreliable. The estimation of the phase of life when a first relapse occurred (question format c.f. Häfner, 1985) also correlates very well when we compare the judgments on the various domains.

\subsubsection{Interjudge agreement - differences between young and old}

The fourth analysis we did in this respect was a comparison between the patients who were young at onset with those who were older. We wanted to know whether differences in what the professionals know about the patients could be detected. Table 10.4 presents some comparisons on current functioning. The same analyses were also carried out to compare men and women, though this comparison yields only minor differences. The results of these analyses were based on a small sample, and should merely be regarded as an indication of a response tendency, not as conclusive findings. When we look at these results, we see some important tendencies. First, there is an important difference in agreement in the domain of "self-care", the agreement being much higher on most of the items in the older patients. Sexuality shows the opposite. Now the agreement on the items "sexual practice" and "sexual problems" is quite good in the younger group. In the domains of "daily 
Table 10.4 Interjudge agreement between patients and professionals with

Pearsons r: differences between young and old patients.

\begin{tabular}{|c|c|c|c|c|c|c|c|c|c|c|}
\hline \multicolumn{2}{|c|}{$\begin{array}{l}\text { Domain } \\
\text { self care }\end{array}$} & support & \multicolumn{2}{|l|}{ sexuality } & \multicolumn{3}{|c|}{ daily obligations } & \multicolumn{3}{|c|}{ social activities } \\
\hline Groups & young old & young ald & young & ald & & young & ald & & young & old \\
\hline $\begin{array}{l}\text { dothing } \\
\text { doaning } \\
\text { phan day } \\
\text { plan long }\end{array}$ & $\begin{array}{l}0.44-0.78 m \\
0.56 m 0.72- \\
0.44-0.27 \\
0.14 \quad 0.42-\end{array}$ & 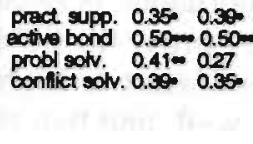 & $\begin{array}{ll}\text { choico } & 0.15 \\
\text { rolation } & 0.61- \\
\text { prection } & 0.420 \\
\text { problems } & 0.49\end{array}$ & $\begin{array}{l}0.37 \% \\
0.63 \\
0.21 \\
0.06\end{array}$ & $\begin{array}{l}\text { ability } \\
\text { work load } \\
\text { coll. } \\
\text { hiorerch. } \\
\text { conflict. }\end{array}$ & $\begin{array}{l}0.27 \\
0.45 \\
0.26 \\
0.10 \\
0.23\end{array}$ & $\begin{array}{l}0.600- \\
0.81- \\
0.21 \\
0.31 . \\
0.47-\end{array}$ & $\begin{array}{l}\text { bore } \\
\text { passive } \\
\text { active } \\
\text { beck or. } \\
\text { persom } \\
\text { mutuel }\end{array}$ & $\begin{array}{l}0.37 \% \\
0.310 \\
0.38 \\
0.12 \\
0.06 \\
0.08\end{array}$ & $\begin{array}{l}0.23 \\
0.20 \\
0.36 \\
0.420 \\
0.411 \\
0.41 \%\end{array}$ \\
\hline man* & 4.8 & 22 & - & - & & 3.1 & 4.1 & & 32 & 4.1 \\
\hline$n=$ & 25 & 32 & $\boldsymbol{2}$ & 12 & & 9 & 19 & & 32 & $\mathbf{z}$ \\
\hline
\end{tabular}

" these mean scores are based on the professional's judgment. - significance level of $p<0.05, \cdots p<0.01, \infty p<0.01$

obligations" and "social activities" we can again see better agreement between professionals and patients in the older patients.

\subsection{Discussion}

As we have stated in the introduction of this chapter, various factors have an effect on interjudge agreement. In this chapter we made an effort to disentangle the influence of the different factors. In the next part of this chapter we will discuss the results separately and relate our findings to comparable research in the field of judgment of social behavior.

\subsubsection{Interjudge agreement on group level}

Concerning the agreement between patients and professionals, the results on the interjudge agreement have to be interpreted with some caution. At first sight, the results on current functioning may seem very poor. Many test psychologists would not at all be impressed by the interjudge agreement presented in Table 10.1 Only four items yield agreement scores above .50 . Seven items yield non-significant agreement scores, lower than .28. When we look at comparable studies on judgment of social behavior, we find comparable correlations to the findings of our study. Funder and Ozer (1983) have shown how several of the most important well defined behavioral traits recorded from the literature of experimental social psychology yielded agreements between .30 and .40. Rosenthal and Rubin (1982) demonstrated mathematically that a correlation of .40 will lead to a correct dichotomous decision $70 \%$ of the time. Finally, Ozer (1985) claimed that the widespread practice of squaring correlations is inappropriate in the first place. According to Ozer's analysis, when two judgments on social behavior are considered to represent the same views, a correlation between them of .40 means that the variable accounts for $40 \%$, not $16 \%$ of their total variance (also cf. Tryon, 1929). So we may conclude that though the results may seem low at first sight, 
they are quite similar to the results we find in other studies on judgment of social behavior.

\subsubsection{Interjudge agreement - response tendencies}

When the data are analyzed in a global way, for example by determining the correlation between sum scores on the composite scales of the instrument or by determination of Kendall's coefficient of concordance between two judges, the results are quite promising. All correlations prove to be either high or satisfactory and Kendall's $\tau$ is over all scales significant to highly significant. This indicates that the sum score correlates quite well, and that the direction of the response tendency is also similar.

\subsubsection{Interjudge agreement - retrospective information}

Regarding the retrospective data on item level, we may also conclude that on a global level the agreement is better than on item level. However, a comparison of past performance on item level has little clinical relevance. For the evaluation of the current possibilities, it is interesting to know if the patient once functioned on a higher level, how long ago and also in which context deterioration took place. The details of functioning at onset are of less importance and served in our instrument as a means to stimulate discussion on the pattern of deterioration, not as information as such. A global judgment on the phase of life when the first relapse occurred, and on the pattern of deterioration, is far more relevant. These variables yield promising correlations. A major conclusion is that when a global judgment is asked, the agreement is good, but when we look at the details the agreement turns sour. So, concerning the data we are interested in, the agreement is quite good.

\subsubsection{Interjudge agreement - determination of agreement by specific response group}

The last question we looked at was whether the professional was better informed of the role performance in a specific selection group, since different groups present different problems. Knowledge on role performance differed in all domains except "support". The professional agreed very well with the patient on the domain of "self-care" in the group of older patients, while this was not so in the younger patients. This may be due to the fact that the older patients do not show many problems in this domain, and consensus on the absence of problems is likely. An interesting point is the fact that the professionals knew little of the sexuality of the older patients, while they were well informed on the sexuality of the younger patients. Sexuality does not seem to be a topic in the care of the older patients in our population. Literature and current experience in mental health care indicates that it is more important in the younger patients. In our response group, sexual problems were either related to development of sexual identity (five respondents), or related to incestuous experiences (four respondents). The low agreements on the domain of "daily obligations" in the younger group is an effect of the very small 
degree to which this domain is applicable to young patients. In the older group, for which the domain is more applicable, we can see that the agreement is quite good, especially on the first three (objectively observable) items, respectively "technical ability", "work load" and "planning of work". In the domain of "social activities", again the professionals know more about the older patients. When we look at the number of social contacts (also Chapter 12 ), we shall see that the younger patients in our sample have more contacts, but predominantly in the sector non-kin, and mostly either acqaintances or people they know in a specific setting. The older patients have a smaller but more dense social network, with more "real friends" and more contacts in the sector kin. Consequently, the information the professional has on older patients concerns fewer people, but will be more accurate.

\subsubsection{Current literature on judgment of social behavior}

Measurement of social behavior has an implicit uncertainty due to the subjectivity of the required information. In measurement of social judgment by informers several confounding factors have to be taken into respect (Bem \& Allen, 1974; Bem \& Funder, 1978). First, what does the judge observe? Second, how is this translated in a judgment, and what is the degree of subjectivity required in that process? Judgment of behavior is always related to norms and subjective. Even if a meticulous coding instruction is provided, and the items crystal clear, the appraisal of the behavior is dependent on the self-awareness and sensitivity of the judge. A third factor is the degree of interpretation required for the coding of the different items.

Funder and Dobroth (1987) found that assessment on judgment of behavior is dependent on the easiness of the trait, reflected by the subjective visibility of the trait. Epstein (1979) distinguishes two major types of items in behavioral assessment. First the subjective, in the sense that they are descriptions of inner states, and second the objective in the sense they can be observed by an external observer. In social behavior each trait bears a certain degree of subjectivity and objectivity, whereas only the objective part may be operationalized. Epstein found a median correlation of self versus others' judgment of 0.44 on traits reflecting self recorded behavior, which also could be externally observed, but a median of only 0.27 on traits reflecting inner states.

This distinction is also relevant for our data. Some items rate directly observable behavior, as e.g. "neatness on clothing". Others rate behavior requiring a great deal of interpretation or a large extent of knowledge about the daily life of the patient. Especially on items in the domains "social activities" and "daily obligations" many case managers run short on information. In the domains "support" and "sexuality" many of the items have to be inferred rather than observed. So when we look at the comparions presented in the current Chapter, we have relate these to the content of the information at a case report level. What do we expect that the professionals 
know of a specific behavior in daily life. What should we expect the professionals to know, for example of the development. To what extent do we expect the patients to provide accurate information. To which extent can the information be interpreted. These response and case related factors have an important effect on the level of detail of the information gathered in the interview and consequently deminish reliability and validity of the data.

\subsection{Summary}

With all these restrictions in mind, and against a background of contemporary research on social judgment the results on interjudge agreement may be regarded fairly promising. The results show that the correlations presented here are comparable to results obtained from research in the field of judgement of social behavior. Most of these findings concern the judgement of two judges applying well defined and specific and detailed criteria in their judgement of behavior. In the current study the data concern the judgement of a researcher using information obtained from patients with the judgement of the professional. The judgement of the professional is not based on direct information obtained from patients but on what the professional knows of the patient. Several uncertainties, both on behalf of the patient and on behalf of the professional determine the degree of correlation.

Self awareness, social desirability and the research alliance may influence the accuracy of the data obtained from the patients. The professional, on the other hand, may be not informed in detail or perhaps may never have discussed a certain topic. We may expect the professional's knowledge to vary from patient to patient, the patients differ in respect to diagnosis, vocational status, dependency on care and presentation of demand, and subsequently the level of knowledge of the professional may differ with respect to the various domains. Despite these limitations the correlations are reasonably comparible to findings in contemporary research. It is especially important to notice the good correlations with respect to the global pattern of relapse and the phase of life when the first relapse occured. These results confirm recent notions in literature, that retrospective information can be be quite reliable when it is focused on specific behavior at a specific period of time in the past, which is easy to recollect. Periods of time such as the weeks before first admission to care or the weeks after a specific important "change point" or "life event". However, despite these promising findings, for definite conclusions on the clinical validity, a far much larger sample has to be investigated. Future investigations will be directed on the development of an instrument which can be applied by less highly professionalized and trained mental health care workers. 


\section{PART 4}

\section{Aspects of validity}

The fourth part of this book contains four chapters on several aspects of the validity of the instrument. Chapter 11 relates the social role performance to the impact of mental illness in daily life. The Sickness Impact Profile is introduced as an external criterion. Chapter 12 describes the differences in role performance between the groups defined in Chapter 7, using simple descriptive statistics. Chapter 13 contains an extensive description of the various profiles of the patients we studied at a case report level. It focuses on the practical value and the clinical validity of the instrument in the daily practice of mental health care. Chapter 14 investigates the discriminatory validity. This chapter briefly compares patients with controls matched by age and social position.

Quick readers may skip Chapter 11 and 12 but shouldn't skip much of the last two chapters, as these deal more extensively with the practical use of the instrument and with the implications of what we measure. 


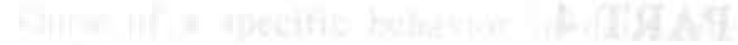




\section{CHAPTER 11}

\section{Concurrent validity}

In this chapter we will present some results on the concurrent validity of our instrument. We used the Dutch version of the Sickness Impact Profile (Luttik et al., 1985) to determine whether the whole instrument and the domains within the Social Role Performance and Development Inventory correlates with related domains measuring comparable traits from a different point of view. In this study we want to know whether the scores we constructed are indeed related to the daily functioning of the chronic mentally ill. Is the measure we constructed sensitive enough to measure differences easily found in another more differentiated instrument? In the previous chapters, we discussed the primary analyses on reliability and validity of the instrument. The present chapter deals initially with the question of what the measure implies in terms of experienced disability.

\subsection{Procedure}

\subsubsection{The issue of concurrent validity}

Concurrent validity is established by prediction of a measure by an external criterion (Merrit, 1966). Concurrent validity is one of several kinds of predictive validity (De Groot, 1975). In the assessment of concurrent validity, the researchers chose a more extensive and detailed instrument (or a number of instruments) as an external criterion. The researcher then establishes whether the measured scores of the instrument under investigation represent different levels of performance as measured by the external criterion. Therefore, the external criterion has to be a validated measure of the phenomenon to be explained. Concurrent validity is established when high scores on one instrument are related to high scores on another instrument. Here, the concurrent validity was determined by means of the Spearman rank order correlation (Spearman, 1910). The Spearman rank order correlation measures the association between two ordinal scales and investigates whether a high score on one scale is related to a high score on another scale. An advantage of the Spearman rank order correlation is that it accepts nonnormal distributions in the scores under investigation. In the comparison, we used the data obtained from the patients, so the method of investigation was the same.

\subsubsection{External criterion}

To determine the concurrent validity of our instrument we used the Sickness Impact Profile, a health status measure developed by Bergner (Carter et al, 
1981, Bergner et al., 1976). The Sickness Impact Profile is an extensively validated instrument which measures the impact of mental or physical disability on social functioning (De Bruin et al., 1992). The Sickness Impact Profile was conceived as a behaviorally based measure of health status. It is a self-report questionnaire, that measures changes in behavior and activities which, according to the respondent, are related to his health. The patient is asked to respond only to those statements to which he is sure that they describe his behavior at the moment of the interview, and which are also related to his state of health. In other words, it measures the consequences of disease or disability on daily activities and behavior. The Sickness Impact Profile is composed of 136 items in 12 categories of activities in daily life. Three of these categories consititute a physical subscore. Four others consititute a psychosocial subscore. Concerning the rank order correlation, we may expect our instruments sumtotal to be inversely related to the psychosocial score on the Sickness Impact Profile. In Table 11.1 (opposite page), we indicate the various domains.

We chose to use the Sickness Impact Profile for concurrent validation for two reasons. The first is that we needed an instrument that can be used for patients with different diagnoses and that specifically measures distinctions from a normal baseline. In the Sickness Impact Profile, this distinction from baseline is made by the patient: he indicates whether a specific behavior is affected by mental or physical health. The Sickness Impact Profile was furthermore explicitly developed for use with different groups and kinds of patients. Most instruments measuring social functioning are very detailed observational scales specifically related to diagnostic categories. Others do not measure behavior on an item level, but indicate disabilities on an aggregate level, as for example the Disability Assessment Scale or its Dutch offspring, the Groningen Social Disability Schedule (GSB, Wiersma et al., 1988).

The second reason is that there is a lot of experience with this instrument in different areas of research, and thus validity and reliability are well tested and described. Results on validity and reliability are positive (Bergner et al., 1981; Bergner \& Gilson, 1981; Pollard et al., 1976; Gilson et al., 1979; Carter et al., 1976; Deyo et al., 1983; De Bruin et al., 1992). The instrument was also validated recently in a psychiatric population with severe disorders (Brooks, 1990). An important difference with our instrument which we have to keep in mind is that the Sickness Impact Profile does not measure actual performance. It measures effects of the illness experienced in daily life. It relates disabilities to what the patients themselves experience as effects of their illness. When they did not show a specific behavior before onset of illness, this remains unobserved. So, when a patient experiences few changes after the onset of mental illness, the score may be low despite major handicaps in social role performance. This also indicates the most important difference between the two instruments. In the Sickness Impact Profile, a high score indicates many limitations, whereas a low score indicates few. In our instrument, a high score 
Table 11.1 Composition of The Sickness Impact Profile related to the domains of social role performance

\begin{tabular}{|c|c|c|c|}
\hline Domains & Dimension & \multirow{2}{*}{$\begin{array}{l}\text { Examples of questions in the } \\
\text { Sickness Impact Profile } \\
\text { - I sit during much of the day } \\
\text { - I sleep less at night for example, wake up too early, } \\
\text { don't fall asleep for a long time, awaken frequently }\end{array}$} & \multirow{2}{*}{$\begin{array}{l}\text { Comparable } \\
\text { domain } \\
\text { of role } \\
\text { performance }\end{array}$} \\
\hline $\begin{array}{l}\text { 1. Sleep and resting } \\
\text { (7 items) }\end{array}$ & - & & \\
\hline $\begin{array}{l}\text { 2. Emotional behavior } \\
\text { ( } 9 \text { items) }\end{array}$ & psy & $\begin{array}{l}\text { - I say how bad and useless I am, for example } \\
\text { that I am a burden for others } \\
\text { - I'm irritated and impatient with myself, for example } \\
\text { talk badly about myself, swear at myself, blame } \\
\text { myself for things that happen }\end{array}$ & support \\
\hline $\begin{array}{l}\text { 3. Body care and } \\
\text { movement } \\
\text { (23 items) }\end{array}$ & phy & $\begin{array}{l}\text { - I am clumsy in my movements and actions } \\
\text { - I dress myself, but very slowly } \\
\text { - I spend most of the time partly dressed or in pyjamas }\end{array}$ & self-care \\
\hline 4. Home management & - & $\begin{array}{l}\text { - I am not doing any of the regular daily work around } \\
\text { the house that I would usually do } \\
\text { - I am not doing any of the house-cleaning that I would } \\
\text { usually do } \\
\text { - I am not doing any of the clothes-washing that I } \\
\text { would usually do }\end{array}$ & self-care \\
\hline $\begin{array}{l}\text { 5. Mobility } \\
\text { (23 items) }\end{array}$ & phy & $\begin{array}{l}\text { - I stay away from home only for brief periods of time } \\
\text { - I stay home most of the time }\end{array}$ & social activities \\
\hline $\begin{array}{l}\text { 6. Social interaction } \\
\text { (20 items) }\end{array}$ & psy & $\begin{array}{l}\text { - I am going out less to visit people } \\
\text { - I am avoiding social visits from others } \\
\text { - I stay alone much of the time }\end{array}$ & social activities \\
\hline $\begin{array}{l}\text { 7. Ambulation } \\
\text { (12 items) }\end{array}$ & phy & $\begin{array}{l}\text { I do not walk at all } \\
\text { - I walk more slowty }\end{array}$ & none specifically \\
\hline $\begin{array}{l}\text { 8. Alertness behavior } \\
\text { (10 items) }\end{array}$ & psy & $\begin{array}{l}\text { - I have difliculty reasoning and solving problems, for } \\
\text { example making plans, making decisions, leaming } \\
\text { new things } \\
\text { - I react slowly to things that are said and done }\end{array}$ & support \\
\hline $\begin{array}{l}\text { 9. Communication } \\
\text { (9 items) }\end{array}$ & psy & $\begin{array}{l}\text { - I am having trouble writing or typing } \\
\text { - I have difficulty speaking, for example, get stuck, } \\
\text { stutter, stammer, slur my words }\end{array}$ & social activities \\
\hline $\begin{array}{l}\text { 10. Work } \\
\text { (9 items) }\end{array}$ & - & $\begin{array}{l}\text { - I am not working at all } \\
\text { - I am working at my usual job with some changes, for } \\
\text { example, using different tools or special aids, } \\
\text { trading some tasks with other workers }\end{array}$ & daiły obligations \\
\hline $\begin{array}{l}\text { 11. Recreation and pastime } \\
\text { ( } 8 \text { items) }\end{array}$ & - & $\begin{array}{l}\text { - I am going out for entertainment less often } \\
\text { - I have more inactive pastimes in } \\
\text { place of my usual activities }\end{array}$ & social activities \\
\hline $\begin{array}{l}\text { 12. Eating } \\
\text { (9 items) }\end{array}$ & $\cdot$ & $\begin{array}{l}\text { - I am eating much less regularty than usual } \\
\text { - I eat with repulsion, just pick or nibble at } \\
\text { my food }\end{array}$ & self-care \\
\hline
\end{tabular}

phy= physical domain / psy = psychosocial domain

implies few limitations. Thus we may expect specific dimensions of the Sickness Impact Profile to be inversely related to specific dimensions of our instrument. Second, we may expect the variance within the large number of dimensions of the S.I.P. to be too low, so we will need to aggregate a number of dimensions before comparing them with the S.R.P.D.I. 


\subsubsection{Comparisons and expectations}

Various correlations were computed. Overall scale correlations were determined by comparing the sum of our instrument with the sum of the psychosocial dimension, the somatic dimension and with the overall sum of the S.I.P. The different domains of our instrument were compared with a number of corresponding categories of the S.I.P. For the purpose of the comparison, we first aggregated a number of the above domains, which we may expect to be related to specific domains in our instrument. Self is an aggregation of "body care" and "movement", "home management" and "eating". Interpersonal functioning is an aggregation of "emotional behavior" and "alertness social interactions". Outward functioning is an aggregation of "social interactions", "mobility", "communication", and "recreation and pastime". Aggregation was performed using the weighed scores proposed by Bergner et al. and computing the aggregated totals on a numer of categories whithin the S.I.P. We performed this kind of aggregation because the scores on the different sub-domains of the S.I.P. provided too low frequencies to allow any comparison with other measures. Consequently, we compared the domain of "self-care" within our own instrument with the categories body care and movement, home management and eating within the Sickness Impact Profile. The domain of "support" was related to the sum of the categories emotional behavior and alertness. The domain of "daily obligations" was related to the category work. The domain social activities, finally, was related to the sum of the categories social interactions, mobility, communication, and recreation and pastime.

\subsection{Important questions}

The Sickness Impact Profile is developed to measure effects of illness on the daily life of the mentally and physically ill. A significant correlation between aspects of "self-care", "support" or social activities with aspects of "self-care", "support" or social activities represented in the Sickness Impact Profile provide a confirmation of the validity of the different categories in our instrument. Observable disabilities may then be proven to be related to experienced disabilities. Questions related to this issue are:

1. To what extent are the scores in our sample comparable with other research populations and perhaps normals?

2. Does a high score on an aggregation of categories within the Sickness Impact Profile correlate with a high score on a comparable domain of social role performance?

In the presentation of the results, we will first present some results on the sumscores of the Sickness Impact Profile within our population. Then we will relate the domains of our instrument to a number of aggregates of the Sickness Impact Profile. 


\subsection{Results}

\subsubsection{Frequencies - sensitivity of the Sickness Impact Profile}

In Table 11.2 we present some frequencies within our population and compare these with frequencies in a population of chronic physically ill and a normal group with and without minor ailments, to illustrate the variability within our population.

Table 11.2 Frequencies of the SIP, a comparison between various samples, using the weighed scores

\begin{tabular}{l|l|l|ll}
\hline Domains & $\begin{array}{c}\text { Sample } \\
(\mathrm{n}=56)\end{array}$ & $\begin{array}{l}\text { Rheumatoid } \\
\text { Disorders(n=377) }\end{array}$ & $\begin{array}{c}\text { NORMALS } \\
\text { no compl.(n=239) }\end{array}$ & compl.(n=349) \\
\hline sleeping & $18.1^{\circ}$ & $18.5^{\circ}$ & 1.0 & 7.3 \\
emotional behavior & $36.5^{\circ}$ & $12.9^{\circ}$ & 0.9 & 6.1 \\
body care \& movement & 4.2 & $16.2^{\circ}$ & 0.2 & 3.0 \\
house management & 15.6 & $33.6^{\circ}$ & 0.2 & 8.0 \\
mobility & $15.3^{\circ}$ & $16.5^{\circ}$ & 0.4 & 3.8 \\
social interaction & $19.2^{\circ}$ & $11.3^{\circ}$ & 1.1 & 6.0 \\
ambulation & 1.9 & $24.0^{\circ}$ & 0.2 & 4.9 \\
alertness behavior & $26.7^{\circ}$ & 12.9 & 0.9 & 7.2 \\
communication & $11.4^{\circ}$ & $8.4^{\circ}$ & 0.4 & 1.5 \\
recreation and pastime & $20.7^{\circ}$ & $24.4^{\circ}$ & 2.2 & 11.4 \\
eating & 4.8 & 3.6 & 0.4 & 1.5 \\
physical & 5.5 & $18.1^{\circ}$ & 0.8 & 5.2 \\
psychosocial & $22.6^{\circ}$ & $11.4^{\circ}$ & 0.3 & 3.9 \\
Total & $13.3^{\circ}$ & $14.6^{\circ}$ & 0.9 & 5.9 \\
\hline
\end{tabular}

- significant difference, $p<0.001$, oneway analysis of variance between normals with complaints and the chronic (mentally) ill. Work is not presented, as it was not assessed in the Normals or the Rheumatoid patients.

These results show that the Sickness Impact Profile is sensitive enough to measure differences in the population we studied. In our sample, disabilities may be noticed predominately in the domains covering experienced psychosocial disabilities. The total of experienced disabilities is comparable to the chronic physically ill ${ }^{24}$.

\subsubsection{Concurrent validity - comparison with the Sickness Impact Profile}

In Table 11.3.we present the results on the comparison between the aggregated categories in the Sickness Impact Profile and an inverse of the sums on Social Role Performance. These results show that the experienced disabilities correlate reasonably well with the related domains of Social Role Performance, indicating that the scores on Social Role Performance reflect different levels of social functioning as measured by an instrument developed 
Table 11.3 The Spearman rank order correlation coefficients between the aggregated categories of the Sickness Impact Profile and the Social Role Performance and Development Inventory

\begin{tabular}{l|cccc|c}
\hline \multicolumn{1}{c|}{$\begin{array}{l}\text { SRPDI Dornains } \\
\text { SIP categories }\end{array}$} & self care & support & daily obligations & social activities & role performance \\
\hline solf & & & & & \\
interpersonal functioning & $0.31^{\circ}$ & 0.08 & 0.24 & 0.26 & $0.42^{-}$ \\
work & 0.21 & $0.37^{\circ}$ & 0.11 & 0.33 & $0.29^{\circ}$ \\
outward functioning & -0.01 & -0.13 & $0.33^{\circ}$ & -0.12 & 0.01 \\
somatic & 0.21 & 0.14 & 0.23 & $0.38^{\circ}$ & 0.10 \\
psychosocial & 0.13 & 0.07 & 0.04 & 0.32 & $0.39^{\circ}$ \\
total & $0.36^{\circ}$ & $0.36^{\circ}$ & 0.19 & 0.20 & $0.32^{\circ}$ \\
\hline
\end{tabular}

esignilicant, $p<0.05$; esignificant, $p<0.001$, two-tailed, for a sample size of $n=40$ (Siegel, 1956).

to measure the effect of illness on daily activities. It is also important to notice that the domain of "daily obligations" is not related to the total score of the S.I.P., but is indeed related to the category work in the S.I.P.

\subsection{Summary}

This chapter dealt with a single aspect of validity, concurrent validity. Concurrent validity is related to the question of whether a measure correlates well with a valid and thoroughly validated external criterion, the Sickness Impact Profile. Extensive literature confirms the validity of the external criterion. Our data confirm that it is a valid instrument sensitive enough to measure health deviation in our population. The results presented in this chapter show that the behavior in terms of role performance reported by the patients reflects their experience of impairments measured by the S.I.P. quite well. The data presented in the current chapter show a reasonable indication of concurrent validity of our instrument with the S.I.P. This indicates that the level of role perfromance is related to the level of experienced impairments in daily life. It also indicates that the distinction of role performance domains in our instrument is confirmed by an external criterion, because the different domains are only related to comparible domains in the S.I.P. 


\section{Differences between groups}

This chapter deals with the discriminative power of the instrument as a whole. Does the instrument sufficiently discriminate between different groups? In short, is it suitable for the purpose we developed it for? Contrary to the previous chapters we will not only look at the development of Social Role Performance, but also pay attention to the degree of social integration, as expressed by the variability of the position roles and the composition of the social network.

\subsection{Procedure}

In this chapter our main focus is on the differences between the four homogeneous groups we selected. A power analysis proved that the four selection groups we identified in Chapter 7 were too small for the analyses we wanted to perform in the current chapter. At least twenty cases in each group are necessary. We solved this problem by performing the analyses on two-bytwo combinations of the selection groups devided into several contrast groups. For example we compared the men with the women, the young at onset with the older at onset, the patients with and without a relationship, and finally the patients with many or fewer experienced discrepancies in the fullfillment of their position roles. The composition of these contrast groups is related to the main hypothesis of the thesis we formulated in Chapters 5 and 6: that current role performance is related to age, sex and marital status at onset of mental illness. All comparisons were performed on both the professional judgments and the patient's interviews. The analyses in this chapter are on an aggregate level. To compute the sums of the various domains, we use the factors we constructed in Chapter 9 by means of the LISREL analysis. We compared the groups not only on the social role performance in the four domains "selfcare", "support", "daily obligations" and "social activities", as we did in former chapters, but also on such variables as the number of social contacts in the sectors of the social network (Baars, 1991) and the number of position roles, as these variables are strongly related to social role performance (Janssen, 1992).

We will compare the different groups using simple descriptive statistics and univariate comparisons. Two tests were used to evaluate the differences. With the Student t-test we compared the differences in the mean number of social contacts in the different sectors of the social network, as well as the number of status and position roles. The Mann-Whitney U non-parametric statistic was used to compare the scores on the four scales as well as the total score of the instrument. 
The results of the above statistics may only be evaluated as indicative in respect of the discriminative power of the instrument. We may not regard the outcome of these comparisons as indicative for characteristics of the population, as the possibility of a type one error becomes very likely in repetitive comparisons ${ }^{25}$. Due to the small groups, even in the two-by-two comparison, the risk of a type II error remains significant. A final limitation concerns the large number of missing values in some of the domains of role performance, which varied from 5\% in the domain of "self-care" to $23 \%$ in the domain of "daily obligations" (also \$9.2.1). The univariate comparisons presented here are performed on reduced data, after exclusion of the missing values. However, the results can give a good indication of the discriminative power of the instrument as a whole.

The first contrast compares the men with the women. From the findings of the several pilots (Romme et al., 1987), we may expect women to function on a higher level in a domain such as "self care" or "support", while the men perhaps should function on a higher level in the domains "daily obligations" and "social activities". The women are expected to fulfill fewer social roles, and have fewer social contacts, as their social context is usually smaller (Dohrenwerd et al., 1980). The second pair of contrast groups compares the unmarried patients who had an early onset of mental illness with the married patients who had a later onset of mental illness. Now we may expect more differences to arise. In Chapter 7 , we saw that the younger group consisted predominately of patients with either personality or psychotic disorders, who are known to be socially isolated. The older group consisted predominately of patients with major depressive disorders, often accompanied by problems at work or at home. This group was socially less isolated. Consequently, we may expect the younger group to have somewhat lower scores in the domains "selfcare", "support" and "social activities".

The third comparison is between the patients with and without a current relationship. Partnership is a major factor in the prevention of dependency on mental health care. Several studies (Dohrenwerd \& Dohrenwerd, 1969; Gove \& Tudor, 1974; Nadelson, 1983) stress the impact of support by an intimate partner on the prognosis of mental illness. So, we may expect patients with a relationship to perform better in most domains. The fourth and final comparison relates the dependent variables in this study, the Social Role Performance, with the achieved status and position roles. This last comparison is not only interesting from a scientific point of view, but also provides an indication of what may be relevant to focus on in the daily practice of rehabilitation of the chronic mentally ill.

With a $p<0.05$, and with 20 repetitive analyses, the probability of a type one error may approach 1 ! The only solution is to set the probability level as low as 0.0025 , but this bears a much greater risk of a type Il error. 


\subsection{Assumptions on outcome and important questions.}

In the present chapter we are interested in whether the instrument measures differences, and whether the differences we expect are confirmed, proving the instrument to be adequately sensitive. On the level of the role performance domains we may expect a number of differences. In the interpretation of the findings we will have to keep the specific characteristics of the sample in mind, as discussed in Chapters 3 and 7 . At this point, we will recapitulate the findings which may influence the interpretation of the data in this chapter.

Composition of the groups. In the sample, a specific selective bias is caused by the choice of the four homogeneous groups. In the whole sample, the young and unmarried at onset are especially overrepresented $(n=36$, vs. $n=20)$. The young and unmarried at onset includes most of the schizophrenics, who mostly have a longer history of mental health care. Men and women. In respect to the difference between men and women, we know that relatively more men have a job, but also that many of them are incapacitated or jobless. Many of the women are housewives. In the sample, many of the men are unmarried, while the women are often divorced. Young versus older chronics. In respect to the differences between the young and unmarried at onset and the older and married at onset patients we know that the former have many problems in social adjustment, and that they are more often either jobless or incapacitated, despite better professional training. The schizophrenics predominate in the younger group, while the older group more often suffers from depressions, anxiety or other neurotic disorders. The social inhibitions of schizophrenics (v.d. Bosch, 1982; Strauss \& Carpenter, 1974) will certainly influence this comparison. Relationship. This factor may be expected to have an effect on social support and to a certain extent on the social activities (Heller et al., 1983). People with a relationship may be expected to have fewer outward activities and less variation in their social contacts (Ivan Nye, 1976), perhaps leading to a lower score in this domain. However, the quality and stability of their social contacts should be better (again, Nye, 1976). The number of social contacts and social roles may, however, be less. Discrepancies. In Chapter 4, we stated that the achieved social position, represented by the status and position roles an individual fulfills, may be regarded as an outcome of the development of social role performance throughout the patient's lifetime. Patients with many discrepancies between what may be expected and what they have achieved, will also have many limitations in their Social Role Performance ${ }^{26}$. We may expect the groups with many discrepancies to score lower in all domains of Social Role Performance. How the number of discrepancies is related to the number of social roles is something we can not conclude from these data. Fulfillment of more roles may provide due to increased probability a larger number of discrepancies. On the other hand, example, when a patient experienced many problems in living up to the expectations of the direct environment, and had few status and position roles, the patient was labeled as a low performer. 
patients with no social roles may also show major discrepancies in relation to what may be expected.

\subsection{Results}

\subsubsection{Differences in the professional judgment}

In Table 12.1 we present the mean scores and the results on the univariate tests on the differences between groups as provided by the professionals. When we look at the different groups, we have to keep in mind that most of the older patients currently have a relationship. Most of the discrepancies between current status and expected status are found in the patients with an early age of onset, though some outliers are found in the group with an older age of onset.

Table 12.1. Univariate comparisons between groups with the data of the judgment of the professionals

\begin{tabular}{|c|c|c|c|c|c|c|c|c|}
\hline \multirow[b]{2}{*}{ predictors } & \multicolumn{2}{|c|}{$\begin{array}{l}\text { men vs. } \\
\text { women }\end{array}$} & \multicolumn{2}{|c|}{ age at onset } & \multicolumn{2}{|c|}{ relationship } & \multicolumn{2}{|c|}{$\begin{array}{l}\text { many vs. fow dis- } \\
\text { crepancies in } \\
\text { status. }\end{array}$} \\
\hline & $m e n$ & women & young & old & yes & no & many & fow \\
\hline $\begin{array}{c}\text { Sludont - t tost } \\
\text { social contacts } \\
\text { kin }\end{array}$ & 4.7 & 5.0 & 4.5 & 5.4 & 5.9 & $4.3^{\circ}$ & 4.7 & 5.0 \\
\hline $\begin{array}{l}\text { informal non-kin } \\
\text { formal non-kin }\end{array}$ & $\begin{array}{l}5.8 \\
2.4\end{array}$ & $\begin{array}{l}3.8^{\circ} \\
2.8\end{array}$ & $\begin{array}{l}5.2 \\
2.5\end{array}$ & $\begin{array}{l}4.3^{\circ} \\
2.6\end{array}$ & $\begin{array}{l}5.6 \\
2.5\end{array}$ & $\begin{array}{l}4.5^{\circ} \\
2.7\end{array}$ & $\begin{array}{l}3.2 \\
2.4\end{array}$ & $\begin{array}{l}6.7^{\circ \bullet} \\
2.7^{\circ}\end{array}$ \\
\hline social roles & 6.8 & $5.0^{\circ}$ & 6.3 & $5.1^{\circ}$ & 7.0 & $5.3^{\circ}$ & 7.8 & $4.1^{\circ}$ \\
\hline $\begin{array}{l}\text { Mann - Whilnay U } \\
\text { role pert. }\end{array}$ & & & & & & & & \\
\hline sell-care & 3.2 & 3.5 & 3.2 & 3.4 & 3.5 & 3.1 & 3.1 & $3.6^{\circ}$ \\
\hline support & 2.4 & 2.3 & 2.3 & 2.5 & 2.9 & $2.0^{\circ}$ & 1.8 & $3.3^{\circ *}$ \\
\hline daily obligations & 2.1 & 1.7 & 2.2 & $1.6^{\circ}$ & 2.5 & $1.3^{\prime \prime}$ & 1.4 & $2.8^{\circ}$ \\
\hline social activitios & 4.5 & 4.3 & 4.2 & $4.7^{\circ}$ & 4.9 & $4.0 \%$ & 4.0 & $5.0^{\circ *}$ \\
\hline
\end{tabular}

- sigiticart differea, $p<0.05{ }^{\circ-}$ sigificant difer ence $p<0.01$

Men and women. When we look at the differences in the role domains, we see that the differences between men and women are negligible. The expected differences in respect to the domains "support" and "daily obligations" are not significant. With respect to social integration, the women indeed show less non-kin contacts and fulfill fewer social roles. Age at onset. The expected differences between the younger and the older patients are not confirmed in the results. The slight difference in the domain of support in favor of the young patients is especially important to notice since it opposes our hypothesis and is contrary to our clinical appraisal of this group. The older have less contacts in the non-kin sector, but more in the kin sector. 
Having a relationship. This comparison shows significant results with respect to most sectors of the social network, the social roles and also most of the domains of role performance. The differences between the groups are greater than the differences we found in the previous two contrasts. Consequently, the current social position may be a more powerful discriminator of role performance than age or social position at onset of mental health care. Discrepancies. The most powerful differences are found between the patients with many and those with few discrepancies between the expected and the fulfilled social roles. The patients with many discrepancies show a significantly lower performance in all domains. The finding that they fulfill more roles may be interpreted as an effect of increased opportunity, because having more roles leads to having more opportunity to experience discrepancies.

\subsubsection{Differences in the patients information}

In Table 12.2 we show these univariate comparisons, using the patient's data. When we look at the simple figures, we should keep in mind that the number of social roles and social contacts reported by the patients are more than the professionals report. The scores of the patients on role performance are almost always lower than the professional judgments.

Table 12.2 Univariate comparisons between groups with the patients' data

\begin{tabular}{|c|c|c|c|c|c|c|c|c|}
\hline predictors & \multicolumn{2}{|c|}{$\begin{array}{l}\text { men vs. } \\
\text { women }\end{array}$} & \multicolumn{2}{|c|}{ age at onsel } & \multicolumn{2}{|c|}{ relationship } & \multicolumn{2}{|c|}{$\begin{array}{l}\text { many vs. fow dis- } \\
\text { crepancies in } \\
\text { status }\end{array}$} \\
\hline \multicolumn{9}{|l|}{$\begin{array}{l}\text { Student t-test } \\
\text { social contacts }\end{array}$} \\
\hline kin & 4.8 & 5.3 & 4.5 & 5.4 & 5.9 & $4.3^{\circ}$ & 4.8 & 5.4 \\
\hline $\begin{array}{l}\text { informal non-kin } \\
\text { formal non-kin }\end{array}$ & $\begin{array}{l}5.7 \\
2.8\end{array}$ & $\begin{array}{l}3.4^{\cdots} \\
2.9\end{array}$ & $\begin{array}{l}5.2 \\
2.5\end{array}$ & $\begin{array}{l}4.3 \\
2.6\end{array}$ & $\begin{array}{l}5.3 \\
2.5\end{array}$ & $\begin{array}{l}4.5 \\
2.7\end{array}$ & $\begin{array}{l}2.9 \\
2.8\end{array}$ & $\begin{array}{l}4.4^{\circ} \\
3.0\end{array}$ \\
\hline social roles & 5.3 & $5.5^{\circ}$ & 6.3 & $5.1^{\bullet}$ & 7.1 & $4.5^{\circ}$ & 6.2 & $4.8^{\circ}$ \\
\hline \multicolumn{9}{|l|}{$\begin{array}{l}\text { Mann - Whitney U } \\
\text { role pert. }\end{array}$} \\
\hline self-care & 2.7 & 2.7 & 2.8 & 2.6 & 2.7 & 2.7 & 2.5 & $3.0^{\circ}$ \\
\hline support & 2.3 & 2.3 & 2.3 & $3.1^{\circ}$ & 2.9 & $2.0^{\circ}$ & 2.0 & $2.6^{\circ}$ \\
\hline daily obligations & 1.8 & 2.0 & 1.5 & $2.5^{\circ \bullet}$ & 2.5 & $1.3^{\circ 0}$ & 1.4 & $2.4^{\circ}$ \\
\hline social activitios & 3.7 & $2.5^{\cdots}$ & 3.4 & $2.6^{\circ \bullet}$ & 3.9 & $3.0^{\circ \bullet}$ & 2.7 & $3.7^{\circ}$ \\
\hline
\end{tabular}

- significant difference, $p<0.05$ - significant difference, $p<0.01$

When we look at the last two comparisons (the third and fourth part of Table 12.2), we see that the differences are fairly concurrent with the differences provided by the professionals. An important feature, however, is that the direction of the difference in the domain of "daily obligations" in the first two comparisons is exactly opposite to the direction of the differences found in the 
material provided by the professionals. We may expect this difference, when we compare these data with the results we presented in Table 10.1. There we saw that professionals virtually disagreed with patients on several items in this domain. Also, their scores are far more positive than the scores obtained from the patients. An investigation of the comments on the questionnaires revealed that quite often the professionals were not fully informed on the details of this domain. Summarizing, the univariate comparisons show that the most important differences are found between the patients with and without a current relationship and between patients with many and with few discrepancies in their social roles. Most of the differences can be seen in the domains of "social activities" and "daily obligations". The results show that most of the expected differences are indeed confirmed, though sometimes only with a $\mathrm{p}<0.05$.

\subsection{Summary}

In this chapter we presented some analyses used to determine the discriminative value of the instrument. We determined the differences on a univariate level with the factors we determined by means of the LISREL confirmatory factor analysis in Chapter 9. We first wanted to know whether the instrument discriminated between the groups we defined a priori and also described in Chapter 7. These groups were the men and women who were unmarried and under 30 years of age at onset (of mental health care) and the men and women who were married and over 30 years of age at onset. Secondly, we compared patients with or without a current relationship, because we expected the current social position to be a major indicator of social role performance. The final comparison was made between patients with either many or few discrepancies between expected and fulfilled social roles. The analysis at a univariate level provided a number of significant differences, of which many had a probability level of 0.001 . The most important finding is that the a priori selection (age and marital status at onset of mental health care) showed only few significant differences, far less than we expected. No major differences between men and women were detected. The comparison between patients with and without a relationship provided conflicting results when comparing the professional judgments with the information obtained from the patients. The comparison between patients with many and few discrepancies in the fullfillment of their position roles provided the most powerful differences, of which a majority had a probability level of 0.001 .

The final conclusion of this chapter is that the instrument does discriminate to a certain extent between different groups, but that further research with a much larger number of patients is necessary to ascertain which aspects of social role performance may be good predictors for the achievement of a position in society. The current sample is far too small to perform more sophisticated multivariate analyses on the discriminative power, such as discriminant analysis. We would need a minimum of 125 subjects. 


\section{Clinical validity: the case reports, the feedback and the data}

The instrument we developed is meant to be used as an aid in the rehabilitation of the chronic mentally ill. In the Chapters 2 and 4 an extensive description of the goals of the instrument is given. This chapter deals with the first efforts to implement the case findings of the instrument in care ${ }^{27}$.

\subsection{Questions related to clinical validity}

During the course of the research an effort was made to give feedback of the findings of the individual interviews. To obtain the cooperation of the mental health professionals and to provide them with useful information it was standard procedure to report the qualitative findings of the research interviews in detailed case reports. In the case report, a short description of the status and position roles was followed by a description of current role performance and related to the developmental history of role performance in the various domains. In this chapter we will describe what kind of descriptive information is gathered with the instrument and how this information is related to the data. We are interested in the clinical validity at of face value, and will address the following questions:

1. Are obvious observable differences reflected by clear distinctions in the data provided by the instrument?

2. Is the instrument sensitive to change?

3. Which parts of the instrument provide the most sensitive information?

Nine case reports covering the various groups of the main study will be used to illustrate the distinctions that can be made with this instrument with regard to the analysis of social integration and rehabilitation. To illustrate how these distinctions affect the data, we also present a short casewise overview of the scores generated by these cases. The case reports demonstrate that there exist quite a few differentiations within the group of chronic mentally ill. This might raise the question as to how we can apply the gathered information in therapeutic interventions. To answer this question is beyond the scope of the current study. Therefore, we will not comment on the therapeutic process and the degree to which analysis of social role fulfillment and gaining a social position may be applied in therapy and rehabilitation. An experimental research design (applied in a follow-up study) is necessary to answer such questions. 


\subsection{Role performance and achievement of position roles}

Role performance may be regarded as one of the most important determinants of interpersonal relationships effectively determining the composition of the personal network (Janssen, 1992). Through his role performance, the individual manipulates his network of social relationships. By initiating a new role, the individual may establish several new relationships; by ending a role he may free himself of old roles (Boissevian \& Mitchell, 1973). When a person suffers a (mental) health deviation he will be no longer able to live up to role expectations. Deviation from the norm leads to labeling and stigmatization and finally social rejection (Philipsen, 1970), while social rejection leads to deviation of the norm and mental health problems (Nijhof, 1978). Chronic deviation induces changes in the dependency balance between the patient and his environment: roles are reallocated or lost. The visibility, the severity, but especially the duration of the deviation determine the impact on role performance. When a health deviation is not disabling, or has no visible effects, the individual is regarded by his environment as normal and remains capable of fulfilling his roles and the relationships with other people are not necessarily affected. When the deviation is important enough to impair various aspects of the individual's social mobility and affluence, the roles involving specific expectations may be gradually affected or lost. Through the loss of opportunity, the individual may lose contact with a part of his social environment. As the proverb says: out of sight, out of mind.

\subsection{Topics of interest in the feedback}

In the evaluation of the process of social role development, we will have to keep these circular relationships in mind. In the case reports, we therefore presented a short comment on current and past social role performance, the variability of the position roles, and the main characteristics of the social network. When we want to set objectives for rehabilitative efforts on the basis of assessment of social functioning, we have to know more than the factual information about the impairment. We will have to know more about the possibilities which the context provides for the individual. We will therefore have to relate the assessment of the individual to the judgment of people in the environment, either professionals or next of kin. In understanding the development of the individual's social position we are interested in the following three topics:

1. the social position related to the variability of position roles - both now and at the onset of mental illness;

2. the development of social role performance;

3. and finally, the number and variability of the current social contacts.

In the presentation of the case reports we will briefly comment on this point. The case reports provide a short overview of current and past social role performance, with some remarks and conclusions on important impairments of social role performance on an individual level. These are related to the social 
position at the moment of the interview as well as at the onset of illness, which creates the possibility of discussing the influence of the therapy on the social position. However, as our research has no experimental design, we will address this tentatively, and not in detail.

A total of 104 case reports were compiled in the various phases of the research. In this Chapter, we will present only the case reports compiled during the main study. In the main study we selected four homogeneous groups (Chapter 7, p. 91). We will present these four groups separately. We interviewed not only the professional but also the patient, and were able to relate information obtained from both sources. The report was discussed with patient and professional, either together or independently, to ascertain the accuracy of the information. In the feedback sessions, we also obtained a rough overview of the course of the mental illness. In this way we obtained information from a total of 45 out of 56 patients in the main study. In most of these cases we had the opportunity of performing a follow-up interview. In eleven cases, feedback and follow-up assessment was not possible, due to several practical obstructions. This is typical for research in a health care setting.

\subsection{Operationalization and data, a recapitulation}

The first part of the interview schedule investigates current status and position roles. We ask the patients what they do in relation to other people and in which settings they operate. A position role represents the placement of the individual within a social substructure. An individual generally performs within a limited number of settings or social contexts; for example, within the family, in relationships with a specific number of close friends, at work, and perhaps in a number of social clubs. Consequently, we may identify the following types of position roles:

a. position roles related to the close and extended family;

b. position roles related to close friends and acquaintances;

c. position roles related to work;

d. position roles related to leisure or social clubs.

Secondly, information is gathered on the status and position roles at onset of care. Thirdly, we investigate the social network. We ask how many people that patient had seen in the last month, who they were, and what kind of social contact it was. Those contacts labeled by the patient as important and meaningful were counted as social contacts (inventory c.f. Janssen, 1992). We relate the contacts to the sectors of the social network, as defined by Janssen, 1992. She identifies three sectors: the kin sector, and the informal and formal non-kin sectors.

The second part of the schedule investigates the development of social role performance in the five domains defined previously: "self-care", "support", "sexuality", "daily obligations" and "social activities". Each domain contains a 
number of scalable items, representing a level of functioning, except the domain of sexuality, in which the items are nominal. The total score on the schedule is calculated by addition of the scale scores in the domains "selfcare", "support", "daily obligations" and "social activities". In the schedule, current role performance in each area is always related to performance before onset of illness. If problems are met in current functioning, further questions are posed in order to gain information on the comparison with onset and, in a broader sense, on the development of the defined area of social role performance. Concerning development, different patterns are assumed in the schedule. We differentiated:

1. a normal development if no problems were met in current functioning;

2. a stagnation in development when there has always been an insufficient level of functioning;

3. a relapse when insufficiency was developed later in life.

In the patient's version of the interview, the questions are posed in an open format, facilitating a dialogue on the content of the performance. Trained interviewers and a detailed response instruction were applied to ensure reliability. In the professional's version of the interview, the professional provided the rating in discussion with the interviewer.

In the following, we first present the case reports, accompanied by some short comments and observations, in the same manner as we presented our findings in the feedback sessions. Then we discuss the data on current role performance, position roles and social contacts generated by these cases. The cases presented here are typical examples of patients in the various selection groups. We avoided selecting the most severe outliers.

\subsection{Case reports}

\subsubsection{The young and unmarried men at onset}

The first and largest group in the sample is the group of unmarried young men at onset $(n=19)$. When we look at the course of lifetime Social Role Performance, we may distinguish three typical patterns. The first concerns patients with limited social integration at onset of mental health care, who have not improved since. The second present a limited social integration at onset but show some improvement. The third were reasonably integrated before onset of care, but show a gradual deterioration with an increasing dependency on care afterwards.

\section{Patient 1 (case number 1): \\ Limited at onset and subsequent stagnation.}

The case concerns a 39 year old man from an ethnic minority. He follows occupational therapy at the day service of a mental hospital. His diagnosis on axis one is an atypical psychosis, in remission since 4 years and on axis two a mixed personality disorder, with passive-aggressive and dependent traits. Onset of mental health care was at age 19. His social position at that time was very isolated. He only fulfilled two roles: the role of son and the role of brother. 
In both roles he depended very heavily on his family. At that time he had never had a partner. Later, he finished school. Ever since, he has not succeeded in keeping a job. Currently, he has the status role of a child, accompanied by only three position roles. He functions in a protected work setting, as a technical assistant. In this setting he has to deal with a superior and with three other colleagues. Second, he fullfills the role of son and brother in his relationship with his kin. Both roles are accompanied by a number of difficulties, primarily because his mother is too old to meet his demand for support. A procedure for admission to a protected housing setting was more than three years underway with little success, as he was very reluctant to leave home.

When we look at his social role performance, we can see in that, in the domain of self-care, only his personal hygiene is sufficient. For all other functions in the domain of self care he is entirely dependent on his mother or on provisions from the mental hospital. Regarding his development he displayed a severe relapse at the age of 20, when he was totally scruffy and had no daily structure whatsoever. With regard to the domain of support, we can see that he almost never provides any practical support for others in his environment. He shows no personal bonding or appreciation for the support others give to him, and has no problem-solving capacity. He regularly has conflicts with others, but always reacts with avoidance behavior. In this domain, his behavior has only slightly changed since the onset of his mental illness. With regard to the third domain, sexuality, he never developed an identity, nor did he succeed in establishing a relationship. In the fourth domain, daily obligations, he stagnated before finishing primary educational training. His current vocational setting is entirely provided by the Mental Hospital, and his participation is reluctant. His social activities, finally, are predominately dependent on the provisions of the mental hospital. His social network is limited to his family; he has no hobbies nor does he show any initiative other than an obsession for pinball and gambling machines. In the domain of social activities we also observe an early stagnation, as an effect of hospitalization and institutionalization.

In the follow-up interview one year later, the admission of the patient to the protected housing arrangement had resulted in major problems in various domains of social role performance. His self-care had deteriorated, he participated less in the protected work setting of the mental hospital. The contacts with his family were sparse and he contacted the outpatient service frequently, with problems mostly related to difficulties in adjusting within the housing project, and with difficulties in the relationship with his superiors and mental health care professionals. In comparison with the first assessment he was less dependent, but more isolated. The assessment in this specific case was impeded by the patient's tendency to over-comply and provide social desirable answers, leading to numerous ambiguities and contradictions in the comparison with the information obtained from the professional.

\section{Patient 2 (case number 5) \\ Limited at onset and subsequentimprovement}

The case concerns a 38 year old man living with a fellow patient he started a relationship with while both were living in a hostel. Onset of care was at the age of 18, while serving in the army. At that time he was diagnosed with a conversion hysteria, resulting in severe pains and intermittent muscle pareses. He was psychotic and showed at times catatonic stupor. From that time on, he was admitted several times to various institutions in connection with recurrent relapses of the psychosis. At age 30 he was referred to a hostel, where he met 
his current partner, with whom he had shared an apartment for 6 years. Currently, he has no axis one diagnosis, apart from psychosis in remission, for which he still receives medication. On axis two he was diagnosed as suffering from a severely dependent personality disorder, with aspects of theatrical behavior.

At onset of care he only had three position roles: the role of son, the role of brother and the role of soldier. He had no friends, no partner, nor did he participate in any kind of social life. He had not grown beyond the status of an adolescent. He had partly finished school, and was looking for acknowledgment and acceptation by peers, in which he did not succeed. At the moment of the interview he is living with his girlfriend, and has a volunteer job as barkeeper.

He has the status role of a fully integrated adult, living with a partner. He has people he calls his friends, and fulfills a number of position roles. In two position roles he encounters some problems: in the role of brother, and in the role of employee. In the first role because he still meets little respect in his family, as the others all have successful careers. In the second role he never succeeded in achieving full integration in a normal vocational setting. When real demands were set he quickly started to develop mental and physical complaints.

With regard to social role performance, there are no impairments in the domains of self-care and sexuality. In the domain of support we may observe a tendency to overprotect his girlfriend. This often leads to conflicts which he only partly succerds in solving. In his daily obligations he experiences few problems; however, when he has to deal with too many new impressions, he may decompensate quickly. His social activities are few and he is predominately occupied with his girlfriend. He may incidentally visit his family, but seldom entertains visitors. His social network is limited to his girlfriend, his family and some acquaintances. Most contacts are superficial.

At a follow-up one year later, we observed the same social position and level of role performance. The only reason for professional help - limited to once in two months - was for control of medication and some support in caring for his girlfriend. In this case the assessment was impaired by a reluctance to provide information, which he felt as an unnecessary prying into his past. The interviewer constantly had to convince the patient of the reasons and implications of the various questions. The assessment of the past consequently showed significant inaccuracies and a number of differences with the more factual information provided by the professional.

\section{Patient 3 (case number 7) \\ Gradual deterioration}

The case concerns a 21 year old man living with his single mother and a twin brother. His first contact with mental health care was at age 17. His complaints were: stress-related stomach ache and transpiration, extreme shyness and feelings of incompetence, concentration deficit, and limited learning abilities. He then came into a carrousel of referrals within the Community Mental Health Center. Contacts with professionals were discontinuous and short-lived. The first professional he met advised family counseling, the second group therapy, the third sent him to job counseling and the fourth provided individual psychotherapy, focused on his social phobia. The professional who dealt with him when we interviewed him had just started family counseling, aimed at disentangling symbiotic relationships. 
When we met the patient he was diagnosed as suffering from a depression disorder on axis one, and was suspect for a schizothymic personality disorder on axis 2. He received this label after being three years in care with little change in his complaints or in the way he spent his day, which usually consisted of three hours in a fitness center and the rest of the day at home, doing mostly nothing and awaiting the moment until his mother, brother or girlfriend turned up. He has the status role of an adolescent trying to maintain his achievements, despite a growing isolation. He also has few position roles, which are limited to his family. He fulfills no outer-directed position roles. As an effect of this he has no social contacts outside the family.

At onset of care his complaints were generally the same: he felt depressed, anxious, insecure. He was self-centered, and he made no effort to uphold his social contacts. In the months after onset of care he lost a great deal of credit in his extended social network. He had just lost position roles as student, club member, friend and acquaintance, and consequently, his social network and social mobility decreased. When we look at his social role performance we see the same pattem of gradual deterioration. When we look at self-care we observe that only his personal hygiene and care for his personal environment are pefformed well. Daily and long-term planning are unstructured, as is his intake of daily meals. In the domain of support his behavior is that of a passive recipient. When we look at what he does in the domain of support, the most important feature is his dependency. He has no initiative, he shows no practical support, is often the cause of problems and conflicts in the context of his family. Concerning his sexuality, his relationship with his girlfriend is also characterized by dependency.

In the domain of daily obligations he has a history of constant failure, reinforcing his insecurity and concentration deficit. In the domain of social activities, finally, we observe an impoverishing social network; the only contacts are with his brother, his girlfriend and his mother. He takes no initiative himself, and is generally inert and bored.

From a follow-up one year later we leamed that the interviewee had suffered an increasingly severe depression accompanied by characteristics of a schizothymic personality disorder. Admission to a mental hospital became inevitable, as the burden on the family had increased excessively. Some time before admission, the relationship with the girlfriend also ended, enforcing the isolation. He is now recieving day treatment and medication therapy. In this case the assessment was fairly accurate and showed few differences with the information obtained from the professional.

In Table 13.1 we present the data generated by these cases. The scores in the domains of social role performance and social role development presented here may be checked by combining the information presented in the case reports with the manual of the instrument (Appendix no. III). We present these data to illustrate how the case level observations presented above are reflected by the scores or the data at various points in the instrument. We present the number of position roles and social contacts, following the categorization presented in $\S 13.4$. The follow-up data of most of the patients are also presented, as an indication of the sensitivity of the instrument. The first case presented a patient who did not develop further than the status role of a child. In this case we may observe that the several shortcomings observed in the case 
Table 13.1 Differentiation of social role performance, social contacts and position roles in the young unmarried men at onset

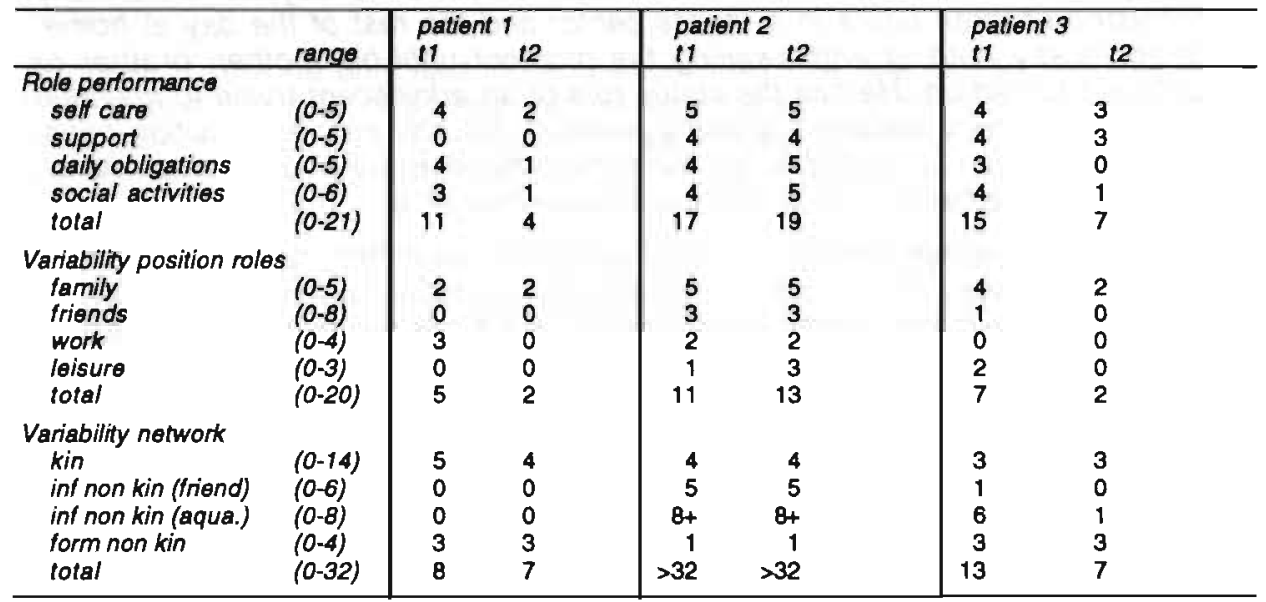

report are also reflected in the data. At the first measurement, his role performance is low in the domains "support" and "social activities". In the second assessment, after the patient had been placed in a protected living environment, we observe a massive decline at various points. Now, his role performance is low in all domains. As we observed in the report, he lost the structuring position roles related to his daily obligations. In the social network, however, we observe the loss of only one contact. The second case illustrates a man who stabilized into a satisfactory, though fragile equilibrium with his personal environment. In this case we observe a score comparable to the means measured in the control population study (presented in the next chapter). Most of the problems in this case lie in the past. Once the equilibrium was established by finding a goal in the support of his girlfriend, the patient started to develop initiative in daily life and an incentive to do something useful. Current contacts with care are focused on dealing with supporting his girlfriend. The third case illustrates a major loss of position roles and an impressive decline in role performance. In this case we observe a severe relapse between the first and the second interview. A decline may be observed in his role performance, in the variability of the position roles as well as in the variability of the social network and is reflected by major changes in the data.

\subsubsection{The young and unmarried women at onset}

The second largest group concerns the unmarried young women at onset $(n=16)$. In this group we may observe a wide variation in the development of social role performance and social context. Some cases remain severely isolated or dependent on their family. Others develop, sometimes after a very 
long period of recurrent relapse of severe psychiatric disorders, a fairly normal and supportive social network together with a satisfactory social position. Some even marry. By and large, the extent of social isolation seems to be less than in the young males we encountered in the study. We will elaborate on two cases, one which developed a satisfactory social position despite a grim history of years in mental institutions, the second which remained isolated.

\section{Patient 4 (case number 24) \\ Satisfactory recuperation}

The case concerns a 30 year old woman, who has intermittently been in care from age 18. At age 24 she wasadmitted to a mental hospital for more than a year after suffering an intermittent psychosis for several months accompanied by severe self-neglect. After discharge she received aftercare at the outpatient service. Several readmissions occurred in the years thereafter. The aftercare was also discontinuous and provided by several professionals who gave her as many different diagnoses, ranging from schizophrenic disorder, schizothymic personality disorder, dependent theatrical personality disorder, to borderline personality disorder. At the moment of the first interview her most important concern was to establish a relationship. She worked for some hours as a music teacher, and followed courses at a music academy. She fulfilled at that moment a satisfactory number of status and position roles, but most were yet unstable and subject to change. Especially the roles in which she had to show some responsibility were impaired and discontinuous.

When we look at the development of her social role performance we observe again a great deal of instability. Periods of satisfactory or good performance are interrupted or followed by periods of severe relapse. Her current self-care is satisfactory. Her personal hygiene is good and she takes good care of her personal environment. The planning of her meals and the organization of her daily life both in the short and long term is less good. In the period before admission her self-neglect was very severe, and it took some years of outpatient care to reach an acceptable level of functioning in this domain. In the domain of support the level of functioning is difficult to ascertain, as the professional and the patient show a largely different view. It is clear that she has very few people with whom she shares confidences. In her own perception she has some people with whom she shares a close personal relationship. After some inquiry we learn that she only reluctantly shows her own feelings in a relationship, as she is preoccupied with her own thoughts. She is not capable of coping with problems others present to her, and conflicts with others are always avoided or postponed. However, in her own perception she has a satisfactory number of good and supportive relationships. The domain of sexuality proved the most difficult to ascertain, and subject to feelings of uncertainty and guilt, as she had to deal with severe traumas in the past. The domain also proved to be her most important preoccupation and the main subject of therapy. Concerning her development in this domain she is very reclusive and sticks to here and now.

She rejects any further investigation. Concerning her daily obligations we may observe the same lack of consequent planning in the same way as in her selfcare. She spends up to twenty hours a week with music, following and giving lessons, and as an accompanist of a church choir. Despite her disorganization, she does have a full agenda of appointments. However, a certain number of these are often canceled. In her daily obligations her main problem is dealing 
with people. Due to her uncertainty, she has to deal with reactions of others to her own behavior, she has disturbances in her concentration and deals badly with problems and conflicts. In the domain of social activities we again observe a combination of many inconsistent activities and social contacts. In her social network she identifies as many as 39 acquaintances by name, but only two real friends. A great deal of her free time is spent alone. The contacts with the close friends proved also to be incidental. Summarizing, we may observe a number of dysfunctions in the various domains of social functioning, but what in her own perception is satisfactory social integration, also expressed in the number and variability of social roles and social contacts.

A follow-up interview one year later revealed she had developed a satisfactory relationship with a person of the opposite sex. The way she spent her day and organized her household was the same as we described above. She remained insecure in her work. The number of close personal relationships was the same. The number of her social contacts had decreased impressively, but the variability of her social roles was also the same. In the domains of "support" and "sexuality", she of course showed a better level of functioning, now being able to relate and express her own feelings and deal with problems and conflicts in the relationship with an important other.

In this case we initially observed a socially isolated individual, with a number of severe impairments in role performance in various domains and a satisfactory number of position roles. Again a major change occurred after establishing a relationship. These changes concerned predominately the domains "support" and "sexuality". In this case the assessment was difficult at the start. However, once a relationship of confidence was established, she loosened up. Certain topics, as for example expressing personal feelings, showing supportive behavior, the expression of intimacy and sexuality, remained difficult to discuss and could not be assessed accurately.

\section{Patient 5 (case number 27)}

Complete stagnation

The case concerns a 25 year old woman, living with her parents. At age 14 her parents had severe problems in handling her behavior and brought her to a child psychiatrist. At age 18 she was admitted to a mental hospital for the first time. Ever since, she has been in and out the mental hospital, subject to various kinds of professional care. Despite good intelligence, her social integration is sparse due to inapt behavior and recurrent psychoses. At onset of mental health care she had the status role of a child, with no important position roles, and a single reasonably incidental and superficial relationship with a girlfriend. At the moment of the interview she had some incidental contacts at a relief center for the mentally ill, and still had the status role of a child.

When we look at her social role performance we observe major impairments in all domains. In the domain of "self-care" she is too chaotic to bring any incentive to a conclusion. Consequently, she continuously needs supervision and control. On the other hand, her mother leaves her no room for any personal initiative. In the domain of "support" we also observe a complete dependency and control of behavior by her family, leading to recurrent conflicts and psychoses. Her experience of sexuality is instrumental, having had incidental contacts with perfect strangers. She is not capable of intimacy and never has had any experience of it. In the domain of "daily obligations", we again observe a total dependency on her family and on the mental hospital. Being intelligent 
enough, she frequently tries getting a short-term job, e.g. in a shop. These initiatives, however, usually end in her recurrent psychoses. Her social activities are limited to situational contacts within settings such as the church choir or while shopping with her mother. She has no friends or social contacts of her own. When we tried to establish a follow-up, we learned that the patient was recently hospitalized for a short time. A follow-up interview was not performed.

In this case we observe a full stagnation in the status role of a child. Her isolation is preserved by the overprotective behavior of her mother. In this case a first-hand assessment from the patient was impaired severely, as she tended to lose concentration and interest rapidly. Several subsequent short interviews were needed to complete the information to a satisfactory extent.

In Table 13.2 we present the data generated by these two cases. The first case presented a patient that showed major, though temporary improvements between the first and the second inteview. The second case illustrates a severely isolated young woman who is living in a highly instable equilibrium with her personal environment. The first patient shows a considerable change between the first interview and the follow-up. We may observe a considerable increase in position roles and social contacts. The second case shows major impairments in all domains of social role performance. In her development we observe a full-blown stagnation at the level of a child in all domains. The only position role she fulfills is the position of daughter in her family. Outside her family and a network of professionals, she has no social contacts. These two cases represent some outliers of the complete selection of the women who were young and unmarried at onset. Especially the second case illustrates the extreme isolation in which some of the patients participating in the study live.

Table 13.2 Differentiation of social role performance, social contacts and position roles in the young unmarried women at onset

\begin{tabular}{|c|c|c|c|c|}
\hline & range & & 12 & $\begin{array}{ll}\text { patient } 2 & \\
11 & 12\end{array}$ \\
\hline $\begin{array}{l}\text { Role performance } \\
\text { self -care } \\
\text { support } \\
\text { daily obligations } \\
\text { social activities } \\
\text { total }\end{array}$ & $\begin{array}{l}(0-5) \\
(0-5) \\
(0-5) \\
(0-6) \\
(0-21)\end{array}$ & $\begin{array}{r}3 \\
3 \\
4 \\
4 \\
14\end{array}$ & $\begin{array}{r}5 \\
4 \\
4 \\
6 \\
19\end{array}$ & $\begin{array}{l}2 \\
1 \\
1 \\
2 \\
6\end{array}$ \\
\hline $\begin{array}{l}\text { Variability position rol } \\
\text { family } \\
\text { friends } \\
\text { work } \\
\text { leisure } \\
\text { total }\end{array}$ & $\begin{array}{l}(0-5) \\
(0-8) \\
(0-4) \\
(0-3) \\
(0-20)\end{array}$ & $\begin{array}{r}4 \\
1 \\
2 \\
3 \\
10\end{array}$ & $\begin{array}{r}4 \\
4 \\
3 \\
3 \\
14\end{array}$ & $\begin{array}{l}1 \\
0 \\
0 \\
0 \\
1\end{array}$ \\
\hline $\begin{array}{l}\text { Variability network } \\
\text { kin } \\
\text { inf non-kin (friend) } \\
\text { inf non-kin (aqua.) } \\
\text { form non-kin } \\
\text { total }\end{array}$ & $\begin{array}{l}(0-14) \\
(0-6) \\
(0-8) \\
(0-4) \\
(0-32)\end{array}$ & $\begin{array}{r}3 \\
2 \\
8+ \\
3 \\
>32\end{array}$ & $\begin{array}{r}3 \\
4 \\
8+ \\
2 \\
>32\end{array}$ & $\begin{array}{l}2 \\
0 \\
0 \\
3 \\
5\end{array}$ \\
\hline
\end{tabular}




\subsubsection{The older and married men at onset}

This group proved to be the hardest to sample, as married men quite often developed problems before age 40 , leaving our selection criterion open to discussion. Lack of consent was a second important problem in the assessment of this group. A total of 24 patients had to be contacted before gathering a coherent group of 9 patients who fit in the criteria. When we compare the histories of the patients, two patterns of relapse arise in this group. First, we may observe 4 patients with a long-standing history of difficulties in maintaining their position in their work. Second, we may observe 4 men who were first referred with an organic disorder, and subsequently suffered a number of social impairments. One man developed a psychotic disorder accompanied by a full-blown delusional system at age 42 . The first case presents an example of a man experiencing recurrent depressions secondary to job stress, leading to a gradual and subtle loss of his social integration; the second case provides an example in which an organic disorder led to subsequent and major impairments.

\section{Patient 6 (case number 34)}

Slow process

The case concerns a 44 year old man who has had a number of minor and two major episodes of severe depression accompanied by suicidal thoughts in the last five years. The depressions were both preceded by a period of stress in his work. The stress always follows the same pattern: he first gains more and more responsibilities, subsequently has to do more and more, and finally collapses after a period of some months. The interview was done when the second depression was coming to an end and he just had started working half time. At the moment of the interview, he has the status role of a man in mid-life with older children and fulfills a satisfactory number of position roles within all domains of daily life. He has just started to regain control of most of his activities, as most of his position roles were only temporarily cut off.

When we look at his social role performance we may observe a temporary relapse, with a number of minor impairments. In the domain of "self-care", a complete lack of planning leads to severe conflicts with his family, especially his wife, as she can not rely on him. In the domain of support, he mentions a large number of people, within the context of the extended family, with whom he has close relationships. Further investigation shows little personal sharing, and a great deal of conflict within these relationships. Even when he feels well, he tends to avoid conflicts. In the domain of sexuality he is quite capable of expressing intimacy, but his expression of sexual drive is impaired as an effect of the medication. The impairments are, however, strictly related to the periods when he uses medication.

In the domain of "daily obligations" he experiences no impairments; on the contrary, he quotes the many compliments colleagues give him for his industrious and reliable way of working. The professional however, points out an inaccurate and at times conflictive way of dealing with his superiors and with stress in his job as the main cause of his recurrent depressions. His social activities are impaired most severely in the periods when he feels depressed. He tends to reject any social contacts and withdraw from all his activities. In the periods when he feels well, he is continuously occupied with club activities and 
all kinds of social obligations. This domain is the only domain where his position roles are affected by the periods when he functions less well, as he often takes on responsibilities which he later cannot finish.

A follow-up one year later showed a complete remission of his problems and complaints. He had started to regain some responsibilities in his work and in social clubs and participated with much pleasure in family life. Summarizing, although most of the impairments only occur in the periods when he feels depressed, some do however limit his possibilities in periods when he has no depression. In this case we may observe the beginning effect of a long-term recurrent mental illness on daily life. No major impairments arise, but subtle changes and loss of responsibility and appreciation may be observed at various points in respect of his job, home and social life. The assessment showed no major differences between the information provided by the professional and the view we obtained from the patient.

\section{Patient 7 (case number 38) \\ Major impairments}

The case concerns a 56 year old man who suffered an ischemic heart attack at age 51. After the attack he remained in coma for some weeks. He also suffered brain damage, with effects on his personality and his memory, but no major effects on his physical condition. He is extremely forgetful, and has frequent attacks of aggression and anxiety. Some months after the incident his wife left him, and he sought professional care. At onset of care, few of his position roles were left: he had lost his job, had no social activities, his wife had divorced him, and he had lost most of his personal network. When we look at his social role performance, we observe a dependency on others in most domains. In the domain of self-care he is only partly able to take care of his body; his food, housekeeping and planning are taken over by home help. When asked about his self-neglect his reaction is evasive. In the domain of support, his only personal contact left is his son, with whom he has a close relationship. This relationship is one-way: he is entirely dependent on his son, and has no ability to give support or recognize and react to arising problems or conflicts. In the domain of sexuality is no longer capable of expressing intimacy and is also reluctant to do so out of fear for physical complications. In the domain of daily obligations he is completely impaired, both because of his physical condition, and because of his forgetfulness. His social activities as well as his social contacts also diminished severely after his heart attack. He currently has some sparse contacts with his children and a few neighbors. A follow-up one year later showed few changes in the above situation.

This case illustrates an almost complete isolation as the effect of a loss of most position roles. Most of the impairments in social role performance are a direct effect of changes in his mobility and in the way he reacts and interacts with his environment. In this case the assessment was difficult, as we had to deal with two factors: first, a memory deficit due the effects of the heart attack; second, a tendency to resist or provide inaccurate information in the interview.

In Table 13.3 we present the data generated by these two cases. The first case shows temporary changes in role performance, but a complete recuperation to a normal level and an increase in the number and the variability of position roles in daily life, as well as an impressive change in the number of social contacts in the last month. 
Table 13.3 Differentiation of social role performance, social contacts and position roles in the older married men at onset

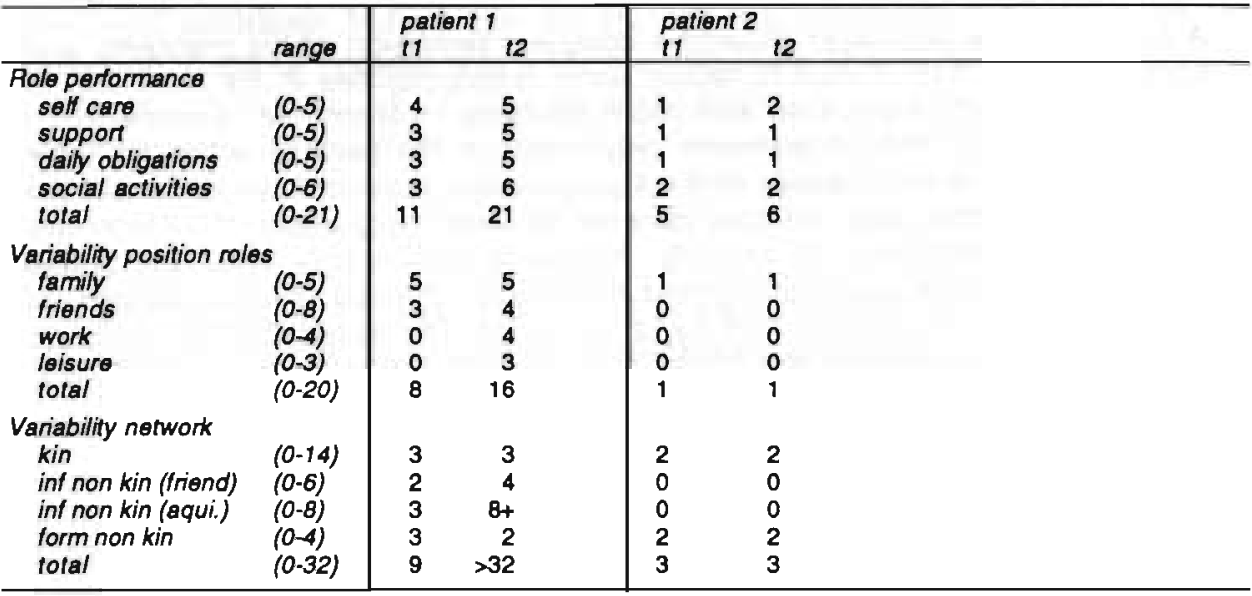

The number of social contacts in the various sectors as well as the number of social roles is at a normal level in the second assessment. In the second case we observe major impairments in all domains, and a nearly complete social isolation, leaving only a sparse contact with his two children.

\subsubsection{The older and married women at onset}

This group proved to be an important group in previous samples (Romme et. al, 1987) as well as in our first pilot study (described in Chapter 1). In the main study we did succeed in gathering a homogeneous, if small, group. Lack of consent was again a major problem. Apart from lack of consent, five patients provided unreliable information in the interview, either hallucinating, showing paranoid behavior, or providing socially desirable but inaccurate information. These cases had to be deleted from the database, as they contained too many unknown variables. Most of the women we encountered in this group suffered a relapse in performance secondary to often severe marital stress, ranging from physical or mental abuse to moral indifference. In a number of cases the relapse could be related to sudden changes in their position as a housewife, e.g. in the case of children leaving home. In the two cases presented here, we may observe that major changes in the social position of the patient preceded the dependency on care.

\section{Patient 8 (case number 46) Empty nest}

This case concems a 64 year old divorced woman, who has been married for 27 years with an alcoholic. Shortly after her divorce in 1976, she was admitted for two months to a mental hospital, suffering a dissociation disorder due to severe marital stress. After discharge she functioned adequately relying partly on supportive outpatient care. Decompensations recurred usually after a 
change in her social context, for example abandonment by a close friend, the marriage of her daughter, or the death of her dog. Before onset of care she had a wide range of position roles, with a number of close friends and was active in social clubs and in her neighborhood. She was continuously occupied with various activities and spent little time on her own or with her children. At the moment of the interview few position roles were left. She had lost contact with close friends, her relationship with her daughter and son are conflictive or indifferent. A severe decimation of her social network had occurred.

When we look at her social role performance we observe a dependency on others in all domains. In the domain of "self-care" she needs supervision and stimulation by a neighbor to avoid neglect and she has no daily or long term planning. Concerning support, she is so isolated from people close to her that most of the items cannot be related to an interaction with another individual. She feels concern and feels attached, but has no means available to express these feelings. In the domain of sexuality she reports no problems but again a complete absence of sharing or intimacy. In her daily obligations she needs continuous stimulation and structuring, which is provided by frequent visits by a neighbor and by the community nurse as well as the mental health professional. Her social activities reflect the same poverty we observed in the other domains. In her activities she currently shows no initiative at all. She has no mutual consented contacts and is extremely dependent in relationships with others.

One year later we could observe a total dependency on a support network provided by various institutions. The contacts with her family had deminished severely, and she even lost contact with the neighbor from whom she had received so much support the year before. Her role performance was impaired in all domains of daily life, and she needed frequent support and supervision. This case illustrates what every professional will recognize as an empty nest. After being preoccupied with her alcoholic husband and the upbringing of her children for years on she suddenly was cut loose, and did not succeed in establishing a new social environment. After a life fully occupied with family and partner, each new loss was accompanied by an even more severe decompensation, with effects spreading into various domains of her daily life. $A$ compensation is only provided by professionals, but her social context remains sparse. In the assessment her own report was accurate and precise, as she did realize the changes which had occurred in her.

\section{Patient 9 (case number 49) \\ Role conflicts}

This case concerns a 57 year old married woman with two children still living at home. Her first contact with professional care concemed child-raising problems, 15 years earlier. One of her children has been raised in an institute for the mentally handicapped from age 5 on, a second showed behavioral problems at age 14. As "onset of mental health care" we chose the period of her life when she was referred to professional care for the first time. Later on, she intermittently received outpatient care, usually for periods of a half year. The last four years she continuously received outpatient care.

When we look at her status and position roles at onset, we observe a variety of position roles within all sectors. However, we may observe some problems in the realization of especially those position roles which were most important for her status role as a married woman and spouse. Both partner and parent roles suffered under her overzealous participation in a social club to which she 
devoted most of her evenings and a part of the day, neglecting her family to a large extent. At the moment of the interview, we observe a totally different situation. Now her attachment to her family is experienced as too strong. In the upbringing of the children she experiences herself as a failure, overcompensating by smothering the children in overprotection, which in itself leads to frequent conflicts within the family. Many of her other position roles have been lost. She fulfills no roles related to the extended family, and also has no close friends left. All her current position roles are related to her immediate family or to professional care.

When we look at her social role performance, we observe various impairments in several domains, all related to the way she handles relationships and personal conflicts. In the domain of "taking care" we observe no impairments whatsoever. In the domain of "support" she reports spending much time in supporting others, practically as well as personally. She regards helping others with their problems as a duty. However, she tends to have frequent conflicts, often related to her being a busybody. The professional observes major problems in all items of this domain. The domain of "sexuality" also shows severe impairments; she never experienced intimacy in a positive way and continuously rejects her husband, leading to frequent conflicts. In the domain of "daily obligations", periods of hard work are followed by periods when she tends to do nothing, feeling ill or incapacitated. She is either too busy or collapses into various illnesses experienced as physical. In the domain of social activities we observe a total absence of mutual social contacts. Outside her family and her work she has no social contacts whatsoever. She also indicates that she has virtually no free time, as she continuously feels compelled to meet her daily duties.

A follow-up one year later showed that the process of losing contact with her family and especially with the children who left home had continued. The number of roles she performed had slightly diminished, and her social contacts were also fewer. This case illustrates how a deficiency in supportive role performance as well as in role performance in the domain of social activities leads to a decline in the number and variability of social roles. In the years after onset of mental health care she lost many of her position roles and increasingly focused on her family. Now, little is left except her family, but her current position is not very well appreciated. In this case, the accuracy of assessment was a major problem. The patient tended to either exaggerate or underestimate her own level of performance, and was sometimes confused or annoyed by the questions posed to her. We had to rely predominately on information obtained from her husband, her son, and from the mental health professional, who shared their opinions. The most important factor limiting an accurate assessment was, of course, her limited appraisal of her own problems and of the effect of her behavior on her social position within her family.

In Table 13.4 (next page) we present the data generated by these two cases, which represent a for women of this age typical pattern of deterioration subsequent to a loss of a meaningful daily obligation. The first case illustrates a powerful deterioration of role performance in most domains. Despite the fact that she recognized that her current state was deplorable, she felt incapable of doing anything during the day. In the second case, we also observe a gradual diminishment of social integration over the period of one year, as may be observed in the variabilty of the social contacts as well as the 
Table 13.4 Differentiation of social role performance, social contacts and position roles in the older married women at onset

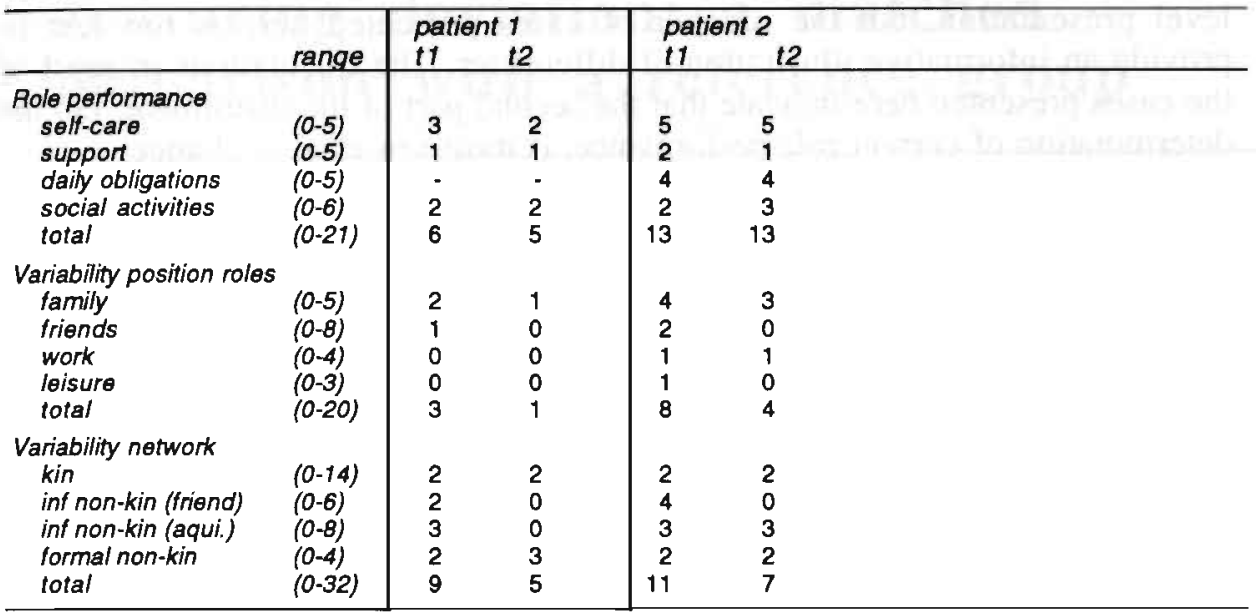

positionary roles. The level of social role performance was almost the same in both assessments.

\subsection{Summary}

At first sight, the figures presented in this chapter demonstrate that the differentiation presented in the case histories is reflected to a large extent by the data. A good social integration is represented by high scores in role performance, a wide variation in the position roles and a large social network. Low role performance is markedly accompanied by fewer roles related to the sectors "friends", "work" and "leisure". We can also see that fluctuations in role performance between the first and the second interview are reflected by the data, indicating a reasonable sensitivity for change in role performance. The large variability in role performance, position roles and social network noted elsewhere (Chapter 10), is confirmed in this excerpt. When we compare the developmental patterns in the case reports, we may observe that only the young unmarried show a stagnation in development, which is a finding confirmed by our data. The pattern of relapse, however, is less clear in a case level presentation, and has more relevance on the level of distinction between groups of patients and identification of factors determining chronicity.

In short, we may conclude that the observable differences in the case histories are reflected by powerful fluctuations in the data provided by the instrument. The fluctuations vary, however. Some cases show important changes in role performance, accompanied by less impressive changes in the position roles or 
the density of the social network; others show more gradual changes in role performance, but more impressive changes in the position roles. When we look at the developmental patterns we observe some differences at the case level presentation, but the number of cases presented here is too few to provide an informative illustration of differences. The fluctuations in most of the cases presented here indicate that the second part of the instrument, i.e. the determination of current role performance, is most sensitive to change. 


\section{Measuring deviation: a matched comparison with a reference group}

Each measurement concerning a deviation deals with a norm. To evaluate the clinical validity of the item choice we have to know whether the instrument discriminates between a normal and a patient sample. Does the information reflect the extent to which the patients are less socially integrated? And secondly, does it reflect information on the extent to which the patients rerform less well? If the data we obtained from normals provide the same $p_{1}$ ture we obtained from patients we may be measuring seemingly valid inf -mation. To deal with this question, we performed a matched comparison with a sample from the registered healthy population of three general practitioners. Only patients with no current medical or psychological complaint or illness were included in the reference group. Secondly, the reference group was matched pairwise on a number of demographic characteristics which determine the status role to a certain extent: age, sex, marital status and social level. The main objective of this chapter is to investigate whether our instrument indeed measures impairments in social role performance and to see whether the differences in role performance are accompanied by differences in the number and variability of position roles as well as social contacts.

\subsection{Hypotheses on differences between patients and references}

In the previous two chapters, we concluded that role performance within the most important domains of social functioning may be regarded as a determinant of the number and variability of the position roles. A high level of social role performance increases the opportunity of obtaining more position roles within different settings. The number and variability of the position roles determine the opportunity which the individual has to establish a social network, and may be expected to be directly related to the size of the personal network. A healthy and variable social network provides many opportunities to relate with people in various ways, i.e. it enhances role performance. So, a circular relation may be assumed as follows: role performance within the most important domains of social functioning may be regarded as a determinant of the number and variability of the position roles (Figure 14.1, next page). The number and variability of the position roles determine the size of the personal network, which in itself enhances role performance. The above interrelationships have some consequences for the interpretation of our data. When we regard the social position an individual has obtained, we may expect the individual to perform within a minimum number of position roles, which may be referred to as the core roles (Walker et al., 1977). A fully integrated 
Figure 14.1 Interrelations between role performance, position roles and personal network.

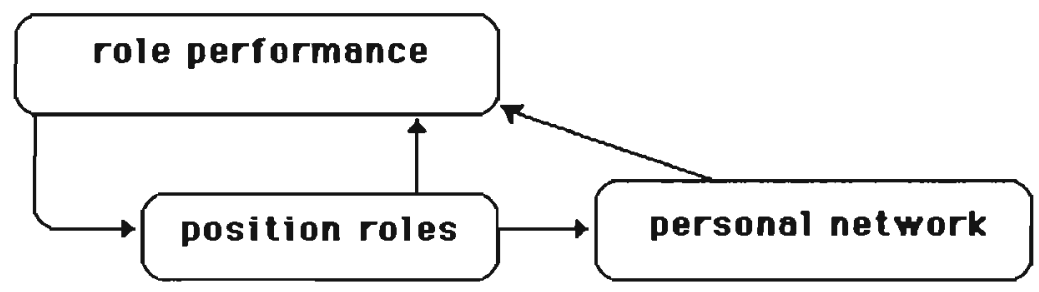

individual may be expected to perform within the family, within a job, to have a number of friends, and to perform some roles within clubs. A chronically handicapped individual may be expected to lose the roles connected to the job. Position roles within clubs are also lost as the individual cannot meet his obligations. Other roles destabilize. The position of the individual is a dependent one, requiring support. Only when the individual has built some credit in his personal network can he rely on receiving support (the sick role, Parsons, 1951). So, we may argue that the individual suffering from a health deviation loses a substantial number of his position roles and may have difficulties in maintaining the status roles. The composition of the personal network also changes, as the individual relies on fewer people, predominately in the kin and formal non-kin sector. Role performance may be expected to be limited in more than one domain. With respect to the comparison between patients and reference group we may formulate the following hypotheses. Patients have:

a. more limitations in role performance, leading to;

b. a decrease in the number and variability of the position roles, and leading

to;

c. less balanced and more instable personal networks.

The last point, the stability of position roles and social network, was not completely investigated as our assessment of the reference group was crosssectional and only covered their current situation. In our comparison we will focus on the current role performance in the five domains. We will assess the differences in the number and variability of the position roles and investigate these differences. In the comparison between patients and reference group we are primarily interested in the differences in impairment of social role performance. Assuming our items only measure deviation, we should expect normals to show low scores. Second, we want to know whether the reference group fulfills more stable and demanding position roles. We expect the reference group to have a larger number of position roles and more roles in the more demanding domains of work and social activities. Third, we want to know whether the reference group has a larger and more differentiated social network. With respect to the variability of the social contacts we assessed the number of social contacts, their spread over the various sectors (Janssen, 
1992). We expect the reference group to have a more equal spread of their contacts over the two sectors kin and informal non-kin. The patients will rely predominately on their family and the formal non-kin sector.

\subsection{Selection procedure}

We were interested in obtaining information from a group of normally integrated people with no psychosocial or psychiatric history. We obtained the reference group using the Registration Network Family Practices (RNH, Metsemakers et al; 1992) and a database of a rural general practice ${ }^{28}$ as we wanted to be sure we gathered references with no previous psychiatric history.

\section{Figure 14.2 Non response}

\section{Selection path}

population:
totol RNH
database
Choice of two
general
practices

Psychological or psychiatric complaints

Motching

Consent

G.P.

Consent potients

\section{Response / non-response}

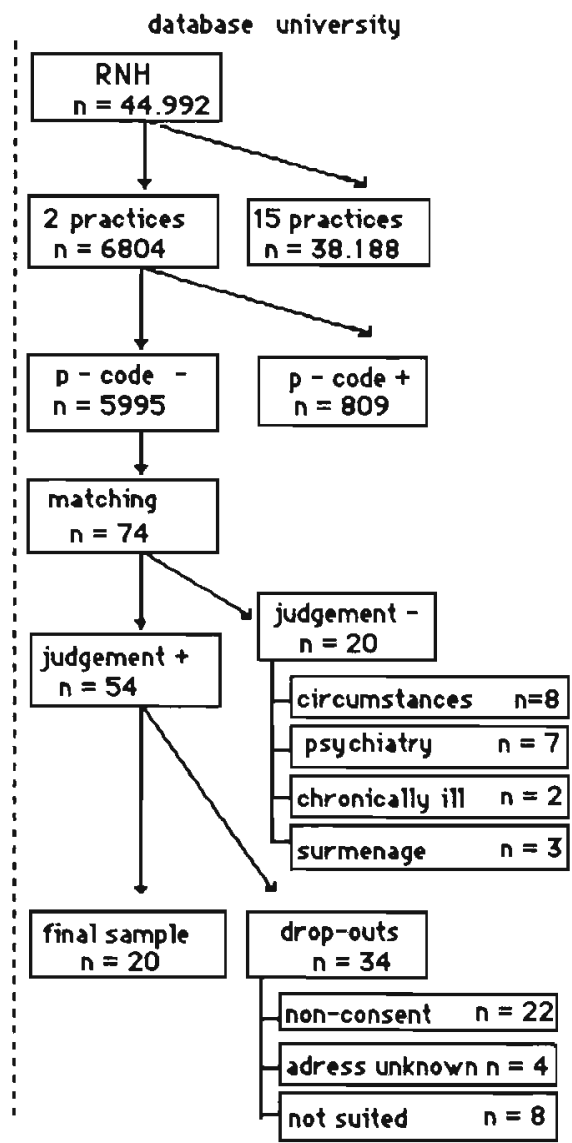

rural G.P.

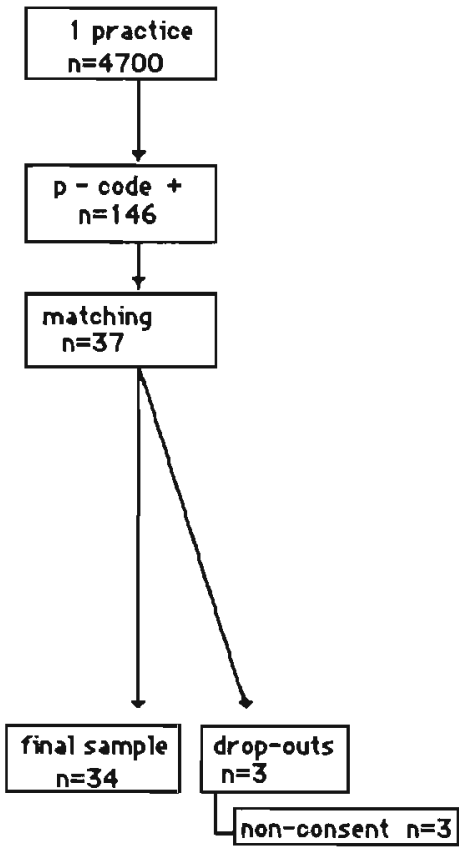


The reference group was matched with the following two patient groups:

1. the group of unmarried men at onset, younger than $30(n=20)$;

2. the group of married women at onset, older than forty $(n=12)$.

With an extensive matching and selection procedure, we made an effort to match each patient with two references. Several problems were encountered. Especially in the first group we could not meet this criterion, as quite often more than one suitable match simply did not exist. Using computerized databases from the general practitioners, we matched the references on the variables "age", "marital status" and "educational training". The last variable was used as an indicator of social class, a variable we wanted to keep under control but which could not be included in the matching procedure because the databases used for the comparison did not contain this variable. It proved, however, to be a good indicator, as few differences arose between cases and references (presented in Table 14.1). The various steps in the procedure together with the selective non-response rates are indicated in Figure 14.2.

In the RNH database, the first four selection steps were performed anonymously. 809 of the 6804 patients in the two general practices had a psychological or psychiatric complaint at the moment we performed the selection. In the database we obtained 74 identification numbers matching the data of our patients. The names of the patients corresponding with these numbers are known only to the G.P. Because the database is updated only once in three months, we asked the G.P. to indicate which patients met our criteria. 54 patients were asked by the G.P. to participate. $28(52 \%)$ consented. Of these, 8 proved not to meet our criteria. Finally, the procedure left us with 20 subjects. To obtain the remaining reference population, we contacted a rural G.P. who performed the same procedure using his administrative database. Now, 37 patients were asked to partcipate. 34 (91\%) consented. Sampling procedures were carried out in three months, thus obtaining 51 references, 27 for the first and 24 for the second group. A net response rate (Kish et al., 1959) of $69 \%$ was obtained.

\subsection{Comparisons}

A brief version of the instrument was developed for the reference group, assessing only the current status and position roles as well as the current role performance, using open-ended questions, formulated in the same way as in the patients interview. Because we wanted to know if we had to correct the outcome of the measured differences for gender, we first investigated the gender differences in social role performance, position roles and personal contacts in the reference group, by means of a Mann-Whitney rank order test and the Student $\mathrm{t}$-test. Then we compared the results of the patient interviews of the cases with self-reports of the reference group, again by means of MannWhitney rank order test and the Student t-test. 
The following variables were included in the comparison:

a. the sumscores on the four domains "self-care", "support", "daily obligations" and "social activities";

b. the total number of position roles, as well as the number of position roles related to family, friends, vocational setting, and leisure;

c. the total number of social contacts, as well as the number of social contacts related to the sectors "family", "friends" and "social services".

In the reference group, we may expect that the older women have less social contacts and perform fewer roles. Their social contacts will be found predominately in the kin sector, while in the young men we may expect the social contacts to be more equally spread over kin and non-kin. On the other hand, we may also expect the role performance to be different. The young men will perhaps perform less well in self-care but better in the domain of daily obligations.

\subsection{Results}

\subsubsection{Outcome of the matching procedure}

The groups "young and unmarried men at onset" and "older married women at onset" were selected for comparison with the reference group. In Table 14.1, the variables applied in the matching procedure are presented. The two gender groups are presented separately. The results indicate that some references were difficult to obtain, e.g. single men in the age group over 40 . Despite some minor differences, we may conclude the matching procedure was successful.

Table 14.1 Demographic characteristics of the reference groups and the cases

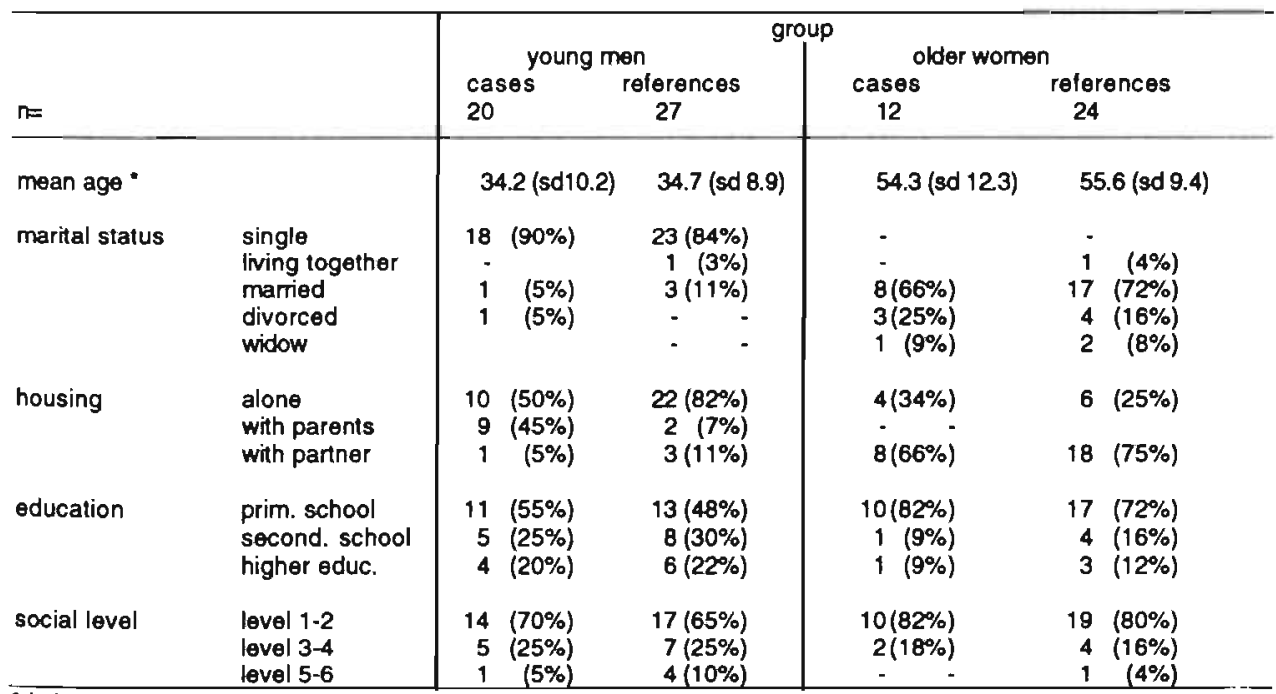

- in brackets we present the standard deviation. 
The only problem encountered was to obtain unmarried references in the older age group. A major difference was the large proportion of young male patients still living with their parents.

\subsubsection{Cases and references: comparison in role performance}

Table 14.2 presents the results on the comparison in role performance between cases and references. The results in this table are an indication of the sensitivity of the instrument. In the domains showing major differences, we may assume that we indeed measured a deviance in role performance. The domains showing no difference have little relevance.

Table 14.2 The comparison on Social Role Performance between the reference groups and the cases

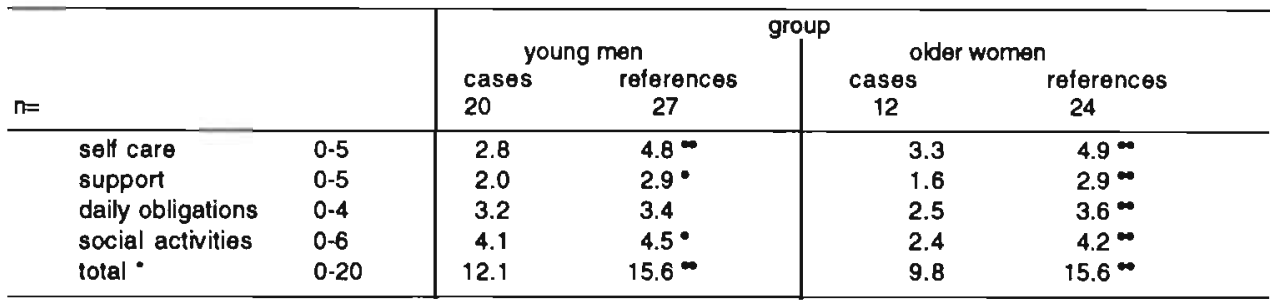

- $p<0.05 \quad p<0.001$. M-W rank order test. " totals over selfc., supp., daily oblig. and social activ.

These data show that most of the domains differentiate well between cases and references. In the domains "self-care", "support" and "social activities" we indeed measure deviations. The total score is also significantly different in both groups $(\mathrm{p}<0.001)$. In the group of older women at onset the differences with the references are more powerful than in the group of young men at onset. The differnces in the young men at onset concerns primarily the domain selfcare, and to a lesser extent the domains "support" and "social activities". In the domain of self care this is primarily caused by the items cleanliness own house and planning on short and long term. Secondly, in the domain of support this is primarily caused by the items problem and conflict solving. Finally, in the domain of social activities this is primarily caused by the items taskoriented interaction, person oriented interaction and mutually consented interaction. The only measure showing no differences between the cases and the references is the domain of "daily obligations" in the group of young men at onset. A possible explanation of this is the large number of missing cases among the patients ${ }^{29}$. This finding fits with the findings in Chapter 7 and 8 , where we also concluded that the domain of daily obligations was difficult to interpret. Contrary to what we may expect - with the stereotype of the young only 6 valid cases. Sexuality contains 15 valid cases $n$ the group of young men, and 7 valid cases in the group of older women. The other domains contain no invalid cases. The references provided a complete response. 
chronic in mind - the measured deviation is more powerful in the group of older women.

\subsubsection{Cases and references: variability of position roles}

Table 14.4 presents the results on the comparison in the number and variability of the position roles between cases and references. We may expect the young men to have fewer roles related to work and leisure, while the older women have more roles related to the family. As our young male patients are known to be socially isolated, we may expect more powerful differences. We also present the standard deviation (in brackets), to indicate the degree of overlap of the reliability intervals. A large overlap indicates that the differences are less powerful.

Table 14.3 The comparison on position roles between the reference groups and the cases

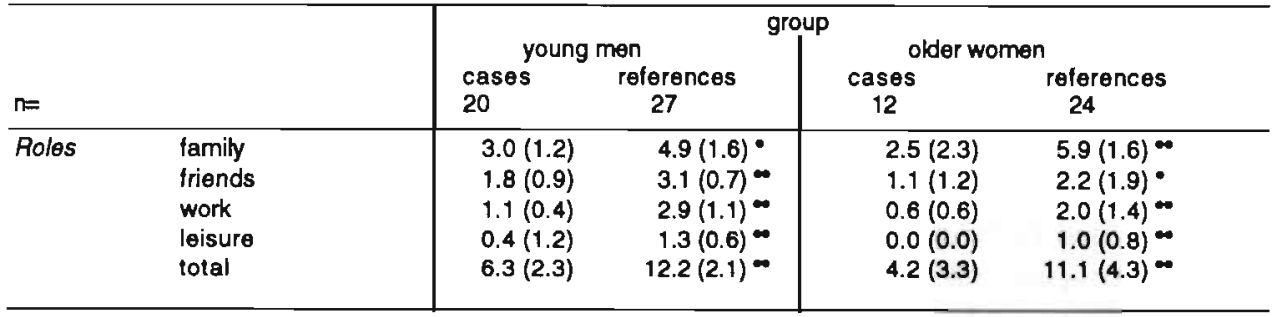

- $p<0.05, \infty p<0.001$, Student t-test. No missing cases.

The results show important differences in all kinds of roles. The number of roles in the family is far less in both groups of patients. Despite the fact that few of the references still live with their parents, they do appraise their interaction with their family as far better than the cases, and mention a wider variety of position roles. A more careful analysis shows that the difference concerns predominately the position roles performed within the extended family. The differences in the sectors "friends" and "leisure" are an effect of less participation in clubs and engagement in fewer outward activities. Roles as "partner", "parent" and "child" are still mentioned, even in the most isolated patients. More than half of the cases in the group of young unmarried men at onset, however, do not mention the role "close friend", while all of the references do. Finally, we may notice the greater variance in the older group, reflected by the data of both cases and references.

\subsubsection{Cases and reference group: network variability}

Table 14.5 presents the results of the comparison in the number and variability of social contacts between cases and references. As the composition of the social network is closely related to number and variability of position roles, we may expect the patients to have significantly fewer contacts in all sectors. 
Table 14.4 The comparison on the variability of the social network between cases and the reference group

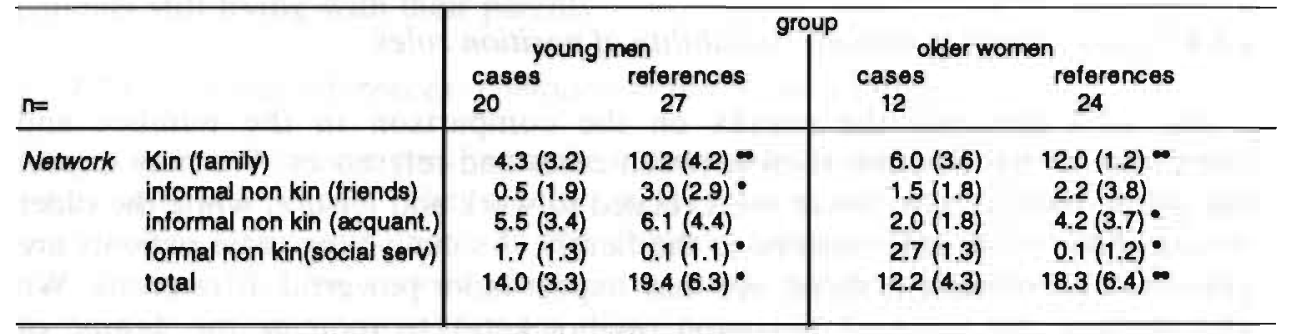

$\cdot p<0.01, \cdots p<0.001$, Student-t test. No invalid cases.

These figures show major differences in all sectors. The findings are, however, less specific than we observed in the position roles, which is due to the large variance. From the literature we know that the size of the social network has little relevance (Tolsdorff, 1976) but that the needs met within the network are far more important. Not the extension of the network, but the functions met within the network may be regarded as being related to (mental) health (Janssen, 1992). Nevertheless, when we take a more careful look at the sector "friends" some differences may be noted. Especially close friends seem to be virtually absent in the young male patients, while older women have fewer acquaintances but some close friends. This perhaps indicates a difference in the composition of the network in patients with an early or a later onset of mental illness, a possibly interesting point in future studies. Again, we observe a focus of the older women on the family, while the younger have more outward social contacts. A salient, but not surprising, finding is the relatively large number of contacts with social service professionals reported by the patients (more than e.g. close friends).

\subsection{An overview of the findings}

The analyses in this chapter were aimed at validating our measurement of deviation in current role performance. We were interested in the social role performance of normals. Second, we wanted to know whether impaired role performance can be related to less variability in the kind and number of position roles, as well as to less variability in the social network. When we compare the two groups of references with one another, we observe some differences in the number and variability of roles in the sectors "family", "friends" and "work" ( $<<0.05)$.

The group of young (predominately unmarried) men show an equal spread of their social contacts over the kin and non-kin sectors $(55 \% / 45 \%)$, while the older (predominately) married women have a focus on their kin $(66 \% / 33 \%)$. Concerning the comparison of role performance, the results show major differences between patients and references in all domains except the domain of daily obligations. This domain measures social role performance only when 
the patient has a job or housekeeping responsibilities. Consequently, the lack of these responsibilities leads to missing values. Most of the patients who do have a job work in a protective setting, where the level of performance is adjusted to their own possibilities.

In the group of young unmarried men at onset, the most powerful deviations are measured in the domain "self-care". A slight deviance was measured in the domain of "support" in both groups, the older showing a slightly greater difference than the younger. In the group of older women we observed the most powerful difference in the domain of social activities. When we look at the variability of the position roles and the composition of the social network, we see a focus on the family in the older women and a wider spread of roles over different sectors in the younger men. Concerning the position roles, the most powerful difference in this respect are found in the roles related to friends and work. Concerning the composition of the social network, the most important difference in the group of young men is the virtual absence of close friends, while the older women have far fewer acquaintances and outward contacts. Both groups show fewer contacts with the extended family.

\subsection{Summary}

The analyses in this chapter show that we need to adjust our measurement of role performance in the domain of daily obligations. All items now concern performance in a vocational setting, whether protective or not. Many patients have lost their work. Other items have to be formulated, relate more to the absence of work.

The measures in all other domains show reasonable differences between cases and references, indicating that we indeed measure a deviation from a norm, and that our measurement has a certain clinical validity. Second, we may conclude that the variability of position roles is a good indicator of the degree of social integration when it is evaluated at a global level and related to specific sectors of relationships. For example, in the context of the family, in relationships with friends, at work, or in roles related to leisure. When we evaluate the variability of the social contacts, the most important differences are found in the contacts with close friends and extended family. The differences here between cases and references are, however, less specific than in the comparison of the achieved position roles. 


\section{PART 5}

\section{Conclusion}

This part has two chapters. Chapter 15 contains the summary and the conclusions as well as the recomendations for further development of the instrument, which will be brought into effect in a follow up project, a collaborative study with a number of Psychiatric Rehabilitation Services throughout the Netherlands (NFGV grant 92\#3089). Chapter 16 contains the Dutch summary and conclusions.

Even the 'quick' readers shouldn't miss much of this part. Family and friends who easily want to read what it is all about in our own language may turn to Chapter 16. 



\section{Summary and conclusions}

This book describes a study into the reliability and validity of an instrument designed to assess social role fulfillment of chronic mentally ill in ambulatory care. The assessment is designed to promote rehabilitation activities for the chronic mentally ill living in the society. In the structure of this book you may recognize two major parts. First, the predominately theoretical preliminaries and pilots leading to a first selection of the items in the Social Role Performance and Development Inventory (presented in the Chapters 1, 2, 4, 5 and 6). This is summarized in paragraph 15.1. Second, the predominately empirical findings on the consistency, reliability and validity of the instrument (presented in the Chapters 8 to 14). These are discussed in paragraph 15.2. In paragraph 15.3. we discuss some methodological problems encountered in the study. In paragraph 15.4, finally, we present the most important conclusions and some choices we have to make before starting a collaborative study with a number of rehabilitation services throughout the Netherlands to implement the instrument in patient care.

\subsection{A summary of the instrument development}

\subsubsection{Preliminaries: Chapter 1 and Chapter 2}

The aim of this thesis is to work out a means of investigating the development of social integration in the chronic mentally ill. In Chapter 1 , we presented an outline of our theoretical considerations. In this chapter we formulated a philosophical choice concerning the definition of the interplay between mental illness and social integration. The philosophical basis of the relationship between cause and effect in this thesis is derived from what Querido formulated as the social homeostasis mechanism. In his opinion, a (mental) disorder may be regarded as a displacement of social integration. Following Querido, we can regard role performance as determinants of social integration, while vice versa social disintegration is determined by deficits in social role performance. In the interaction of the individual with the social environment, the individual and the environment always seek an equilibrium. Disruption of the equilibrium always introduces a compensatory mechanism, either within the person or by the environment. Social rehabilitation has to focus on this interaction with on one side the individual and his or her possibilities for change in order to take a more complete membership of society and on the other side the possibilities of changing the forces that have led to the loss of membership. 
This view stresses the need for an inventory which not only addresses current performance, but tries to relate this to understanding the development of social role fulfillment and social integration. In our opinion, a detailed and systematic knowledge of current as well as past performance is essential for the planning of interventions. This view also relates to our choice concerning the format of the instrument: an open qualitative - interview based assessment. This method leaves some room for focusing the interview on specific areas. Thus, the assessment can be tailored for the specific needs of the patient.

In Chapter 2 we presented our first effort to apply these ideas in the construction of an instrument in greater detail. We discussed the need for a systematic and practical inventory assessing the main problem areas of the chronic mental patient within his social context. The basic principles described above are applied in a first operationalization of the instrument. In contrast to the current view in most instruments, we do not focus on the disturbance, i.e. the abnormality, but we focus on the degree of normality. In this we formulated our choice for the concept of social role performance, concerning five areas of daily life: "self-care" and "care for others", "support", "sexuality", "daily obligations" and "social activities". The selection of these areas is based on the theory of the organization of society as formulated by $U$. Gerhardt (1971), combined with relevant aspects of the theory of socialization as formulated by $\mathrm{K}$. Hurrelmann (1983). We presented a case history illustrating an interaction process leading to a deadlock between the individual and the direct environment. This case presentation clarifies the application of the instrument in the daily practice of mental health care.

\subsubsection{Sample selection: Chapter 3}

The second part of this book provides information on our definition of chronicity and the selection of the samples in the study. Chapter 3 starts with a summary of several views on chronicity in psychiatry. These views are used to formulate the definition of chronicity we apply in this study. Two kinds of chronic mental patients are distinguished. Firstly, those not yet - but at risk of becoming - chronic mentally ill, with a history of care longer than one year and shorter than two years, and with a dysfunction on more than two levels of the four subsequent levels: the somatic level, the individual level, the micro social level and the mesosocial level. Secondly, those defined as chronic mentally ill; having had a history of care longer than two years, and a dysfunction in more than two levels. This definition is applied in the selection procedures in the various samples of the study. A pilot was carried out within the "not yet chronic" population. The main study was carried out in the population defined as "chronic". The chapter finishes with a description of the samples we investigated. Using a number of variables concerning diagnosis, patient career and a number of sociodemographic characteristics, we show that the samples are a fairrepresentation of the population in care at the Rehabilitation Service of the Community Mental Health Center Maastricht. 


\subsubsection{Theory and conceptual definitions: Chapter 4}

In Chapter 4 , a theoretical framework concerning both achievement of social roles in terms of status and position roles as well as role performance, role transitions and lifetime human development is presented and related to the lifetime histories of the mental patients. To describe fulfillment of role, two dimensions were introduced after an extensive consideration of relevant theories:

1. What has the individual achieved? Two outcome parameters were introduced as indicators of what the patient has achieved in terms of social integration:

a. the number of position roles;

b. the number of social contacts.

2. How was this achieved? Five domains of social role performance were introduced as relevant areas of daily functioning in which behavior develops:

a. self-care and care for others;

b. support;

c. sexuality and intimacy;

d. daily obligations;

e. social activities.

This theoretical framework is transformed into a model relating the concept of social role to the concept of rehabilitation.

\subsubsection{The need for a new instrument: Chapter 5}

Chapter 5 presents a comparison of our theoretical framework with the current state of the art. A selection of the most important instruments concerned with the judgment of social behavior in psychiatry is reviewed. We conclude that only a few instruments meet both our practical criteria and our theoretical propositions. Many instruments prove to be much too detailed to be practical. The few instruments which meet our most important criterion ("relating the performance of the individual to the demands set by the environment") leave out an essential feature for the chronic mentally ill: an assessment of the patient's possibilities. All focus on shortcomings rather than on abilities. Only the recently developed instruments provide a reliable assessment of the patient's development. Finally, most of the instruments were constructed using empirical data, with often few theoretical suppositions. We concluded that we needed to construct a concise, simple, practical and reliable instrument, which to a certain extent would be valid for its purpose: the assessment and judgment by mental health professionals of (the development of) role performance.

\subsubsection{Item selection procedure: Chapter 6}

In the construction of our instrument, therefore, we combined theoretical concepts on social integration and socialization theory with the practical input 
of a panel of experts. The items selected to judge the level of role performance had to relate to the daily practice of care, while the operational definitions concerning the level of social integration had to be simple and understandable. In Chapter 6 we discuss the operational definitions of the instrument in two sections "achieved social position" and "development of role performance". This chapter further contains the item-selection procedure in the five domains of social role performance. Each of these five domains was covered by a number of items. After determination of current functioning, we assessed to which extent the level of functioning at onset of care differed from current role performance. A reiterative panel study was performed as a first step in the construction of the instrument, the establishment of the content validity of these domains. In the development of our instrument we chose an extensive qualitative procedure in collaboration with a expert panel. Concerning the description of current role performance, the instrument was reduced from 68 to 30 items. In the final draft, 15 items covered the development of role performance. 20 items covered the background information, the status and the position roles.

\subsection{Findings of the main study}

\subsubsection{The main study, the design and objectives: Chapter 7}

In Chapter 7 we present the design of the main study. We chose to select four homogeneous groups with a specified age, sex and marital status at onset of mental health care. In the main study, information was gathered from patients and their professionals. The main study was carried out in 1990 and concerns the testing of the instrument. The first dimension - what the individual has achieved: the assessment of the achieved social position in terms of status and position roles - gathers factual information. Therefore, the main study focused on the reliability and validity of the second dimension, the performance on the items within the five domains of social role performance. In this part of the instrument the interpretations of the judges (either researcher or professional) are more important. Questions dealing with reliability and validity need to be adressed. The analysis performed and described in the Chapters 8 up to 14 are subsequently summarized in a logical order. Each analysis is a prelude for the next analysis.

\subsubsection{Reproducibility of the ratings: Chapter 8}

In the main study, our first concern was the reliability and reproducibility of the coding instruction. Data were generated by coding and recoding the information obtained from the patients by means of open-ended questions. The results in Chapter 8 show that the reproducibility was rather good, as most of the Kappa's were either substantial or good (criteria of behavioral research, Laundis \& Koch, 1977). A number of items were left out of further analyses, as they proved to be either indiscriminate (as the item "cleanliness own body"), or irrelevant (as the sub-domain "care for others"). Another problem noticed 
in this chapter was the moderate reliability of the items "sexual practice" and "experienced problems" in the domain of "sexuality". Quite a number of vague, indefinite or reluctant answers resulted in substantiate amount of missing values. We concluded, after performing some further analyses, that the moderate kappas in these two items were primarily an artifact of the method of analysis and to a lesser extent an effect of unclear responses.

\subsubsection{Construct and content validity: Chapter 9 and Chapter 10}

Our second concern was the validity of the division of the instrument into the five domains discussed above. In Chapter 9 we performed a number of simple analyses on the internal consistency of the schedule. Four of the five domains "self-care", "support", "daily obligations" and "social activities", proved to reflect distinct levels of functioning within coherent domains. The domain of "sexuality" proved to contain inconsistent items which were also entirely independent of the items in the other domains. We concluded that having a partner and being able to show a intimate and sexual behavior may rather be a predictor of role performance than a part of the construct. A confirmatory factor analysis was performed on the data of both professionals and patients and proved that the remaining four domains provided a valid construct of role performance, allowing the sum scores to be used in further analyses. This construct was used in the analyses presented in part IV (the Chapters 11 to 14).

An important conclusion was that the professionals provided the most consistent information, which may however be an effect of the more global and distant viewpoint of the professional. The professionals may be expected to have a more distant and global view of the performance of the patients, leading to a more global evaluation of the items, and a consequently better consistency. This is a factor we only can control when the assessment is done by a large number of professionals and a large number of patients, giving us the opportunity to correct for specific characteristics which determine the extent of the professional's knowledge of the role performance of his patients.

Our third concern was a further assessment of the content validity of the information. We wanted to know if the observations of the researchers were shared by the professionals. In Chapter 10 we compared the information obtained from the patients by means of open ended questions with the judgments gathered from the professionals by means of precoded items. When we reckon with a difference of opinion and viewpoint, we may again conclude that the findings are promising, and that the scores provided by the professionals and the researchers correlate in a satisfactory manner. At item level, the concurrence was the best in the most clear-cut domain of "self-care". Slight differences were observed predominately in domains as "support" and "social activities", while the domain of "daily obligations" provided some inconsistencies. At a scale level, the analysis of concordance shows a good agreement between patients and professionals. 
A correction of these analyses for the selection group, assuming the professional would know more about some groups than others, yielded no significant differences. We concluded that, against the background of contemporary research on judgment of behavior, our results are fairly promising.

\subsubsection{More complex aspects of validity: the Chapters 11, 12, 13 and 14}

The first analysis of an aspect of external validity was the establishment of the concurrent validity. Concurrent validity is established by comparison of a measure to an external criterion The external criterion has to be a validated measure of the phenomena to be explained. The results presented in Chapter 11 show that the behavior in terms of role performance reported by the patients reflects their experience of impairments in daily life quite well. For this purpose, we compared our instrument with an already existing instrument: the Sickness Impact Profile. Different versions of this instrument were chosen as an external criterion. The concurrent validity proved to be sufficient.

The second analysis concerning the construct validity was an analysis of the discriminative power of the instrument. In Chapter 12 we present a number of comparisons. These comparisons show that some important differences arise when we compare the patients with many discrepancies in their position roles with patients who have fewer discrepancies. The comparison between patients with and without a partner also revealed clear differences. The a priori selection, the age and marital status at onset of mental health care, proved to be less important than we expected. Also, no major differences between men and women were detected. We may conclude from these analyses that the instrument discriminates reasonably well between different groups and that the current achievement of position roles is a powerful indicator of social role performance as measured with our instrument.

The third analysis concerns a check of the clinical validity of the instrument at face-value level. Nine cases with typical patterns of role performance were selected and a follow-up interview was performed to assess the sensitivity of the instrument for change. The various comparisons in Chapter 13 show an important sensitivity for change over time, and also important fluctuations in the scores obtained from the various cases.

The fourth analysis concerns a comparison of a number of the patients with a number of matched references with no previous history of psycho-social complaints, selected from a number of general practices. This analysis shows that important differences arise when we look at role performance or when we evaluate the variability of achieved position roles. The difference in the number and variability of social contacts is less significant. However, our data only provide information of the structure of the social network, not on its more important functional characteristics. The main conclusion of this chapter is that most of the domains show important differences between patients and references, indicating that the instrument indeed measures deviation. 


\subsection{Methodological problems encountered in the study}

In the current study interpretation of the analysis is influenced by the limited number of patients included in the main study as well as the substantial amount of missing values in several domains. Starting with a total of 94 patients which fit our inclusion criteria 56 patients completed the whole protocol. The missing values occurred especially in the (sub) domain "taking care of others", and the domains "support", "sexuality" and "daily obligations". The missing values occurred for several reasons (also discussed in Chapter 9). The most important reason was that the patient was reluctant to provide an answer, which occurred quite often in the domain of sexuality. In a number of cases, the patient did provide an answer, but the answer proved to be too incoherent or vague to interpret. Because of these two problems a number of the analyses were performed on a borderline sized database. Further analysis on differences between the groups, presented in Chapter 12, showed that the missing values were not correlated to the diagnosis or the severity of the mental illness and also randomly spread over the selection groups. This problem effected especially the more complex analysis, such as the confirmatory factor analysis (Chapter 9) and the comparison with the healthy reference population (Chapter 14 ). The conclusions from these analyses should be looked upon as hypotheses to be tested in further research, rather than as definite answers to questions in this study. However, in most of the analyses the interpretation of the outcome remains feasible.

\subsection{Conclusions}

The main study shows that we developed an instrument that gathers information on development of role performance in a reliable and valid way. The two independent raters of the statements provided by the patients have a high level of agreement. The main cause of a less impressive level of agreement on some of the items was a low response rate, which is an effect of the relatively small number of patients participating in the study.

The agreement between the judgment of the professional and the judgment of researchers on the information obtained from the patients is satisfactory and even quite good when compared with the main body of literature on the judgment of social behavior. Even the assessment of the past provided reliable and valid information, a finding which is consistent with recent studies dealing with lifetime-assessment inventories. Our study confirms the current notion that retrospective assessment can be reasonably reliable if it is related to specific moments in life, major life events or important changing points. This finding led to a more specific formulation of the questions dealing with the past in the current version of the instrument which is applied in the follow-up study. In the follow-up study we emphasize a consistent specification of both current as well as past performance. In our experience, professionals often explore too much the personal feelings and experiences, rather than dealing concretely with what the patient really does, i.e. his performance. 
The study further shows that the instrument discriminates reasonably well between patients with a different level of functioning, a finding we analyzed at group level and at individual level. The results show that "having a partner" is an important predictor of the level of role performance as expressed in the sum score of the domains "self-care", "support", "daily obligations" and "social activities", a finding consistent with recent research. We may conclude that role performance can be measured by calculating the scores on the four domains "self-care", "support", "daily obligations" and "social activities".

When we look at the experience during the field work of the current study and relate this to recent developments in our field of research we may conclude that especially when we want to develop an instrument for such a heterogeneous group as the chronic mentally ill, an open interview covering a number of domains and embedded concerns is the most promising method of assessment. An open communication with the patient is the best way to establish reliable information, because it is less influenced by the patients own notions or by social desirability. To obtain reliable information this method requires an extensive training of the interviewer but is best tailored for the chronic mentally ill.

Finally, the instrument also proved to discriminate well between patient and healthy sample and proved to have a reasonable concurrent validity. This indicates that the instrument is sensitive enough to measure deviance, and that the items indeed represent distinct levels of functioning.

The most powerful differences in role performance between patients and references is found in the domains "self care" (primarily the young men) and "support" (primarily the older women) and "social activities" (all groups) and on items which are related to planning, initiative and dealing with problems and conflicts.

For use in daily practice, we propose that a feedback of the assessment with the patient and the professional has to cover:

a. a short overview on current and past status and position roles, thus providing an insight in major changes in social integration of the patient;

b. a short overview of the social contacts relating these contacts to the various settings the patient may function in;

c. a short overview of the social role performance and development focusing at the strong points as well as the dysfunctions of the patient;

d. a summary of the information gathered with this instrument related to the illness process and the process of disintegration, in order to deduct rehabilitation efforts. 


\section{HOOFDSTUK 16}

\section{Samenvatting en conclusies}

Dit boek beschrijft het onderzoek naar de betrouwbaarheid en validiteit van een instrument ontwikkeld om de hulpverlener te ondersteunen in zijn analyse van de chronisch psychiatrische patiënt in ambulante zorg. Het instrument kreeg de naam: de Vragenlijst Sociale Rolvervulling en Ontwikkeling (The Social Role Performance and Development Inventory). In de structuur van dit boek kunt u deze twee hoofdmoten herkennen. In de hoofdstukken 1, 2, 4, 5 en 6 van dit boek vindt $u$ eerst een verslag van de voornamelijk theoretische voorstudies en de pilot studies die geleid hebben tot een eerste itemselectie. Dit wordt samengevat in paragraaf 16.1. In hoofdstukken 8 tot en met 14 treft u het empirisch gedeelte aan met de bevindingen van de hoofdstudie. Hierin hebben we gekeken naar de reproduceerbaarheid van de coderingen. We hebben de interne consistentie (de samenhang tussen de vragen) onderzocht. Tenslotte hebben we een verschillende kanten van de validiteit (de geldigheid) van het instrument onderzocht. Dit wordt samengevat in paragraaf 16.2. Paragraaf 16.3 bespreekt een belangrijk methodologisch probleem, nl. hoe we om zijn gegaan met ontbrekende antwoorden. In paragraaf 16.4 staan de conclusies en bespreken we de keuzes die we moeten maken voor we het instrument in een vervolgstudie in de praktijk implementeren.

\subsection{Een samenvatting van de instrumentontwikkeling}

\subsection{De voorstudies: Hoofdstuk 1 en Hoofdstuk 2}

In deze dissertatie is gewerkt aan een methode om hulpverleners inzicht te geven in de ontwikkeling van de sociale integratie van chronisch psychiatrische patiënten. In hoofdstuk 1 presenteren we een schets van onze theoretische overwegingen. We beginnen met een filosofische benadering van de relatie tussen psychiatrische ziekte en sociale integratie. Deze filosofische benadering werd door Querido genoemd: het sociale homeostase mechanisme. Dit werd het theoretisch uitgangspunt van deze studie. Querido's sociaal homeostase mechanisme gaat er ten eerste van uit dat het individu voor zijn voortbestaan is aangewezen op geïntegreerd sociaal functioneren met andere individuen. Indien dit verstoord is, kan hij zichzelf aanpassen of zich buiten de maatschappij plaatsen, o.a. in ziekte of criminaliteit. Het individu zal zich buiten de maatschappij plaatsen als de discrepantie tussen individu en omgeving te groot is. Dit betekent dat ziekte de plaats inneemt van (een deel van) het sociaal functioneren. Ten tweede gaat de homeostasetheorie er vanuit dat herstel alleen mogelijk is indien het individu met anderen een coalitie kan maken. Meer mensen zullen dan met hem de situatie willen veranderen, iets 
waartoe hij alleen niet in staat is. Het belang van dit uitgangspunt, dat ziekte het geïntegreerd sociaal functioneren vervangt, is dat we in de omgang met patiënten een doel creëren en ons niet vastleggen op de middelen. Psychotherapie, gezinstherapie, netwerkopbouw en dies meer zijn allen slechts middelen. In deze theoretische conceptie betekent diagnostiek het maken van een persoonlijke theorie waaruit naar voren komt welk deel van het sociaal functioneren door de ziekte wordt vervangen, welke factoren in dat proces een rol hebben gespeeld en welke factoren beïnvloedbaar zijn, en vervolgens welke middelen we daarop moeten richten. In deze en tevens onze optiek behoort sociale rehabilitatie ofwel te werken aan een verandering van het individu, zodat deze in staat is weer deel te nemen van de maatschappij, dan wel te werken aan een verandering van de krachten die hebben geleid tot een verlies van lidmaatschap aan de maatschappij.

Deze visie heeft gevolgen voor de de manier waarmee de hulpverlener met de problemen van patiënten omgaat. Voordat de hulpverlener een behandelingsinterventie begint, zal hij zich goed dienen te realiseren of wat hij de patiënt wil bijbrengen ook toegepast kan worden in de levenssituatie van de patiënt. Daarom is het ook noodzakelijk niet alleen aandacht te besteden aan het huidig functioneren van de patiënt, maar dit ook te relateren aan inzicht in de ontwikkeling de sociale integratie van de patiënt. Deze visie hangt ook samen met onze keuze over de vorm van het instrument: een open vragenschema geörienteerd op kwalitatieve informatie door de hulpverlener te verzamelen. Deze methode is naar onze mening de meest adequate voor het verkrijgen van betrouwbare infromatie van chronisch psychiatrische patiënten, omdat daarmee ruimte ontstaat om het gesprek te richten op specifieke onderwerpen. Het geeft de mogelijkheid het interview op de maat van de specifieke behoeften van de patient te snijden.

In hoofdstuk 2 wordt beschreven hoe de theorie waar we vanuit gaan, geoperationaliseerd kan worden. Daarbij worden twee theoretische tussenstappen gemaakt. Met behulp van de theorie van Ute Gerhardt hebben we ervoor gekozen om maatschappelijke integratie af te meten aan de vervulling van positierollen en het hebben van statusrollen. Met behulp van de socialisatietheorie van Hurrelmann hebben we aangegeven dat het vervullen van positierollen alleen mogelijk wordt waneer op een vijftal levensgebieden adequate rolvervulling plaatsvindt. Deze vijf te onderscheiden domeinen zijn: "zelfverzorging" en "verzorging van anderen", "steun geven", "sexualiteit", "dagelijkse verplichtingen" en "sociale activiteiten". In tegenstelling tot de meeste huidige instrumenten richt de vragenlijst zich niet op de afwijking, het abnormale, de stoornis, maar op datgene wat nog over is van het "normale". In een gevalsbeschrijving laten we zien hoe een impasse kan optreden in de relatie van een chronisch psychiatrische patiënt en zijn directe omgeving. De gevalsbeschrijving illustreert de toepassing van het instrument in de dagelijkse praktijk van de zorg. 


\subsubsection{Selectie van de onderzoeksgroepen: Hoofdstuk 3}

Hoofdstuk 3 geeft een overzicht van verscheidene visies op chroniciteit in de psychiatrie zoals deze in de literatuur worden beschreven. Deze visies worden door ons gebruikt om een definitie van chroniciteit te formuleren, die we later in het onderzoek toepassen. Twee typen chronisch psychiatrische patiënt worden onderscheiden:

1. diegenen die langer dan een jaar, maar korter dan twee jaar in zorg zijn met dysfuncties in meer dan twee van de volgende vier niveaus van functioneren: somatisch, individueel, in de kleine groep en in de maatschappelijke verhoudingen;

2. de groep chronisch psychiatrische patiënten, die langer dan twee jaar in zorg zijn en met dysfuncties in meer dan twee van de genoemde vier niveaus van functioneren.

De eerste groep benoemen we in dit proefschrift als "verhoogd risco om chronisch te worden", de tweede als "chronisch". Het hoofdstuk eindigt met een beschrijving van de onderzoeksgroepen in de verschillende fasen van het onderzoek. Aan de hand van een aantal sociaal demografische en diagnostische variabelen tonen we aan dat deze groepen een goede vertegenwoordiging zijn van de volledige populatie in zorg bij de Sociaal Psychiatrische Dienst van het RIAGG te Maastricht.

\subsubsection{Theorie en conceptuele defenities: Hoofdstuk 4}

In hoofdstuk 4 werken we het theoretisch raamwerk uit. In dit theoretisch raamwerk relateren we een aantal begrippen aan elkaar. Het bereiken van sociale rollen in termen van status- en positierollen (wat heeft iemand bereikt), koppelen we aan de begrippen rolinvulling (wat doet iemand, concreet, op de bovenstaande domeinen) en roltransities (hoe liggen de overgangen door het leven heen). Deze algemene begrippen relateren we aan de levensgeschiedenissen van chronisch psychiatrische patiënten. $\mathrm{Na}$ een uitgebreide overweging van relevante theorieën onderscheiden we twee dimensies bij de invulling van het begrip sociale rol:

1. Wat heeft het individu bereikt? We onderkennen twee indicatoren van wat een patiënt bereikt heeft in termen van sociale integratie:

a. het aantal positierollen;

b. het aantal sociale contacten.

2. Hoe werd dit bereikt? We onderscheiden vijf domeinen van sociale rolvervulling :

a. zelfuerzorging en verzorging van anderen;

b. steun geven;

c. sexualiteit en intimiteit;

d. dagelijkse verplichtingen;

e. sociale activiteiten. 
Tenslotte werken we in dit hoofdstuk het raamwerk uit in een theoretisch model, waarin we het concept van sociale rolinvuling en rolontwikkeling verbinden met het begrip rehabilitatie.

\subsubsection{Literatuur overzicht: Hoofdstuk 5}

Hoofdstuk 5 geeft een vergelijking van ons theoretisch raamwerk met de huidige stand van zaken in de literatuur. Een selectie van de meest relevante instrumenten op het gebied van de beoordeling van het sociaal functioneren in de psychiatrie passeren de revue. We concluderen dat alleen een enkel instrument voldoet aan zowel onze practische als onze theoretische criteria. Een aantal instrumenten komen tegemoet aan ons belangrijkste criterium: komt de rolvervulling overeen met de verwachtingen van de omgeving". Deze instrumenten missen echter een ander essentieel kenmerk, namelijk een inventarisatie van de mogelijkheden van de patiënt. Deze instrumenten richten zich allen op tekortkomingen zonder in te gaan op de mogelijkheden van de patiënt. Slechts een enkel, recent ontwikkeld instrument, voorziet in een betrouwbare inventarisatie van de ontwikkeling van de patiënt op het gebied van het sociaal functioneren. Tenslotte zijn meeste instrumenten geconstrueerd met behulp van empirische gegevens, zonder een goed gefundeerde theorie.

We concludeerden dat we een kort, zo eenvoudig mogelijk, praktisch bruikbaar, en betrouwbaar instrument dienden te ontwikkelen, welke een waarde heeft voor het volgende doel: een inventarisatie en beoordeling van de huidige sociale rollen en de ontwikkeling van de sociale rolvervulling door hulpverleners.

\subsubsection{Item selectie procedure: Hoofdstuk 6}

In hoofdstuk 6 presenteren we de concrete operationalisatie van het instrument in de dimensies "bereikte status en positierollen" en"ontwikkeling van rolinvulling". In dit hoofdstuk bespreken we vervolgens de selectieprocedure van de items in de vijf domeinen van sociale rolvervulling. We hebben elk van de domeinen met behulp van een aantal items gemeten. Nadat het huidig functioneren van de patiënt was bepaald, inventariseerden we het verschil tussen het huidig functioneren en het functioneren in de periode rond de aanvang van de hulpverlenings-geschiedenis.

Het hoofdstuk bespreekt vervolgens de resultaten van een herhaalde panelstudie. Deze studie was de eerste stap in de validering van de constructie van het instrument: het bepalen van de inhoudsvaliditeit. In deze stap keken we met name naar de afgrenzing van de domeinen. In samenwerking met een panel van ervaren hulpverleners en senior-onderzoekers hebben we getracht items te selecteren die zouden kunnen differentiëren tussen mensen met een verschillend niveau van functioneren in de onderscheiden domeinen. In verscheidene rondes werd het instrument ingekort en bijgeschaafd. Wat betreft de beschrijving van de huidige rolvervulling werd het instrument ingekort van 
68 naar 30 items. In de versie die in de hoofdstudie is gebruikt dekten vervolgens 15 items de rolontwikkeling en 20 items de achtergondgegevens, de status en de positierollen.

\subsection{Bevindingen van de hoofdstudie}

\subsubsection{De hoofdstudie, ontwerp en doelen: Hoofdstuk 7}

In hoofdstuk 7 bespreken we de opzet van de hoofdstudie. We hebben er voor gekozen vier homogene groepen te selecteren uit de patiënten in behandeling bij de Sociaal Psychiatrische Dienst van de RIAGG Maastricht. In de hoofdstudie vergaarden we de informatie bij patiënten en hulpverleners. De hoofdstudie werd uitgevoerd in 1990 en richt zich op het testen van verscheidene betrouwbaarheids- en validiteitskenmerken van het instrument. Het eerste gedeelte van de vragenlijst - wat heeft het individu bereikt in termen van status- en positierollen - verzamelt feitelijke informatie. De hoofdstudie richt zich daarom voornamelijk op de betrouwbaarheid en validiteit van het tweede gedeelte, het voldoen aan de items in de vijf domeinen van sociale rolvervulling. Hierbij speelt de interpretatie door de hulpverlener een grotere rol en worden vragen naar betrouwbaarheid en geldigheid belangrijker. In hoofdstuk 7 geven we tevens een korte samenvatting van de analyses die in de daaropvolgende hoofdstukken 8 tot en met 14 volgen. Iedere analyse in de studie is te beschouwen als een logische stap in de verdere beoordeling van de betrouwbaarheid en de geldigheid van het instrument.

\subsubsection{Reproduceerbaarheid van de coderingen: Hoofdstuk 8}

In de hoofdstudie was onze eerste zorg de betrouwbaarheid. Dat betekent: in hoeverre zijn de codes herhaalbaar. Als ik een vragenlijst aan twee onafhankelijke codeurs voorleg, komen beiden tot dezelfde scores? De resultaten in hoofdstuk 8 laten zien dat de herhaalbaarheid van de coderingen behoorlijk te noemen is. De Kappa's - een vrij strenge maat van overeenstemming - zijn substantieel tot goed. In de daaropvolgende hoofdstukken hebben we een aantal items uit de verdere analyses weggelaten, omdat ze binnen de onderzochte populatie niet discrimineerden (zoals bijvoorbeeld het item zichzelf wassen). Andere items hebben we niet meegenomen omdat ze te weinig van toepassing waren in de onderzochte populatie (zoals de items in het deelgebied verzorging van anderen).

Een belangrijk punt dat opviel was de wat matige betrouwbaarheid van de items "uiting sexualiteit" en "ervaren problemen op gebied van sexualiteit": vage, onduidelijke of afwijzende antwoorden resulteerden in vele onbekende waarden. Toch hebben we besloten het domein wel in de daaropvolgende analyse te betrekken, omdat de matige Kappa's niet alleen het gevolg waren van onduidelijkheden in de antwoorden, maar ook samenhingen met de wijze waarop we de analyse hebben uitgevoerd. 


\subsubsection{Construct en inhoudsvaliditeit: Hoofdstuk 9 en Hoofdstuk 10}

Onze tweede zorg was de geldigheid (validiteit) van de opdeling van het instrument in de vijf bovenvermelde domeinen. In hoofdstuk 9 beschrijven we een aantal eenvoudige analyses naar de interne consistentie van het instrument. Vier van de vijf domeinen - te weten zelfverzorging, steun geven, dagelijkse verplichtingen en sociale activiteiten - bleken verschillende nivo's van functioneren weer te geven binnen intern goed samenhangende domeinen. Het domein sexualiteit bleek minder consistente items te bevatten, die ook in het geheel onafhankelijk waren van de andere domeinen. We concludeerden dat de aanwezigheid van een partner en het uiting geven aan sexualiteit eerder voorspellers zijn van een goede rolvervulling, dan dat ze deel uitmaken van ons construct. Behalve deze eenvoudige analyses voerden we een "Confirmatorische Factor Analyse" uit op de gegevens van zowel de hulpverleners als de patiënten. Deze analyse liet zien dat het model niet verworpen werd, en dat de vier domeinen een redelijk valide construct vormen van sociale rolvervulling. Deze conclusie gaf ons de gelegenheid de somscores van de vier domeinen zelfverzorging, steun geven; dagelijkse verplichtingen en sociale activiteiten toe te passen in de verdere analyses, die we in de laatste hoofdstukken van dit boek bespreken.

Een tweede conclusie was dat de hulpverleners het meest consistente antwoordenpatroon lieten zien. Echter, van hulpverleners mag een meer afstandelijk en globaal oordeel verwacht worden. Dit leidt tot een globalere evaluatie van de items, en dientengevolge tot een betere consistentie. Dit gegeven kunnen we alleen controleren als we het instrument toepassen op een groter aantal hulpverleners die daarmee een groter aantal patiënten beoordelen, dan waaraan we toekwamen in deze studie. Dan kunnen we ook rekening houden met specifieke factoren die van invloed zijn op diepgang in de kennis van de hulpverlener over zijn patiënten op het gebied van sociale rolvervulling.

Onze derde zorg was de inhoudsvaliditeit van de informatie die we met behulp van het instrument hebben verzameld. We wilden weten of hulpverleners vergelijkbare beoordelingen gaven als de onderzoekers uit de interviews met de patiënt haalden. In hoofdstuk 10 vergeleken we de informatie, die we verkregen via de open vragen in de patiëntenversie van het instrument, met de gecategoriseerde beoordelingen van de hulpverleners. Als we rekening houden met verschillen van positie en visie, kunnen we concluderen dat de overeenkomsten tussen beide redelijk goed te noemen zijn. Op itemnivo was de overeenkomst het beste in het meer concrete domein van zelfverzorging. We observeerden geringe verschillen in de domeinen steun geven en sociale activiteiten, terwijl het domein van dagelijkse verplichtingen meer verschillen liet zien. Kijkend naar de vijf domeinen laten de analyses zien dat er een goede overeenkomst is in het antwoordenpatroon van patiënten en hulpverleners. Eindconclusie was dat de resultaten veelbelovend zijn, met name tegen de 
achtergrond van huidig onderzoek op het gebied van de beoordeling van sociaal gedrag.

\subsubsection{Meer complexe kenmerken van validiteit: Hoofdstuk 11, 12, 13 en14}

De eerste analyse van een aspect van de validiteit betrof "de concurrente validiteit". Concurrente validiteit wordt bepaald door een meetinstrument met een extern criterium te vergelijken. Dit extern criterium moet een geldige en gevalideerde maat zijn van de fenomenen die men wil meten. Als vergelijkingsmaat hebben we de in het Nederlands vertaalde versie van de Sickness Impact Profile (De Witte, 1987) genomen. De resultaten in hoofdstuk 11 laten zien dat het instrument, dat wij als vergelijkingsmaat hebben gekozen, gevoelig genoeg is om afwijkingen van het normale in onze selectie van patiënten te meten. Verder zien we dat gedrag in termen van rolvervulling redelijk samenhangt met beperkingen die in het dagelijks leven worden ervaren. De concurrente validiteit met het gekozen externe criterium, de Sickness Impact Profile is voldoende te noemen.

De tweede analyse van een aspect van de validiteit betrof het "discriminerend vermogen" van het instrument. In hoofdstuk 12 presenteren we een aantal vergelijkingen. Deze vergelijkingen laten belangrijke verschillen zien als we patiënten met vele discrepanties in de vervulling van hun positierollen vergelijken met patiënten met weinig discrepanties. De vergelijking tussen patiënten met en zonder een partner liet ook duidelijke verschillen zien. De a priori selectie, gebaseerd op leeftijd, geslacht en burgerlijke staat bij aanvang van hulp, gaf minder belangrijke verschillen dan we op grond van de pilotstudies verwachtten. Tenslotte vonden we geen belangrijke verschillen tussen mannen en vrouwen. We concluderen uit deze analyses dat het instrument redelijk goed differentieert tussen de verschillende groepen, en dat vooral de huidige vervulling van positierollen een belangrijke indicatie geeft van sociale rolvervulling zoals gemeten met ons instrument.

De derde analyse ging over de klinische waarde van het instrument: geeft het instrument ook verschillen weer tussen patiënten binnen een groep. We selecteerden negen casussen. We voerden ook ongeveer een jaar na dato van het eerste interview een follow-up interview uit, om een indruk te krijgen van de gevoeligheid van het instrument voor veranderingen. De vergelijkingen gepresenteerd in hoofdstuk 13 laten een gevoeligheid van het instrument voor veranderingen over de tijd zien, en ook duidelijke fluctuaties in de scores verkregen in de verscheidene casussen.

De vierde analyse betreft een vergelijking van een deel van de patiënten met een aantal gematchte "gezonde" proefpersonen zonder psychosociale klachten in de anamnese. Deze proefpersonen werden geselecteerd uit de geürbaniseerd praktijken van het Registratie Net Huisartsenpraktijken en uit een perifere praktijk in Gelderland. In hoofdstuk 14 laten we zien dat er belangrijke verschillen zijn tussen de patiënten en de proefpersonen als we kijken naar de sociale rolvervulling of als we kijken naar het aantal en de variabiliteit in de 
positie rollen. Het aantal en de variabiliteit van de sociale contacten laat minder duidelijke verschillen zien. Echter, onze gegevens geven alleen informatie over structurele kenmerken van het netwerk, niet over functionele kenmerken van het netwerk. De belangrijkste conclusie van dit hoofdstuk is dat de meeste domeinen duidelijke verschillen laten zien tussen patiënten en "gezonden", wat aangeeft dat het instrument inderdaad een verschil meet.

\subsection{Methodologische problemen die we in de studie tegenkwamen}

In deze studie wordt de wijze waarop we de data konden analyseren en interpreteren, beïnvloed door het beperkte aantal patiënten die deelnamen evenals het behoorlijke aantal onbekende waarden (missing values) in sommige domeinen. Van de 94 patiënten die voldeden aan de insluitcriteria hielden we 56 patiënten over voor de analyses. De onbekende waarden kwamen vooral voor in het (sub) domein "verzorging van anderen" en in het domein "dagelijkse verplichtingen", maar ook in de domeinen "steun geven" en "sexualiteit". Deze onbekende waarden kwamen om verschillende redenen voor (zie ook hoofdstuk 9). De belangrijkste reden was dat de patiënt de informatie niet wenste prijs te geven, zoals in het domein sexualiteit een aantal malen is gebeurd. In een aantal gevallen gaf de patiënt wel antwoord, maar dan was het antwoord te onsamenhangend of te vaag om een interpretatie toe te laten. Als gevolg van deze twee problemen werden een aantal analyses uitgevoerd op een databestand dat maar net aan de statistische eisen voldoet.

Verdere analyses op verschillen tussen groepen zoals we in het kort aanstippen in hoofdstuk 11, laten evenwel zien dat de onbekende waarden niet specifiek samenhangen met de diagnose, de ernst van de stoornis, of met een van de selectiegroepen. Deze problemen hadden vooral gevolgen op de interpreteerbaarheid van de complexere, multivariate analyses, de "Confirmatorische Factor Analyse" die we in hoofdstuk 9 laten zien, en de vergelijking met de "gezonde" referentiegroep die we in hoofdstuk 14 bespreken. De conclusies van deze analyses moeten daarom eerder gezien worden als hypothese vormend dan als definitieve antwoorden op vragen in deze studie. De meeste analyses zijn echter goed te interpreteren. We beschouwen de meeste bevindingen van de meer simpele univariate analyses sterk genoeg om de conclusies mee te nemen in de verdere ontwikkeling van het instrument.

\subsection{Conclusies}

De studie laat zien dat we een instrument ontwikkeld hebben dat betrouwbare en valide informatie verzamelt. De twee onafhankelijke codeurs die de uitspraken van patiënten scoorden, laten een behoorlijk goede overeenkomst zien. Sommige vragen uit het instrument waren slechts op een klein aantal respondenten van toepassing. Dit is de belangrijkste reden van minder goede resultaten op enkele onderdelen van het instrument. Daarom is de volledige 
subdimensie "zorg voor anderen" weggelaten uit de verdere analyses. Het oordeel van de hulpverleners en het oordeel van onafhankelijke onderzoekers over het functioneren van de patiënt laat een behoorlijke mate van overeenkomst zien, zeker als we onze resultaten vergelijken met hedendaags onderzoek op het gebied van beoordeling van sociaal gedrag.

Zelfs de inventarisatie van retrospectieve informatie leverde betrouwbare en valide informatie. In die zin bevestigt deze studie de huidige lijn in de literatuur, waarin gesteld wordt dat een betrouwbare retrospectieve beoordeling van het functioneren wel degelijk mogelijk is als het gerelateerd wordt aan specifieke momenten in het leven, bijvoorbeeld belangrijke levensgebeurtenissen of belangrijke veranderings-momenten in het leven. Dit gegeven (uit recent onderzoek) heeft geleid tot een meer specifieke uitwerking van de onderdelen van de vragenlijst die op het verleden ingaan in de versie van het instrument welke in de vervolgstudie wordt toegepast. In de toepassing van het instrument in de vervolgstudie benadrukken we het belang van een consistente methode van doorvragen en concretisering van zowel het huidig functioneren als het functioneren in het verleden. In onze ervaring hebben hulpverleners vaak de neiging sterk in te gaan op persoonlijke gevoelens, ervaringen en belevingen, zonder expliciet in te gaan op dat wat de patiënt daadwerkelijk doet, met andere woorden zijn rolvervulling.

De studie toont vervolgens aan dat het instrument vrij goed discrimineert tussen patiënten met verschillende niveaus van functioneren, een gegeven dat we zowel op indivdueel als op groeps niveau hebben geanalyseerd. De resultaten van hoofdstuk 12 laten zien dat het hebben van een partner een belangrijke voorspeller is van het niveau van sociaal functioneren blijkend uit de somscores van de domein "zelfverzorging", "steun geven", "dagelijkse verplichtingen" en "sociale activiteiten", een bevinding die ook consistent is met recent onderzoek op dit gebied. We kunnen concluderen dat het huidige niveau van rolvervulling goed wordt weergeven in de somscore van de vier domeinen "zelfverzorging", "steun geven", "dagelijkse verplichtingen" en "sociale activiteiten". "Sexualiteit" (c.q. de partnerrelatie) bleek een onafhankelijke voorspeller te zijn van dit construct.

Als we kijken naar de ervaring opgedaan in het veldwerk van deze studie en dit vergelijken met recent ontwikkelingen op ons terrein van onderzoek, kunnen we concluderen dat als we een instrument willen ontwikkelen voor een dergelijke heterogene groep als de chronisch psychiatrische patiënt, een open interview met aandachtspunten de meest veelbelovende methode is. Een open communicatie met de patiënt is de beste wijze om betrouwbare informatie te verkrijgen, omdat door een goede training van de interviewer het risico op beïnvloeding door de eigen interpretaties van de patient of de neiging tot het geven van sociaal wenselijke antwoorden zo veel mogelijk gereduceerd kan worden. 
De analyses lieten tenslotte zien dat het instrument goed discrimineert tussen patiënten en een gezonde referentiepopulatie. Dit geeft aan dat het instrument gevoelig genoeg is om een afwijking van het normale te meten, en dat de items inderdaad - afgemeten aan een externe maat - verschillende niveaus van functioneren weergeven. De sterkste verschillen in rolvervulling tussen de patienten en de referentiepopulatie van gezonde proefpersonen werd gevonden in de domeinen "zelfverzorging" (voornamelijk bij de jonge ongehuwde mannen), "steun geven" (voornamelijk bij de oudere gehuwde vrouwen) en "sociale activiteiten" (in alle groepen), maar ook bij items die in gaan op planning, initiatief en de omgang met problemen en conflicten.

Voor het gebruik in de dagelijkse praktijk van de zorg stellen we voor dat een terugkoppelling met patiënt en hulpverlener de volgende aspecten moet behandelen:

a. een kort overzicht van de huidige en vroegere (maximaal bereikte) status en positierollen, om zo inzicht te krijgen in veranderingen in de maatschappelijke integratie van de patiënt;

b. een kort overzicht van de sociale contacten gerelateerd aan de verschillende situaties waarin de patiënt zich beweegt;

c. een kort overzicht van de sociale rolvervulling en -ontwikkeling die zich richt op de sterke maar ook de zwakke punten in het functioneren van de patiënt;

d. een samenvatting, waarin de bovenstaande infromatie wordt gerelateeerd aan de het verloop van de ziekte en het proces van sociale (des)integratie, om daaruit de noodzakelijke rehabilitatie interventies af te leiden. 


\section{REFERENCES}

Adams, B.N. (1967). Interaction theory \& social network. Sociometry, 1, 65-77.

Adler, D.A. (1984). Viewing chronic mental illness: a conceptual framework. Comprehensive Psychiatry, 25, 192-207.

Affleck, J.W., Mcguire, R.J. (1984). The measurement of psychiatric rehabilitation status, a review of needs and a new scale (the MRSS). British Journal of Psychiatry, $145,517-525$.

American Psychiatric Association (1976). Global Assessment Scale as a procedure for measuring overall severity of psychiatric disturbance., Archives of General Psychiatry, 33, 766-771.

American Psychiatric Association (1976).The DSM-III, Washington, DC.

American Psychiatric Association (1987). The DSM-III revised, Washington, DC.

Anthony, W.A., (1980). A rehabilitation model for rehabilitating the psychiatrically disabled. Rehabilitation Counseling Bulletin, 24, 6-21.

Anthony, W.A., Cohen, M.R., Cohen, B. (1983). The philosophy, treatment process and principles of the Psychiatric Rehabilitation approach. New Directions in Mental Health, 17, 7-79.

Anthony, W.A., Liberman, R.P. (1986). The practice of psychiatric rehabilitation: historical, conceptual and research base,.Schizophrenia Bulletin, 12:4, 542-558.

Anthony, W.A. (1982). Explaining psychiatric rehabilitation by an analogy to "physical rehabilitation". Psychosocial Rehabilitation Joumal, 5, 61-65.

Andel, H. van, Dutterloo A. van (1986). Besluitvorming van en rondom chronisch psychiatrische patienten. NCGV-rapport, Utrecht.

Asselbergs, L. (1989). Sociaal beperkt. Thesis, NCGV, Utrecht.

Baars, H.M.J. (1984). Sociale Netwerkbenadering in de Gezondheidszorg geîllustreerd aan de hand van praktijkvoorbeelden. Metamedica, 63,:1, 68-77.

Baars, H.M.J., Romme, M.A.J. (1986). De invloed van opvattingen over geestesziekte op de behandeling, Metamedica, 65:5, 371-383.

Baars, H.M.J., Uffing, J.Th.F. (1987). Sociale Netwerken, reservoirs van hulp bij problemen in de geestelijke gezondheid. Metamedica, 66, 138-148.

Baars, H.M.J., Uffing, J.Th. F. (1988). Het Sociale Netwerk, een bouwplaats van geestelijke gezondheid, Metamedica, 67:5, 315-331.

Baars, H.M.J., Uffing, J.Th. F., Dekkers, G. (1990). Sociale Netwerkstrategiën in de sociale psychiatrie. Antwerpen: Van Loghem-Slaterus.

Bachrach L.L. (1976). Deinstitutionalisation: an analytical review and a sociological perspective. Rockville, MD: National Institute of Mental Health.

Bachrach, L.L. (1980). Overview: model programs for chronic mental patients. American Journal of Psychiatry. 137:9, 1023-1031.

Bachrach, L. L. (1981). Continuity of care for chronic mental patients, a conceptual analysis. American Joumal of Psychiarry, 138:12, 1449-1456.

Bachrach, L. L. (1982). Young adult chronic patients, an analytical review of literature. Hospital and Community Psychiatry, 33, 189-197.

Bachrach, L. L. (1982). Assessment of outcomes in community support systems: results, problems, limitations. Schizofrenia bulletin, 8:1, 39-60.

Bachrach L.L. (1983). New directions in mental health service San Francisco: JosseyBass.

Bachrach L.L. (1984). Principles of planning for chronic psychiatric patients: a synthesis. In: Talbott, J.A. (ed.). The chronic mental patient. New York.

Bachrach L.L. (1986). The challenge of service planning for chronic mental patients. Community Mental Health Journal, 22:3:, 70-174.

Bachrach L.L. (1988). Defining chronic mental illness: a concept paper. Hospital and Conmunity Psychiatry, 39, 383-388.

Baker, R., Hall, J. (1983). Rehabilitation evaluation of Hall and Baker (REHAB), Aberdeen: Vine Publishing. 


\section{REFERENCES}

Bates, J. (1956). Position, role and status: a reformulation of concepts. Social Forces, 34, 313-321.

Barker, R.G. (1963). Stream of behavior. New York: Appleton.

Baumrind, D. (1980). New directions in socialisation research. American Psychologist, $35,630-661$.

Bem, D.J., Allen, A. (1974). On predicting some of the people some of the time: the search for cross-situational consistencies in behaviour. Psychological Review, 81:6, 506-520.

Bem, D.J., Funder, D.C. (1978). Predicting more of the people more of the time: assessing the personality of situations. Psychological Review, 885, 485-501.

Bebbington, P., Hurry, J., Tennant, C., Sturt, E., Wing, J.K. (1981). Epidemiology of mental disorders in Camberwell. Psychological Medicin, 11,561-579.

Bennett, D.H. (1978). Social forms of psychiatric treatment. In: Wing, J.K. (ed.). Schizofrenia, towards a new synthesis. London: Academic Press.

Bennett, D.H. (1983). The historical development of psychiatric rehabilitation,. In: Watts, F.N., Bennett, D.H. Theory and practice of psychiatric rehabilitation. London: Academic Press.

Bergner, M., Bobbitt, R.A., Carter, C.W., Gilson, B.S. (1981). The Sickness Impact Profile: development and final revision of a health status measure. Medical care, 8 , 787-805.

Bergner, M., Gilson, B.S. (1981). The Sickness Impact Profile: the relevance of social science to medicin. In: Eisenberg, L., Kleinman, A. The relevance of social science for medicin. Dordrecht.

Bergner, M. Bobbitt, R.A., Pollard, W.E., Martin, D.P., Gilson, B.S. (1981). The Sickness Impact Profile : validation of a health status measure. Medical care, 14, 57 67.

Bertalanuffy, L. von (1950). An outline of General Systems theory. British Journal of Philosophy of Science, 134-165.

Biddle, R. (1979). Role theory, expectations, identities and behaviors. London: Academic Press Inc.

Bleuler, E. (1911). Dementia Preacox oder Gruppe der Scizophrenien. Teil IV. Leipzig und Wien: Frantz Deuticke.

Bleuler, M. (1972). Die Schizophrenen Geistesstörungen. Stuttgart: Georg Thieme Verlag.

Boissevian, J., Mitchell, J.C. (1973). Network analysis: Studies in human interaction. The Hague, Mouton \& co.

Boomsma, A. (1983). On the robustness of LSIREL confirmatory factor analysis. Dissertation, Amsterdam: U.V.A. publishers.

Bowlby, J. (1969). Attachment and loss. London: Hogarth Press.

Bosch, R.J. van den (1982). Attentional correlates of schizofreniea and related disorders. Dissertation, Maastricht.

Brescoe, M. (1982). Sex differences in psychological well-being, Psychological medicine, suppl.

Brim, O.G. (1966). Socialisation throughout the life cycle. In: Brim, O.G., Wheeler, S. (eds.). Socialisation after childhood. New York, Wiley-Interscience.

Brim J.A. (1974). Social network correlation and avowed happiness. Journal of Nervous and Mental Diseases, 6, 432-439.

Brook, F.G., Hamers, H. (1985). GG-zorg gepeild. Een vergelijkend onderzoek met behulp van twee registers voor de Geestelijke Volksgezondheid. Tijdschrift voor Psychiatrie, 2:2,1 15-127.

Brooks, W.B., Jordan, J.S.. Divine, G.W., Smith, K.S., Neelon, F.A. (1990). The impact of psychological factors on measurement of functional status: assessment of the Sickness Impact Profile. Medical care, 28, 793-804.

Brown, G.W., T. Harris (1978). Social origins of depression. London: Tavistock Publications.

Bruin, A.F. de, Witte, L.P. de, Stevens, F.C.J., Diederiks, J.P.M. (1992). De Bruikbaarheid van de Sickness Impact Profile als generieke maat voor functionele toestand. Tijdschrift voor Sociale Gezondheidszorg, 70:3, 160-170. 


\section{REFERENCES}

Bruin, A.F. de, Witte, L.P. de, Stevens, F.C.J., Diederiks, J.P.M., Philipsen, H. (1991). The Sickness Impact Profile can a famous functional status measure be improved, Proceedings and Abstract Book of the Third European Health Services Research Meeting, NIVEL \& UCL, 13-14 december, Univ Coll London.

Bruhn, J.G. (1977). Effects of chronic illness on the family. Journal of Family Practice, $4,6$.

Burnes, A.J., Roen, S.J. (1967). Social roles and adaptation in the community. Community Mental Health Journal, 3, 153-158.

Carter, W.B, Bobbitt, R.A., Bergner M., Gilson, B.S. (1976). The validation of an interval scaling: the Sickness Impact Profile, Health Services Research, 516.

Centraal Bureau Statistiek (1990). Census demography of the Dutch population of 1989.

Centraal Bureau Statistiek (1991a). Census demography of the Dutch population of 1990.

Centraal Bureau Statistiek (1991b). Uitkomsten bevolkingsprognose 1985-1990. CBSpublicaties. Den Haag: SDU.

Ciompi, L., Miller, E. (1976). Lebensweg und Alter der Schizophrenen, eine katamnestische Langzeitstudie bis ins Zenium. Berlin: Springer Verlag.

Clare, A., Cairns, V.E. (1978). Design, development and use of a standarised interview to assess social maladjustment and dysfunction in community studies. Psychological Medicine, 8, 598-604.

Clausen, J.A. (1983). Sex roles, marital roles and response to mental disorder. Research in Community and Mental Health, 3, 165-208.

Cohen, J. (1968). Weighted Kappa: nominal scale agreement with provision for scaled disagreement or partial credit. Psychological Bulletin, 70, 213-220.

Cooper, J. (1980). A hierachical typology of mental illness, Acta psychiatrica scandinavia, 13, special issue, proceedings of the International Congress of Psychiatry, Stockholm.

Corson, J., O'Leary-Corson, P.W. (1980). Working situations and psychopsiological pathology - a systems approach. In: Levinson et. al. (eds.). Stress in working situations: report of an international Congres. Stockholm: University press.

Corney, R.H., Clare, A.W., Fry, J. (1982). The development of a self-report questionaire to identify social problems - a pilot study. Psychological Medicin, 12, 903-909.

Cotrell, C.L. (1942). The adjustment of the individual to his age and sex roles. American Sociological Review, 7, 617-620.

Cronbach, L.J. (1951). Coefficient alpha and the internal structure of tests. Psychometrica, 16, 297-334

Cronbach, L.J. (1955). Construct validity in psychological tests. Psychological bulletin, $52,177-193$.

Dahrendorf, R. (1958). Homo soziologicus. Ein versuch zur Gesichte, Bedeutung und Kritik der Kategorie der sozialen Roll. Kölner Zeitschrift für Soziologie und Sozialpsychologie, 10, Teil 1\&2.

DeVries M.W. (ed.). (1992).The experience of psychopathology. Cambridge: Cambridge University Press.

Deyo, R.A., Inui, T.S., Leninger, J.D., Overmann, S.S. (1983). Measuring functional outcomes in chronic disease: a comparison of traditional scales and a selfadministered health status questionaire in patients with rheumatoid arthrithis, Medical Care, 21, 180 192.

Dingemans P., Engeland, H. van, Dijkhuis, J.H., Bleeker , J. (1988). De Diagnostic Interview Schedule (DIS). Nederlandse versie, Amsterdam.

Dingemans P. (1986). Psychiatrische classificatie. Thesis, Amsterdam.

Dohrenwerd, B.P., Snell-Dohrenwerd, B. (1969). Social status and psychological disorder: a aasual inquiny. New York: Wiley - Interscience.

Dohrenwend B.P. (1975). Sociocultural and social-psychological factors in the genesis of mental disorders. Journal of Health and Social Behavior, I6:114, 365-392.

Dohrenwend B.P., Yager, T.J., Egri, G., Mendelsohn, F.S. (1978). The Psyciatric Status Schedule as a measure of dimensions of psychopathology in the general population. Archives General Psychiatry, 35:6, 731-737. 
Dohrenwend B.S., Dohrenwend, B.P. (1978). Some issues in research on stressful life events. Journal of Nervous Mental Disease, 1, 7-15.

Dohrenwend, B.P. (1978). Psychiatric Status Schedule as a measure. Archives General Psychiatry, 35:6, 731-737.

Dohrenwend B.P. (1980). Nonspecific psychological distress and other dimensions of psychopathology. Archives General Psychiatry, 37, 1229-1236.

Dorhrenwerd, B.P., Dorhrenwerd, B.S., Gould, M.S., Link, B., Neugebauer, R., Wunsh-Hitzig, R. (1980). Mental illness in the United States: epidemilogical estimates. New York: Prager.

Dohrenwend, B., Snell, B. (1981). Measurement of social functioning in community populations. In: Wing, J.K. (et.al. ). What is a Case? London: Grant Mc Intryre.

Duncan-Jones, P. (1981). The structure of social relationships: an analysis of a survey instrument, part 1. Social Psychiatry, 16, 55-61.

Duvall, E.M. (1967). Family Development. NewYork/ Philadelphia/ Toronto: J.B Lippincott \& Co.

Dym, B. (1987). The cybemetics_of physical illness. Family process; 26, 35-48.

Engel, G.L. (1977). The need for a New Medical Model: a challenge for biomedicine. Science; 196, 129-135.

Endicott J., Spitzer, R.L., Fleiss, J.L. (1975). Mental Status Examination Record (MSER): reliability and validity.Comprehensive Psychiatry, 16 :3, 285-301.

Endicott J., Spitzer, R.L. (1978). A diagnostic interview: the schedule for affective disorders and schizophrenia. Archives General Psychiatry, 35, 837-844.

Endicott J., Spitzer, R.L. (1972). Current and past psychopathology scales (CAPPS): rationale, reliability, and validity. Archives General Psychiatry, 27, 678-687.

Epstein, S. (1979). The stability of behaviour: on predicting most of the people much of the time. Joumal of Personality and Social Psychology., 37:7, 1097-1126

Erickson, E.H. (1963). Childhood and society. New York: W.W. Norton \& Co.

Erickson, E., (1974). The life cycle completed. New York: W.W. Norton \& Co.

Frickson, G. D. (1984). A framework and themes for Social Network intervention. Family Process, 23, 187-197.

Erickson, G.D., (1976). Personal networks and mental illness. Dissertation, New York.

Escher, A..D.M.A.C, Romme, M.A.J., Breuls, M., Driessen, G. (1987). Maatschappelijk kwetsbaar en langdurig psychiatrisch ziek zijn. Tijdschrift voor Psychiatrie, 29:5, 266-281.

Evers, G. (1989). Appraisal of selfcare agiency: the A.S.A. - scale. Dissertation, Maastricht.

Fabrega, H., (1982). Culture and psychiatric illness: biomedical and ethnomedical aspects. In: Marsella , A.J., White, G.M., (eds.). Cultural conceptions of mental health and therapy. Berlin: Riedel publ. company.

Farkas, M.D., Cohen, M.R., Nemec, P.B. (1988). Psychiatric rehabilitation programs: pulting concepts into practice? Conmunity Mental Health Joumal, 24:1, 7-21.

Faltermaier T., Wittchen, H.U., Ellmann, R., Lassle, R. (1985). The Social Interview -Schedule (SIS) - content, structure and reliability. Social Psychiatry, 20, 115-124.

Faulkner, L.R. (1984). Productive activities for the chronic patient. Community Mental Haelth Joumal; 20, 109-123.

Fiske, D.W. (1971). Measuring the concepts of personality. Chicago: Adline Publishing company.

Fisher, R.A. (1934). Statistical methods for research workers (5th ed.). Edinburgh: Oliver \& Boyd.

Förester, H. von(1983). Information processing and data processing in the individual. In: The cybernetics of human behavior. Forester, H. von (ed.), London: Tavistoc publications.

Funder, D.C. (1987). Errors and mistakes: evaluating the accuracy of social judgement, Psychological Bulletin, 101:1, 75-90.

Funder, D.C, Dobroth, K.M. (1987). Differences between traits: properties associated with interjudge agreement. Joumal of Personality and Social Psychology, 52:2, 409418. 
Funder, D.C., Ozer, D.J. (1983). Behaviour as function of the situation. Journal of Personality and Social Psychology, 44, 107 -112.

Gable, G. (1987). Procedures in test analysis. New York: Sage publications.

Gallagher., B. J. (1987). The sociology of mental illness. London: Prentice- Hall.

Gelooven, R.M.W. van (1990). Drinksituaties en drinkgedrag, alcoholgebruik in het dagelijks leven. Dissertation, Maastricht.

Gerhardt, U. (1971). Rollenanalyse als kritische Soziologie. Neuweid: Luchterhand Verlag.

Gerhardt, U. (1980).Towards a critical analysis of role. Social Problems; 27:6: 556-569.

Gerhardt, U. (1986). Patientkarierren: eine medizinsozologische Studie. Frankfurt: Suhrkamp Verlag.

Gersons, B.P.R. (1981). Over wegen en waarderen in de psychiatrie. Lezing vierde P.U.K.- symposium over het gebruik van meetmethoden in de psychiatrie. Utrecht.

Giel, R., Dijk, S. van, Weerden-Dijkstra, J.R. van. (1978). De nieuwe chronisch psychiatrische patiẻntenpopulatie: mededelingen uit het centrale patiẻntenregeister. Tijdschrift voor Psychiatrie, 20, 601-616.

Giel R., F. Bogaarts (1980). Diagnostische classificatie en codering in de psychiatrie. Tijdschrift voor Psychiatrie, 22:5, 327-335.

Giel R., Ten Horn, (1981). De verhoudingen tussen hulpvraag en -aanbod risicogroepen in de GGZ. Tijdschrift voor Psychiatrie, 23:9, 504-521.

Giel, R. (1984). Onze moeite met moelijke mensen. Tijdschrift voor Psychiatrie, 26:4, 244-259.

Giel R. (1986). Care of chronic mental patients in The Netherlands. Social Psychiatry, $21,25-32$.

Giel R., Wiersma, D., Jong, A. de (1987). Sociale klasse en psychische stoornissen: een Hollands drama?. Tijdschrift voor Psychiatrie, 29:3, 129-146.

Gift, T.E., Strauss, J.S., Barry, A., Ritzler, A., Kokes, R.F., Harder, D.W. (1986). Social class and psychiatric outcome. American Journal of Psychiatry, 143:21, 222224.

Gilson, B.S., Bergner, M., Bobbit, R.A., Caner, W.A. (1979). The Sickness Impact Profile: final development and testing, 1975-1978. Washington: University of Washington.

Glick, P. (1978). Neue Entwicklungen im Lebenszyklus der Familie. In: Kohli, $\mathbf{M}$. (Hrsg.). Soziologie des Lebenslaufes. Darmstadt:Luchterhand Veriag.

Goldman H.H., Regier, D.A., Taube, C.A., Redick, R.W., Bass, R.D. (1980). Community mental health centers and the treatment of severe mental disorder. American Journal of Psychiatry, 137, 83-86.

Goldman, H.H., Gattozzi, A.A., Taube, C.A. (1981). Defining and counting the chronic mentally ill. Hospital \& Community Psychiatry, 32, 21-27.

Goldman, H.H., Morrissey, J.P. (1985). The alchemy of mental health policy: homelessness and the fourth cycle of reform. American Joumal of Public Health,75. 727-731.

Goldberg, D., Huxley, P. (1980). Mental illness in the community. The pathway to psychiatric care. London: Tavistock.

Goffmann, G. (1959). The presentation of self in everyday life. New York: Doubleday anchor books.

Gove, W., Tudor, J. (1974). Adult sex roles and mental illness. American Joumal of Sociology, 80, 205-215.

Grob, S.J.,(1981). Socialisation. In: Talbott, J.A. (ed.). The chronic mentally ill treatment, programs, systems. New York: Human sciences press.

Groot, A.D. de. (1975). Methodologie, grondslagen van onderzoek en denken in de gedragswetenschappen. Den Haag: Mouton \& co.

Gruenberg, A., Archer, J. (1979). Abandonment of responsability for the seriously mentally ill. Millbank Memeorial Fund Quarterly / Health and Society, 57:4, 485-507.

Gruenberg. A. (1962). Identifying cases of the social breakdown syndrome, ref.: obj. appraisal of deterioration in a group of long stay patients. Milbank Memorial Fund Quarterly, , 40, 90-100. 


\section{REFERENCES}

Gruenberg, E.M. (ed.) (1966). Evaluating the effect of Community Mental Health Services. New York: Milbank Memorial Fund.

Gruenberg, E.M. (1967). The social breakdown - some origins. American Handbook of Psychiatry, 123:12, 1483-1489.

Gruenberg, E.M. (1974). The social breakdown and its prevention, American Handbook of Psychiatry, 47, 697-711.

Gruenberg, E.M., Pepper, B. (1985). Definition of the terms 'chronic', 'disorder', 'disability' and 'patient'. Iin: Radebauch, T.S., Gruenberg, E.M., Kramer, M., Cooper, B. (ed.). The chronic mentally ill. An international perspective. Baltimore: John Hopkins University.

Gruenberg E.M., Pepper, P.H., Pepper, B. (1982). Definition of (I) mental illness (II) patient (III) disability (IV) chronic. Paper presented on WPA conference on chronically mentally ill, an international perspective. Baltimore.

Hafner, H. (1974). Der Einfluß von Umweltfaktoren auf die seelische Gesundheit. Ergebnisse moglichkeiten und Grenzen der Forschung. Psychiatr.Clin. , 7:4-5, 199225.

Hafner, H. (ed.). (1979). Estimating needs for mental health care. Berlin: Springer Verlag.

Hăfner, H., Klug, J. (1982). The impact of an expanding community mental health service on patterns of bed usage: evaluation of a four year period of implementation. Psychological Medicine, 12, 177-180.

Hafner, H., Heiden, W. von der (1983). The impact of changing system of care on patterns of utilisation by schizophrenics. Social Psychiatry, 18,153-160.

Hafner, H., Heiden, W. von der (1984). Evaluation of long term community care for patients with schizophrenia. In: Helgason, T. (ed.). The long term treatment of functional psychosis. Cambridge: Cambridge University Press.

Hafner, H. (1985). Changing patterns of mental health care. Acta Psychiatrica Scandinavica, supp. 319, 151-164.

Haffner, H., Heiden, W. von der (1986). The Mannheim case register: the longstay population. In: Horn, G.H.M.M. ten, Giel, R., Gulbinat, W.H., Henderson, J.H. (eds.). Psychiatric case registers in public health. Amsterdam: Elsevier.

Hafner, H. (1987). Do we still need beds for psychiatric patients? Acta Psychiatrica Scandinavica, 75, 113-126.

Hafner, H. Reichler-Rossler, A., Hambrecht, K., Maurer, S., Meissner, A., Schmidtke, A., Faktenheuer, T., Loffler, W., Heiden, W. von der (1992). IROAS: an instrument for the assessment of onset and early course of schizophrenia. Schizpohrenia Research, 3, 209-224.

Haveman, M. J. (1980). Nieuwe langblijvers in psychiatrische ziekenhuizen. $M G V, 7$, 642-651.

Haveman, M. J. (1987). Van klinisch verblijf naar vervangende zorg. Een onderzoek naar ontslagbelemmerende factoren bij lang opgenomen patienten in psychiatrische ziekenhuizen. Dissertation, Maastricht.

Hamers, H.J.F.R., Driessen, G.A.M. (1985). Risico op GG-zorg. Tijdschrift voor Sociale Gezondheidszorg, 63, 966.

Hamers, HJ.F.R., Driessen, G.A.M. (1986). De geestelijke gezondheidszorg en haar risico-groepen. Tijdschrift voor Sociale Gezondheidszorg, 17, 562-567.

Hamers, H., Romme, M.AJ., Driessen, G. (1985). Het (on)bedoelde gebruik van meer GGZorgvoorzieningen. Tijdschrift voor Sociale Gezondheidszorg, 13, 506-511.

Hamers, H. (1987). De GGZ als systeem in wankel evenwicht. Dissertation, Maastricht.

Hedlund, H. (1980). The brief psychiatric rating scale (BPRS) - a comprebensive review. Journal of Operational Psychiatry, 48-65.

Heller, K., Swindle, R.W., Dusenbury, L. (1986). Component social support processes: comments and integration. Joumal of Counsulting and Clinical Psychology, $54: 4,466-470$.

Henkelman, L. (1987). Een onderzoek naar chronisch psychiatrische patiěnten en hun omgeving: theoretische overwegingen. Tijdschrift voor Psychiatrie, 29, 282-295.

Hill, J. (1989). Adult personality functioning assesment, an investigator-based standarised interview. British Joumal of Psychiatry, 155, 24-35. 


\section{REFERENCES}

Honig, A., Radstake, D.W.S., Romme, M.A.J., Breuls, M.G.G.J. (1987). Problem analysis: an instrument in the rehabilitation of chronic psychiatric patients in the community. The International Joumal of Social Psychiatry, 33:4, 303-311.

Honig, A. (1989). Mind the body. Dissertation, Maastricht.

Horst, F. v.d. (1988). Gezondheid en niet werken. Dissertation, Maastricht.

Hout, A.C. van den (1987). Chroniciteit, invaliditeit en voorzieningen: Nationale Ziekenhuisraad.

Hout, A.C. van den (1983). Ontslagen uit het psychiatrisch ziekenhuis. 'n Schets van een sociologische probleemstelling. Tijdschrifi voor Psychiatrie, 25:2, 97-113.

Huber, G., Gross, G., Schuttler, R. (1979). Schizophrenie, eine verlaufs- und sozialpsychiatrische Langzeitstudie. Berlin: Springer Verlag.

Hurrelmann, K. (1983). Zur Programmatik einer umfassenden Sozialisationstheorie. In: Hurrelmann, K. (Red.). Handbuch der Sozialistionstheorie. Berlin: Springer Verlag.

Hurry, J. (1983). Socio-demographic associations with social disablement in a community sample. Social Psychiatry, 18, 113-123.

Hurry, J., Sturt, E. (1981). Social performance in a population sample: relation to psychiatric symptoms. In: Wing, J.K., Bebbington, P., Robbins, L.N. What is a case? London: Grant McIntyre.

Ivan Nye, F. (1976). Role analysis as analysis of the family. New York: Sage publications.

Jablenski, A., Scwartz, R., Tomov, T. (1980). WHO collaborative study on impairments and disabilities associated with schizofrenic disorders. A preliminary communication: objectives and methods. Acta Psychiatrica Scandinavia, suppl 285:62, 152-163.

Janssen, M. (1992). Personal networks of chronic patients. Dissertation, Maastricht.

Jong, A. de (1986). Relationship between symptomatology and social disability. Social Psychiatry; 21, 200-205.

Jong, A. de (1985). Social disability outcome in schizophrenic patients. British Joumal of Psychiarry; 149, 147-152.

Jong. A. de (1983). Sociale beperking t.g.v. funktionele psychosen I: een ontwerp van een model voor ontwikkeling sociale beperkingen. Tijdschrift Sociale Gezondheidszorg, 3, 78-85.

Jong, A. de, Molenaar, I. (1987). An application of Mokken's model of stochastic, cumulative scaling in psychiatric research. Journal of Psychiatric Research, 21, 137 149.

Jong, A. de, Ormel, J., Wiersma, D. (1987). De Groningse Sociale Beperkingenschaal: ontwikkeling en beschrijving van het instrument, betrouwbaarheid en de hierarchie in sociale rollen. Tijdschrift Sociale Gezondheidszorg, 65, 706-712.

Jong, A. de, Lubbe, P. v.d. (1991). Een vragenlijst over sociaal gedrag (onderzoeksversie), Groningen, Rijksuniversiteit Groningen, Afdeling Sociale Psychiatrie.

Jong, A. de (1991). Afwijkend sociaal gedrag van psychiatrische patiênten. Theoretische achtergronden, instrumenten en classificatie, Tijdschrifi voor Psychiatrie, 33:5, 299316.

Joreskog, K.G. (1978). LISREL IV. Users guide. Chicago: National Educational Resources.

Jöreskog, K.G., Sorebom, D. (1981). LISREL V. Users guide. Chicago: National Educational Resources.

Kastrup, M. (1987). Sex differences in the utilization of mental institutions, a nationwide register study. International Journal of Social Psychiatry, 33, 171-184.

Kahn, R.L. (1974). Conflict, ambiguity and overload: three elements in job stress. In: Mclean, A. (ed.). Occupational stress. Springfield, III: Thomas.

Kahn, R.L. (1978). The taking of organisational roles. In: Katz, D., Kahn, R.L.. The social psychology of organisations (2nd ed.). New York: Wiley \& sons.

Kaplan, Ch., D., Vries, M.W. de, Grund, J.P.C., Adraans, N.F.P. (1990). Protective factors: Dutch intervention, health determinants and reorganisation of addiction life. In: Godse, A.H., Kaplan, Ch., D., Mann, R.D. (eds.). Drug Misuse and dependence. London: Tavistock. 


\section{REFERENCES}

Katz, M.M., Lyerly, J. (1965). Methods for measurement of symptoms and social behavior in the community: rationale, discriminative validity and development. Psychological Reports, 13, 502-533.

Kendall, M.G. (1948). Rank correlation methods. London: Griffin.

Kendall, M.G. (1947) The variance of $t$ when both rankings contain ties. Biometrica, 36, 177-193.

Killian, L.T. (1991). Sociological investigations of mental illness: a review. Hospital and Community Psychiatry, 4:8, 902-911.

Kish. J. (1959). Some statistical problems in research design. American Sociological Review, 1959:24, 328-338.

Klerk, J.M. de, Petersen C.J., Diependaal C.G. (1983). Diagnosecategorie V: psychische stoomissen en de WAO: een nadere beschrijving. Tijdschrifi voor Sociale Gezondheidszorg, 2, 13-21.

Knibbe, R. (1981). Leermiddel rol, verbeterde versie. Interne publ. Medische sociologie, Rijksuniversiteit Limburg.

Knibbe, R. (1982). Probleemdrinken in Limburg. Dissertation, Maastricht.

Kohli, M. H. (1983). Lebenslauftheoritische Ansătze in der Sozialisationsforschung. In: Hurrelmann, K. (Red.). Handbuch der Sozialistionstheorie. Berlin:Springer Verlag.

Kraaikamp, H. (1992). Moeilijke rollen. Dissertation, Groningen.

Krauss-Whitborne, S. (1979). Adult development, the differentiation of experience. New York: Holt, Rinehart \& Winston.

Krauss-Whitbome, S.(ed.) (1982). Identity development throughout liefetime. Berlin: Springer verlag.

Kreamer, H.C., Thiemann, S. (1987). How many subjects? Statistical power analysis in research. New york: Sage publications.

Kreaplin, E. (1897). Dementia preacox. In: Cuttling J., Sheperd, G. (eds., 1981). The Clinical roots of the schzophrenia concept. Cambridge: Cambridge University Press.

Kreaplin, E. (1913). Klinische Psychiatrie. Univerisität Leipzig.

Kreppener, K. (1982). Sozialisation in der Familie. In: Hurrelman, K., Ullich, D. (eds., 1983). Handbuch der Sozialisationsforschung. Weinheim und Basel: Beltz Verlag.

Lamb, H. R. (1979a). Roots of neglect of long-term mentally ill. American Journal of Psychiairy, 136, 201 e.v.

Lamb, H. R. (1979b). Staff burn out in work with long-term patients. Hospital and Community Psychiatry, 30, 396-398.

Laundis J.R., Koch, G.G. (1977). The measurement of observer agreement for categorical data. Biometrics, 33, 159-174.

Lavik, N.J. (1983). Utilisation of mental health services over a given period. Acta Psychiatrica Scandinavia, 67, 404-413.

Lazarus, R.S. (1981). Some thoughts about stress and the work situation. In: Levi, L. (ed.). Sociery, stress and disease, vol. 4. Working life, based on the International Interdisciplinary Symposium in Society Stress and Disease, Univerity of Uppsala, WHO, Stockholm.

Leff, J. (1982). Clinical and methodological problems in interaction studies. In: Lognon, G., Bellantuono, C., Lader, M. (eds.). Epidemiological impact of psychotropic drugs. Amsterdam: Elsevier.

Levenson, R.J. (1978). Towards the assessment of social competence. Joumal of Consulting and Clinical Psychology, 46:3,453-462.

Levinson, D.J., Darrow, C.N., Klein, E.B., Levinson, M.H., McKee, B. (1978). The Seasons of a man's life. New York: Sage Publications.

Levinson, D. J., Darow, C.M., Klein, E.B., Levinson, M.H. (1974). The psychosocial development of men in early adulthood. In : Ricks \& Thomas (eds.). Life Hhstory research in psychopatholgy (vol 3). Mineapolis: University of Minnesota Press.

Lewine, R., Burbach, D., Meltzer, voorletter(s)1984). Sex differences in age of symptom onset and first hospitalization in schizophrenia. American Journal of Orthopsychiatry, 14, 84-87.

Levy, M.J. (1952). The structure of society. Princeton, N.J.: Princeton University press. 


\section{REFERENCES}

Lidz, Th. (1968).The person, his and her development throughout the life cycle. New York: Basic books Inc., publ.

Libermann, R.P., Meuser, K., Jacobs, H.E., Eckmann, T., Massel, H.K., Wallace, C.J. (1986). Training skills in the psychiatric disabled: learning coping and competence, Schizophrenia Bulletin, 12:4, 635-647.

Libermann, R.P. (1986). Psychiatric rehabilitation. Schizofrenia Bulletin (special issue) $, 12: 4$.

Libermann, P.B. (1989). Objective methods and subjective experiences. Schizophrenia Bulletin, 15:2, 267-275.

Linton, R. (1936). The study of Man. New York: Appelton - Century Publ.

Linton, R. (1945).The cultural background of personality. New York: Appelton Century Publ.

Luttik, A., Jacobs, H.M., Witte, L.P. de (1985). De Sickness Impact Profile: een meetinstrument waarmee de invloed van ziekte en/of gezondheidsklachten op het dagelijks functioneren kan worden vastgesteld. Nederlandse versie. Vakgroep Huisartsgeneeskunde, Rijksuniversiteit Utrecht.

Lynch, M.A., Kruzich, J.M. (1986). Needs assessment of the chronic mentally ill: practicioner and client perspectives. Administration in Mental Health 13:4, 237-248.

Link, B.G., Mesago, F.P., Lubner, M.E., Dohrenwerd, B.P. (1990). Problems in measuring role strains and social functioning in relation to psychological symptoms. Joumal of Health and Social Behaviour, 31, 354-369.

Lorr M., (ed.) (1967). The Inpatient Multidimensional Psychiatric Scale. In: Exploration of psychosis. New York: Pergamon Press.

Mackenbach, J.P., Maas, P.J. van der (1987). Sociale ongelijkheid en verschillen in gezondheid, een overzicht van de belangrijkste onderzoeksbevindingen. In: $D e$ ongelijke verdeling van gezondheid. Wetenschappelijke raad voor de volksgezondheid. Den Haag: Staatsuitgeverij.

Mann H.B., Whitney, D.R. (1947). On a test wether one of two random variables is stochastically larger than the other. Annuals of Mathimathical Statistics, 18, 50-60.

Marrelo, A. van (1986). Beleidsplan SPD . R.I.A.G.G. Maastricht e.o.

Marsella, A.J. (1982). Culture and Mental health: an overview. In: MarselJa, A.J. and White, G.M.(eds.). Cultural conceptions of $m$ ental health and therapy. Berlin: Riedel publ. company.

Marx, A.J., Test, M.A., Stein, L.I. (1973). Exterohospital management of severe mental illness, Archives of General Psychiatry, 29:11, 505-511.

Maslow, H. (1970). Motivation and personality,. New York: Harper \& Row, Inc.

McGuffin, P., Katz, R., Aldrich, J. (1986). Past and present state examination: the assessment of 'lifetime ever' psychopathology. Psychological Medicin, 16, 461-465.

Mead, G.H. (1934). Mind, self and society. Chicago: University of Chicago Press.

Mendell, W.M., Rapport, S. (1969). Determinants of the discision for psychiatric hospitalisation. Archives General Psychiatry, 20:3, 321-328.

Merrit, R.L. (1966). Symbols of American community, New Haven: Yale Univeristy Press.

Meyer, A. (1936). Fundemental conceptions of Dementia Preacox. In: Winters E.E., (ed.). A. Meyer's Collected works, vol II. Baltimore: Johns Hopkins Press, 1951.

Mirabi, M. (1984). The chronic mentally ill : research and services. London: MTP Press.

Mokken, R.J. (1971). A theory and procedure of scale analysis. Paris/ The Hague: Mouton \& co.

Morrison, R.L., Bellack, A.S. (1987). Social functioning of schizophrenic patients: clinical and research issues. Schizophrenia Bulletin, 13:4, 715-723.

Nadelson, C.C. (1983). The psychology of women. Canadian Joumal of Psychiatry, 28, $210-212$.

Newcomb, T.M. (1950). Social psychology . New York: Dryden.

Nijhof, G. (1989). Factoren die chroniciteit bepalen. Interne publicatie, Nijmegen.

Nijhof, G. (1978). Sociale ongelijkheid en psychiatrische problemen. Nijmegen:

Uitgeverij Link. Nijhoff; J. (1980). Individualisering en uitstoting. Dissertation,

Nijmegen. 


\section{REFERENCES}

Nijhuis, F., Soeters, J. (1982). Werk en ziekte: een onderzoek naar afwezigheid wegens ziektte en arbeidsongeschiktheid. Inteme publicatie, in opdracht van Ministerie van Sociale Zaken en werkgelegenheid, RL, Maastricht.

Nijhuis, F. (1984). Beoordeling van organisatiekenmerken: een sociaal gezondheidkundige studie naar organisatiekenmerken en ziekteverzuim. Dissertation, Maastricht.

Noorthoorn, E.O., Romme, M.A.J., Hamers, H., Vallenga, L. (1991). Sociale rolontwikkeling bij ambulante chronisch psychiatrische patienten verduidelijkt met een gevalsbeschrij ving, Tijdschrift voor Psychiatrie, 33:2, 84-99.

Noorthoorn, E.O., Romme, M.A.J., Philipsen, H. (1991). Toepassing van social rolanalyse in de ambulante praktijk van de zorg aan chronisch psychiatrische patienten, een onderzoeksvoorstel. NFGV $92 \# 3089$.

Nunnally, J.C. (1967). Psychometric theory. London : Mcgraw-hill.

Ormel, J. (1980). Moeite met leven of een moeilijk leven: een vervolgonderzoek naar de invloed van psychosociale belasting op het welbevinden van driehonderd Nederlanders. Dissertation, Groningen.

Ormel, J., Sandermas, R., Raats, G. (1986). Het chronische karakter van psychisch onwelbevinden. Tijdschrift voor Psychiatrie, 28:9, 604-611.

Ormel, J., Sandermas, R., Stewart, R. (1988). Personality as modifier of the life events distress relationship. A logitudinal structural equation model. Personality and Indivdual Dfferentiation, 9:6, 973-982.

Ozer, D.J. (1985). Correlation and the coefficient of determination. Psychological bulletin, 97, 307-319.

Overall, J.E., Gorham, P.R. (1962). The Brief Psychiatric Rating Scale. Psychological Reports, 10, 799-812.

Parsons, T. (1951). The social system. Glencoe, III: The free press.

Patton, J. (1987). Qualitative methods in program evaluation. New York: Sage publications.

Pearson, E.S. (1967). Biometrica tables for statisticians, Vol 1. Cambridge: Cambridge University Press.

Poelijoe, N.W., Wijngaarden, B. van (1990). De schaalbaarheid van de Groningse sociale beperkingenschaal. Tijdschrift Sociale Gezondheidszorg, 66:7, 293-297.

Platt, S., Weyman, A., Hirsch, S., Hewitt, S. (1980). The Social Behaviour Assesment Schedule (SBAS): rationale, contents, scoring, and reliability of a new interview schedule. Social Psychiatry, 15, 43-55.

Pepper, B. (1982). The chronic mentally disabled and deinstitutionalisation. Annual Review of Public Health, 445-468.

Philipsen, H. (1985). Rationaliteit en ons oordeel over de verdwijnende patient. Gezondheid en Samenleving, 142-151.

Philipsen, H. (1970). Afwijkend gedrag, etikettering door de samenleving en strategiën voor afwijkers, Sociologische Gids, 17, 350-367.

Philipsen, H. (1990). Onderoek als datamatrix. Interne publicatie, RL.

Pollard, W.E, Bobbit, R.A., Bergner, M., Martin, D.P., Gilson, B.S. (1976). The Sickness Impact Profile: reliabilty of a health status measure. Medical care, 14, 146155.

Querido, A. (1956). Multipele equilibria. In: Romme, M.A.J. (red.). Werk in uitvoering. Leiden: Uitgeverij Stenfort Kroese N.V., 1970.

Querido, A. (1959). Prognose en katamnese. Tijdschrift Sociale Geneeskunde, 37, 6970.

Querido, A. (1960). Over de verantwoordelijkheid voor de zorg voor de geestelijke volksgezondheid.Tijdschrift Sociale Geneeskunde, 38, 145-156.

Querido, A. (1962). Geestelijke gezondheid in de wereld van vandaag. Maandblad Geestelijke Gezondh, 17.

Radstake, D.W.S. (1985). Probleemanalyse als onderdeel van de omgang met chronisch psychiatrische patiènten in de ambulante GGzorg. In: De chronisch psychiatrische patiënt - Evaluatierapport Gezondheidszorgontwikkelingsprojekt LSB team 19811985. Interne publicatie Vakgroep Sociale Psychiatrie, RL. 


\section{REFERENCES}

Radstake, D.W.S., Romme, M.AJ., Baars, H.M.J., Breuls, M., Escher, A., Uffing, J.Th., Hamers, H. (1985). Evaluatierapport Gezondheidszorgontwikkelingsprojekt LSB team 1981-1985, Interne publicatie Vakgroep Sociale Psychiatrie, RL.

Remmington, M., Tryer, P.J. (). The Social Functioning Schedule. A brief semistructured interview. Social Psychiatry, 14, 151-157.

Richartz, M. M. W. (1981). Segregatie of integratie. Tijdschrift voor Psychiatrie, 23, 347-349.

Robins, L.N., Wing, J.K., Helzer, J.E.(1985). WHO-ADAMHA Composit International Diagnostic Interview,. Geneva/ Washington.

Robins, L.N., Helzer, J.E., Rattcliff, K.S., Seyfried, W. (1981). National Institute of Mental Health Diagnostic Interview Schedule: its history, characteristics and validity. Archives of General Psychiatry, 38, 381-389.

Rodgers, R.H. (1962). Improvements in the construction and analysis of family life cycle categroies. Kalamazoo: Westem Michigan University Press.

Rodgers, R.H. (1964). Towards a theory of family development, Journal of Marriage and the family, 26, p 262-270.

Romme, M.A.J., Kraan, H., Rotteveel, R. (1981).Wat is Sociale Psychiatrie? Alphen a.d. Rijn: Samson.

Romme, M.A.J. (1979). Oneindige behoefte - oneindige zorg. Psychiatrische epidemiologie en planning van voorzieningen. $M G V, 11,726-737$.

Romme, M.A.J., Escher, A., Radstake, D., Breuls, M. (1987). Een indeling in groepen van patienten met een langdurige psychiatrische patientencarrierre. Tijdschrift voor Psychiatrie; 29, 4, 197-211.

Romme, M.A.J. (1991). Preventie en sociaal psychiatrische praktijk. In: Vandereycken, W., Hoogduin C.A.L., Emmelkamp, P.G.M. (red.). Handboek psychopathologie.

Romme, M.A.J., Noorthoorn, E.O., (1991). Misbruik van sociale wetgeving? Of is sociale wetgeving ongeschikt voor arbeidsrevalidatie omdat de arbeidsomstandigheden de ziektekiem vormen voor de invaliditeit? Een discussiestuk. Tijdschrift Gezondheid en Politiek, 3, 12-17.

Rommeviet, J. (1955). Social roles and norms. Mineapolis: University of Minnesota Press.

Rosenfield, S. ( 1982). Sex roles and societal reactions to mental illness : the labeling of 'deviant' deviance. Joumal of Health and Social Behavior, 23, 18-24.

Rosenthal, R., Rubin, D.B. (1982). A simple, general purpose display of magnitude of experimental effect. Journal of Educational Psychology, 50, 130-142.

Rostow, C.D., Smith, C.E. (1975). Effects of contingency management of chronic patients on ward control and behavioral adjustment. Journal of Behavior Therapy and Experimantal Psychiatry, 6,1-4.

Rotteveel, R., Uffing. J.Th. F. (1988). Valkuilen in de zorg aan chronisch psychiatrische patiënten. Maandblad Geestelijke Volksgezondheid, 3, 198-204.

Saris, W., Stronkhorst, H. (1984). Causal modelling in nonexperimental research. An introduction to the LISREL Approach. Amsterdam: Sociometric research foundation.

Sackett, G.P. (1978). Measurement in observational research. In: Sackett, G.P. (ed.). Observing behavior Vol 2 Data collection and analysis methods'. Baltimore: University press.

Scheffe, H. (1959). The analysis of variance. New York: Wiley \& Sons.

Scholte, J., Uffing, J.Th.F (1982). Langdurig verblijf in het algemeen psychiatrisch ziekenhuis. Een vergelijkende studie, in opdracht van de Ziekenfondsraad. Interne publicatie. Maastricht.

Schruers, M., Wiesma, D., (1992). Chronisch psychiatrische patiënten in MiddenTwente: een epidemiologisch onderzoek naar hun functioneren en hun zorgbehofte. Tijdschrift voor Psychiatrie, 34:4, 255-267.

Serban, G. (1978). Social Stress and Functioning Inventory (SSFIPD): measurement and prediction of schizophgrenic's community adjustment. Comprehensive Psychiatry; $19,337-347$.

Siegel, S. (1956). Nonparametric statistics for the behavioral sciences. London: Mcgrawhill. 


\section{REFERENCES}

Siegler, M., Osmond, H. (1966). Models of madness. British Journal of Psychiatry; $112,1193-1203$.

Skinner, H. (1981). Toward the integration of classification thoery and methods. Journal of Abnormal Psychology, 90, 68-87.

Skinner, H., Blashfield, R.K. (1982). Increasing the impact of cluster analysis research: the case of psychiatric classification. Joumal of Consullting and Clinical Psychology, 50:5, 727-735.

Shepherd M., Cooper B., Brown A.C. and Kalton G.W.(eds) (1966). Psychiatric illness in general practice. London: Tavistock publications.

Shepherd, M. (1989), Rehabilitatie van de chronisch psychiatrische patiënt. Utrecht: Bohn, Scheltema \& Holkema.

Simmons R. (1979). Research in community and mental health. Greenwich: JAI Press.

Sorbom, D. (1975). Detection of correlated errors in longitudinal data. British Journal of Mathemathical and Statistical Psychology, 28, 138-151.

Spearman, C. (1910). Correlation calculated from faculty data. British Journal of Psychiatry, 3, 271-295.

Speck, R.V., Atteneave, C.L. (1973). Family networks, a new approach to family problems. New York: Vintage books.

Spitzer, R.L., Endicott, J., Fleiss, J.L., Cohen, J. (1970). The Psychiatric Status Schedule: a technique for evaluating psychopathology and the impairment of role functioning. Archives of General Psychiatry, 23, 41-55.

Staal, J.L., Ormel, J., Schoenmaker, J., Koeter, M., Barneld, G, Brink, W. . van der (1989). Het beloop van psychopathologie en sociale beperkingen. Een exploratieve voorstudie onder psychiatrische polikliniekpatielnten. Tijdschrift voor Sociale Gezondheidszorg, 67, 92-95.

Stein, M. A., Test L.I. \& Marx, A.J. (1973). Extrohospital management of severe mental illness, Archives gen. psychiarry, 29, p. $505-511$.

Stein, M. A., Test L.I. (1976). Practical guidelines for the community treatment of marked impaired patients, Conumunity mental health journal, 12, p. 72.

Stein, M. A., Test L.I. (1978). Special living arrangements. A model for decisionmaking. Hospital and community psychiatry, 29, p. $608-610$.

Stein, M. A., Test L.I. (1985). Characteristics of young adults with schizophrenic disorders treated in the community. Hospital and Community Psychiatry, nr. cursief toevoegen, 853 e.v.

Stephens, R.C. (1991). The symbolic interactionist perspective of role. In: Stephens, R.C. The street addict role, a theory of heroin addiction. Albany: State of New York Univerity Press.

Stevens, A. (1991). Needs assessment. Health Trends, 11, 200-205.

Stone, G.P. (1962). Appearance and the self. In Rose, A.M.. Human behavior and social process, an interctionist apprach. London: Routledge.

Strauss, J.S. (1981) Clinical questions and real research. American Journal of Psychiatry, 138, 1592-1596.

Strauss, J.S., Carpenter W.T. (1972). The prediction of outcome in schizophrenia I: characteristics of outcome. Archives of General Psychiatry, 27, 739-746.

Strauss, J.S., Carpenter W.T. (1974). The prediction of outcome in schizophrenia II: relationship between predictor and outcome variables. A report from the WHO intemational pilot study of schizophrenia. Archives of General Psychiatry, 31, 37-42.

Strauss, J.S., Carpenter W.T. (1977). The prediction of outcome in schizofrenia III: Five year outcome and its predictors. Archives of General Psychiatry, 34, 159- 163.

Strauss,J.S. (1985). The course of psychiatric disorder III; longitudinal principles. American Joumal of Psychiatry, 142, 289-296.

Stryker, S., (1957). Role taking accuracy and adjustment. Sociometry, 20, 286-296.

Sturt, E., Wykes, T. (1987). Assessment schedules for chronic psychiatric patients, Psychological Medicine, 17, 485-493.

Sullivan, H.S. (1940). Conceptions of modern psychiatry. New York: Norton.

Sullivan, H.S. (1953).The intrapersonal theory of psychiatry. New York: Norton.

Sullivan, H.S. (1973).Clinical studies in psychiatry. New York: Norton. 


\section{REFERENCES}

Swanborn, P. (1987). Methoden van sociaal-wetenschappelijk onderzoek; inleiding in ontwerpstrategièn. Meppel: Uitg. Boom.

Tabachnick, B.G., Fidell, L.S. (1989). Using multivariate statistics. New York: Harper \& Row.

Talbott, J.A. (1981).The chronic mentally ill: treatment programs, systems. New York: Human Sciences Press.

Talboth, J.A. (1984a).The chronic mental patients, five years later. Orlando: Grune \& Stratton.

Talbott, J.A. (1984b). The chronic mental patients - a national perspective. In: M Murabi. The chronic mentally ill. Lancaster: Research and services Lancaster.

Tansella M., Micciolo, R., Balestrieri, M., Gavioli, I. (1986). High and long-term users of the mental health services. Social Psychiatry, 21, 96-103.

Tansella M. (1989). Community-based psychiatry. Patterns of care in South-Verona Research Report, Institutio di Psychiatria, Universita di Verona, Verona.

Test, M.A., Stein, L.I. (1978). Community treatment of the chronic mental patient: a research overview. Schizophrenia Bulletin, 4, 354-360.

Tinsley, H., Weiss, D. (1975). Interrater reliability and agreement of subjective judgements. Journal of Counseling Psychology, 22, 358-376.

Tolsdorf, C.C. (1976). Social networks, support and coping. An exploratory study. Family Process, 4, 407-417.

Tryon, R.C. (1929). The interpretation of the correlation coefficient. Psychological Review, 36, 419-445.

Vaillant, G.E. (1976). Natural history of male psychological health, the relation of choice of ego mechanisms of defense to adult adjustment. Archives of General Psychiatry, $33: 5,535-545$.

Vallaint, G.E. (1977). Adaption to life. Boston: Little Brown.

Valliant, G.E. (1984). A critical review on the DSM-II. American Journal of Psychiatry, 141: 4, 539-542.

Visser, A.Ph., Vlien, E. van de, Heine, E.J.H. ter ,;Winnubst, J.A..M. (1983). Rollem, persoonlijke en sociale invloeden op her gedrag. Meppel: Uitg. Boom.

Walker, K.N., Macbride, A., Vachon, M.L.S. (1977). Social support networks and the crisis of bereavement. Social Science and Medicin, 11,35-41.

Watts, F.N., Bennett, D.H. (1983). Theory and practice of psychiatric rehabilitation London:John Wiley \& sons.

Weber, M. (1947). Wirtschaft und Gesellschaft, Grundriß der verstehenden Soziologie (Studienausgabe). 5e gereviseerde oplage door Winckelman, J.C.B. Mühr, Tübingen; 1972.

Weeghel, J., Zeelen, J. (1987). Over arbeid, handicaps en rehabilitatie. Tijdschrift voor Psychiatrie, 29:7, 417-431.

Weissmann, M.M., Prussof, B.A., Thopmson, W.D., Harding, P.S., Meyers, J.K. (1978). Social adjustment by self-report in a community sample and in psychiatric outpatients. The Journal of Nervous and Mental Disease, 166:5, 317-326.

Weissmann, M.M., Sholomskas, J.K. (1981). The assessment of social adjustment, an update. Archives of General Psychiatry, 38:11, 1250-1258.

Wenniger, W., Romme, M.A J. (1978). Een onderzoek naar het opnamepatroon bij ouder wordende chizofrenen. Onderzoeksverslag Praeventiefonds.

World Health Organisation, (1973). International pilot study on schizofrenia. Vol 1,7377 , Geneva.

World Health Organisation, (1977). Intemational pilot study on schizofrenia. Geneva

World Health Organisation, (1978). Psychiatric and personal history schedule. WHO $5365 \mathrm{NMH}$.

World Health Organisation, (1980). Intermational classification of imparments, disabilities and handicaps. A manual of classification relating to the consequence of disease. Geneva.

World Health Organisation, (1988). Psychiatric Disability Assessment Schedule (WHO / DAS).

Wiersma, D., Jong, A. de , Ormel, J. (1984). De Groningse Sociale Beperkingen Schaal $(G S B)$. Handleiding en vragenschema's voor respondent en informant. Groningen. 


\section{REFERENCES}

Wiersma, D., Giel, R., Jong, A. de, Sloof, C.J. (1983). Sociale beperkingen ten gevolge van functionele psychosen II.Tijdschrift voor Sociale Gezondheidszorg, 61: $5,168-174$.

Wiersma, D., Giel, R., Jong, A. de, Sloof, C.J. (1984). Chroniciteit bij functionele psychosen.Tijdschrift voor Psychiatrie, 26, 402-419.

Wiersma, D. (1986). Psychological impairments and social disabilities: on the applicability of the ICIDH to psychiatry. International Rehabilitation Medicin, 8,3-7.

Wiersma, D., Jong, A. de, Ormel, J. (1988). The Groningen Disabilities Schedule: development, relationship with the ICIDH, and psychometric properties. International Jourmal of Rehabilitation Research, 11, 213-224.

Wiersma, D., Jong, A. de , Kraaikamp, H.M.J., Ormel, J. (1990). De Groningse Sociale Beperkingen Schaal (GSB). Tweede versie. Een interviewschema voor het beoordelen van beperkingen in het social rolfunctioneren. Groningen.

Wittchen, H.U., Robins, L.N., Cottler, L.B., Burke, J.D., Regier, D. (1991). Crosscultural feasability and sources of variance of the Composit International Diagnostic interview (CIDI). British Journal of Psychiatry, 159, 645-653.

Witte, L.P. de, Jacobs, H., Horst, F. van der, Luttik, A., Joosten, J. Philipsen, H. (1987). De waarde van de Sickness Impact Profile als maat voor het functioneren van patienten. Gezondheid en Samenleving, 8, 120-127.

Witte, L.P. de, (1991). After the rehabilitation centre: a study into the course of functioning after discharge from rehabilitiion. Dissertation, Maastricht.

Wing, J.K., Brown G. (1970). Institutionalism and schizofrenia. Cambridge: Cambridge University Press.

Wing, J.K., Cooper, J.E., Sartorius, N. (1973). Present state examination (PSE). Cambridge: Medical research council / Cambridge University press.

Wing, J.K., Cooper, J.E., Sartorius, N. (1974). The measurement and classification of psychiatric symptoms. An instruction manual for the Present state examination (PSE) and CATEGO Program. Cambridge: Medical research council / Cambridge University press.

Wing J.K., Mann, S.A., Leff, J.P. , Nixon, J.M. (1978). The concept of a case in psychiatric population surveys. Psychological Medicine, 8, 203-217.

Wing, J.K., Morris, B (eds.) (1981). Handbook of psychiatric rehabilitation practice. Oxford: Oxford University Press.

Wing J.K., Bebbington, P., Robins, L.N. (1981). What is a case? The problem of definition in psychiatric community surveys . Oxford: Oxford University Press.

Wing, J.K. (1989). The measurement of 'social disablement': the MRC social behavior and social role perfromance schedules. Social Psychiatry and Psychiatric Epidemiology, 24, 173-178.

Wykes T. (1982). A hostel ward for 'new' longstay patients: an evaluative study of a ward in a house. In: 'Longterm community care: an experience in a London borough'. Psychological Medicine, 12, 57-63.

Wykes, T.L., Sturt, E. (1986), The measurement of social behaviour in psychiatric patients: an assessment of the reliability and validity of the SBS schedule. British Journal of Psychiatry, 148:1, 1-11.

Zeelen, (red.) (1988). Psychiatrie, arbeid en samenleving. Verslag van een congres. Culemborg: Uitgeverij Lemma. 


\section{Eerste versie, september 1987}

1. Ongehuwde man bij begin hulpvraagcarriere.

- niet toegekomen aan sexuele intimiteitsrelatie in de adolescentie;

- sexuele relatielegging nog steeds een sociale functiestoornis en wens tot relatieleggen blijt bestaan;

- terugtrekgedrag in het gezin van herkomst, bij familie of in het pensiontehuis; nauwelijks in staat tot zelfstandigheid in huishoudelijke taken, werk, studie.

Hulpvraagcarrière: lang tot zeer langdurend; psychotische decompensaties; leaving home, routine dagstructuur, bewaking expressed emotion, leren omgaan met hallucinaties, medicijn.

2. Ongehuwde man bij begin hulpvraagcarrière.

na teleurstelling in de intimiteitsrelatie waarbij wel coiltus-contact heeft plaatsgevonden is deze wens tot het aangaan van een nieuwe relatie opgegeven of word met veel rationalisaties algewezen of vermeden;

- kunnen zich redelijk zelfstandig handhaven qua huishoudelijke taken, werk en studie.

Hulpvraagcarrière: middellang; neurotische decompensaties.

3. Ongehuwde man bij begin hulpvraagcarrière.

uit het gezin van herkomst weggelopen of weggestuurd voor het $18 \theta$ jaar (rondom 15e);

zeer wisselend arbeidsverloop en wisselende relaties;

vaak overmatig alcohol- en druggebnuik.

Hulpvraagcarrière: korte periodes en herhalingen, vaak persoonlijkheidsstoornissen; support bij voorzieningen, structuur werk e.d.

4. Gehuwde man bij begin hulpvraagcarrière.

- een reeds jaren durende arbeidsproblematiek, verweven met somatisch functionele klachten en somatische tixatie;

- het verlies van werk (meestal via afkeuring WAO of vervroegd pensioen) wordt negatief beleeld of vanwege onheus behandeld voelen, of vanwege roherlies en verlies waardering e.d.;

- het geheel van gedraging en gebeurtenissen hebben een negatieve invloed op de huwelijksrelatie.

Hulpvraagcarrière: langdurend; somatische fixatie; compensatie in een of andere gewaardeerde rol.

5. Gehuwde man bij begin hulpvraagcarrière.

- intimitertsrelatie in huwelijk (sexualiteit) verstoord en bedreigd met het verlies van werk en/of bedreigd met financiële problemen;

- alcoholgebruik/verslaving/te veel gebruik reeds gedurende lange tijd (jaren).

Behandeling is gericht op consequenties drankgebruik zoals problemen werk lichamelijke ziekten, huwelijksproblemen, andere sociale conflicten. Vraag om support en belangenbehartiging, niet om verandering eigen problemen of drankgebruik.

Hulpvraagcarrière: wisselende instellingen; hulpverlening richten op belangenbehartiging; dit heeft nog het meeste succes.

6. Gescheiden man bij begin hulpvraagcarrière.

problemen met verzorging in huishoudelijke zin en/of zeggenschap t.a.v kinderen en/of behuizingsproblemen; vrouw, in het beleven van de man, vrij onverwacht weggelopen van huis en het initiatief tot de scheiding ligt bij de vrouw.

Hulpvraagcarrière duurt zolang tot het vinden van een nieuwe partner duurt: hulpverlening richten op compensatie geleden verliezen en rouwverwerking.

7. Gescheiden vrouw bij begin hulpvraagcarrière.

- problemen met financiêle mogelijkheden envof sociale contacten;

- het zelfstandig bestaan als alleenstaande al of niet met kinderen schrikt ze af en ze blijven zoeken naar een nieuwe partner;

- de agressie t.a.v. de ex-man is minder groot dan de angst alleen te blijen (bij de gescheiden man is dit eerder omgekeerd).

Hulpvraagcarrière: lang, vaak tot dat nieuwe partner is gevonden: hulpvertening richten op de compensatie van geleden verliezen en beïnvloeding van selfesteem.

8. Alleenstaande oudere vrouw bij begin van de hulpvraagkarriere.

- sterk vereenzaamd, dwz. slechts e日n enkel sociaal contact;

- nauwelijks in staat op behoorlijke wijze het huishouden te organiseren en te onderhouden;

- paranoïde verschijnselen, meest wanen als vorm van psychopathologie;

- gesteld op zellstandigheid.

Hulpverlening: in de vorm van gezinshulp en relatie met enkele sociale contacten stimuleren. Medicatie meestal niet mogelijk wegens gebrek aan compliance. 
9. Gehuwde vrouw aan het begin van de hulpvraagcarrière.
huwelijksrelatie wordt als problematisch ervaren met geringe intimiteit;

- huwelijksrelatie staat mede onder druk van stress van buitenaf (verandering financiên of rol man, of stress vanuit reeds lang durend slecht passend partnerschap b.v andere milieus van herkomst, of stress van binnen het gezin (ziekte kinderen)):

- rolverlies of rolverandering in het gezin met weinig alternatieven buiten het gezin noch in het gezin, geeft ook onvrede over de rolverdeling:

- lichamelijke klachten en depressieve of paranoïde denkinhouden.

Hulpverlening: gericht op compensatie rolverlies.

10. Gehuwde vrouw bij het begin van de hulpvraagcarrière.

- zwakbegaafd of debiel;

- kan taak in haar huishouden enof opvoeding kinderen niet meer aan nadat een steunfiguur is weggevallen of als gevolg van een doorgemaakte verzwakkende ziekteperiode;

- angst voor positie- en rolverlies doet hen ontkennen dat ze hun taak niet meer aankunnen. Deze ontkenning is enigszins gesteund door de omgeving die vindt dat ze het niet meer aankunnen, zodat er ook geen oplossing wordt gezocht.

Hulpverlening: herstel van oorspronkelijk evenwicht voor het verlies van steunfiguur door vervanging of ondersteuning in taken zonder confrontatie zelf aan te gaan.

11. Ongehuwde vrouw bij het begin van de hulpvraagcarrière.

- probleemgeschiedenis begint tussen de 12 en de 18 jaar;

- is tussen de 12 en de 18 jaar uit het gezin van herkomst weggelopen of weggeplaatst, of heeft in het gezin van herkomst een te belastende taak opgekregen gezien de leeftijd;

- heeft niet geleerd conflicten op te lossen, geeft blijk dat ook slecht te kunnen en conflicten worden niet in harmonie opgelost: $\theta$ is hulp van buttenat bij nodig:

- een geringe frustratietolerantie;

- kan wel relaties leggen maar deze zijn niet hecht of houden niet lang stand.

Hulpverlening: gericht op structurering en belangenbehartiging.

12. Ongehuwde vrouw bij het begin van de hulpvraagcarrière.

- psychotisch gedecompenseerd in late adolescentie;

- niet in staat zelfstandig te functioneren, afhankelijk van de zorg van anderen (moeder, gezinszorg, pension). Hulpverlening?

13. Vrouw waar de hulpvraag begonnen is na een traumatisch ervaren verandering in het leven of een gebeurtenis.

- deze gebeurtenis wordt als centraal probleem in de eigen problematiek ervaren (maar is pas bekend na geruime tijd in de hulpverlening);

- deze gebeurtenis heeft niet zoveel aandacht gekregen in de hulpverlening zodat het nog onverwerkt zijn van de gebeurtenis opvalt.

Hulpverlening: inhalen van emotionele verwerking van gebeurtenis en uitbreiden van interesse in eigen psychisch functioneren zonder confrontatie maar als verbreding van geïnteresseerd raken in eigen beleven.

Stap 1 in de indelingsprocedure behelst het vaststellen van de hoofdgroep, aan de hand van leeftijd, geslacht en burgerlijke staat bij aanvang van de hulpverlening.

Stap 2 behelst het vergelijken met de bovenstaande omschrijvingen. 
APPENDIX

\title{
APPENDIX II - MANUAL
}

HANDLEIDING < INTERVIEWERS INSTRUCTIE > EN CODEBOEK VRAGENLIJST SOCIALE ROLVERVULLING EN ONTWIKKELING

\author{
INSTRUMENT TER BEOORDELING \\ VAN DE HUIDIGE \\ EN VROEGERE \\ SOCIALE ROLVERVULLING
}

DRS. E.O. NOORTHOORN PROF. DR. M.A.J. ROMME

DR. H. HAMERS

DR. H. KRAAN

C Januari 1990, Vakgroep Sociale Psychiatrie, Rijksuniversíteit Limburg 
Allereerst worden de algemeen demografische gegevens en de Sickness Impact Profile door, dan wel samen met de cliënt ingevuld. Vervolgens worden deze gegevens door de hulpveriener aangevuld, die dan tevens een diagnose volgens de DSM-III toekent, medische gegevens verstrekt en de Foulds index, BPRS evenals de SFCL invult. Het invullen van de achtergrondgegevens samen met de client vergt een gesprek van een uur. In twee tot drie gesprekken van een uur wordt de Vragenlijst ter becordeling van de Sociale Rolvervulling \& Ontwikkeling met de cliënt dan wel met de hulpverlener doorgenomen.

$$
\text { 1. INLEIDING HANDLEIDING }
$$

De handleiding is bedoeld als naslagwerk voor hulpverlener en onderzoeker: als basis voor het standaard invullen van het instrument. Het gaat in dit instrument om een globale becordeling van de sociale rolvervulling aan de hand van bepaalde handelingen of bepaald gedrag door de client. Omdat het in de sociale aanpassing bij chronische cliënten gaat om een resultante van een ontwikkeling door de jaren heen wordt ook deze ontwikkeling op een globaal nivo nagegaan. Verondersteld worct dat meer inzicht in de patronen waarlangs deze ontwikkeling zich voltrekt aangrijpingspunten kan geven voor de behandeling. Het instrument is in de eerste plaats bedoeld als een aanvulling op de huidige diagnostiek van de chronisch psychiatrische cliēnt. Scoring van het instrument is pas mogelijk als de hulpverlener de cliēnt goed kent. Daarom wordt, zeker in de fase waarin het instrument worct ontwikkeld, als minimum de termijn van tenminste een half jaar behandeling aangehouden. De procedure waarin het instrument wordt afgenomen is als volgt:

1. Uitleg aan de hulpvertener over het instrument met behulp van deze handleiding.

2. De onderzoeker neemt met de hulpverleners de vragen door in een eerste interview.

3. Een tweede interview waarin de openstaande vragen uit het eerste interview worden aangevuld en gecompleteerd.

in deze handleiding worden eerst een aantal algemene definities beschreven en een aantal algemene richtlijnen aangegeven hoe het instrument is opgebouwd. Er wordt ingegaan waaraan voldaan moet worden om tot scoring over te gaan. Vervolgens wordt elk item apart besproken en een scoringsadvies gegeven. Dit scoringsadvies wordt met voorbeeiden toegelicht. Allereerst is van belang te weten wat een rol is en hoe wij deze meetbaar hebben gemaakt.

\section{WAT IS EEN ROL}

In het proces van socialisatie, van ontwikkeling en inpassing in je sociale omgeving (maatschappelijke integratie) vindt een ontwikkeling plaats, waarbij met het veranderen van wat je bent en wat je doet (veranderen van kind naar volwassene, gaan werken en trouwen) de verwachtingen veranderen die aan je gedrag worden gesteld. Deze verandering van verwachtingen vinden het eerst plaats in het eigen gezin. Hier zijn de eisen nog niet zo hoog en bestaat een zekere flexibiliteit en variatie ten aanzien van de verwachtingen. Later bij inpassing in complexere sociale systemen (kennissen c.q. vriendenkring en arbeidssituatie) zijn de eisen doorgaans hoger, terwijl de flexibiliteit en variatie geringer is. Dit proces vindt plaats in het spanningsveld tussen de individuele wensen en de bewegings ruimte die hel individu door zijn sociale orngeving gegeven wordt. De sociale omgeving vormt de structuur voor het menselijk handelen. Sociaal verkeer vindt plaats in rollen. Een rol wordt gedefinieerd als een samenhangend geheel van gedragingen, die kenmerkend zijn voor een sociale relatie. Een voorbeeld is de rol als ouder: om een goed ouder te zijn moet je een goed voobeeld zijn voor je kinderen, normen en structuur kunnen aanbieden zodat het kind weet waar het aan toe is, je moet verantwoordelijkheid leren nemen en met anderen leren omgaan om je zelfstandig te ontwikkelen. De definitie van rol zoals in het instrument is als volgt:

De rol wordt beschouwd als het gedrag dat gerelateerd is aan een beperkte interactie met andere mensen.

Een sociale rol betreft de combinatie van verwachtingen met betrekking tot gedrag in een welomschreven sociale positie met de activiteiten die de actor daarin vervult. Met andere woorden, een rol is de activiteit van een perscon in een bepaalde positie waaraan ornschreven verwachtingen kunnen worden toegekend.

Verwachtingen veranderen naarmate men zich naar een andere status ontwikkelt (b.v. die van kind naar volwassene). Het uitvoeren van de sociale rollen die passen bij de ontwikkelde status typeren de maatschappelijke integratie. Het niet uitvoeren van de sociale rollen die bij een status worden venwacht markeren de (mate van) sociale of maatschappelijke desintegratie. Om de verwachtingen te relateren aan "de plaats in de maatschappij" wordt aangesloten op de sociologische begrippen zoals statusrol, positierol en situatierol.

Deze begrippen rangschikken de duurzaamheid van de verwachtingen aan een rol gesteld. Status-, positie- en situatierollen zijn abstracties die het kader bepalen van het dagelijks handelen. Onder statusrol wordt begrepen de typering die aan iemand gegeven wordt als je beschrijt wat hij/zij "is" in een bepaalde levensfase, zoals bijvoorbeeld de "jongere man" of de "oudere vrouw". Dit is een typering die op iedereen toepasbaar is en markeert de ontwikkeling die je als mens onontkoombaar meemaakt. Onder positierollen worden duurzaam verkregen rollen in het dagelijks leven begrepen zoals "gehuwde", "buschauffeur" maar ook "vader"; rollen waaraan je verwachtingen stelt. Onder situatierollen worden de rollen in situaties in het dagelijks leven begrepen die in de directe interactie met andere mensen ontstaan zoals "groepsleider", "groepslid"; rollen waaraan geen hoge verwachtingen worden gesteld. De vervulling van de situatierollen bepalen wel welke positierollen je op den duur kunt innemen: een geboren leider wordt directeur of voorzitter. Evenals dat je status bepaalt welke positierollen je kunt innemen. De situatierollen zijn in het onderzoek verder geen punt van aandacht. Het gaat immers bij chronische cliëten om zaken die zich op de lange duur ontwikkelen.

Resumerend: het vaststellen van iemands statusrol geschiedt aan de hand van geslacht, leeflijd, burgelijke staat en etnische achtergrond. In onze samenleving wordt verwacht dat de persoon een bij die status passend aantal positierollen uitvoert (echtgenoot, moeder, werknemer etc.). 
Om te beoordelen of iemand de positierol werkelijk vervult, hebben wij een vijftal basisgebieden voor de roluitvoering geselecteerd. Bij deze basisgebieden kan men van mening verschillen of het een capaciteit, een ideaal of een verworvenheid is. Waar het ons om gaat is of mensen hel verwachte gedrag in deze basisgebieden uitvoeren. Kortom verzorgen ze zichzelf of een ander, ja of neen, geven ze steun, ja of neen, etc. We zijn van mening dat informatie over deze basisgebieden noodzakelijk is om een oordeel te vellen over de rollen die de cliênt vervult. Het functioneren in deze basisgebieden vormen een randvoorwaarde voor de vervulling van de positierollen Basisgebieden zijn:

1. verzorging: zelfverzorging en verzorging van anderen;

2. hechting en steun: aan ouders, belangrijke anderen, partner en gezin;

3. sexualiteit: ontwikkeling van sexualiteit en vervulling van sexualiteit;

4. dagelijkse verplichtingen; in beroep, opleiding en carriëre;

5. sociale activiteiten: het ondememen van activiteiten en het gebruik maken van een sociaal netwerk. Deze basisgebieden zijn een voorwaarde om de positierollen te vervullen. Er zijn in de directe interactie met andere mensen vele positierollen te onderscheiden, bijvoorbeeld partner, echtgenoot, ouder, kind, familielid, gezinslid, buur, vriend, werkgever, collega, hulpverlener, vrijwilliger, winkelier, scholier, verenigingslid, buurtbewoner, dorpsgenoot, ect. De positierollen bepalen de verwachtingen die aan de statusrol gesteld kunnen worden en de basiselementen vormen de voorwaarden voor het vervullen van positierollen.

Met behulp van de deficiënties in het uitvoeren van de basisgebieden kan worden vastgesteld in hoeverre positierollen al dan niet worden ultgevoerd en daardoor al dan niet voldaan worct aan de verwachtingen passend bij de ontwikkelde status. De discrepantie die hierbij naar voren treedt markeert de mate van maatschappelijke desintegratie. Deze discrepantie zou opgevuld worden met (psychiatrisch) ziektegedrag, zoals ziekte wordt gezien als vervangend voor sociaal functioneren. De achterliggende theorie is de theorie van het sociaal homeostase-mechanisme. De sociale homeostase theorie van Querido (1956) stelt kort samengevat, dat de mens in interactie met zijn omgeving zoekt naar een evenwicht zowel op somatisch als sociaal gebied. Verstoring van het evenwicht heeft altijd een compensatie mechanisme tot gevolg, zij het door de omgeving, zij het door de persoon zelf. In het theoretisch model van Querido wordt ziekte opgevat in termen van functieverties en herstel in termen van functiewinst.

Samenvattend: de cliëntcarrière kan beschreven worden als de ontwikkeling en verandering van het rolfunctioneren in de tijd. Het rolfunctioneren kan beschreven worden aan de hand van gedragsobservaties, c.q. uitvoering van handelingen in elk der vijf basisgebieden. De ontwikkeling kan beschreven worden aan de hand van fluctuaties binnen de basisgebieden, dan wel op het nivo van de basisgebieden.

\section{DEFINITIES GEBIEDEN SOCIALE ROLVERVULLING}

$$
\text { (SOCIAL ROLE PERFORMANCE DOMAINS) }
$$

1. Verzorging: zelfverzorging en verzorging van anderen. Aan de zeltverzorging kunnen worden onderkend: de persoonlijke hygiëne, de verzorging van de kleding, de regelmaat van en de verzorging van de voeding, het dagritme en de eigen omgeving. Bij de verzorging van anderen gaat het om wat de persoon doet in de verzorging van anderen. Het gaat hierin om functies in de huishouding. onder te verdelen in planning, financieel beheer en verzorging van het huis, eten koken, kleren verstellen, etc. en daarnaast de voorziening van het levensonderhoud via het verwerven van het inkomen.

2. Steun geven : aan ouders, belangrijke anderen, partner en gezin. Aan het steun geven kunnen de aspecten hechting, probleemoplossend vermogen, conflictoplossend vermogen en steun geven worden onderkend. Er is sprake van een relatie met anderen in de vorm van een binding waarin deze het steun geven ten uitvoer brengt. Nagegaan moet worden naar welke anderen het steun geven wordt uitgevoerd. Het gaat om de steun die gegeven wordt en niel om de steun die verkregen wordt.

3. Sexualiteit: ontwikkeling van sexualiteit en vervulling van sexualiteit. Hieronder wordt begrepen het onderkennen van een sexuele identiteit, een keuze voor een ander van een bepaalde sexe, het onderhouden van een al of niet stabiele sexuele relatie met een ander, het bepalen van een eigen opstelling daarin en het onderkennen en accepteren van de wensen van de ander. Daamaast kan er al dan niet in het kader van een stabiele relatie uiting gegeven worden aan de sexualiteit.

4. Daglijkse verplichtingen: in beroep, opleiding en carrière. Onder het domein dagelijkse verplichtingen wordt begrepen het hebben van een gestructureerde daginvulling. Deze daginvulling kan plaatsvinden binnen de opleiding, het beroep of een beschermde werkomgeving. Van belang is dat de cliēnt aen het beroep of aan de vervulde dagelijkse verplichtingen een identiteit ontleent en verantwoording moet afdragen aan anderen.

5. Sociale activiteiten: het ondernemen van sociale activiteiten en het gebruik maken van een sociaal netwerk. Onder de sociale activiteiten wordt ten eerste verstaan het kunnen gebruikmaken en aanspreken van een sociaal en nominaal netwerk. Concreet kan gedacht worden aan het omgaan met familieleden (sociaal netwerk), contacten met anderen in de vrije tijd in gestructureerd verband van bijvoorbeeld een vereniging (nominaal netwerk), het omgaan met anderen (nominaal netwerk), het gebruik maken van relaties (extended netwerk). Ten tweede gaat het om het soort activiteiten dat de cliênt ontplooit in zijn vrije tijd, dus buiten de bovenbeschreven dagelijkse verplichtingen om. Het gaat daarbij om die activiteiten die de cliënt met een zekere vrijblijvendheid onderneemt, en waar hij geen verantwoording naar anderen voor hoeft af te leggen. We onderscheiden solitaire bezigheden, zowel passief als actief. Verder bezigheden samen met anderen, die taakgericht zijn, meer op de persoon gericht zijn, dan wel op wederzijdse belangen gebaseerd zijn. 
Het instrument bestaat uit twee delen:

a. deel een, waarin een navraag naar de hulpvraagcarrière en waarin de huidige maatschappelijke positie wordt beschreven;

b. deel twee, waarin de rolvervulling en rolontwikkeling wordt geïnventariseerd aan de hand van verscheidene items;

c. ieder basisgebied bevat een doorvraagsectie, waarin de rolontwikkeling verder wordt uitgediept;

d. een samenvattende sectie, waarin een globaal oordeel wordt gevraagd.

ad a.) Deel een. Hierin worden de huidige status- en positierollen en de status-en positierollen bij aanvang van de hulpvraagcarriöre nagevraagd. Tevens wordt in deze sectie de hulpvraagcarrière zowel binnen als buiten de G.G.Z. geînventariseerd. Deze informatie is te beschouwen als achtergrondinformatie t.b.v. voorlopige conclusies.

ad b.) Het algemeen oordeel over het basisgebied. In het onderzoek richten we onze aandacht allereerst op datgene wat de cliênt in de bovengenoemde 5 basisgebieden - verzorging, hechting en steun, sexualiteit, dagelijkse verplichtingen, sociale activiteiten - in het heden daadwerkelijk doet. Dit wordt nagevraagd onder de sectie "algemeen oordeel......". In deze sectie wordt het absolute oordeel over een aantal gedragingen gevraagd. Bij gedragsobservaties onderkent men wat iemand doet en hoe iemand iets doet. Gedrags-(c.q "rol") verwachtingen worden bepaald zowel door het "wat" als het "hoe". Het "wat" betekent: voert iemand iets in het basisgebied uit. Het "hoe" betekent: doet iemand het gevraagde met een zekere regelmaat, heeft iemand aansporing nodig, moet hij/zij continu gecorrigeerd worden? leder item kent een uitwerking van deze twee dimensies. Per vraag wordt een advies gegeven waarin aangegeven wordt wanneer "ja" of "neen" of "niet relevant" kan worden gescoord.

Doorvragen. Een aantal vragen van het algemeen oordeel worden met "neen" of "niet relevant" beantwoord. De cliët voert dan een bepaald aspect van de rol niet uit, of heeft problemen met de uitvoering. Om na te gaan hoe de cliênt zelf, de omgeving en de hulpverlener tegen het al dan niet uitvoeren van de handeling aankjiken, wordt alleen bij de niet volledig/adequaat uitgevoerde gedragingen doorgevraagd.

ad c.) De ontwikkeling van de basisgebieden. In de ontwikkeling van de basisgebieden wordt wederom uitgegaan van de handelingen die de cliënt in het heden niet optimaal vervult. Gevraagd wordt de wijze waarop het gedrag in het heden wordt uitgevoerd te vergelijken met de wijze waarop dit gedrag in het verteden in te omschrijven periodes is uitgevoerd. Vervolgens wordt nagegaan of zich in het verleden periodes van stagnatie of terugval hebben voorgedaan. Drie patronen worden onderscheiden:

1. Stagnatie: nooit verder gekomen.

2. Tijdelijke terugval met onvolledig herstel: is bijgetrokken.

3. Continue terugval: terugval met stagnatie op een lager nivo.

Met de vraag wat de oorzaak is van de stagnatie c.q. tijdelijke terugval wordt geinformeerd naar de reden waarom de hulpverlener vindt dat er sprake is daarvan. Een antwoord kan zijn: cliênt werd opgenomen in het psychiatrisch ziekenhuis wegens een psychotische decompensatie en verzorgde zichzelf in die periode niet". Later is herstel opgetreden maar de zelfverzorging is nog steeds gebrekkig. Als de terugval meer continu van aard is, of indien er sprake is van een langdurige stagnatie in de ontwikkeling van het basisgebied, wordt gevraagd op welke leeftijd en in welke levenslase dit "verval" heeft plaatsgevonden.

ad d.) Samenvatting. Hierin wordt de samenhang tussen de uitgevoerde status en positierollen en het functioneren binnen de verschillende basisgebieden nagegaan. Kort samengevat vindt interactie met andere mensen op een aantal gebieden plaats. Het functioneren in deze gebieden kan in detail beschreven worden in het heden: de huidige rolvervulling en meer globaal in het verleden: de rolontwikkeling. Per basisgebied zijn er ten aanzien van rolvervulling een aantal handelingen of gedragingen herkenbaar, en ten aanzien van rolontwikkeling een aantal typeringen te onderscheiden. Per basisgebied wordt dit apart toegelicht ( $\$ 6$ e.v. van deze handleiding). Tenslotte wordt in een alrondende sectie een globaal oordeel gevraagd over de huidige rolvervulling en word een samenvatting gegeven van de ontwikkeling op verschillende basisgebieden. Indien er problemen zijn wordt hierop in de doorvraagsectie verder ingegaan. De toelichting van deze vragen wordt aan het einde van deze handleiding gegeven. Na een korte schets te hebben gegeven van de huidige plaats van de cliënt in de maatschappij door middel van een beschrijving van status- en positierollen wordt het huidig functioneren en de ontwikkeling in tien secties aan de hand van items uitgevraagd. Niet alle vragen zijn op iedereen van toepassing. De items zijn gegroepeerd binnen de vift genoemde basisgebieden waarin roluitvoering plaatsvindt. De secties "algemeen oordeel" zijn op iedereen van toepassing. Bij die aspecten, waar in het algemeen oordeel is geconstateerd dat het functioneren niet optimaal is word doorgevraagd in hoeverre de geconstateerde lacune een probleem is voor de cliënt, omgeving of hulpverlener. Ook de ontwikkeling van een bepaald basisgebied hoeft alleen dan ingevuld te worden als het huidig functioneren binnen dat basisgebied niet optimaal is. Dit stramien geldt voor elk basisgebied. De lijst wordt afgerond met een korte samenvatting van zowel het huidig functioneren als de ontwikkeling. 
Inleiding INSLUITCRITERIUM:

Voorafgaand aan de inventarisatie van de rolvervulling in de vijf basisgebieden worot ter verduidelijking van de achtergrond van de clïent een korte schets van de huidige status- en positierollen en de status- en positierollen bij aanvang van de hulpvraag gevraagd, na een inventarisatie van enkele algemene demografische gegevens als "opwarmer" (deze zijn immers reeds verwerkt bij de algemene inventarisatie in de intake).

ITEM 01: HOOFDGROEP

$$
\begin{aligned}
& \text { p jonge }(<30) \text { ongehuwde man bij aanvang van hulp } \\
& \text { p jonge }(<30) \text { ongehuwde vrouw bij aanvang van hulp } \\
& \text { p oudere }(>40) \text { gehuwde man bij aanvang van hulp } \\
& \text { p oudere }(>40) \text { gehuwde vrouw bij aanvang van hulp }
\end{aligned}
$$

\begin{tabular}{|c|c|c|c|}
\hline \multicolumn{2}{|c|}{$\begin{array}{l}\text { INVENTARISATIE DEMOGRAFISCHE GEGEVENS } \\
\text { NU }\end{array}$} & \multicolumn{2}{|c|}{$\begin{array}{l}\text { INVENTARISATIE DEMOGRAFISCHE GEGEVENS BIJ } \\
\text { AANVANG VAN DE HULPVERLENING }\end{array}$} \\
\hline $\begin{array}{l}\text { DEMO } 01 \\
\text { DEMO } 02 \\
\text { DEMO } 03 \\
\text { DEMO } 04 \\
\text { DEMO } 05\end{array}$ & $\begin{array}{l}\text { leeftijd } \\
\text { burgerlijke staat } \\
\text { geslacht } \\
\text { samenstelling huishouden } \\
\text { werksituatie }\end{array}$ & $\begin{array}{l}\text { DEMO } 06 \\
\text { DEMO } 07 \\
\text { DEMO } 08 \\
\text { DEMO } 09 \\
\text { DEMO } 10\end{array}$ & $\begin{array}{l}\text { leeftijd bij aanvang hulpvraag } \\
\text { burgerlijke staat bij aanvang hulpvraag } \\
\text { geslacht bij aanvang hulpvraag } \\
\text { samenstelling huishouden } \\
\text { bij aanvang hulpvraag } \\
\text { werksituatie bij aanvang hulpvraag }\end{array}$ \\
\hline
\end{tabular}

ITEM $02 / 03 / 04$

Huidige sociale context: de volgende kaart wordt voorgelegd:

\section{KAART SOCIALE CONTEXT}

\begin{tabular}{|c|c|c|c|}
\hline \multicolumn{2}{|l|}{ Relatie: } & \multicolumn{2}{|l|}{ Vrienden: } \\
\hline $\begin{array}{c}01 \\
02 \\
\text { Kinderen: } \\
03 \\
04\end{array}$ & $\begin{array}{l}\text { partner } \\
\text { ex-partner } \\
\text { zoon/dochter } \\
\text { partner van zoondochter }\end{array}$ & $\begin{array}{l}33 \\
34 \\
38-46 \\
47-50 \\
51 \\
55\end{array}$ & $\begin{array}{l}\text { vriend/vriendin } \\
\text { partner vriend/vriendin } \\
\text { huisgenoot } \\
\text { bevriende collega } \\
\text { buur } \\
\text { kennis }\end{array}$ \\
\hline $\begin{array}{l}11 \\
12 \\
13 \\
14 \\
15 \\
16 \\
17-19 \\
20-25\end{array}$ & $\begin{array}{l}\text { vader } \\
\text { moeder } \\
\text { schoonvader } \\
\text { schoonmoeder } \\
\text { broer/zus } \\
\text { partner broer/zus } \\
\text { overige gezinsleden } \\
\text { overige familieleden }\end{array}$ & $\begin{array}{c}\text { Maatschappelijk } \\
\qquad \begin{array}{c}65 \\
66 \\
69 \\
77\end{array}\end{array}$ & $\begin{array}{l}\text { Jiensten of mensen van het werk: } \\
\text { mensen van school } \\
\text { mensen van het werk } \\
\text { huisarts, maatschappelijk werk, } \\
\text { specialisten in het ziekenhuis etc } \\
\text { overigen }\end{array}$ \\
\hline
\end{tabular}

De sociale context bestaat uit mensen met wie $u$ in het dagelijks leven omgaat. Dit kunnen bijvoorbeeld familieleden, vrienden of mensen van het werk zijn. Het gaat erom dat u de mensen noemt die u de laatste maand ten minste éénmaal hebt gezien.

ITEM 02 Wie heeft u de laatste maand gezien?

ITEM 03 Wie heeft u de laatste maand telefonisch gesproken?

ITEM 04 Zijn er voor u belangrijke mensen die u de laatste maand noch gezien noch telefonisch gesproken heeft? 
ITEM 05 Levensfase NU:

Hiertoe wordt een algemene beschrijving van de levenssituatie op dit moment gevraagd. Hoe oud is cliënt, woont cliënt nog thuis, is hij/zij schoolgaand of al getrouwd met kinderen. Dan volgt een plaatsing in een der levensfasen vgl. de definities (S. Krauss in: Adult development, the differentiation of experience, 1979 en Daniel Levinson: Tijdperken in het leven van een man, 1978):

(01) vroege jeugd. 0-12 jaar, voor de pubertijd, heeft nog geen complexere sociale verantwoordelijkheden, gaat om met leettijdgenoten met geringe verplichtingen en veel bewegingsruimte. Nog beperkte of geen verantwoordelijkheden binnen het gezin en geen eigen verantwoordelijkheid ten aanzien van het voorzien van de basisbehoeften, nog geen sexuele keuze.

(02) preadolescent. 12-16 jaar, nog thuiswonend, in de bescherming van het gezin, c.q. van zorg van anderen athankelijk; enige eigen verantwoordelijkheid binnen hel gezin, een eerste sexuele keuze. Voor meningsvorming en bepaling eigen grenzen nog van anderen afhankelijk (ouders, gezinsvervangende zorg e.d.). In deze periode vindt de definitieve persoonlijkheids-vorming plaats. Een stagnatie in deze fase kan alleen geconstateerd worden als aan geen van de aspecten van zelfstandige persoonlijkheids-ontwikkeling ooit aan de orde zijn gekomen.

(03) adolescentie: 16-20 jaar, nog thuiswonend, maar met eigen verantwoordelijkheid in het gezin ten aanzien van het voorzien van basisbehoeften, periode van persoonlijke ontwikkeling en experimenteren met eigen sexualiteit en grenzen. Er is nog geen duidelijke keuze ten aanzien van beroep en maatschappelijke positie. In deze periode wordt het persoonlijkheidstype gevormd. Discrepanties tussen verwachtingen en mogelijkheden leiden in deze periode tot als hettig ervaren stress. De adolescentie is doorgaans de fase waarin een eerste decompensatie plaatsvind.

(04) vroege volwassenheld : 20-30 jaar, de basis voor de volwassen identiteit wordt in deze fase gelegd, keuzen worden gemaakt: huwelijk, werkkring, woonplaats en levensstijl, het is een tijd waarin vele verplichtingen nagekomen moeten worden en waarin een bijdrage wordt geleverd aan de instandhouding van de soort: verwekken en opvoeden van kinderen, arbeid in dienst stellen van de economie en het opbouwen van een plaats binnen de maatschappij. De identiteit wordt in deze periode gevormd, individuele behoeften worden uitgekristalliseerd. In deze periode wordt een keuze gemaakt naar aard en inhoud van een binding met een ander. Na uittesten van de eigen mogelijkheden wordt een aanzet gemaakt in een carrière. Verwachtingen vanuit hel ouderlijk gezin gesteld, moeten worden waargemaakt, hetgeen tot conflicten kan leiden.

(05) vroege middelbare volwassenheid: $30-40$ jaar, dit wordt aangegeven als de periode waarin de verdere consolidatie en uitbouw plaatsvindt van de plaats binnen de maatschappij, het aanschaffen van een huis, krijgen en opvoeden van kinderen, er treedt een aanpassing aan een stabiele situatie op. De positie die men in de maatschapij inneemt stabiliseert in deze levensfase. Veranderingen zijn in deze levensfase minder gemakkelijk aan te brengen.

(06) midlife crisis. 40-45 jaar, na een periode van consolidatie treedt doorgaans weer een periode van veranderingen op, de verantwoordelijkheden binnen het gezin nemen af (omdat de kinderen hun eigen verantwoordelijkheden overnemen en uit huis gaan), zodat een herbezinning plaatsvindt over de eigen positie in de maatschapij. De midlife crisis betrett de afronding van een periode van opbouw en een evaluatie daarvan met eventueel een verandering naar een andere positie binnen de maatschappii.

(07) latere middelbare volwassenheid: 45-65 jaar, na de herbezinning treedt ofwel een periode van verdere opbouw en uitbouw van de mogelijkheden op, al naar gelang het bereikte succes in de vroege middelbare volwassenheid. Dit is de periode waarin leidinggevende posities worden verworven, dan wel een eerste aanzet tot het afbouwen van de maatschappelijke positie wordt gezet. De verantwoordelijkheden binnen het gezin nemen af, de zorgen blijen echter nog.

(10) ouderdom: 65+ hierin vindt een afbouw plaats van de positie in de maatschappij, zowel die als ouder, als die in de arbeidssituatie. Ten gevolge van lichamelijke aftakeling treedt later athankelijkheid op.

ITEM 06/07 Beschrijving status- en positierollen nu:

ITEM 06 Onder statusrel wordt begrepen de typering die aan iemand gegeven wordt als je beschrifh wat hij/zij "is" in een bepaalde levensfase, zoals bijoorbeeld "jongere man", de "oudere viouw". Dit is een typering die op iedereen toepasbaar is. De onderzoeker / hulpverlener kan dit zelf toekennen. Onder pesitierollen worden duurzaam verkregen rollen in het dagelijks leven begrepen, zoals "gehuwde", "buschautfeur", maar ook vader"; rollen waaraan je verwachtingen stelt. Dit is een typering die men verwertt. In deze vraag wordt geînformeerd naar een schels van een aantal te objectiveren gegevens, zoals burgerlijke staat, geslacht en leeftijd, vervolgens naar de levensfase, waarvan de delinities hierop aansluitend zullen worden uitgelegd, en tot slot naar de werk- en woonsituatie. 
Een standaard kaart wordt voorgelegd:

\section{KAART POSITIEROLLEN}

Positierollen zijn rollen die mensen in het dagelijks leven hebben. Het gaat over de plaats die u ten opzichte van iemand anders inneemt. U bent bijvoorbeeld partner (van uw man), kind (van uw ouders) of werknemer (van uw baas of het bedrijf). U kunt als hulpmiddel gebruik maken van het zinnetje: "Ik ben .................." en vult dan alle rollen die op u van toepassing zijn in op de stippellijn.

\begin{tabular}{|cl|ll|}
\hline Familierollen: & Werkrollen: & \\
01 & partner & 21 & werknemer \\
02 & ouder & 22 & werkgever/eidinggever \\
03 & kind & 23 & collega \\
04 & broer/zus & 24 & vrijwilliger \\
05 & schoonzoon/schoondochter & 25 & huisvrouw/huisman \\
student/leerling/stagiaire & \\
06 & zwager/schoonzus & 26 & \\
07 & opa/oma & Vrije tijdsrollen: & \\
08 & schoonvader/moeder & 31 & verenigingslid \\
09 & overig familielid & 32 & bestuurslid \\
& & 33 & lid politieke organisatie \\
11 & vriend(in) & & \\
12 & kennis & & \\
13 & buur & & \\
14 & bevriende collega & & \\
& & & \\
Vriendenrollen: & & & \\
\hline
\end{tabular}

ITEM 08 Beleving positierollen nu: een Likert schaal met keuzemogelijkheden lopend van 0-7.

ITEM 09 Discrepanties tussen verwachtingen en de vervulling status en positierollen nu: dit is een open vraag welke ten behoeve van het case report wordt gesteld.

ITEM 10 Hulpvraag op dit moment zoals door de cliênt zelf wordt verwoord.

ITEM 11 Psychiatrische diagnose nu.

ITEM 12 Eventuele somatische diagnose nu.

ITEM 13 Jaar aanvang: aanvang hulpvrasgcarriere: jaar, instelling en soort behandeling wordt gevraagd. Toelichting: met behulp van de informatie van hel dossier wordt de aanvang van de hulpvraagcarrière gedefinieerd als het eerste contact bij de GGZ.

ITEM 14 Sociale context bij aanvang van de hulpvraag - voor zover terug te halen. <Onbekend> invullen als de cliënt of de hulpverlener onduidelijke antwoorden geeft.

ITEM 15 Levensfase bij aanvang hulpvraaggeschiedenis. Met behulp van ITEM 08 <Jaar aanvang>, en demografische gegevens aanvang \& levenssituatie aanvang wordt de levensfase bij aanvang bepaald, volgens de definities van ITEM 02: Hiertoe wordt een algemene beschrijving van de levens situatie rond aanvang van hulp gevraagd. Hoe oud was cliēnt, woonde cliênt nog thuis, was hij zij schoolgaand of al getrouwd met kinderen. Dan volgt een plaatsing in een van de levensfasen.

ITEM 16/17 Status- en positierollen bij aanvang hulpvraag - toelichting: de status-en positierollen rond de aanvang van de hulpvraagcarriere worden gevraagd om te vergelijken met de status- en positierollen in het heden om de hypothese te toetsen dat gedurende de psychiatrische carriere hier weinig verandering in komt. Het gaat in deze vraag niet om interpretaties, maar om gegevens uit het dossier of via de cliēnt verworven.

ITEM 18 Discrepanties tussen verwachtingen en vervulling status- en positierollen bij aanvang van de hulpvraag: dit is een open vraag welke ten behoeve van het case report wordt gesteld.

ITEM 19 Hulpvraag zoals deze bij aanvang van de hulp volgens de dossiergegevens door de cliênt zelf werd verwoord.

ITEM 20 Psychiatrische diagnose aanvang van de hulp volgens de dossiergegevens. 


\section{DEEL TWEE: SOCIALE ROLVERVULLING}

DOMEIN 1 Subdomein ZELFVERZORGING. In dit domein gaat het om dichotome items, met een onderliggende veronderstelling van continuilteit. De scoringen per item zijn attijd gebaseerd op 3 ankerpunten (te beoordelen aan de hand van uitspraken over wat iemand doet). Eén waarin het "resultaat" wordt beschreven en twee waarin de wijze waarop het resultaat wordt bereikt, wordt beschreven. De score is van toepassing als sprake is van 2 van de 3 uitspraken, mits niet anders vermeld is. De scores "neen" "niet relevant", of "geen beroep gedaan op" zoveel mogelijk via doorvragen vermijden.

DOMEIN 1 ZELFVERZORGING - inleidende vraag: wat doet u aan zeltverzorging / hoe verzorgt u zkchzelf; indien we kijken naar de laatste maand. In deze sectie moet expliciet worden gevraagd of de cliēnt de handeling in het kader van de zelfverzorging doet. Het al dan niet adequaat doen wordt afgemeten aan wat de cliënt doet voor zichzelf. Hoewel het gaat over dezelfde handelingen als besproken in het kader van de verzorging van anderen zijn de eisen die t.a.v. de zelfverzorging anders (lager) dan t.a.v. de verzorging van anderen. De veronderstelling is dat de items in dit domein een toenemende moeilijkheidsgraad kennen.

ITEM 21 Hoe vaak wast u zich per week - krijgt u wel eens opmerkingen dat u zich niet vaak genoeg wast? Het gaat hier om de vraag of de cliënt voldoet aan de "algemeen maatschappelijk aanvaarde norm", niet om wat de hulpverlener denkt wat de cliênt kan of dat de cliënt het gezien zijgn mogelijkheden redelijk doet. Ankerpunten:

1e: resultaat: ziet er gewassen en verzorgd uit.

2e: wijze waarop: frequentie- dagelijks/voldoende vaak om er redelijk verzorgd en gewassen uit te zien.

3e: wijze waarop: zelístandigheid hoeft niet aangespoord te worden.

scoring: "ja"(1) als de cliënt dit dagelijks doet, dan wel voldoende vaak om er redelijk verzorgd en gewassen uit te zien, daarin niet aangespoord hoeft te worden, zodat de cliênt uit zichzelf er redelijk gewassen uitziet.

"neen"(0) als de cliēnt dit niet dagelijks doet, zichtbaar afwijkt van wat als aanvaardbaar kan worden beschouwd, of als de cliēnt aansporing behoeft.

"niet relevant"(8) als de cliënt, zoals bij een klinische of semimurale opname daar zelf geen inbreng in heeft maar daarin volledig gestuurd wordt. Dit is een nuance van de score "neen".

ITEM 22 Trekt u regelmatig schone kleren aan - krijgt u wel eens opmerkingen van anderen dat u er onverzorgd uitziet? Het gaat in deze vraag erom of de cliênt zelf voor zijn kleding zorg draagt, afhankelijk van de volgende drie ankerpunten:

1e: resultaat: er verzorgd uit zien.

2e: $\quad$ wijze warop: zelfstandig doen.

3e: wijze waarop: geen aansporing nodig hebben om het te doen.

scoring: $\quad$ "ja" (1) als de cliēnt dit geheel zelf doet, geen aansporing nodig heeft en er verzorgd uit ziet.

"neen"(0) als de cliēnt dit wel zelf, maar niet adequaat doet, ofwel als de cliént dit niet volledig zelf doet. Ten tweede "neen" als de cliënt riekt naar dagen lang ongewassen kleren, opvalt wegens de verkreukelde keding. Ten derde "neen" als de cliënt voor het op peil houden van de kleding door omgeving of hulpverlener gewezen moet worden op zijn beperking.

"niet relevant"(B) als de cliēnt daar zelf geen aandacht aan behoeft te besteden, doordat anderen hem helpen, doordat anderen volledig de zorg van het kleden overmemen.

ITEM 23 Houct u uw omgeving netjes en schoon - Krijgt u wel eens opmerkingen van anderen dat uw omgeving er vies of rommelig uitziet? Het gaat er in deze vraag weer om of de cliẻnt binnen een aanvaardbare norm aandacht heeft voor zijn eigen omgeving en er prijs op stelt dat deze er redelijk verzorgd en netjes vitziet. In deze sectie wordt gevraagd naar het voldoen aan de algemeen maatschappelijke norm, voldoet de cliënt aan de in het algemeen als "redelijk netjes" beschouwde norm. Scoring is athankelijk van de volgende ankerpunten:

1e: resultaat: omgeving ziet er notjes uit.

20: wijze waarop: zelfstandig, cliént draagt er zelf zorg voor, hoeft niet te worden aangespoord.

3e: wijze waarop: besteect er op wekelijkse basis aandacht aan.

scoring: $\quad$ "ja" (1) is van toepassing als de cliënt er zeltstandig zorg voor draagt dat zijn directe orngeving wordt verzorgd en onderhouden. De cliēnt dient daar op wekelijkse basis aandacht aan te besteden, heeft er oog voor en stelt het op prijs dat het er redelijk netjes uit ziet.

"neen"(0) is van toepassing als de cliēnt daar absolut geen oog voor heeft, daar zelden of nooit aandacht aan besteedt en zijn orngeving ook verwaarloost.

"niet relevant" (8) is van toepassing als de zorg door anderen wordt overgenomen, en dit overnemen conform de verwachting is, bijvoorbeeld omdat het gaat om een man wiens vrouw voor het huishouden zorgt, of omdat de client in een pensiontehuis is opgenomen. 
Kunt u uw dag goed indelen; heeft u een regelmatige dagstructuur - krijgt u wel eens opmerkingen van anderen dat $u$ uw dag slecht indeelt? Bent u vaak te laat, vergeet $u$ vaak afspraken?

Hoe is uw planning op langere termijn (bijvoorbeeld het beheer van geld, of uw wekelijkse inkopen - koopt u de juiste zaken in of heeft u soms onnodige voorraden die u toch niet opmaakt? Krijgt u wel eens opmerkingen van anderen over hoe u uw zaakjes organiseert?

ONTWIKKELING ZELFVERZORGING - (DEZE VRAGEN UITSTELLEN TOT NA VERZORGING ANDEREN INDIEN ER ANDEREN ZIJN OM TE VERZORGEN) Inleidende vragen: Terugkjikend naar het moment dat $u$ voor het eerst met de hulpverlening in contact kwam, hoe voldeed $u$ toen aan wat ik hierboven heb gevraagd, in vergelijking met nu?

$\begin{array}{ll}\text { wassen } & \text { - beter gelijk slechter } \\ \text { aankleden } & \text { - beter gelijk slechter } \\ \text { opruimen } & \text { - beter gelijk slechter } \\ \text { dag indelen } & \text { - beter gelijk slechter } \\ \text { plannen } & \text { - beter gelijk slechter }\end{array}$

Heett u (andere) perioden gekend waarin het bovenstaande beler ging?

Heeft $\mathrm{u}$ (andere) perioden gekend waarin het bovenstaande minder goed ging ?

Geef op basis van bovenstaande gegevens aan of er sprake is van stagnatie of terugval (N.B.: OORDEEL VAN DE INTERVIEWER):

$$
\text { - } 0 \text { - stagnatie }>\text {.... in welke leeftijd: ...... }
$$

terugval, deze is: - 0 - zeer tijdelijk van aard en eenmalig (enige maanden daarna verbeterd).

- 0 - zeer tijdelijk van aard en recidiverend (iedere keer enige maanden daama beter).

- 0 - tijdelijk van aard (niet langer dan een jaar een lerugval)

- 0 - voorbijgaand van aard (meer dan een jaar nodig voor herstel)

- 0 - continu van aard.

In welke levensperiode zijn de bovengenoemde problemen manifest geworden?

"stagnatie"(3) als de ontwikkeling op een onvolledige nivo is blijven steken, er een levensfase, periode of moment aanwijsbaar is waarin dat gebeurd is en zich daarna geen verdere ontwikkeling heeft voltrokken.

"terugval tijdelijk'(2) als de ontwikkeling zich tot het normale nivo heet voltrokken, een terugval heeft plaatsgevonden, maar het huidige nivo hoger is dan op het moment van terugval (minder beperkingen).

"terugval continu"(1) als de ontwikkeling zich tot het normale nivo heeft voltrokken, een terugval heeft plaatsgevonden, maar het huidige nivo niet hoger is (evenveel of meer beperkingen) dan op het moment van terugval.

In welke levensperiode zijn de bovengenoemde problemen manifest geworden?

\section{GEEF EEN BESCHRIJVING VAN HET BELOOP (T.B.V. HET CASE REPORT)}

SUBDOMEIN VERZORGING ANDEREN. ANKERPUNTEN Inleidende vraag: wat doet $u$ aan de verzorging van anderen, indien we kijken naar de laatste maand. In dit deelgebied gaat het erom of een cliēnt meer of minder doet dan men van hem verwacht. Het gaat vooral erom of de indruk wordt opgedaan dat er sprake van is dat de client minder, evenveel of meer doet dan men van hem verwacht. Dat kan minder zijn dan hij in het verleden deed, of dan de cliënt zou doen als hij zich niet ziek, depressief of anderzins niet gezond "zou voelen". Het gaat in dit basisgebied om materiēle verzorging van anderen, het gaat niet om emotioneel getinte "zorg" voor anderen, die kormt in het steun geven aan de orde. In dit domein gaat het om hel bepalen van de mate van inzet in de verzorging van anderen. Er is geen veronderstelling over een toenemende moeilijkheid.

SUBDOMEIN VERZORGING ANDEREN - inleidende vragen: Wilt u nogmaals in het kort herhalen met wie u het huishouden deelt? Indien "geen anderen", waarom niet?

Wat doet $u$ daadwerkelijk in het huishouden (1) - Maakt $u$ het huis schoon - Vindt $u$ dat $u$ hier voldoende aandacht aan besteect? Vinden anderen dat ook? scoringen te weinig (0) - voldoende (1) - te veel (2)

Wat doet u daadwerkelijk in het huishouden (2) - Besteect $u$ aandacht aan het onderhoud Vindt $u$ dat $\mathrm{u}$ hier voldoende aandacht aan besteedt? Vinden anderen dat ook ? scoringen te weinig (0) - voldoende (1) - te veel (2)

Hoe deelt u de gezamenlijke taken in, plant u dit samen met anderen of bedenkt nu wat u over een kwartier gaat doen? Vindt u dat $u$ hier voldoende aandacht aan besteect? Vinden anderen dat ook? scoringen te weinig (0) - voldoende (1) - te veel (2) 


\section{APPENDIX}

ITEM 32

ITEM 33

ITEM 34

scoring:

ITEM 35

DOMEIN 2

Plant u (eventueel samen met anderen) op langere termijn de wekelijkse inkopen en beheert u samen het geld? Vind $u$ dat $u$ hier voldoende aandacht aan besteedt? Vinden anderen dat ook? scoringen te weinig (0) - voldoende (1) - te veel (2)

Wat verwachten degene waarmee u leeft van u? (0) - anderen verwachten dat ik (bijna) alles doe.

(1) - anderen verwachten dat ik het grootste deel doe, maar helpen wel eens mee.

(2) - anderen venwachten dat we de taken gelijkwaardig verdelen.

(3) - anderen verwachten niets, maar desondanks doe ik wel wat.

(4) - anderen verwachten niets, en ik doe ook niets.

SUBDOMEIN VERZORGING ANDEREN ONTWIKKELING - Inleiding: Welke anderen had u bij aanvang van de hulpverlening te verzorgen (benoemen)? Terugkjjkend naar het moment dat u voor het eerst met de hulpverlening in contact kwam, hoe voldeed u toen aan wat ik hierboven heb gevraagd?

Het schoonmaken van het huis

Het doen van taken in de huishouding

De planning van de dag, eventueel samen met anderen

De planning op langere termijn

Heeft $u$ (andere) perioden gekend waarin het bovenstaande beter ging?

- beter gelijk slechter

- beter gelijk slechter

- beter gelijk slechter

- beter gelijk slechter

Heett u (andere) perioden gekend waarin het bovenstaande minder goed ging?

Geef op basis van bovenstaande gegevens aan of er sprake is van stagnatie of terugval (N.B.: OORDEEL VAN DE INTERVIEWER):

$$
\text { - } 0 \text { - stagnatie >-..- in welke leeftijd: ..... }
$$

terugval, deze is: - 0 - zeer tijdelijk van aard en eenmalig (enige maanden daarna verbeterd)

- 0 - zeer tijdelijk van aard en recidiverend (iedere keer enige maanden daama beter)

- 0 - tijdelijk van aard (niet langer dan een jaar een terugval)

- 0 - voorbijgaand van aard (meer dan een jaar nodig voor herstel)

- 0 - continu van aard

"stagnatie"(3) als de ontwikkeling op een onvolledige nivo is blijven steken, er een levenstasse, periode of moment aanwijsbaar is waarin dat gebeurd is en zich daarna geen verdere ontwikkeling heeft voltrokken.

"terugval tijdelijk"(2) als de ontwikkeling zich tot het normale nivo heeft voltrokken, een terugval heeft plaatsgevonden, maar het huidige nivo hoger is dan op het moment van terugval (minder beperkingen).

"terugval continu"(1) als de ontwikkeling zich tot het normale nivo heeft voltrokken, een terugval heett plaatsgevonden, maar het huidige nivo niet hoger is (evenveel of meer beperkingen) dan op het moment van terugval.

In welke levensperiode zijn de bovengenoemde problemen manifest geworden?

GEEF EEN BESCHRIJVING VAN HET BELOOP (T.B.V. HET CASE REPORT)

STEUN GEVEN Het steun geven hangt samen met de mogelijkheid om de steun te tonen: aan wie wordt daadwerkelijk steun gegeven. Als definitie geldt:

"Het tonen van een verbondenheid mel de ander, het zowel praktisch als persoonlijk delen en overnemen van verantwoordelijkheid van de ander waaraan steun wordt gegeven en het helpen problemen op te lossen" (therapeutic role domain. F. Ivan Nye, 1976).

Dit basisgebied omvat een aantal abstracte gegevens. Voordat de rol besproken wordt zal enige discussie en toelichting nodig zijn om het eens te worden of datgene wat de hulpverlener onder steun geven verstaat ook voor de onderzoekers geldt. Deelaspecten van steun zijn in toenemende mate van complexiteit, c.q een tcenemende moeilijkheidsgraad:

1. Het geven van praktische hulp.

2. Hechting: het tonen van verbondheid (attachment) en van vertrouwen. Dit kan expliciet gebeuren (actief), dan wel niel expliciet (uit gewoonte, passief).

3. Probleemoplossen: luisteren, het luisteren naar problemen, het zoeken naar een oplossing en het kunnen aandragen van oplossingsstrategieẻn om het probleem op te lossen.

4. Conflictoplossen: het onderkennen van tegenstellingen en het bij een ruzie bijdragen aan het oplossen van de tegenstellingen.

1,2 en 3 vallen onder de definitie van "therapeutic role"- Ivan Nye, 1976. Conflictoplossen is loegevoegd, omdat dit een bij het probleemoplossen horende dimensie is waar bij de doelgroep frequent problemen optreden.

Uitleg aan cliënt: Bij het steun geven gaat het om uw dagelijkse relaties in het gezin, met de ouders, in een werksituatie, of met belangrijke anderen. Het gaat er vooral om of uw omgang met anderen al dan niet "soepel" verloopt en of zich regelmatig problemen voordoen. 
Inleidende vragen: Kunt u mensen noemen waar $u$ enige steun aan geeft, of die voor u belangrijk zijn? (Bij geen antwoord: noem eens de mensen waarmee u regelmatig omgaat, namen van mensen die in u opkomen, die u bijvoorbeeld een verhuisbericht zou sturen). Indien "geen anderen", waarom niet?

ANKERPUNTEN. In dit basisgebied gaat het gaat erom een globaal oordeel van de eigenschap te krijgen in de omgang met anderen, waarbij er sprake is van een persoonlijke relatie, d.w.z., naar belangrijke personen in het netwerk. Het gaat er niet om exact aan te geven naar welke personen wel en welke niet. Ten tweede gaat het erom dat de eigenschap geuit wordt. Bijoorbeeld iemand die een verzorgend beroep heeft, waarin de vier ankerpunten voldoende aan bod komen, maar e.e.a. naar belangrijke personen binnen het nefwerk niet laat blijken zal een score "weinig" of "nauwelijks of niet" meekrijgen. In dit domein gaat het om dichotome items, met een onderliggende veronderstelling van continuiteit. In de eerste drie items geldt: "vaak" (3) als twee van de drie ankerpunten naar de meeste belangrijke personen binnen hel netwerk worden geuit.

"regelmatig"(2) als twee van de drie ankerpunten naar sommige belangrijke personen binnen het netwerk wel en naar anderen niet worden geuit.

"weinig"(1) als een van de drie ankerpunten naar maar enkele belangrijke personen binnen het netwerk wel en naar anderen niet worden geuit.

"nauwelijks of niet"(0) als maar een enkel van de vier ankerpunten naar maar enkele personen binnen het netwerk wel en naar anderen niet worden geuit.

Doet u wel eens iets voor anderen? Zo ja, wat? (Het gaat in deze vraag vooral om praktische zaken, b.v. een klus in het huis doen, boodschappen doen voor een bejaarde buurvrouw, e.d.). Doet $u$ dat vaak? LIKERT SCHAAL: vaak- regelmatig-soms-zelden-nooit

Ondersteuning kent de volgende drie ankerpunten:

$1 \theta$ het geven van praktische hulp

20 het geven van materiäle hulp

3e het verbaal laten blijken van ondersteuning

ITEM 37 (passief) Voelt u zich aan anderen gehecht? Heeft u dat gevoel vaak- regelmatig-soms-zeldennooit?

Passieve hechting kent de volgende drie ankerpunten:

1e het openlijk tonen van verbondenheid

$2 \theta$ het uiten van emotionele warmte

3e het open zijn naar anderen toe

ITEM 38 (actief hechting) Hoe laat u dit blijken? (Laat u dit zelf duidelijk blijken, of komt het initiatief meer van anderen?). Laat u dat zelf vaak- regelmatig-soms-zelden-nooit blijken?

Actieve hechting kent de volgende drie ankerpunten:

10 het voelen van verbondenheid, erbij horen, zonder dat expliciet te tonen

$2 \theta$ andere mensen belangrijk vinden, mensen kunnen aanduiden die belangrijk zijn

3e het tonen van vertrouwen

ANKERPUNTEN. Voor de volgende twee items, omdat deze vier ankerpunten kennen, geld:

"vaak'(3) als drie van de vier ankerpunten naar de meeste belangrijke personen binnen het netwerk worden geuit.

"regelmatig"(2) als twee van de vier ankerpunten sommige belangrijke personen binnen het netwerk wel en naar anderen niet worden geuit.

"weinig"(1) als twee van de vier ankerpunten naar maar enkele belangrijke personen binnen het netwerk wel en naar anderen niet worden geuit.

"nauwelijks of niet"(0) als maar een enkel van de vier ankerpunten naar maar enkele personen binnen het netwerk wel en naar anderen niet worden geuit.

ITEM 39 Lost $u$ in het dagelijks leven wel eens problemen op voor en in de relatie met anderen? Wat voor scort problemen zijn dat? Doot $u$ dat vaak vaak- regelmatig-soms-zelden-nooit?

Probleemoplossen kent de volgende vier ankerpunten:

$1 \theta$ het luisteren naar problemen

$2 \theta$ het zoeken naar oplossingen

3e het aandragen van rë̈le oplossingsstrategiēen

$4 \theta$ het actief bijdragen aan de oplossing

ITEM $40 \quad$ Lost $u$ wel eens ruzies of conflicten op voor en in de relatie met anderen? Wat voor soort conflicten zijn dat? Met wie?

Conflictoplossen kent de volgende vier ankerpunten;

1e het onderkennen van tegenstellingen

$2 \theta$ het in ruzie zoeken naar oplossingen

3e het in ruzie aandragen van reēle oplossingen

40 het actiel bijdragen in het opheffen van de conflicten 
ONTWIKKELING STEUN GEVEN: Terugkjikend naar het moment dat u voor het eerst met de hulpverlening in contact kwam, wie waren toen voor u belangrijk, aan wie gaf u steun? (Bij geen antwoord: noem eens de mensen waarmee u toen regelmatig omging, namen van mensen die in u opkomen, die u bijvoorbeeld een verhuisbericht zou hebben gestuurd.

INTERVIEWER: bespreek de diepgang van de relatie; is sprake van een persoonlijke band?). Terugkijkend naar het moment dat u voor het eerst met de hulpverlening in contact kwam, hoe voldeed $u$ toen aan wat ik hierboven heb gevraagd? doen van praktische dingen voor anderen het laten beleven van gehechtheid aan anderen (passief) het laten blijken van gehechtheid aan anderen (actief) problemen oplossen in relatie met anderen conflicten/ruzies oplossen in relatie met anderen Heeft u (andere) perioden gekend waarin het bovenstaande beter ging?

- beter gelijk slechter - beter gelijk slechter

- beter gelijk slechter - beter gelijk slechter - beter gelijk slechter Heett u (andere) perioden gekend waarin het bovenstaande minder goed ging?

TEM 41

ITEM 42

Geel op basis van bovenstaande gegevens aan of er sprake is van stagnatie of terugval (N.B.: OORDEEL VAN DE INTERVIEWER): - 0 - stagnatie $>$-... in welke leettijd: .....

terugval, deze is: - 0 - zeer tijdelijk van aard en enmalig (enige maanden daarna verbeterd)

- 0 - zeer tijdelijk van aard en recidiverend (iedere keer enige maanden daama beter)

- 0 - tijdelijk van aard (niet langer dan een jaar een terugval)

- 0 - voorbijgaand van aard (meer dan een jaar nodig voor herstel)

- 0 - continu van aard

In welke levensperiode zijn de bovengenoemde problemen manifest geworden?

DOMEIN $3 \quad$ SEXUALITEIT EN INTIMITEIT In dit deelgebied is het belangrijk het “ijs eerst te breken". Stel daartoe enkele inleidende vragen, zoals: ik wil het nu met u hebben over hoe u met sexualiteit en intimiteit omgaat. Allereerst wil ik weten of u dit een moeilijk onderwerp vindt. (Geef een informatiekaart). Hieronder wordt begrepen het hebben van een relatie met een sexuele dan wel een intieme beleving. Verder speelt een rol de keuze voor een ander van een bepaalde sexe, het onderhouden van een al of niet stabiele sexuele relatie met een ander, het bepalen van een eigen opstelling daarin en hel onderkennen en accepteren van de wensen van de ander. Aan de hand van een open omschrijving van de huidige sexuele relatie wordt besproken of de cliënt in een bepaalde ontwikkelingsnivo geplaatst kan worden. In de discussie moet er op gelet worden dat dit wel op een objectieve wijze gebeurt. Dat wil zeggen dat dit niet wordt bepaald aan de hand van de levensfase waarin de cliënt zich bevindt, maar aan de hand van de omschrijving van de sexualiteitsbeleving.

ANKERPUNTEN. In dit domein gaat het om nominale items, zonder een onderliggende veronderstelling van continuïteit.

ITEM 43

Keuze sexe van de partner

$\begin{array}{rll}\text { partners van de: } & 1 . & \text { nog geen } \\ 2 . & \text { eigen sexe } \\ 3 . & \text { andere sexe } \\ 4 . & \text { beide sexen } \\ 5 . & \text { anders, n.l. }\end{array}$

ITEM 44

Hoe ziet de relatio er uit er is sprake van:

1. een relatie in het kader van een huwelijk/samenwonen

2. een relatie die reeds meer dan twaalf maanden duurt

3. een relatie die minder dan twaalf maanden duurt

4. van nogal vluchtige en nogal eens wisselende contacten

ITEM 45 Uiting geven aan sexualiteit - Welke van de volgende uitspraken is op u van toepassing is:

1. ik kom nu niet toe aan enige sexuele viting, ook niet aan

zeltbevrediging.

2. ik kom nu alleen toe aan zelfbevrediging.

3. in mijn sexuele activiteit gaat het meer on de daad dan om de

band die ik met de ander heb, maar ik kom daar wel toe.

4. in mijn sexuele contacten gaat het mij vooral om het strelen, de

intimiteit en niet zozeer om de lichamelijkheid, "de daad".

5. in mijn sexuele contacten gaat het zowel om de intimiteit als om de lichamelijkheid, ik kom ook aan beide toe.

De veronderstelling is dat dit tiem een toenemende moelijkheidsgraad kent. 


\section{APPENDIX}

ITEM 46

DOMEIN 3

ITEM 47

ITEM 48

DOMEIN 4

ITEM 49

Problemen in de uiting van sexualiteit / neen / ja, welke?

Er is sprake van:

$$
\begin{aligned}
& \text { - } 1 \text { - afkerigheid of weerzin } \\
& \text { - } 2 \text { - angstbeladenheid } \\
& \text { - } 3 \text { - instrumentaliteit (te weinig intimiteit, de } \\
& \text { lichamelijkheid is (te) belangrijk) } \\
& \text { - } 4 \text { - fysieke beperkingen } \\
& \text { - } 5 \text { - komt niet toe aan gewenste frequentie } \\
& \text { - } 6 \text { - andere problemen:............. }
\end{aligned}
$$

ONTWIKKELING SEXUALITEIT EN INTIMITEIT-Inleidende vragen: Heeft $u$ in het verleden ooit perioden met problemen gehad in de uiting van uw sexualiteit? Welke problemen? Welke perioden in uw leven? Heeft u er toen hulp voor gezocht? Terugkijkend naar het moment dat u voor het eerst met de hulpverlening in contact kwam, hoe werd de uiting van de sexualiteit toen beleefd?

- 0 -prettiger - 0 -even goed als nu - 0 - minder prettig

Hoe gaf $u$ in de periode rond uw eerste hulpvraag uiting aan uw sexualiteit (bijoorbeeld $u$ heeft zojuist genoemd "....??)

Heeft u (andere) perioden gekend waarin u minder toekwam aan de uiting van uw sexualiteit ? Heeft u (andere) perioden gekend waarin u meer toekwam aan de uiting van uw sexualiteit ?

Geef op basis van bovenstaande gegevens aan of er sprake is van stagnatie of terugval (N.B.: OORDEEL VAN DE INTERVIEWER):

$$
\text { - } 0 \text { - stagnatie >-.. in welke leeftijd: ...... }
$$

terugval, deze is: - 0 - zeer tijdelijk van aard en eenmalig (enige maanden daarna verbeterd)

- 0 - zeer tijdelijk van aard en recidiverend (iedere keer enige maanden daama beter)

- 0 - tijdelijk van aard (niet langer dan een jaar een terugval)

- 0 - voorbijgaand van aard (meer dan een jaar nodig voor herstel)

- 0 - continu van aard.

In welke levensperiode zijn de bovengenoemde problemen manifest geworden?

\section{GEEF EEN BESCHRIJVING VAN HET BELOOP (T.B.V. HET CASE REPORT)}

DAGELIJKSE VERPLICHTINGEN Onder dagelijkse verplichtingen wordt begrepen het hebben van een gestructureerde daginvulling in een locatie in samenwerking met anderen. Er wordt niet mee bedoeld dat de vervulling leidt tot het verwerven van inkomen. Belangrijkste criterium is dat de dagstructurering mede door anderen waarmee men al of niet samenwerkt wordt bepaald. Er moet met anderen rekening worden gehouden en voldaan worden aan een aantal verwachtingen die de arbeidssituatie stelt.

- Uitleg cliënt: Onder dagelijkse verplichtingen word verstaan die activiteiten, waarvoor verantwoording naar een of meer anderen dient te worden afgelegd. Dit kan zijn in het kader van een al dan niet gestructureerd werkverband. Het kan ook zijn het kader van het samenteven in een gezin of andere vorm van langerdurende samenwoning. Het zijn die activiteiten waar ieder mens zijn eigenwaarde en identitert aan ontleent, door te zeggen "ik ben: ...................... Allereerst gaan we in op de situatie van de laatste maand. Inleidende vragen: Wat doet u overdag?

< in het geheel niets / opleiding / huishouden / vrijwilligerswerk / beroep > Hoeveel tijd besteedt u hieraan ? Gestructureerde dagbesteding is: > ... uur.

TEN BEHOEVE VAN HET CASE REPORT: Als u geen dagelijkse verplichtingen of bezigheden heeft, waarom niet? Wat betekent het niet hebben van dagelijkse verplichtingen of bezigheden voor u? Als u wel dagelijkse verplichtingen hebt zou ik u willen vragen of u de volgende vermogens hebt, en als er problemen zijn aan wie dat ligt: aan uzelf of aan anderen? .

ANKERPUNTEN. In dit domein wordt allereerst gevraagd of er sprake is van problemen in het voldoen aan verwachtingen op een specifiek item. Het is altijd gerelateerd aan de werksituatie, voldoet de cliënt aan de verwachtingen die in zijn werksituatie, dan wel - als huisvrouw in de thuissituatie - aan hem of haar gesteld worden. We kunnen twee subdimensies onderscheiden gerelateerd aan werk: a) lukt het om taken te vervullen en b) lukt het om de taken in een goede samenwerking met anderen te vervullen. De veronderstelling is dat de items in dit domein een toenemende moeilijkheidsgraad kennen. Ten tweede willen we t.b.v. het case report weten waar de oorzaak van "onvoldoende functioneren" op een item ligt. In dit domein gaat hel om dichotome items, met een onderliggende veronderstelling van continuñteit.

Handigheid: bent u wel/niet handig? / doorvraag t.b.v. het case report: als het problemen oplevert, aan wie ligt dat dan? "neen" als de cliênt problemen heeht op het gebied van praktische vaardigheden, niet handig genoeg is. 
ITEM 50 De hoeveelheid werk: kan weV niet aan / doorvraag: als het problemen oplevert, aan wie ligt dat dan? "neen" als de cliēnt de uitvoering van de dagelijkse verplichtingen zwaar valt en de cliënt geen continuiteit hierin kan aanbrengen, het voortdurend niet af krijgt "orndat het te veel is".

ITEM 51 De indeling van hel werk: welgeen probleem / doorvraag: idem "neen" als als de cliênt niet goed op lange termijn kan plannen en datgene wat van de cliēnt venwacht wordt (of dit nu het huishouden of werktaken zijn) niet afkrijgt.

ITEM 52 Kunt u goed omgaan met gelijken/ doorvraag: idem "neen" als de cliënt problemen heeft in de omgang met collega's binnen de werksituatie, medescholieren en opleiders binnen de opleidingssituatie of gezinsleden, partner binnen de thuissituatie, al naar gelang wat van toepassing is (opleiding, beroep of huishouden).

ITEM 53 Kunt u goed omgaan met mensen boven/onder w doorvraag: idem "neen" als de cliënt problemen heeft in het in de gaten houden van de hiërarchie in de samenwerking met collega's binnen de werksituatie, medescholieren en opleiders binnen de opleidingssituatie of gezinsleden, of in de omgang met de partner binnen de thuissituatie, al naar gelang wat van toepassing is (opleiding beroep of huishouden).

ITEM 54 Kunt u problemen of conflicten op het werk aan/ doorvraag: idem "neen" als de cliẽnt regelmatig arbeidsconflicten heeft (n.b. het gaat niet erom of hij de schuld heeft, dan wel anderen, het gaat erom dat de cliënt ze heeft).

DOMEIN 5 ONTWIKKELING DAGELIJKSE VERPLICHTINGEN - Terugkijkend naar de periode dat u voor het eerst met de hulpverlening in contact kwam, hoe voldeed u toen aan wat ik hieboven heb gevraagd?

handigheid

het aankunnen van de hoeveelheid werk de indeling van het werk de omgang met gelijken de omgang met mensen boven of onder u het oplossen van problemen of conflicten op het werk

- beter gelijk slechter

- beter gelijk slechter

- beter gelijk slechter

- beter gelijk slechter

- beter gelijk slechter

- beter gelijk slechter

Heett u (andere) perioden gekend waarin u minder toekwam aan de uiting van uw sexualiteit? Heett u (andere) perioden gekend waarin u meer toekwam aan de uiting van uw sexualiteit?

ITEM 55 Geef op basis van bovenstaande gegevens aan of er sprake is van stagnatie of terugval (N.B.: OORDEEL VAN DE INTERVIEWER):

$$
\text { - } 0 \text { - stagnatie >...- in welke leeftijd: ..... }
$$

terugval, deze is: - 0 - zeer tijdelijk van aard en eenmalig (enige maanden daarna verbeterd)

- 0 - zeer tijdelijk van aard en recidiverend (iedere keer enige maanden daama beter)

- 0 - tijdelijk van aard (niet langer dan een jaar een terugval)

- 0 - voorbijgaand van aard (meer dan een jaar nodig voor herstel)

- 0 - continu van aard.

ITEM 56

In welke levensperiode zijn de bovengenoemde problemen manifest geworden?

\section{GEEF EEN BESCHRIJVING VAN HET BELOOP (T.B.V. HET CASE REPORT)}

DOMEIN 5 SOCIALE ACTIVITEITEN - Onder sociale activiteiten wordt verstaan het kunnen gebruik maken en aanspreken van familie, vrienden, kennissen, vrienden van vrienden en relaties binnen o.a. een verenigingsverband. Vrije tijdsinvulling kan een basis kan zijn voor het opdoen van een netwerk. Om het beeld van de cliënt rond te krijgen zullen wel enkele aanvullende vragen over de vrijetijdsinvulling gesteld worden. Concreet kan gedacht worden aan het omgaan met familieleden en belangrijke vrienden, het gebruik maken van en de omgang met relaties en vrienden van vrienden. Voor onze vraagstelling is verder van belang in hoeverre de cliēnt gebruik maakt van zijn omgeving. In dit basisgebied wordt als defintie de"recreative role" vgl. Ivan Nye aangehouden: "die activiteit die niet vah onder de dagelijkse verplichting en die gericht is op ontspanning of zelfontplooiing. of op de omgang met anderen op informele basis". Uitleg cliënt: in het hiernavolgende wil ik het er met u over hebben hoe u uw vrije tijd invult en wat $u$ in uw vrije tijd onderneemt. Het gaat daabij om die activiteiten die u met een zekere vrijblijvendheid onderneemt, en waar u geen verantwoording naar anderen voor hoett af te leggen. Welke activiteiten heeft u zoal de laatste week ondemomen (bij weinig response), of de laatste maand?

ANKERPUNTEN, In dit domein gaat het om dichotome items, met een onderliggende vooronderstelling van continuiteit. leder item staat los van de vorige. De items zijn geformuleerd met een toenemende moeilijkheidsgraad. Voor het instrument t.b.v. de hulpverlener gaat het erom een oordeel te geven over wat de hulpverlener vindt t.a.v. het betreflende item; de formulering "Ik verveel me/ doe vaak niets" wordt dan: "verveelt de cliënt zich vaak?" 


\section{APPENIDIX}

ITEM 57

lik vorveol ma/ doo vaak niets zolden(0)-soms(1)-regelmatig(2)-vaak(3) (2-3-ja 10-1 =noen)

TTEM 58 Ik besteed mïn vrije tijd alben .

- mel passieve bezgheden zalden(0)-soms(1)-regelmatig(2)-vaak(3) (2-3-ja 10-1-neen)

TTEM 59 ik besteed mijn vijp tjd alleon -

"met maer actiove dingen zolden(0)-soms(1)-rogelmatig(2)-vaak(3) (2-3-ja / 0-1-neen)

TTEM $60 \quad$ Ik ondemeern activiteiten samen

mot anderen

- hot gaat or mij om iets to doeen.

mot wio maakt mij niet uit

ja/nem

fa/neen

ja/neen

ITEM 63 Ondemeemt u uw (de client zin )activitaiten op oigen iniliatief Likert schasl: veak-regeimatig-soms-zolden-nooit

ITEM 64 Komt u (de client) hiertij buitenshuis

Likert schaal: vaak- regeimatig-soms-zelden-nooit

DOMEIN 5 ONTWIKKELING SOCIALE ACTIVITEITEN -

Tenugkikend near het moment dat $u$ het eerst met de hupverlening in contact kwem, hoe voldeod $u$ wen aen wat

ik hiertoven heb gevraegd?

Ik vervelde me, doed vaak niets meer gelijk minder

ben vulde ik mijn tijd alleen

- met passieve beźgheden

- met meer ecteve dingen

Ik ondemem activiterten samen met anderen

- hel ging er mij om iets te doen.

met wis maakto mij niel uit

- het ging er mij om samen met enderen

iets to doen, ik deed het om mensen to leren kennen

- do contacten waren wederzids, enderen vonden

het cok leuk samen mel mij wats to doen

deed $u$ deze activiteitan op eigen initiatiof

kwam u hierbij buitenshuis

\begin{tabular}{|c|c|c|}
\hline meer & gelijk & minder \\
\hline $\begin{array}{l}\text { meer } \\
\text { meer }\end{array}$ & $\begin{array}{l}\text { golijk } \\
\text { golijk }\end{array}$ & $\begin{array}{l}\text { minder } \\
\text { minder }\end{array}$ \\
\hline mear & golijk & minder \\
\hline meor & gellijk & minder \\
\hline $\begin{array}{l}\text { meer } \\
\text { meor } \\
\text { meer }\end{array}$ & $\begin{array}{l}\text { golijk } \\
\text { godijk } \\
\text { golijk }\end{array}$ & $\begin{array}{l}\text { minder } \\
\text { minder } \\
\text { minder }\end{array}$ \\
\hline
\end{tabular}

Heaf u (andere) perioden gekend waarin u minder toekwam aan de uiting van uw sociale activibiten?

Heeft u (andere) perioden gokend waarin u meor bekwam aan de uiting van uw sociale activitoiton?

ITEM 65

Ge日f op basis van bovenstaande gegevens aan of er sprake is van stagnatie of terugval (N.B.: OORDEEL VAN DE INTERVIEWER):

$$
\text { - } 0 \text { - stagnatie >--- in welke leeftijd: ..... }
$$

terugval, deze is: - 0 - zeer tijdelijk van aard en eenmalig (enige maanden daarna verbeterd)

- 0 - zeer tijdelijk van aard en recidiverend (iedere keer enige maanden daama beter)

- 0 - tijdelijk van aard (niet langer dan een jaar een terugval)

- 0 - voorbijgaand van aard (meer dan een jaar nodig voor herstel)

- 0 - continu van aard.

In welke levensperiode zijn de bovengenoemde problemen manifest geworden?

GEEF EEN BESCHRIJVING VAN HET BELOOP (T.8.V. HET CASE REPORT) 


\section{SAMENVATTENDE SECTIE (ACHTERPAGINA INSTRUMENT)} GLOBAAL OORDEEL HUIDIG FUNCTIONEREN

In de samenvatting gaat het erom een graad van emst van het dysfunctioneren op de verschillende basisgebieden te geven.

Scoring:

"geen/zelden problemen" als geconstateerd kan worden dat er vrijwel geen problemen/ beperkingen zijn en het genoemde basisgebied geen aandachtspunt voor de hulpverlening is.

"soms problemen en hulp nodig, meestal niet" als geconstateerd kan worden dat er wel problemen/ beperkingen zijn en het genoemde basisgebied aandachtspunt voor de hulpverlening is, maar niet centraal staat in de hulpverlening.

"meestal serieuze problemen, veel hulp nodig" als geconstateerd kan worden dat er wel problemen/beperkingen zijn, het genoemde basisgebied aandachtspunt voor de hulpverlening is en ook centraal staat in de hulpverlening.

"vrijwel geen activiteit, volledig passief" als in het genoemde basisgebied sprake is van een ernstige dysfunctio.

\begin{tabular}{ll|ll}
\hline ITEM 67 & & zeltverzorging & \multicolumn{1}{c}{ STANDAARD KEUZEMOGELIJKHEDEN: } \\
ITEM 68 & verz. anderen & $-\quad$ geen / zelden (1) \\
ITEM 69 & steun geven & $-\quad$ soms, en beetje hulp nodig (2) \\
ITEM 70 & sexualiteit & $-\quad$ veel ernstige problemen, wel enige rolvervulling vaak hulp (3) \\
ITEM 71 & daginvulling & - & vrijwel geen rolinvuling (4) \\
ITEM 72 & sociale activiteiten & - & niet relevant/ niet te beoordelen / n.v.t. (8; missing value) \\
\hline
\end{tabular}




\section{APPENDIX III - $\quad$ THE QUESTIONNAIRE ITEMS (IN DUTCH)}

De items zoals deze in de vragenlijst-versie, welke werd toegepast in de hoofdstudie, worden gegeven (de "final draft").

\section{DEEL EEN ACHTERGRONDEN EN STATUS EN POSITIEROLLEN}

1.

2.

3

4.

5.

6.

7.

8.

9.

10.

11.

12.

13.

14.

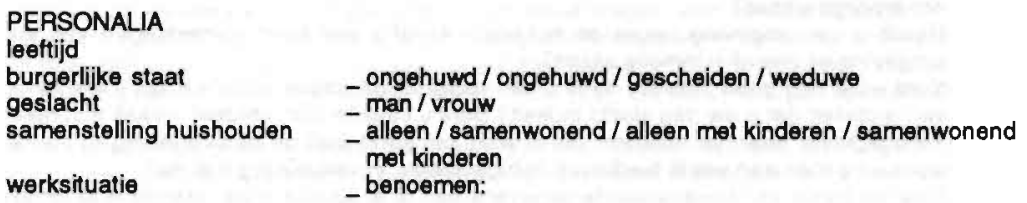

PERSONALIA BIJ AANVANG

leeftijd bij aanvang hulpvraag: .....jr.

burgerlijke staat bij aanvang hulpvraag _ ongehuwd / ongehuwd / gescheiden / weduwe geslacht bij aanvang hulpvraag

samenstelling huishouden bij aanvang hülpvraag _ alleen / samenwonend / alleen met

werksituatie bij aanvang hulpvraag

kinderen / samenwonend met kinderen _benoemen:

\section{Groepindeling volgens insluitcriteria}

Uw sociale contacten (Interviewer: toon kaart 1):

- Wie heeft $u$ de laatste maand gezien?

- Wie heeft u de laatste maand telelonisch gesproken?

- Zijn er voor u belangrijke mensen die u de laatste maand noch gezien noch telefonisch gesproken heett?

(Interviewer) Geef een beschrijving van de huidige levensfase van de cliënt.

(Interviewer) Geef een beschrijving van de huidige statusrol van de cliënt.

(Interviewer, toon kaart 2) _. Welke rollen zijn op u van toepassing? U kunt zich dat beter voorstellen door te zeggen "ik ben ......"

Heeft u problemen in de uitvoering van deze rollen?_(geen (1) ...veel (7)) (geef een cijfer).

(Interviewer) Geef een beschrijving van de discrepanties tussen verwachtingen en de vervulling status en positierollen op dit moment

- Benoemen:

- Zijn dit er: geen (1) enkele (2) tamelijk veel (3) erg veel (4).

Waarom bent u nu gekomen ( met welke vraag).

Psychiatrische diagnose: - DSM-IIIR:

Somatische diagnose: _benoemen:

Medische voorgeschiedenis:

jaar eerste behandeling bij een GGZ instelling:

instelling_intra (1) semi (2) extra (3)

behandeling:.

Sociale context bij aanvang van de hulpvraag: met wie ging u om toen u voor het eerst in zorg kwam?

(Interviewer) Geel een beschrijuing van de levensfase bij aanvang hulpvraaggeschiedenis.

(Interviewer) Geel een beschrijving van de stalus- en positierollen bij aanvang hulpvraag.

(Interviewer) Geef een beschrijving van de discrepanties tussen verwachtingen en vervulling status en positierollen bij aanvang van de hulpvraag.

Hoe is de hulpvraag bij aanvang van de zorg in het dossier beschreven?

Wat was de psychiatrische diagnose bij aanvang van de hulpvraaggeschiedenis?

_ DSM-IIIR: 


\section{DEEL TWEE: SOCIALE ROLVERVULLING}

\section{ZELFVERZORGING}

20. Wat doet $u$ aan zelfverzorging / hoe verzorgt u zichzelf; indien we kijken naar de laatste maand.

21. Hoe vaak wast u zich per week - Krijgt u wel eens opmerkingen dat u zich niet vaak genoeg wast?

22. Trekt u regelmatig schone kleren aan - Krijgt u wel eens opmerkingen van anderen dat $u$ er onverzorgd uitziet?

23. Houct u uw omgeving netjes en schoon - Krijgt u wel eens opmerkingen van anderen dat uw omgeving er vies of rommelig uitziet?

24. Kunt u uw dag goed indelen; heeft $u$ een regelmatige dagstructuur - Krijgt u wel eens opmerkingen van anderen dat $u$ uw dag slecht indeelt? Bent u vaak te laat, vergeet $u$ vaak afspraken?

25. Terugkijkend naar het moment dat u voor het eerst met de hulpverlening in contact kwam, hoe voldeed u toen aan wat ik hierboven heb gevraagd, in vergelijking met nu?

26. Geef op basis van bovenstaande gegevens aan of er sprake is van stagnatie of terugval.

27. In welke levensperiode zijn de bovengenoemde problemen manifest geworden?

\section{VERZORGING ANDEREN}

28. Wat doet $u$ aan de verzorging van anderen, indien we kijken naar de laatste maand?

29. Wat doet u daadwerkelijk in hel huishouden (1) (schoonmaken, etc.)?

30. Wat doet u daadwerkelijk in het huishouden (2)?

31. Hoe deelt $u$ de gezamenlijke taken in, plant $u$ dit samen met anderen of bedenkt nu wat $u$ over een kwartier gaat doen? Vind u dat u hier voldoende aandacht aan besteect? Vinden anderen dat ook?

31. Plant $u$ (eventueel samen met anderen) op langere termijn de wekelijkse inkopen en beheert $u$ samen het geld? Vindt $u$ dat $u$ hier voldoende aandacht aan besteedt? Vinden anderen dat ook?

32. Wat verwachten degene waarmee u leeft van u?

33. Welke anderen had u bij aanvang van de hulpverlening te verzorgen? Noemen. Terugkijkend naar het moment dat u voor het eerst met de hulpverlening in contact kwam, hoe voldeed u toen aan wat ik hierboven heb gevraagd?

34. Heeft u (andere) perioden gekend waarin het bovenstaande beter ging?

35. Heeft $u$ (andere) perioden gekend waarin het bovenstaande minder goed ging?

36. Geel op basis van bovenstaande gegevens aan of er sprake is van stagnatie of terugval.

37. In welke levensperiode zijn de bovengenoemde problemen manilest geworden?

\section{STEUN GEVEN}

38. Kunt u mensen noemen waar u enige steun aan geeft, of die voor u belangrijk zijn?

39. Doet u wel eens iets voor anderen? Zo ja, wat? (Het gaat in deze vraag vooral om praktische zaken, b.v. een klus in het huis doen, boodschappen doen voor een bejaarde buurvrouw, e.d.). Doet u dat vaak?

40. Voelt $u$ zich aan anderen gehecht?

41. Hoe laat u dit blijken?

42. Lost $u$ in het dagelijks leven wel eens problemen op voor en in de relatie met anderen? Wat voor soort problemen zijn dat?

43. Lost $u$ wel eens ruzies of conflicten op voor en in de relatie met anderen? Wat voor soort conflicten zijn dat? Met wie?

44.. Terugkijkend naar het moment dat u voor het eerst met de hulpverlening in contact kwam, hoe voldeed u tcen aan wat ik hierboven heb gevraagd, in vergelijking met nu?

45. Geel op basis van bovenstaande gegevens aan of er sprake is van stagnatie of terugval.

46. In welke levensperiode zijn de bovengenoemde problemen manilest geworden?

\section{SEXUALITEIT EN INTIMITEIT}

Inleidende vraag, bijvoorbeeld: ik wil het nu met u hebben over hoe u met sexualiteit en intimiteit omgaat. Allereerst wil ik weten of $u$ dit een moeilijk ondenwerp vinct.

47. Keuze sexe van de partner

48. Hoe ziet de relatie er uit? Er is sprake van (duur weergeven):

49. Uiting geven aan sexualiteit.

50. Problemen in de uiting van sexualiteit.

51. Heett $u$ in het verleden ooit perioden met problemen gehad in de uiting van uw sexualiteit? Welke problemen? Welke perioden in uw leven? Heeft u er toen hulp voor gezocht? Terugkijkend naar het moment dat $u$ voor het eerst met de hulpverlening in contact kwam, hoo werd de uiting van de sexualiteit toen beleefd? Heeft u (andere) perioden gekend waarin u minder toekwam aan de uiting van uw sexualiteit? Heeft u (andere) perioden gekend waarin u meer toekwam aan de uriting van uw sexualiteit?

52. Geef op basis van bovenstaande gegevens aan of er sprake is van stagnatie of terugval.

53. In welke levensperiode zijn de bovengenoemde problemen manifest geworden? 


\section{DAGELIJKSE VERPLICHTINGEN}

54. Inleidende vraag: Onder dagelijkse verplichtingen wordt verstaan die activiteiten, waarvoor verantwoording naar een of meer anderen dient te worden algelegd. Dit kan zijn in het kader van een al dan niet gestructureerd werkverband. Het kan ook zijn het kader van het samenleven in een gezin of andere vorm van langerdurende samenwoning. Het zijn die activiteiten waar ieder mens zijn eigenwaarde en identiteit aan ontleent, door te zeggen "ik ben: " we in op de situatie van de laatste maand. Inleidende vragen: Wat doet u overdag?

55. handigheid: bent u weV niet handig? / doorvraag: als het problemen oplevert, aan wie ligt dat dan?

56. de hoeveelheid werk: kan weV niet aan / doorvraag: als het problemen oplevert, aan wie ligt dat dan?

57. de indeling van het werk: weV geen probleern/ doorvraag: als het problemen oplevert, aan wie ligt dat dan?

58. kunt u goed omgaan met gelijken/ doorvaag: als het problemen oplevert, aan wie ligt dat dan?

59. kunt $u$ goed omgaan met mensen boven/onder $w /$ doorvraag: als het problemen oplevert, aan wie ligt dat dan?

60. kunt u problemen of conflicten op het werk aan/ doorvraag: als het problemen oplevert, aan wie ligt dat dan?

61. Terugkijkend naar het moment dat u voor het eerst met de hulpverlening in contact kwam, hoe voldeed u toen aan wat ik hierboven heb gevraagd, in vergelijking met nu?

62. Geef op basis van bovenstaande gegevens aan of er sprake is van stagnatie of terugval.

63. In welke levensperiode zijn de bovengenoemde problemen manifest geworden?

\section{SOCIALE ACTIVITEITEN}

64.

In het hiernavolgende wil ik het er met u over hebben hoe u uw vrije tijd invult en wat $u$ in uw vrije tijd onderneemt. Het gaat daarbij om die activiteiten die u met een zekere vrijblijvendheid onderneemt, en waar u geen verantwoording naar anderen voor hoeft af te leggen. Welke activiteiten heeft u zoal de laatste week ondernomen (bij weinig response), of de laatste maand? Welk van de volgende uitspraken is op u van toepassing (geef op allen aan of dat zelden, dan wel vaker op u van toepassing is)

65. Ik verveel $\mathrm{me} / \mathrm{doe}$ vaak niets.

66. Ik besteed mij vrije tijd alleen - met passieve bezigheden.

67. Ik besleed mij vrije tijd alleen - met meer actieve dingen.

68. Ik onderneem activiteiten samen met anderen.

- het gaat er mij om iets te doen, met wie maakt mij niet uit.

69. Ik onderneem activiteiten samen met anderen.

- het gaat er mij om samen met anderen iets te doen, ik doe het om mensen te leren kennen.

70. Ik onderneem activiteiten samen met anderen.

- de contacten zijn wederzijds, anderen vinden het ook leuk samen met mij iets te doen.

71. Onderneemt u uw activiteiten op eigen initiatiel?

72. Komt u hierbij buitenshuis?

73. Terugkijkend naar het moment dat $u$ voor het eerst met de hulpverlening in contact kwam, hoe voldeed u toen aan wat ik hierboven heb gevraagd, in vergelijking met nu?

74. Geef op basis van bovenstaande gegevens aan of er sprake is van stagnatie of terugval.

75. In welke levensperiode zijn de bovengenoemde problemen manifest geworden?

\section{SAMENVATTENDE SCORING}

76.

77.

78.

79.

80 . zellverzorging / verz. anderen steun geven sexualiteit

daginvulling sociale activiteiten

\section{ISTANDAARD KEUZEMOGELIJKHEDEN:}

geen / zelden problemen(i)

soms problemen en beetje hulp nodig (2)

veel emstige problemen, wel enige

rolvervulling, vaak hulp nodig(3)

vrijwel geen rolvervuling (4)

niet relevant / niet to beoordelen / n.v.t. 


\section{APPENDIX IV - CASE REPORT}

Onderstaand verslag is in twee rondes nabesproken: allereerst met de hulpverlener, later met samen met hulpverlener en cliënte. Aanvullingen uit de verschillende gesprekken worden apart weergegeven. Het onderstaande verslag is door haarzelf gezien, gecorrigeerd en geannonymiseerd voor zij toestemming gaf ter publicatie in het proefschrift.

Eerate interview, deel 1; achtergronden, status- en positlerollen: Schels achtergrond: het betreft een 29-jarige ongehuwde vrouw, die op 20-jarige leeftijd voor het eerst hulp heeft gezocht, met als Klachten angst en problemen in contact leggen. Ze heeft in haar opleidng en haar levenssituatie verscheidene teleurstellingen te verwerken gehad. Geboren in Nederland heeft ze een groot deel van haar jeugd in de tropen doorgebracht. Dit maakt dat zij zich altijd een vreemdeling voelt, en moeilijk aansluiting krijgt. Eenmaal terug in Nederland heeft ze verscheidene opleidingen afgebroken. Steeds met andere redenen. Na 3,5 jaar een opleiding gevolgd te hebben, heett zij deze opleiding in het praktijkjaar moeten afbreken. ('79-'82). Na twee jaar een andere opleiding tot medisch secretaresse gevolgd te hebben brak zij ook deze opleiding af (zelf) na een operatie te hebben ondergaan, maar ook wegens het gegeven dat haar toenmalige partner kanker had ('82-83). Deze heett zij de twee daaropvolgende jaren verzorgd. Vervolgens heeft ze een derde opleiding gevolgd, waar zij wegens angst en contactproblemen na korte tijd weer werd ontslagen ('85). In de tussentijd heeft zij wegens angstklachten in ' 83 hulp gezocht bij de GGZ, team Kortdurende Hulpverlening, na korte tijd is zij verwezen naar een psychotherapuet, waar zij met een onderbreking van 6 maanden (nov ' 85 tot april ' 86 ) in behandeling is geweest tot de verwijzing naar een therapeutische gemeenschap. Maart ' 86 heeft zij opniew hulp gezocht en werd ze verwezen naar het psychiatrisch ziekenhuis, die niet veel verder gekomen zijn dan een inventarisatie en haar terugverwezen naar de psychotherapuet. Zij verkoos februari ' 87 zelf een verblijf in dezelfde therapeutische gemeenschap, waar ze na 11 maanden weer ontslagen werd en terugverwezen naar het psychiatrisch ziekenhuis. Vevolgens is $z \theta$ een half jaar weer in behandeling geweest van het psychiatrisch ziekenhuis. Eind ' $88 \mathrm{c.q}$ begin ' 89 is zij enige tijd weer opgenomen geweest in de therapeutische gemeenschap. Mei ' 89 heeft ze zelf contact opgenomen met de RIAGG en is ze in ambulante zorg gekomen.

Aanvullingen h.v.: Jonge ongehuwde, alleenstaande vrouw, die het leven als alleenstaande weinig vorm kan geven. In het contactleggen komt zij steeds dezelfde problemen tegen: zij stelt zich zeer afhankelijk op van anderen die ze leert kennen, legt een claim en wordt vervolgens afgewezen. Omgang met alleen zijn, met alhankelijkheid van anderen staat centraal in de behandeling. Door haar afhankelijke houding weert ze juist mensen af.

Status- en positierollen bij aanvang: Ongehuwde alleenwonende vrouw, bezig met de afronding van de opleiding tot kinderverzorgster. Positierollen: partner, dochter, zus, vriendin, leerling-lerares, huisgenote, huisvrouw, cliènte, buurvrouw, verenigingslid. Met de rol als lerares/leerling had $2 \theta$ moeite, met name in het contactleggen en overbrengen van informatie op anderen. De rol als dochter was eveneens problematisch. Ze was er toen bang voor, maar wist niet waardoor. Met name de rollen als huisgenote en partner waren toen leuk. De sociale context bestond uit haar partner, enige vrienden, mensen van school (waar ze echter geen nauw contact mee had) en uit het verenigingsleven. Met het stamgezin waren de contacten beperkt.

Status- en positierollen momenteel: Ongehuwde alleenwonende vrouw, werkend als autoverzorgster, 20 uur per week. Positierollen; "weduwe", dochter, zus, vriendin, collega, vriendin van kennissen uit de kliniek, huisvrouw, cliēnt, verenigingslid. Heeft met ex-partner weinig contact, heeft incidentele contacten mel 2 oude bekenden uht de kliniek, een tennispartner, een kennis die ze via school kent en met de huisarts. De hulpverlener ziet ze nog het meeste. Het contact met deze hulpverlener is voor haar momenteel het meest belangrije. Er is in de relatie met de ouders wel sprake van enige betrokkenheid. maar dit is oppervlakkig. Werksituatie en sociale context instabiel, ze heeft moeite dit in stand te houden. Ook het alleenwonen gaat haar niet goed af. Ze voelt zich nog өen afhankelijk kind.

Aanvullingen h.v.: Qua leeftijd vroeg volwassen. Echter: geen beroepsidentiteit, geen vaste werkkring of beroepskeuze, geen stabiliteit in persoonlijks sfeer. Zij is achter in levensfase. Zij past qua rolinvulling meer in de adolescentie. Ze voldoet niet aan de verwachtingen passend bij haar levensfase. Ervaart dit zelf ook zo: raakt de aansluiting met leeftijdgenoten kwijt, met uitzondering van diegenen die ook in het psychiatrisch circuit zitten. Mening h.v. over discrepanties: Voldeed bij aanvang van de hulpverlening met moeite aan de status van ongehuwde jong volwassen vrouw. Had een aanvang gemaakt met relatievorming en was begonnen aan opleiding. Huidige status: qua arbeidssituatie, stabiliteit vriendenkring, afhankelijkheid van hulpverlening en stamgezin, ongehuwde, in adolescentiefase teruggevallen jonge vrouw. Terugval secundair aan teleurstellingen in combinatie met terugtrekgedrag. 
2. tweede interview, deel 2, soclale rolanalyse: Beperkingen in de huidige en vroegere rolvervulling. Wat betreft de ontwikkeling worden een aantal perioden aangegeven waarin het haar in het algemeen minder goed ging. Tot '79 was haar leven "een grote puinhoop". Van ' 79 lot ' 85 ging het haar beter, met een optimum tussen ' 83 en '84 toen ze samenwoonde. Van ' 85 tot ' 89 zeer slecht, ze kwam nauwelijks buitenshuis, was in deze periode ook verscheidene malen opgenomen in de kliniek. Van ' 88 tot oktober ' 89 ging het redelijk, maar sedert oktober '89 gaat het weer heel slecht.

\section{Zelfverzorging:}

Ontw. zelfverzorging:

Aanvullingen h.v:

Steun geven:

praktisch

hechting (passief)

hechting (actief)

probleemoplossen

conflictoplossen

Aanvulling h.v:

Ontw. steun geven:

Aanvullingen h.v.:

Sexualiteit:

Aanvulling $3 e$ interview:

Ontwikkeling sexualiteit:

Aanvullingen h.v.:
Momenteel geen beperkingen. Dagindeling is volgens een strak stramien, maar is op momenten wel een probleem (c.q. m.n. de daginvulling).

$\mathrm{Z}$ geeft wel aan dat zij in de periode ' 86 -'89 hieraan minder aandacht schonk. m.n. opruimen, geldbeheer en dagindeling was een probleem. Er is sprake van tijdelijke terugval van meer dan een jaar van duur met daarna een herstel.

Geelt geen beperkingen aan. Geen mening over het verleden.

Geeft zelf op dit moment niemand aan waar ze steun aan geeft. De hulpverlener noemt twee vriendinnen, die cliènte via het psychiatrische circuit kent.

Staat wel klaar om voor anderen praktische zaken te doen, maar bij doorvragen blijkt het niet vaak voor te komen.

Heeft een sterke betrokkenheid bij en afhankelijkheid van de hulpverlener, maar heeft verder niemand anders die ze zelf benoemt als iemand waarmee ze zich verbonden voelt.

Weet het niet, kan het wel tegen een vriend uiten. Bij navraag hoe ze het laat blijken kan ze geen duidelijk antwoord geven.

Anderen helpen gaat minder moeilijk dan de eigen problemen oplossen. Ze doet het zelden, omdat er weinig anderen zijn.

Ze voelt zich door anderen bedrogen, anderen reageren niet op wat zij wil, ze kan met tegenstellingen niet goed uit de voeten. Ze maakt dit vaak mee, maar komt er nooit uit.

Deze geeft op de eerste drie punten dezelfde score aan, maar is wat probleem en conflictoplossen betreft positiever - m.n. in de relatie met de twee vriendinnen, die cliênte via het psychiatrische circuit kent.

In periodes dat het haar minder ging (zie boven) deed ze wel vaker iets aan praktisch steun geven, het blijk geven van gehechtheid was helzelfde als nu problemalisch (zij voelt zich afhankelijk, is gesloten en laat zelf weinig blijken). Ze was slechter in staat om problemen en conflicten op te lossen. Er is sprake van een continue terugval op dit gebied sedert het overlijden van de vriend (Deze eerste vriend is de enige waar ze een hechte wederzijdse relatie mee gehad heeft).

Stagnatie na overlijen vriend, maar ook sprake van niet goed tot bloei gekomen zijn in de jeugd. Zij is opgegroeid in een qua persoonlijke relaties ongeïnteresseerd gezin. De omgang met en afhankelijkheid van anderen is een centraal punt in de behandeling - het leren afstand te nemen van mensen die te zeer op haar steunen en het leren zichzelf afhankelijker van anderen op te stellen.

Over het heden praat ze met enige terughoudendheid. Ze heeft wel ooit een wederzijds als prettig ervaren relatie gehad, met de viend die nu overleden is.

Bij het vervolginterview gal $z e$ aan dat ze op korte termijn hier wel aandacht aan wil besteden, omdat zij sinds kort een nieuwe relatie aan het aanknopen is en merk dat ze moeite heeft een binding aan te gaan uit angst voor teleurstelling.

Er is sprake van een terugval op dit gebied sedert het overlijden van de vriend. $Z_{\theta}$ heeft wel enige tijd later een jongen leren kennen, die relatie was meer van korte duur, met deze heeft ze nog wel contact. In haar jeugd was sexualiteit altijd moeilijk bespreekbaar. Anijd conflicten omdat zij zich onvoldoende gedroeg zoals "een meisje dat hoort".

Heeft geen relatie, maar wel duidelijke wensen. Ziet op tegen nieuwe relatie wegens angst voor verlating. Heeft in het verleden meegemaakt dat anderen haar in de steek lieten zodra zij zelf steun vroeg in de relatie, c.q. zichzelf te afhankelijk ging opstellen.

Stagnatie is opgetreden na overlijden vriend waar ze enkele jaren mee heeft samengewoond. Relatievorming is wel aandachispunt, w.b. het leggen van contacten. Sexualiteit is geen aandachtspunt geweest. 


\section{APPENDIX}

Dagelijkse verplichtingen:

Aanvulligen h.v:

Ontw. dagelijkse verpl.:

Aanvulling $3 e$ interview:

Aanvullingen $\mathbf{h}, \mathbf{v}$ :

Sociale activiteiten:

Ontw. sociale activiteiten:

Aanvullingen h.v.:
Ze heeft 2 maanden gewerkt, op de ochtend van het eerste interview was ze ontslagen. Tot die ochtend werkte ze 20- 27 uur per week. Probleem was dat ze het tempo niet aankon. Het niet meer hebben van werk ervaart ze als een ramp, als persoonlijk falen. Alle genoemde items - handigheid, hoeveelheid werk aankunnen, indeling van het werk, omgang met gelijken c.q. hiërarchisch hogeren en probleem- en conflictoplossen worden als problemen aangegeven. De eerste drie wijt ze aan de eisen van de omgeving; de laatste drie aan zichzelf.

Ook hierin is de hulpverlener positiever. Naar zijn mening is ze wel voldoende handig en kan ze wel de hoeveelheid werk aan, maar liggen de problemen meer op het persoonlijk vlak. $Z_{\theta}$ is te traag om in het vrije bedrijfsleven optimaal te werken. Ervaart haar aanpassing aan de werkdruk zelf ook als continu probleem.

Het ging op dit gebied eigenlijk altijd slecht. Het is alsof ze "te langzaam leeft". De onige periode waarin het beter ging was najaar ' 88 tot oktober ' 89 . Het ging al mis toen $z e$ thuis woonde. Op school moest ze altijd voldoen aan hooggespannen verwachtingen van de ouders en hard werken. Daarna is ze een aantal zaken begonnen die allen mislukt zijn.

$\mathrm{Er}$ is sprake van een stagnatie rond de afronding van opleidingen, c.q het zelfstandig werken in het bedrifisleven.

Vanuit het Arbeidsbureau heeft ze een maand lang een cursus gevolgd ter voobereiding van een inschrijving bij de MTB. In de wachtperiode daarvoor hoopt $z e$ bij een timmenwerkplaats bij het Citycentrum terecht te kunnen.

$\mathrm{Ze}$ heeft in het verleden ooit op een hoger nivo gefunctioneerd en werkt nu ook onder haar capaciteiten. Stagnatie is opgetreden bij het aangaan van verantwoordelijkheden, zodra anderen iets van haar verwachtten. Daginvulling en structurering is naast de omgang met anderen ook een van de centrale punten in de behandeling.

De laatste maand onderhield ze o.a. contacten met de ex-partner, de ouders, vrienden en kennissen en mensen die ze via het werk, de hulpverlening en cursussen kent.

Haar vrije tijd besteect ze met name alleen, met passieve dingen, ze onderneermt wel activiteiten met anderen, waabij het haar gaat om samen met anderen iets to doen. Het meeste wat ze doet is op eigen initiatief, ze komt daabij soms buitenshuis.

In het verleden kwam ze meer tot het ondernemen van activiteiten samen met anderen op basis van wederzijdsheid. In periodes gerakend gaat het dan met name om de periode toen de vriend nog leefde en toen ze daarna de relatie met diegene aanging die ze nu als ex-partner beschrijt.

Qua aantal mensen heeft ze een redelijk uitgebreid netwerk. Ze gaat om met familieleden, vrienden, buren, collega's, mensen die ze via cursussen kent, via groepsbijeenkomsten en in het verenigingsleven. De hulpverlener beschrijft momenteel als belangrijkste beperking: haar angst om nieuwe activiteiten te beginnen. 


\section{APPENDIX V - TABLE BOOK}

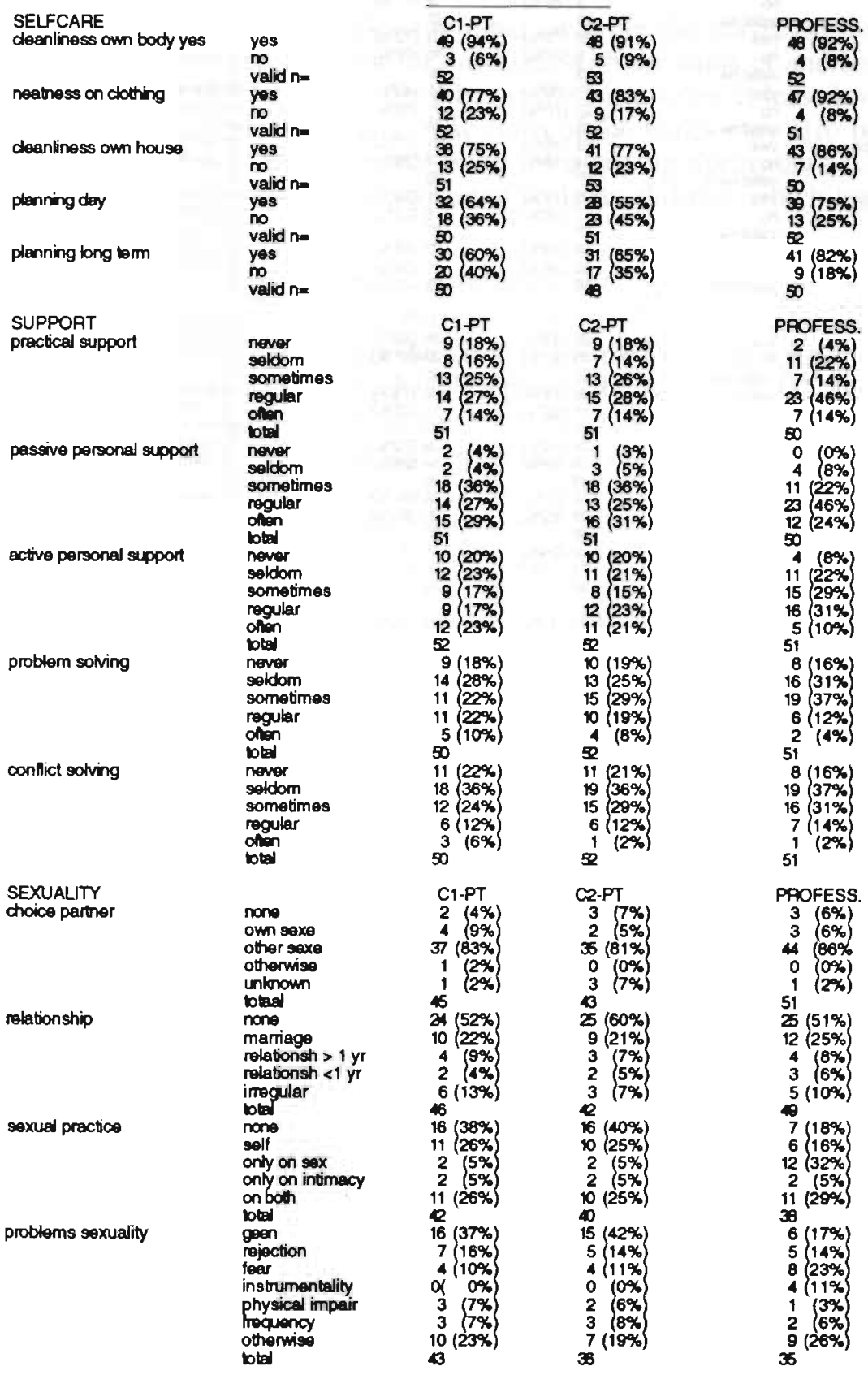

\footnotetext{
"Courtesy to Wiessette Krol, who meticuously prepared the data and compiled this table book.
} 


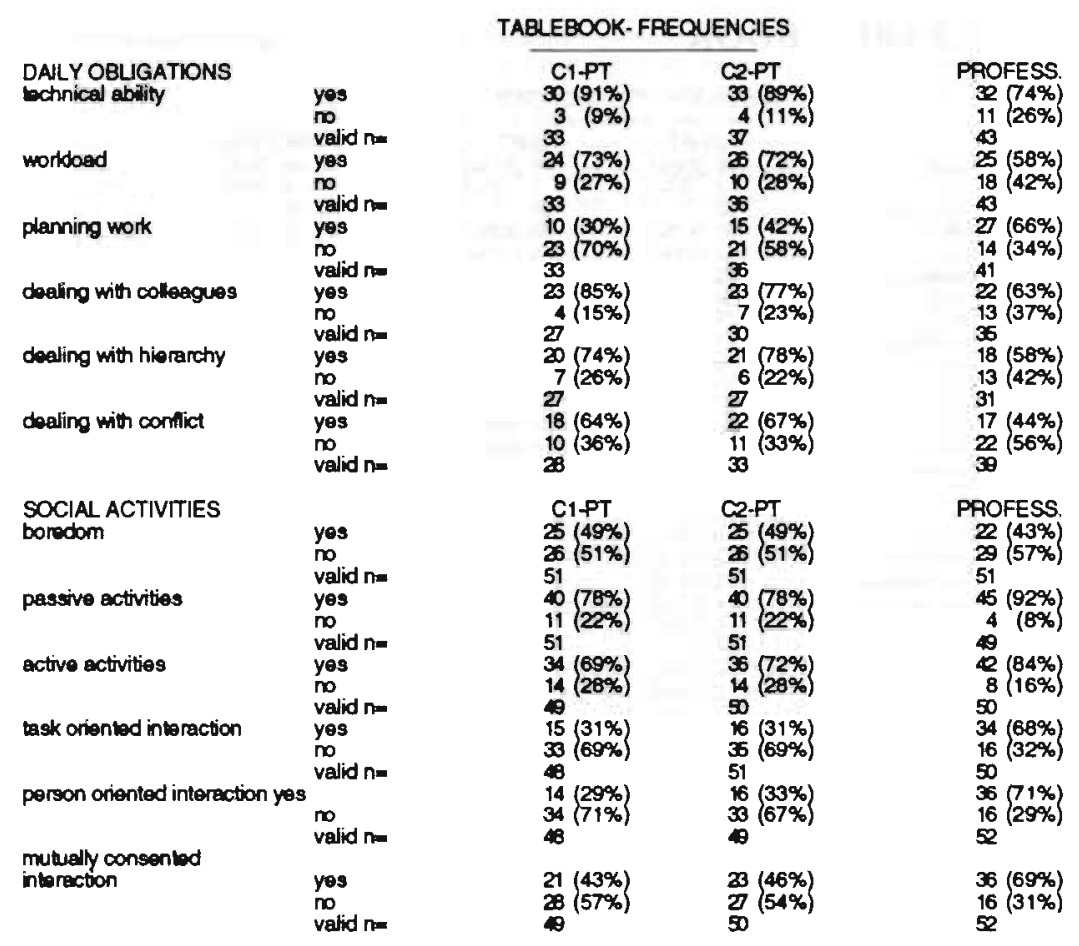

\section{APPENDIX VI -}

$\mathrm{x} \quad=$ observed variables

$\xi_{\mathrm{j}} \quad=$ the latent factors

$\delta=$ the unique variances are presented as circles

$\Phi_{i} \quad=$ the correlation between the factors

$\lambda_{i}=$ the loadings of the items on the factors

$\Theta_{i, j}=$ the correlation between the unique components of each item

In the defined model all loadings were set equal to 0 , except those fixed on the specific factors; all unique components $(\delta)$ were independent, i.e.: $\Theta_{x, y} \neq \Theta_{y, x}$ and all factors were not equal and relaxed from the model, i.e. $\Phi_{\mathrm{i}, \mathrm{j}} \neq \Phi_{\mathrm{j}, \mathrm{i}}$.

The proposed model is as follows:

$\xi_{i}=\lambda_{i}^{*} \xi_{1}+\delta_{i}$, for $1 \leq i \leq 4$,

$\xi_{i}=\lambda_{i}{ }^{*} \xi_{2}+\delta_{i}$, for $5 \leq i \leq 8$,

$\xi_{i}=\lambda_{i}^{*} \xi_{3}+\delta_{i}$, for $9 \leq i \leq 12$,

and $\xi_{i}=\lambda_{i}{ }^{*} \xi_{4}+\delta_{i}$, for $13 \leq i \leq 18$;

while $\Phi_{\mathrm{i}, \mathrm{j}}{ }^{\star} \xi_{\mathrm{i}, \mathrm{j}}=\Phi_{\mathrm{j}, \mathrm{i}^{\star}} \xi_{\mathrm{j}, \mathrm{i}}$ for $1 \leq \mathrm{i}, \mathrm{j} \leq 4$ (i.e., the factors $\xi_{1}$ to $\xi_{4}$ are dependent).

The model was identified, i.e. all parameters could be uniquely estimated. 
APPENDIX VII - THE CORRECTED ITEM SUMTOTAL CORRELATION

This was applied in the following table covering the corrected item sumtotal correlations between the items of one scale with the sums of another scale. The correlations with the sum of the other scales have to be at least lower than the correlations with the own scale. The sums of the scales may also be correlated and compared with the scale reliability, by applying Spearman's correction for attenuation (1912) to the comparison of scale reliabilities, which leads us to the following formula:

$$
\text { corrected correlation } \mathrm{R}=\frac{\mathrm{r}_{1,2}}{\sqrt{\alpha_{1}{ }^{*} \alpha_{2}}}
$$

In this formula $r_{1,2}$ represents the observed correlation between the sumscores of the scales, and $\alpha_{1}$ the Cronbach's alpha of the first scale, $\alpha_{2}$ the Cronbach's alpha of the second scale. This corrected measure provides information on the true correlation between the traits represented in the scales sums, independent of power of the intercorrelations or the hight of the different $\alpha$ 's. When the scales are sufficiently independent we may hope $R$ to be substantially smaller than the subsequent $\alpha$ 's. Only in $n=11$ all items are applicable, indicating that when an item is applicable in one scale it not neccesarily is applicable in another. Thereto, we present the number of applicable cases per item. A limited number of variables reach $\mathrm{p}<0.05$ and only 2 reach $\mathrm{p}<0.01$. We present the computations on the data of the professionals.

\section{APPENDIX VIIA - THE CORRELATION MATRIX}

\begin{tabular}{|c|c|c|c|c|}
\hline & $\begin{array}{l}\text { sumscore } \\
\text { sellcare } \\
(a=0.83) \\
r(\operatorname{vald}(n))\end{array}$ & $\begin{array}{c}\text { sumscore } \\
\text { support } \\
(a=0.86) \\
r \text { (valid (n)) }\end{array}$ & $\begin{array}{c}\text { sumscore } \\
\text { daily obligations } \\
(a=0.77) \\
r(\text { valid }(n)) \\
\end{array}$ & $\begin{array}{c}\text { sumscore } \\
\text { social activities } \\
(a=0.61) \\
r(\text { valid }(n))\end{array}$ \\
\hline $\begin{array}{l}\text { cleanliness own body } \\
\text { neatness on clothing } \\
\text { cleanliness own house } \\
\text { planning short term } \\
\text { planning long term } \\
\text { practical support } \\
\text { passive personal support } \\
\text { overt personal support } \\
\text { problem solving } \\
\text { conflict solving } \\
\text { technical ability } \\
\text { getting work done } \\
\text { planning work } \\
\text { dealing with colleagues } \\
\text { dealing with hierarchy } \\
\text { dealing with conflict } \\
\text { boredom } \\
\text { passive activities } \\
\text { active activities } \\
\text { task oriented interaction } \\
\text { person oriented interaction } \\
\text { mutually cons. interaction }\end{array}$ & $\begin{array}{l}- \\
- \\
- \\
- \\
.27(48) \\
.11(48) \\
.26(48) \\
.29(49) \\
.24(38) \\
.55(30) . . \\
.08(29) \\
.38(25) \\
.29(24) \\
.29(24) \\
.17(18) \\
.25(47) \\
. .05(48) \\
.29(48) \\
.28(48) \\
.41(48)^{*} \\
.45(48)^{* *}\end{array}$ & $\begin{array}{l}-.09(23) \\
.06(19) \\
.29(21) \\
.35(21) \\
.36(23) \\
- \\
- \\
- \\
- \\
- \\
.45(17) \\
.15(18) \\
.19(17) \\
.11(13) \\
.26(13) \\
.30(15) \\
. .19(27) \\
-.39(28) \\
.09(27) \\
.13(23) \\
.26(18) \\
.38(15)^{.}\end{array}$ & $\begin{array}{l}. .15(19) \\
.24(18) \\
.24(23) \\
.05(24) \\
.34(22) \\
.22(24) \\
.18(24) \\
.38(24) \\
.41(22) \\
.30(22) \\
. \\
- \\
- \\
- \\
- \\
- \\
.31(24) \\
-.17(24) \\
.16(24) \\
.19(22) \\
.35(22) \\
.35(24)\end{array}$ & $\begin{array}{l}.24(51) \\
.30(51) \\
.27(51) \\
.34(51) \\
.35(49) \\
.28(48) \\
.25(48) \\
.28(48) \\
.28(49) \\
.26(48) \\
.33(48) \\
.27(48) \\
.11(48) \\
.05(49) \\
.14(48) \\
.05(47) \\
- \\
- \\
- \\
- \\
- \\
-\end{array}$ \\
\hline
\end{tabular}

"sign, $p<0.05 *$ sign, $p<0.01$ 


\section{APPENDIX VIII - CALCULATION OF THE MINIMUM SIZE}

In the last draft a score of less or equal than 20 is abnormal. The critical effect size is $n$ (domains) $+1: n$ (vars) $=6: 26=0.23$. Throughout the main study we deleted several items as the analyses proved they were irrelevant or not valid. The critical effect size in the final version is however almost the same: $5: 21=$ 0.24 . For a $80 \%$ power and a significance level of 0.05 in an one-tailed test, having a critcal effect size of 0.24 , a sample size of 105 is required (Kreamer, $1987)$. When we are satisfied with a power of $50 \%$, and are dealing with a critical effect size of 0.24 , a sample size of 47 is required. This example concerns the identification of deviance, using a Student t-test or, as in the current study, a non-parametric rank order test (e.g. the Mann-Whitney U measure, as in Chapters 12 and 14 of this thesis). The values of the power vary for the various statistics we applied. In a matched sample using a correlational measure such as Cohen's Kappa, we need a sample of 106 observations for a $80 \%$ power at a significance level of 0.05 . 53 patients are sufficient for a analysis of the interrater agreement. In most of the univariate comparisons, the power will be fairly similar in this example. When several multi-level analyses are applied to investigate the same psychometric characteristics, Kreamer \& Thieman (1987) proved that the sample size may be reduced impressively.

\section{APPENDIX- IX THE STANDARIZED CRONBACH'S $\alpha$}

The Standarized Cronbach's $\alpha$ represents the reliability of sumscore of a test by relating the item-sumtotal correlations to the number of items in a test, after correcting for different item variances, and is based on the next formula:

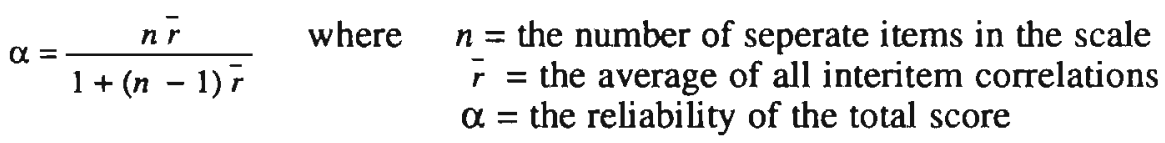

This formula makes it clear that the reliability of a scale depends on its internal consistency or homogenity $(\bar{r})$ and its length $(n)$. As far as the influence of the number of items is concerned, a small number of items measuring slightly different aspects of the same concept with a high $\alpha$ is what we want. We then know that we are measuring a single trait. But a high $\alpha$ is also obtained in a scale of almost identical items. Rather, the items of a given scale should cover distinct, but closely related aspects of the trait to be measured. With perfectly reliable items all measuring the same thing, any one of the items would be all what is neccesary to measure the particular dimension with a perfect reliability. For such items the value of $(\bar{r})$, and the value of $\alpha$ would be 1.0 . For example, asking in five ways the colour of hair provides a perfect though irrelevant scale. 


\section{CURRICULUM VITAE}

Ik ben geboren op 3 juni 1958 te Leiden. Na een jeugd in Indonesië, India en Japan, doorliep ik tussen 1970 en 1976 de middelbare school te Epe (Gelderland). De studie Geneeskunde te Maastricht werd in mei 1984 afgerond. Na enige professionele omzwervingen als arts in een kazerne, een huisartsenpraktijk, het G.A.K. en tenslotte de Wetenschapswinkel werd ik augustus 1987 Assitent-onderzoeker in Opleiding (A.I.O.) bij de vakgroep Sociale Psychiatrie in Maastricht. Na afronding hiervan was ik in de gelukkige omstandigheid dat ik datgene wat in dit proefschrift werd ontwikkeld ook mocht overdragen naar het praktijkveld. Naast mijn werk in dit project ben ik mij meer en meer in de psychiatrische epidemiologie en patiëntgebonden onderzoek aan het verdiepen. Tevens heb ik door de jaren heen mij in de ondersteunende en adviserende zin ingezet voor anderen binnen en buiten de vakgroep, hetgeen resulteerde in de volgende wat gemeleerde publicatielijst:

1. Noorthoorn, E.O., Joosten, J., Diederiks, J. (1988). Onderzoeksverslag Zeswegen, een onderzoek naar ervaren gezondheid en milieuperceptie in een Heerlense wijk. Onderzoeksverslag Wetenschapswinkel RL.

2. Noorthoorn, E.O., Romme, M.A.J., Hamers, H., Kraan H. (1988). Maatschappelijke integratie van de ambulante psychiatrische patiënt. Constructie van een instrument. Tijdschrift Sociale Gezondheidszorg, (11), 40-41.

3. Noorthoorn, E.O., Romme, M.A.J., Hamers, H., Vallenga, L. (1991). Sociale rolontwikkeling bij ambulante chronisch psychiatrische patiënten, verduidelijkt met een gevalsbeschrijving. Tijdschrift voor Psychiatrie, (2), 84-99 (Hoofdstuk 2 van dit proefschrift).

4. Noorthoorn, E.O., Romme, M.A.J., Philipsen, H. (1991). Betrouwbaarheid van sociale rolanalyse bij ambulante chronisch psychiatrische patiënten. Tijdschrift Sociale Gezondheidszorg, (14), 23-24.

5. Noorthoorn, E.O., Romme, M.A.J., Vallenga, L. (1990). Sociale rolontwikkeling bij ambulante chronisch psychiatrische patienten: een voorstel tot een analysemethode. Forum, SOGG (5), 50-53.

6. Noorthoorn, E.O., Romme, M.A.J., Dijkman, C.I.M., Escher, A.D.M.A.C. (1989). Resultaten van een enquête onder mensen die stemmen horen. In: Omgaan met stemmen. M.A.J. Romme, A.D.M.A.C. Escher (red.), Vakgroep Sociale Psychiatrie, Maastricht.

7. Noorthoorn, E.O., Romme, M.A.J., Dijkman, C.I.M., Escher, A.D.M.A.C. (1990). Wat kunnen mensen die stemmen horen de psychiatrie leren? In: Sociale dienstverlening in Nederland, E. Hiks (red.), SISWO, Amsterdam. 
8. Noorthoorn, E.O., Romme M.A.J. (1991). Social role development as an instrument in the ambulatory rehabilitation of chronic mentally ill. Poster and paper presentation for the Conference on "Longitudinal Research: Challenges for the Future", Budapest, 21-23 March, Proceedings Published by the European Science Foundation, Prof. Dr. D. Magnusson (Chairman \& Ed.), University of Stockholm.

9. Noorthoorn, E.O., Romme, M.A.J, Philipsen, H., Vallenga, L. (1993). Role theory in the analysis of the social development of chronic mentally ill: a single case study. The International Journal of Social Psychiatry, in press. (Hoofdstuk 2 van dit proefschrift).

10. Noorthoorn, E.O., Romme, M.A.J., Philipsen, H., Krol. W. (1993). Reliability of social role analysis in a community sample of chronic mentally ill.The International Journal of Social Psychiatry, submitted. (Hoofdstuk 9 en 10 van dit proefschrift).

11. Noorthoorn, E.O., Romme, M.A.J., Philipsen H., Buiks, A.A.J.G.M. (1993). Levensloop en sociale rolvervulling bij chronisch psychiatrische patiënten: betrouwbaarheid, validiteit en toepasbaarheid van een interviewschema. Tijdschrift voor Psychiatrie, submitted. (Hoofdstuk 9 en 10,14 en 15 van dit proefschrift).

12. Romme, M.A.J., Honig, A., Noorthoorn, E.O., Escher, A.D.M.A.C. (1992). Coping with hearing voices: an emancipatory approach. British Journal of Psychiatry (161), 99-103.

13. Gunther, N., Noorthoorn, E.O., Hamers, H., Romme M.A.J., Kaplan, C.D., De Jong, J.T.V.M., Devries, M.W. (1993). De Buurt als sleutel: de voorspellende waarde van sociale indicatoren op het gebruik van GGZ voorzieningen. Tijdschrift voor Psychiatrie, accepted.

14. Honig, A., Hoffmann, A., Hilwig, M., Noorthoorn, E.O. (1993). Psychoeducational multiple family groups for bipolar disorder. Submitted.

15. Romme, M.A.J., Noorthoorn E.O. (1991). Sociale wetgeving is ongeschikt voor arbeidsrevalidatie omdat de arbeidsomstandigheden de ziektekiemen vormen voor de invaliditeit. Tijdschrift Gezondheidszorg en Politiek, (6), 16-22.

16. Romme, M.A.J., Noorthoorn, E.O. (1991). The Dutch Social Security System, must it shift its focus. Major contribution, proceedings XVIIe Congres of the International Academy of Law and Mental Health, 28-51991, Prof. Dr. J. Casselman. (Ed.) Leuven.

17. Escher, A.D.M.A.C., Noorthoorn, E.O., Honig, A., Dijkman, C.I.M. (1991). Stemmen horen in een breder perspectief gezet. In: Stemmen horen accepteren, M.A.J. Romme, A.D.M.A.C. Escher, Vakgroep Sociale Psychiatrie, Rijksuniversiteit Limburg. 



\section{Social roles and lifetime development in the chronic mentally ill}

A study into the reliability and validity of the Social Role Performance and Development Inventory: an open interview-based lifetime assessment of the social integration of chronic mentally ill.

\section{E.O. Noorthoom van der Kruijff}

Successful rehabilitation of the chronic mentally ill quite often depends on interventions in the social environment. In this book a sociological frame of reference is operationalized into an assessment schedule: the Social Role Performance and Development Inventory (SRPDI). The SRPDI provides a comprehensive description of the way a (chronic) mentally ill patient is embedded in his or her social environment. The SRPDI is concerned with the discription of the development of the social integration of (chronic) mentally ill. It consists of two parts, each requiring a single interview of approximately one hour. Part one is concerned with what the patient has achieved in terms of position roles. Part two is concerned with how the patient has achieved these roles in terms of role performance in five domains of daily life: "taking care", "support", "sexuality", "daily obligations" and "social activities".

Currently, the instrument is implemented in several in- and outpatient services for chronic mentally ill throughout the Netherlands (Nationaal Fonds Geestelijke Volksgezondheid, grant 92\#3089).

Eric Noorthoorn van der Kruijff works as a research fellow at the Division of Social Psychiatry and Psychiatric Epidemiology, Academic Psychiatric Centre, University of Limburg, Maastricht. 